University of Louisville

ThinkIR: The University of Louisville's Institutional Repository

8-2015

\title{
Youth graffiti vandalism : liminal perspectives in the light of masculinity, social contract theory and transformative process.
}

Alton C. Frabetti

University of Louisville

Follow this and additional works at: https://ir.library.louisville.edu/etd

Part of the Philosophy Commons

\section{Recommended Citation}

Frabetti, Alton C., "Youth graffiti vandalism : liminal perspectives in the light of masculinity, social contract theory and transformative process." (2015). Electronic Theses and Dissertations. Paper 2256.

https://doi.org/10.18297/etd/2256

This Doctoral Dissertation is brought to you for free and open access by ThinkIR: The University of Louisville's Institutional Repository. It has been accepted for inclusion in Electronic Theses and Dissertations by an authorized administrator of ThinkIR: The University of Louisville's Institutional Repository. This title appears here courtesy of the author, who has retained all other copyrights. For more information, please contact thinkir@louisville.edu. 


\title{
YOUTH GRAFFITI VANDALISM: LIMINAL PERSPECTIVES IN THE LIGHT OF MASCULINITY, SOCIAL CONTRACT THEORY AND TRANSFORMATIVE PROCESS
}

\author{
By \\ Alton C. Frabetti \\ B.A., University of Massachusetts, Amherst, 1992 \\ MA, MFA, Stony Brook University, 2007 \\ Dissertation \\ Submitted to the Faculty of the \\ College of Arts and Sciences of the University of Louisville \\ in Partial Fulfillment of the Requirements \\ for the Degree of
}

Doctor of Philosophy in Humanities

Department of the Humanities

University of Louisville

Louisville, KY

August 2015 
Copyright 2015 by Alton C. Frabetti

All rights reserved 

YOUTH GRAFFITI VANDALISM: LIMINAL PERSPECTIVES IN THE LIGHT OF MASCULINITY, SOCIAL CONTRACT THEORY AND TRANSFORMATIVE PROCESS

$$
\text { By }
$$

Alton C. Frabetti

B.A., University of Massachusetts, Amherst, 1992

MA, MFA, Stony Brook University, 2007

\section{A Dissertation Approved on}

July 15,2015

By the following Dissertation Committee:

Director, Dr. Diane Pecknold

Dr. Annette C. Allen

Prof. Ying Kit Chan

Dr. Gary Walton 


\section{DEDICATION}

to my wife, Sylvia, and my brother, Michael 


\section{ACKNOWLEDGEMENTS}

My first thanks go to my committee. Dr. Pecknold agreed to a difficult role, to chair a committee for the first time for a candidate who would be writing from long distance. Her insightful comments and precise suggestions throughout the editing process have made this paper vastly improved and easier for me to edit. Dr. Allen was my mentor throughout my doctoral studies and I have appreciated her support for my creative ideas. Prof. Chan was also my enthusiastic and supportive graduate adviser and frequently combated my cynicism about my prospects in the academic job market. His thoughts about liminal aesthetics as well as general suggestions on the elements of the dissertation directly relating to the field of the visual arts were very helpful. Dr. Walton, my outside reader, was the first to publish my writings on graffiti at the outset of my research and demonstrated patience and thoughtfulness for the later process of the dissertation defense.

Any work on graffiti would be remiss not to acknowledge the researcher's indebtedness to the vast population of individuals who make graffiti, which I do so now. Similarly, its antagonists, abatement crews and enthusiasts also create the culture of graffiti and have my thanks. Most of my ideas were founded upon my personal intuitions and insights; however, from a scholarly perspective, they were inspired initially by Lisa Macdonald's The Graffiti Subculture. 
Finally, I would like to thank the two people to whom this work is dedicated. Researching and writing a dissertation requires time and patience both from the writer as well as those closest to him or her. My wife, Sylvia, has been supportive throughout the process and has endured with me its challenges. She has provided me feedback whenever needed. The other person is my brother, Michael. His den in the Midwest created my first grounds for transplant; he aided me in creating a new home in Louisville; and he assisted me in moving from Louisville back to Boston. He showed continued support throughout all my studies (he attended my Masters commencement ceremony at Stony Brook University, New York) and assisted me even up through the final defense. Those of us in his extended 'pack' count ourselves lucky to be so bastioned. 


\title{
ABSTRACT \\ YOUTH GRAFFITI VANDALISM: LIMINAL PERSPECTIVES IN THE LIGHT OF \\ MASCULINITY, SOCIAL CONTRACT THEORY AND TRANSFORMATIVE PROCESS
}

\author{
Alton C. Frabetti
}

August 1, 2015

American adolescents experience liminality as their rights, obligations and cognitive development place them in a transitional life-period between childhood and adulthood. This liminal period inspires compensatory activities, such as identification with mainstream popular styles, radical adherence to an ideology or religion, or, for those especially struggling, destructive behavior.

Graffiti is one such compensatory activity. Its practitioners' risky conduct, as well as their overall claims to exalted artistic activity, are especially appealing to certain males attempting to construct a retrogressive notion of masculinity and self-esteem in response to the further condition of male liminal identity. The practice of graffiti confronts the political and social contradictions of adolescence in many aspects, even in the very process of its performative construction, resulting in a variety of effects upon the liminal state of the youth involved. This effects includes how all aspects of graffiti involvement both build upon and yet undermine their male identity; assert the freedom and rights of rebellion-oriented members while tending to preserve their status as law-abiding citizens; 
and involve them in a 'career' which undulates between layers of liminality: its renewal, avoidance, aesthetic encounter/disencounter and eventual semi-termination.

Males of a specific character who tend toward the Schillerian savage find themselves rejecting societal codes due, in part, to the liminality invoked by the unusual invocation of their rights and limitations on their civic powers. Rejecting societal laws and codes, they identify with the savagery and retrogressive masculine virility of graffiti as a flight from liminality, even while still preserving it to some degree. In the process of their involvement and production, such as the disciplined labor of making complex masterpieces, they actually undermine the savage elements that appealed to them at the outset. Their mindset undergoes a transformation as they contemplate what they consider to be the beauty of exceptional graffiti, maturing them out of its illegality into full citizenship. The main obstacle that remains for them might be the enduring legal record for those who were at some point arrested by authorities. 


\section{TABLE OF CONTENTS}

I. INTRODUCTION

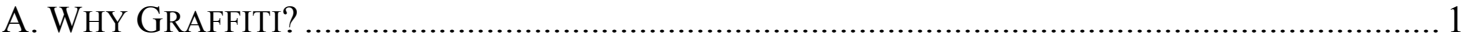

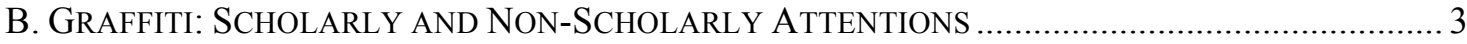

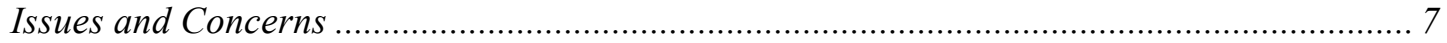

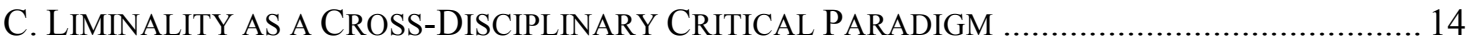

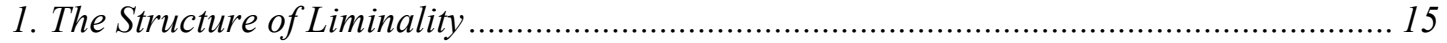

2. Four Characteristic Qualities of Liminality .................................................................... 18

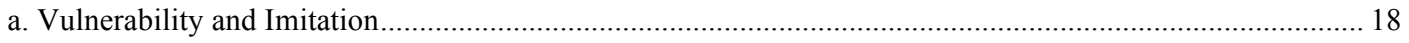

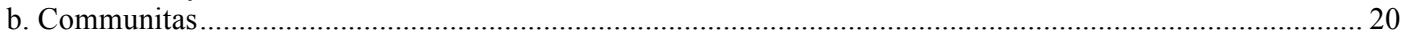

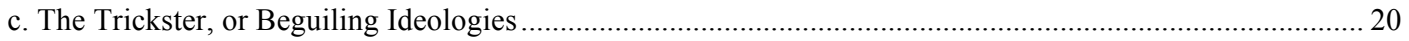

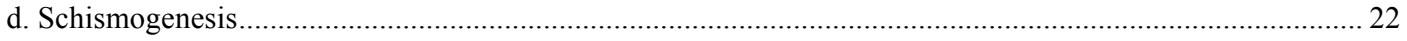

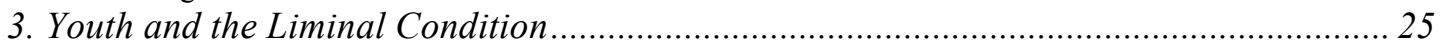

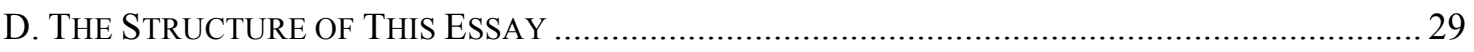

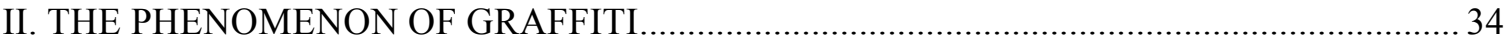

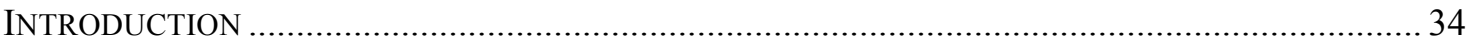

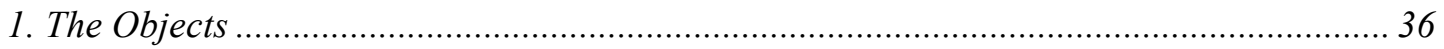

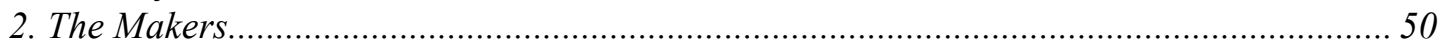

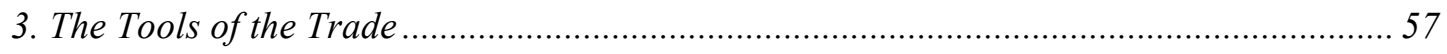

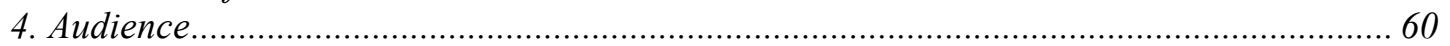

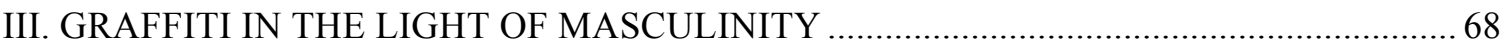

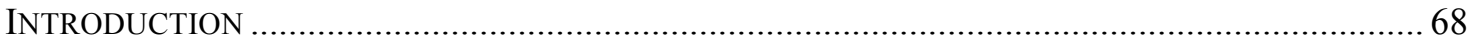

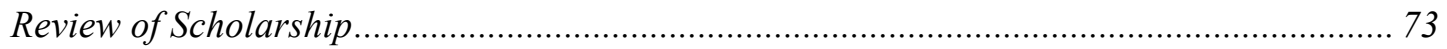

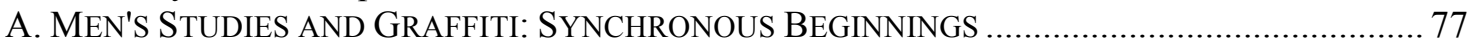

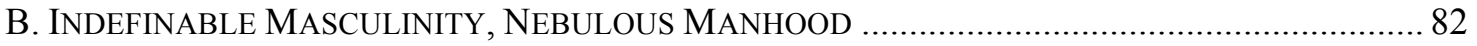

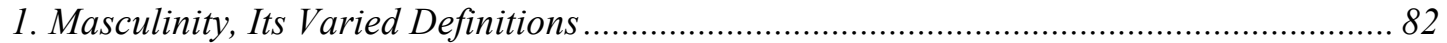

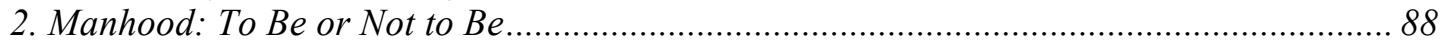

C. Males Adrift within/out Hegel's Dialectic ....................................................................... 91

D. GENDERING THE OPPOSITION: CONSUMPTION, SOCIETY, PUBLIC SPACE ............................ 101

1. The "Consumer Republic" and Changing Public Space ................................................ 102

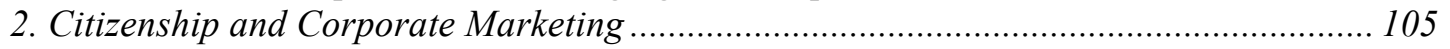

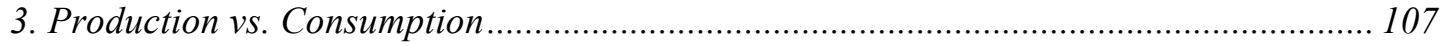

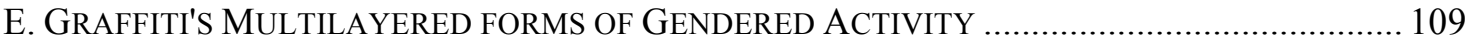

1. Masculine Prowess: Legal and Physical Risks........................................................... 110

1a. Competing Masculinities: Illegality and Militaristic Terminology …………………………………….... 116

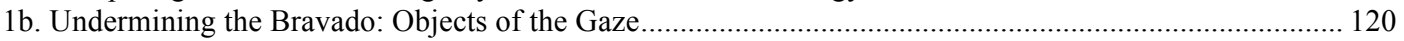

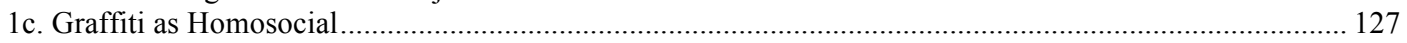

2. The Heroic Artisan: A Variant Masculinity ……......................................................... 130

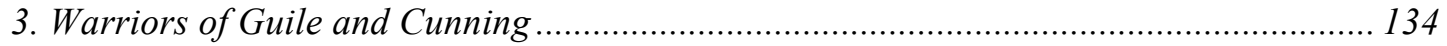

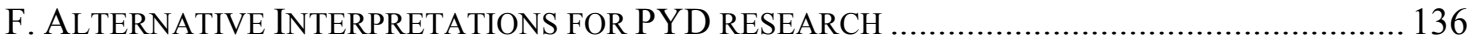

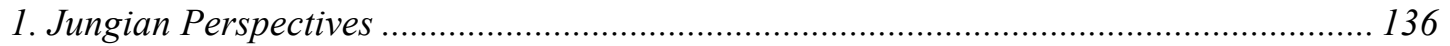




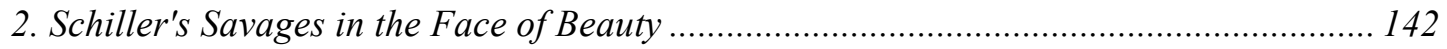

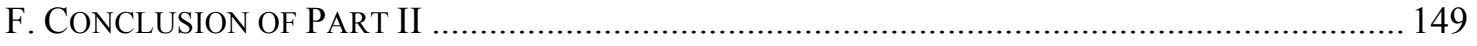

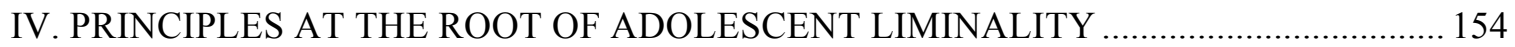

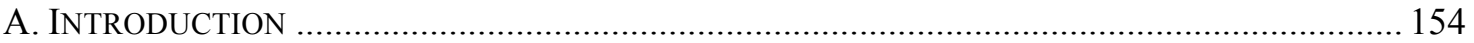

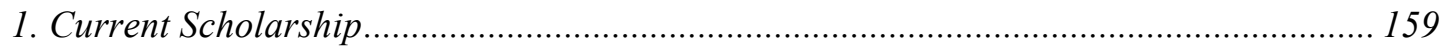

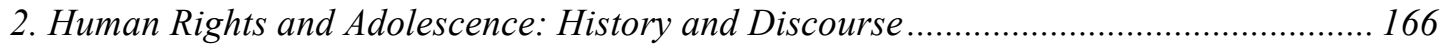

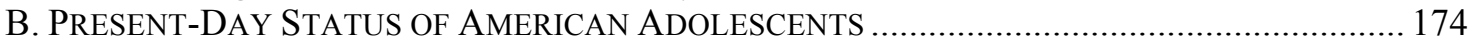

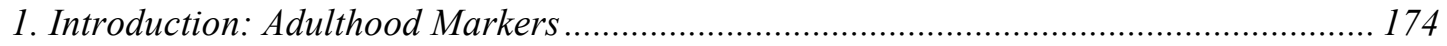

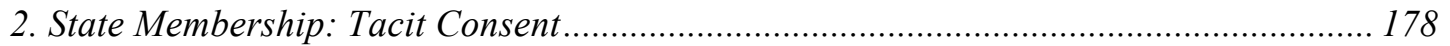

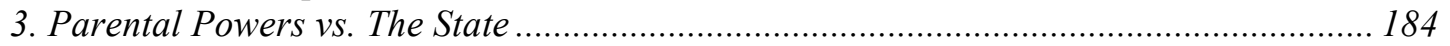

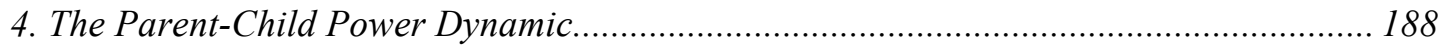

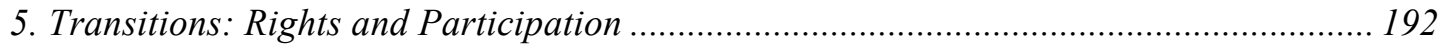

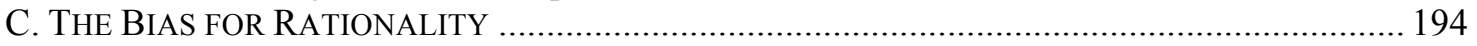

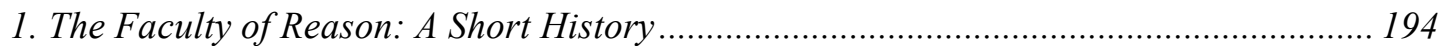

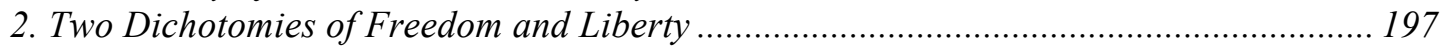

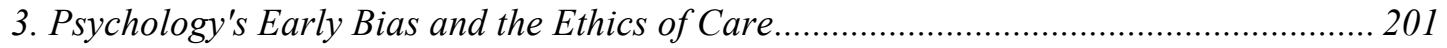

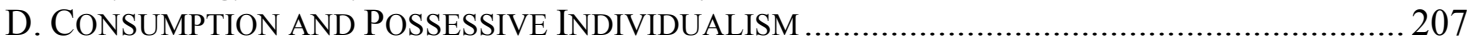

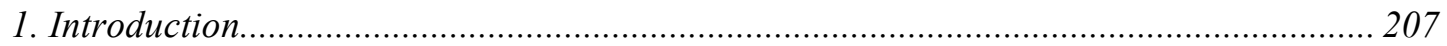

2. Locke and the Consequences of Money upon Natural Rights.......................................209

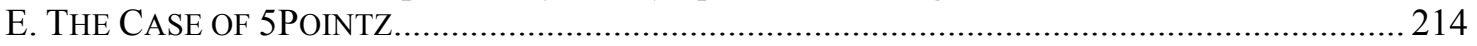

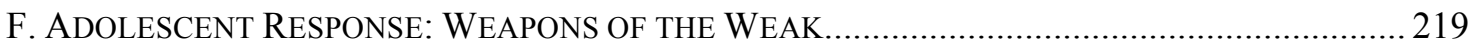

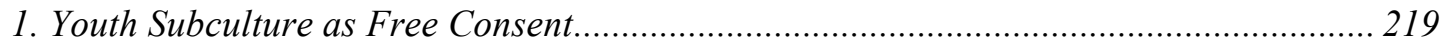

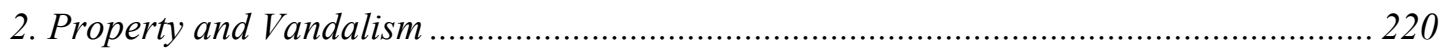

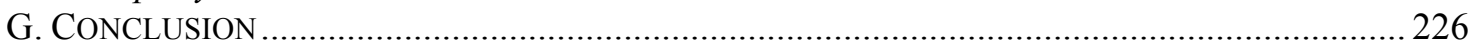

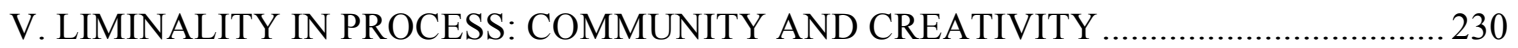

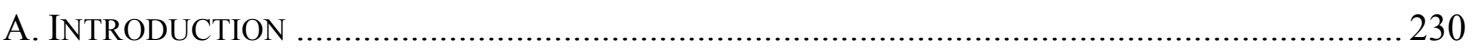

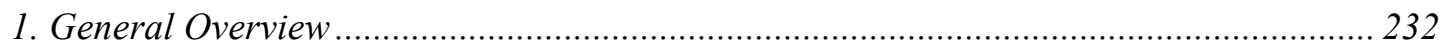

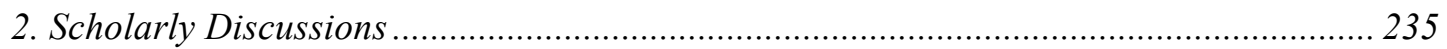

B. ESTABLISHING THE PARAMETERS OF WHAT IS LIMINOID ART …....................................... 241

1. The Three Basic Classification of Art Forms in Relationship to Liminality..................... 242

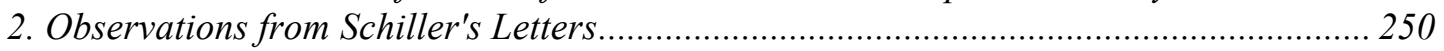

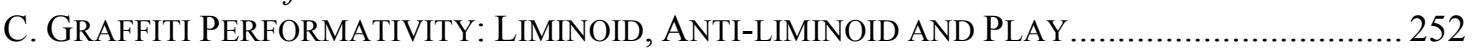

1. Initial Involvement - The Rite of Passage to Community .................................................2.252

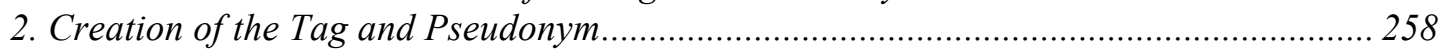

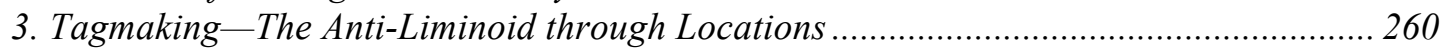

4. Masterpiece Murals: The Anti-Liminoid in Process..................................................... 264

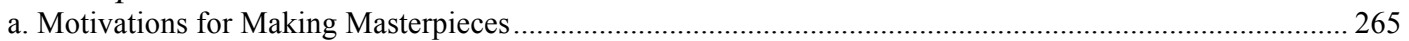

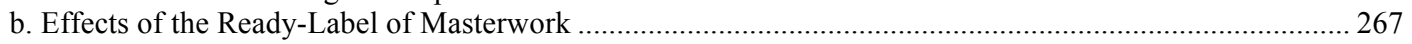

c. Compositions and Makings: Further flights from Liminality.................................................................. 272

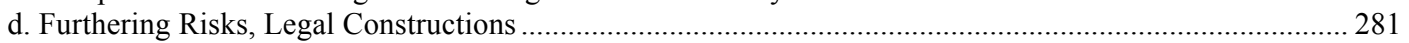

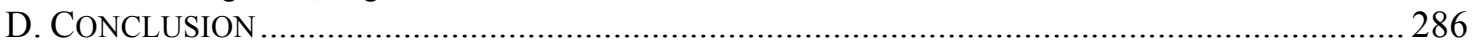

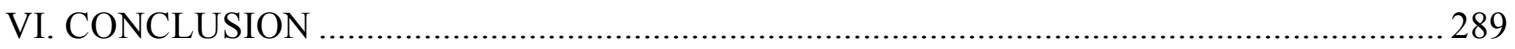

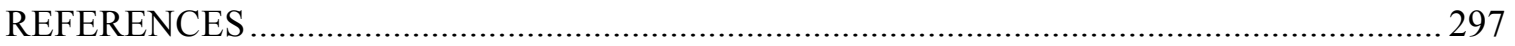

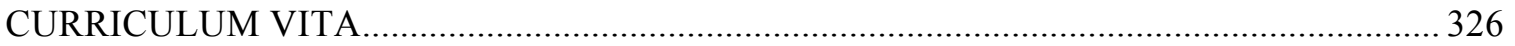




\section{INTRODUCTION}

\section{A. Why Graffiti?}

Adolescents in the West, and particularly in the United States, experience to varying degrees a state referred to in anthropology as 'liminal,' as their rights, obligations and cognitive development place them in a transitional life-period between childhood and adulthood. This liminal period results in varying degrees and sources of difficulties due to the ambiguities in which it dwells. These difficulties, from the biological to the philosophical, in turn inspire compensatory activities, such as identification with mainstream popular styles, radical adherence to an ideology or religion, or, for those especially struggling with their liminal condition, destructive behavior.

I argue that graffiti is one such activity whose principle origin is in the liminal condition of adolescence. Its practitioners' risky conduct, as well as their overall claims to exalted artistic activity, are especially appealing to certain males attempting to construct a retrogressive notion of masculinity and self-esteem characteristic of models dominant at the turn of the twentieth century. The practice of graffiti confronts the political and social contradictions of adolescence in many aspects, even in the very process of its performative construction, resulting in a variety of effects upon the liminal state of the youth involved. This effects includes how all aspects of graffiti involvement both build upon and yet undermine their male identity; assert the freedom and rights of rebellionoriented members while tending to preserve their status as law-abiding citizens; and 
involve them in a 'career' which undulates between layers of liminality: its renewal, avoidance, aesthetic encounter/disencounter and eventual semi-termination. Indeed, many diverse cultural factors converge upon graffiti—masculinity, psychology, political philosophy, sociology, and anthropology—making it a highly relevant, if not exciting, phenomenon for humanistic study.

Under the latest terms of developmental psychology's model of Positive Youth Development (PYD), a youth's involvement in graffiti should be evaluated as to how it affects the burgeoning individual's psyche and that individual's psyche's relationship to society (as well as proposals to address urban policies in relationship to their involvement in graffiti). In this sense, graffiti demonstrates two sides, negative and positive. It is problematic in terms of its vandalism and possible arrest records, the latter contingent, in fact, upon policy itself. However, it is positive in its development of community involvement (such as the subculture's mentorship), aesthetic awareness (for the more artistically inclined) and as an alternative to more destructive options.

Graffiti therefore engenders a multidisciplinary analysis of a turbulent, transitional state that all members of society experience to varying degrees, either as adolescents or at later periods in life in which a liminal condition arises. Graffiti is simply a response to a specific youthful existential experience with which we are all, to greater or lesser degrees, familiar, even if time and aging have distanced us from our teen angst. In truth, my interest in graffiti is not in the subculture per se, but in what it reveals about ourselves in terms of gender concerns, Western contradictions in conceptions of rights and powers and the influences of art and community. This concern is reflected throughout this paper. The resulting analysis can serve as a model for understanding other 
phenomenon where liminality is a central element.

\section{B. Graffiti: Scholarly and Non-Scholarly Attentions}

Graffiti has been in the public consciousness since at least the 1970s, but not analyzed from the perspective of liminality. While its birth is considered generally to have taken place in New York City and Philadelphia, the practice has continued to the present day. The essential tradition established in the New York-Pennsylvania corridor has remained relatively intact as it has spread worldwide, such as the style of the production, the locations of significance and the career of its participants. Even today, its primarily anonymous population follow a standard trajectory: they begin by making 'tags;' they express a rebellious philosophy in the face of societal laws and corporate power; they risk their lives and/or legal status by vandalizing property; some evolve their craft through a progression that starts with tags and finishes with elaborate 'masterpieces;' they defend their practice as an expressive art; and, finally, with the typical exceptions expected of large population samples, they cease involvement by the time they enter adulthood—when their liminal condition more or less subsides.

Despite this continued tradition, I have found that there have been recent changes that have had a marked effect on the practice, in particular in the realm of technology. Since the illegal works are often removed ('buffed'), the youth use digital technology like smartphones to document their productions. They upload the digital recordings to web sites like Photobucket, YouTube, blogs and extensive community forums like 12OZProphet.com. These sites function to generate both a permanent virtual portfolio and an international audience. The anonymity of the real world graffiti practice finds 
kinship in the anonymity of the internet. This new aspect of graffiti culture would be difficult to conceive from the perspective of someone acting in the 1970s, when cheap Polaroids were the only reliable and anonymous means of recording one's productions. This aspect of graffiti obviously is not included in pre-internet ethnologies.

Due to its long history, graffiti has invited analysis from scores of thinkers, from humanists, journalists, art critics and especially anthropologists and ethnographers. These studies serve as a basis for my research. They include scholarly ethnographic studies such as Lachmann's seminal 1988 article "Graffiti as Career and Ideology," which I find useful for understanding the process of youth involvement, and Nancy Macdonald's published dissertation The Graffiti Subculture: Youth, Masculinity and Identity in London and New York, 2002, especially pregnant with ideas about masculinity; the formal analysis of the complexities of the masterpiece in Lisa Gottlieb's Graffiti Art Styles: A Classification System and Theoretical Analysis informs my thoughts on masterpieces, and, similarly, Christian P. Acker's Flip the Script provides insight into the variety in tags themselves; graffiti's association with gang markers in articles such as the antiquated 1974 David Ley essay "Urban Graffiti as Territorial Markers," (an article I can ignore due to my focus on its gang elements); personal accounts and stories, such as Stephen Powers' 1999 nostalgic The Art of Getting Over, which aids me in appreciating the role of technology today for its current practitioners; the emphasis on audience and performance in such writings as Jeff Ferrell and Robert D. Weide's 2010 article "Spot Theory," reinforcing my thoughts on the nature of the tag, as well as Evan Roth's popular digital graffiti blackbook analysis; various debates and criticism about its status as art or vandalism, ranging from full-length dissertations and popular media discussions to curated shows in prestigious 
museums; ${ }^{1}$ and, finally, the rising dominance of the importance of digital documentation of graffiti as a product in itself, such as by its actual creators on forums on sites like 12ozProphet.com to grafarc.org's Graffiti Archeology sophisticated time-analyses. This last element, the digital, represents a metatext which is often ignored in thoughts about graffiti, one which I include in my reflections. We might also add to this collection of categories the 'outliers' whose work is often improperly classed with graffiti by the general public, such as BLU's videos of animated street art, Shepard Fairey's Obey Giant logo, Banksy's renowned oeuvre, from his street work to the 2010 film Exit Through the Gift Shop, green graffiti (art of constructing imagery and messages through exact removal of city grime, using the resulting negative space), and MobiSpray (digital graffiti mapped unto public space). These outliers inform my work in that the renown of their makers, as well as the fame of the objects they produce, allow them to speak for principles of street art in general. Finally, there are compilations of the history of graffiti, such as Craig Castleman's Getting Up, Joe Austin's Taking the Train, and Roger Gastman's and Caleb Neelon's The History of American Graffiti, books which demonstrate in-depth scholarship especially about the practice's origins and general history. These are very useful for me and any enthusiast of graffiti in that they summarize many of the insights of scholarship of their day.

Of course, this is not an exhaustive list or summary of the writings to date; to do so would require a volume in itself. My reasons for listing them here is to demonstrate the diversity of research that graffiti has inspired from scholars, thinkers, academic

I refer to this debate in its most generalized sense throughout this paper, namely that graffiti's status or non-status as art is contested by mainstream media sources as well as some research papers. 
researchers, graffiti enthusiasts and the non-academic community at large. In fact, one might consider another paper on graffiti to be redundant with these past efforts.

However, my work here, while relying upon these other thinkers, analyzes graffiti involvement in terms of liminality (and the recent focus of developmental psychology's Positive Youth Development). I offer nuances on graffiti's masculinity, the contradictions facing youth in terms of their rights, and how youth in graffiti might behave throughout the duration of their involvement.

Finally, graffiti crosses the categories of various art genres. Its status as art is contested heavily in the United States. Whether or not it always succeeds as art does not deny it its category as an art form. It is primarily a visual art form — street art — and merits its own status as 'graffiti art.' One might categorize it as public art, even if it is not always commissioned as such, since its appearance as vandalism (and legal mural) is in predominantly visible locations.

It could also be understood as a combination of installation/site-specific art and performance art. Its forms and colors change somewhat based upon the location where it is made; the youth sometimes film themselves in the act of production, for an emphasis on the act itself for an audience; and finally, as a disruptive 'happening,' someone might chance upon graffiti either as an unexpected finished product or even someone in the act of making it.

It can even be considered under other categories of art. For a brief period it was avant-garde when it made its appearance in galleries in the early 1980s. Its youthful population tends to be untrained, so in this sense one might consider it outsider art (without the reference to disabilities). Its documented form on the internet makes it a 
quasi-electronic form of art, although this attribution is dubious. (Electronic art specifically refers to the creative use of electronic media. In graffiti, electronic media is used to document. The key exception is the work of BLU, whose stop-motion animations of graffiti are visible only in their video form.) Finally, it has a political dimension as political art, especially due to its illegality. Public space is inherently political; graffiti 'bombers' vandalize corporate billboards as a statement against corporate power; and in many parts of the world graffiti has assumed a specific political expression.

The culmination of social debates and artistic criticisms, museum shows and police arrests, uploads of YouTube videos by practitioners, and the passionate participation of its mostly youthful population makes for a medley of confusing attributes. The general consensus, from those both pro- and anti-graffiti, is that the graffiti masterpiece tends towards fine art, whereas the tag is simply vandalism, however one wishes to further categorize the practice. I accept this consensus while acknowledging exceptions. There is a performative dimension in the realm of gender, not aesthetics, which is the subject of Part III, and there is also a subtle political dimension in the production of graffiti which is the topic of Part IV.

\section{Issues and Concerns}

There are popular, non-scholarly interpretations of graffiti that rest upon the influence of Marxist currents on intellectual thought of the past century, persisting even today despite the supposed dismantling of Marxism in both postmodernism and the fall of the Soviet Union. ${ }^{2}$ They are representative, possibly even derivative, of early works on

2 It seems that there has been a return of Marxist paradigms of class conflict in popular culture since 
subculture, in particular Dick Hebdige's Subculture: The Meaning of Style. In fact, I shared this tendency when thinking about graffiti in the early stages of my research. According to this theoretical framework, I had assumed that graffiti came into existence as a protest against a dominant, property-owning class and its power in public space. This property-owning class is perceived by youth in the power of corporations and therefore the limited population of their stockholders, dominated by white upper-middle class North Americans. I imagined that the graff producers, whom I generically assumed to be poor blacks (and serving as mental placeholders for the proletariat), waged a guerrilla war against the intrusion of marketing in city space by either defacing billboards, making visible art and/or creating an avenue of spontaneous expression that redefines the everyday experience of the public space.

I am not alone in these assumptions. For example, Banksy, the articulate voice for street art in general, illustrates this conception of graffiti from the perspective of its makers in Wall and Peace, 2009:

The people who truly deface our neighborhoods are the companies that scrawl giant slogans across buildings and buses trying to make us feel inadequate unless we buy their stuff. They expect to be able to shout their message in your face from every available surface but you're never allowed to answer back. Well, they started the fight and the wall is the weapon of choice to hit them back. (9) ${ }^{3}$

mainstream thought now considers Marxism safely deceased, or is completely unfamiliar with it. For example, the books (and films) The Hunger Games (2008-) are based on class conflict.

3 I use Banksy as an illustration of a mindset, not as evidence, as his thought and activities have influenced a generation of graffiti producers. This tendency places all corporations into a singular type and, in the same act, all street artists and graffiti writers in the other. It is unusually reductionist. In this vein, the anonymous writer 'Standard Bearer' of International Get-Hip Times (no date) typifies this view. He states in response to New York City's crackdown on graffiti vandalism the following: 
I soon learned, however, that was incorrect in assuming this stance. It serves, unfortunately, as a distraction from the more relevant issue of the liminality of the youth and their gendered interests. Banksy gives voice to liminal vulnerability in which a masculine response is one of aggression. I have since learned that the ethnicity, class and race of graffiti producers are not limited to any group, nor is there any evidence that they are predominantly a part of any specific racial or class group other than youth and males. One can even assume that most graffiti is made by white middle class teenage males by dint of demographics since they comprise the largest population. This represents a shift from its probable origins in lower-class youth. For example, Joe Austin writes in Generations of Youth: Youth Cultures and History in Twentieth Century America about the population changes:

Writing began in predominantly African American and Puerto Rican American working-class neighborhoods, which tended to be the most socially "invisible" areas of the city. But the practice had spread significantly across class and race lines by the mid-to-late 1970s. Writing culture seems to have been relatively immune to the racial polarization that marked most of the rest of the urban population. Race and class harmony was facilitated by the writer's ethical codes.

Nancy Macdonald, in her thoughtful aforementioned book The Graffiti Subculture, confronts the class (and race) consciousness tendency in critical thought, in her case the Marxist "British New Wave Subcultural Theory" in its "Marxist understandings of social relations which see society divided in terms of power and

"NYC - the big cultural capital city of the world. The Big capital K-Kaptives of Kulture and Kapital. NYC rules-your ass, that is..." (quoted in Taking the Train, 227). 
control of forces of production" (37). She concludes that theorists using this perspective tend to ignore age and gender, key attributes of the graffiti practitioners (if not the key attributes). ${ }^{4}$ Nevertheless, Macdonald emphasizes masculinity while ignoring youth issues independent of male identity, particularly the liminality adolescents experience as they shift from childhood to adulthood.

The fact remains that we know little today about who makes graffiti. Ignorance of its population's demographic highlights a key problem in understanding graffiti. The subculture acts anonymously, but not quietly. There exist, several bodies of evidence regarding the subculture's membership and thought: police records of captured vandals, revealing a specific age range of 12-19; statements in interviews ${ }^{5}$ and in online communities that confirm the subculture's strong investment in male identity; aggressive public assertions from community members through anonymous postings and comments of more famous, older (if not 'retired') members that evince a passionate concern in maintaining graffiti's status as a work of art; some generalized tendencies in its development in a single practitioner's career (as evinced from ethnographic research); the objects that graffiti writers construct, such as tags, throw-ups and masterpieces, as well as

4 Here, too, I am not claiming that this is a bias of scholarship, but a tendency in thinkers without any necessary ramifications about the actual scholarship in existence. I can recall, when I first encountered graffiti in graduate school, how immediately specific mental 'gears' were set in motion, automatically circumscribing the phenomenon within class, race and 'protest' style activities. I do not believe I am alone in these kinds of thinking in which a (good) tendency of both tolerance and "assumed value/intent" is immediately put forth, almost as an apology or even defense, long before any knowledge of the practice is understood. In fact, I was stunned when I came to the realization that the typical 'face' of graffiti in the United States was most likely a middle-class white teenager. Maggie Dickinson states in her article "The Making of Space, Race and Place" that it was former New York Mayor Rudolph Giuliani's anti-graffiti campaign that (inadvertantly) caused the general public to associate graffiti with poor minorities.

5 Specific scholarly anthropological studies have used interviews and ethnographies, hoping that the tiny sample population is indicative or, if not, at least credible, due to the honesty of the sources. For example, Richard Lachmann interviewed twenty-five graffiti practitioners for his aforementioned article; authors Monto, Machalek, and Anderson interviewed a single crew (a small team of producers working together); and Nancy Macdonald interviewed twenty-nine. 
the nature of their locations; and documented productions or acts of producing (such as in videos). From these basic elements, a somewhat firm ground can be found to critique graffiti, accepting that there exist practitioners who are exceptions to the rule.

The previously cited scholarly productions (such as Taking the Train by Joe Austin), while well-researched and intelligently constructed, conceive of the practice from a fragmented perspective. My fundamental concern is a failure to recognize the role of liminality in adolescence in general and how this informs the construction of masculinity, the assertion of freedom and rights, and the overall phases of the process of involvement. These aspects - masculinity, liminality, and notions of freedom-are intertwined. For example, one might analyze the complex issues of masculinity inherent in the practice, as Macdonald does in The Graffiti Subculture, but fail to address how those gender dynamics are compensatory to adolescent liminality itself. This liminality is in turn not limited to males, making categorical statements about masculinity and the whole graffiti community problematic, even if insightful for the specific males involved. The authors of the article "Spot Theory," former practitioners of graffiti, use terminology and values for the performative aspect of the practice, including references to masculinity, yet are themselves no longer youth. Hence, they do not address the instability that motivates young males to the practice, despite their genuine concern for making the practice better understood. They also ignore performance studies while describing performative behavior. Similarly, debates for or against the artistic status of graffiti vandalism, whether sophisticated or vulgar, ignore that its status as a work of art actually serves an important function in the sphere of the community's conception of liberties. 
Similarly, philosophical analyses of social contract theory ignore the practical effects of today's societal laws in relationship to the principles of those philosophies. A critique on John Locke's philosophical views on children, such as Yolton's John Locke \& Education, completely ignores how the period of adolescence and how it rests in an inbetween space of mixed powers and partial rights—-born from specific, real world laws. This 'space,' liminal space, is not compensated for within social contract theories. It is not childhood-versus-parental rights that is typically of issue today, since pre-adolescent children by and large accept the powers of parents. It is adolescents who rebel, aggravated by their status as non-adults in a state of familial dependence while yearning for the powers and rights of maturity. Hence this requires an analysis both of how actual societal laws function as well as the deeper conundrums of the philosophical principles they reflect, such as the role of the public bias over the superiority of rationality and the tacit nature of the age of political consent.

Positive Youth Development theory, in fact, emphasizes that consideration of how policy may affect youth is an essential, if not obligatory, tool of any analysis. The editors of the third edition of the Handbook of Adolescent Psychology write that

... we are in a phase of science defined by theoretically framed, research-based applications to programs and policies that advance understanding of the basic, individual-context relational process of adolescent development and, as well, that enables policy makers and practitioners to collaborate with scientists to enhance the course of development. (12)

More specifically, Jacqueline V. Lerner, Erin Phelps, Yulika Forman, and Edmond P. Bowers, in their book section entitled "Positive Youth Development" write 
that the shift to PYD is a change from past tendencies which held a "negative, deficit view of youth" (524). PYD establishes how a society (such as the United States) wishes youth to develop through and emerge from adolescence instead of correcting deviant behavior. For example, youth development programs were surveyed by the aforementioned authors to see if they included "(1) specific program activities, (2) atmosphere, and (3) goals" (530) as "defining aspects" that differentiate them from nondevelopmental youth programs. Other important qualities for youth development include the ability to transition from school to work, general motivation to act positively within unstructured time periods (instead of delinquency) and resilience in the face of psychological and sociological stress.

Positive Youth Development also emphasizes a new mode of perceiving youth growth. According to Lerner, Phelps, Forman, and Bowers, it embraces many of the changes brought upon by postmodernity. It perceives youth not simply as isolated individuals but agents that are both movers of their contexts as well as affected by them. It emphasizes "plasticity" (541) of the human organism as an "opportunity for change" (541), such as how one experiences through time a given set of cultural relations. Finally, unlike past instances of psychology, it embraces "multidisciplinarity and the need for change-sensitive methodologies" (541) I have reflected these above concerns in this paper when approaching graffiti by including the contextual experience of masculinity in terms of social history, rights and the Hegelian dialectic; the context of youth and their relationship to the ambiguous changes in their relationship to rights and powers; and, finally, I analyze the involvement in the graffiti subculture from the perspective of the plastic changes within its processes. 


\section{Liminality as a Cross-Disciplinary Critical Paradigm}

Richard M. Lerner and Laurence Steinberg, editors of the third edition of the Handbook of Adolescent Psychology, remark in their introduction that there has been a surge in recent years in interest in adolescent development because it serves as a "'natural developmental laboratory' for elucidating issues of interest across the entire life span" (10). The 'plasticity' of youth in their engagement with the contexts in which they develop while they themselves are also in continuous growth serves as a model for understanding any aspect of human existence in which difficult transitions occur. Youth change and so do their environments, making an individual $\leftrightarrow^{6}$ context study pregnant with variables and hence possibilities. In short, adolescence is a hot topic.

Liminality is the equivalent model to youth plasticity in the humanities and youth are often used as the de facto example ${ }^{7}$ of this liminal state. An interest in youth cultures, crises and philosophies are relevant for the humanities for the same reason that developmental psychology is currently focused upon adolescence. Youth and their response to liminality is, in many ways, representational of how, to a lesser degree, adults also confront liminality. Since it is youth that make graffiti, liminality is an essential grounds for understanding their emotional and psychic experience independent of the practice and how it is confronted therein.

Though the term 'liminal' might be unfamiliar to scholars in the humanities and elsewhere, its history and use has been extensive, especially in anthropology. It was first

6 The double arrow symbol $(\leftrightarrow)$ is used heavily in developmental psychology to emphasize the dual nature of influence of individuals and their contexts.

7 When books wish to create an illustration to understand liminality, they often mention adolescence. It is used always as its premier instance in that all adults have experienced it, to greater or lesser degrees. For example, van Gennep mentions this in The Rites of Passage, as do Victor Turner (The Ritual Structure) and Arpad Szolcakzai ("Liminality and Experience"). 
coined by Arnold van Gennep in his 1909 book Le Rites des Passage. His research focused upon the traditions created to affect male youth in tribal societies. His efforts, largely ignored in anthropological circles for the first half of the 20th Century, were developed when Victor Turner, recognizing their diverse applicability, continued the model from the late 1950s in such works as his book The Ritual Process. Turner expanded upon the structured form of liminality suggested by van Gennep and applied it to all aspects of human life, including non-traditional areas such as arts and entertainments (calling the states invoked by these 'liminoid' as opposed to 'liminal') and, later, performance studies with Richard Schechner. Graffiti, for example, is a liminoid practice in response to a liminal (adolescent condition), creating further layers of liminal experience within the subculture itself (such as the rite of passage into membership). Today, humanist thinkers such as Arpad Szacholczai are furthering Turner's expansion of the use of liminal models for understanding all aspects of changing and transformative human behavior. It is, in short, a good time for humanists to become familiar with the paradigm.

\section{The Structure of Liminality}

According to van Gennep, liminality is structured, and this structure informs how we might understand youth before, during and after their involvement in graffiti. It proceeds, ideally, according to a specific sequence of experience. The liminal stage typically follows a previous rite of separation that distinguishes if from the 'preliminal' state and is then followed by a subsequent rite of incorporation, by which the individual passes into a 'postliminal' stage. This, he argued, was the dynamism of ceremonial rites- 
preliminal, liminal, postliminal—such as rites of passage for male youth entering adulthood. Youth, before the onset of adolescence, are 'preliminal;' when they become adults, they are 'postliminal.' Adolescence is the liminal period.

Rites of passage typically exhibited this threefold movement and today, in both popular culture and Men's Studies, are heavily associated with male rites of passage into manhood. For this reason, masculinity studies sometimes references such rites and even proposes to reinvent them, as in mythopoeic movements. Indoctrination into membership into the graffiti subculture, for example, could be conceived of as a 'rite of passage' for youth. However, the term 'liminal' covers all shifts in any group undergoing a critical transition. ${ }^{8}$ If one extends the notion of transition to be one of existential states, liminality may be used to understand aspects of social life not normally analyzed as such. For example, the category of liminal group can encompass an entire nation, such as preWorld War II Germany and the recent (and ongoing) situation in 2015 Ukraine. In his article entitled, "The Uses and Meanings of Liminality," Bjorn Thomassen suggests just this expansion of the term, far beyond its use by van Gennep and Turner. He writes, using Turner's own words, that

8 'Marginalized' is not the same as liminal, though the terms may refer to the same population under certain conditions. In the history of the United States (and the West in general), there emerged many movements of various liminal groups that sought to transform mainstream structures. For example, women were in a state of permanent second-class citizenship, i.e. marginalized. Women became a 'liminal' group from the beginnings of the First Wave of feminism, from Margaret Fuller to the efforts of suffragettes, once they challenged social doctrines on the status of women, since their status began to change. Liminality, in this instance, becomes applicable because the ethical and social grounds on which a woman's consciousness and identity rested became untenable. The old 'structure' was broken courageously. From the struggles of African-Americans and Civil Rights to individuals with disabilities and the Americans with Disabilities Act of 1990, the United states mainstream social edifice experienced widespread challenges and, finally, ethical transformations in the last 150 years thanks to these groups. According to the Turner (in his study of small village life), this is the important function of liminal groups in that they enable a society to renew itself. Thomassen writes that in "his analysis of Ndembu ritual, Turner ... showed how ritual passages served as moments of creativity that freshened up the societal make-ups, and argued ... that rituals were much more than mere reflections of "social order" (14). 
liminality refers to any "betwixt and between" situation or object. It is evident that this understanding opens up space for possible uses of the concept far beyond that which Turner himself had suggested ... Liminality can also be applied to both single individuals and to larger groups (cohorts or villages), or whole societies, or maybe even civilizations. (16)

Graffiti also is appealing to males since male identity in the twentieth century was in a period of great transition even before graffiti's beginnings. ${ }^{9}$ Arpad Szacholczai argues further in his article "Liminality and Experience" that for all human learning, the "structure of lived experience" follows "the sequential order of a rite of passage" (147). The formative experiences of a human being cause him or her to experience some kind of emotionally challenging situation that takes him or her outside his or her realm of the known before subsequently reincorporating the knowledge back into his or her life. He writes of experiences:

The consequences are subjectivity and manifoldness. Subjectivity, as existential involvement renders the understanding of our own experiences one-sided, opaque; and manifoldness, first because our life we are faced with so many events that they overwhelm us; and second, as participating in events helps us to acknowledge perspective. (147)

Graffiti involvement exhibits this one-sided dedication of its practitioners through its strict regimen of tag production, law breaking and ideology. Also, it offers them the 'expansion' of their social network through its international community. For example, one

9 Michael Kimmel's Manhood in America documents these changes, specifically in Parts II-IV, "The Unmaking of the Self-Made man at the Turn of the Century," "The New Man in a New Century, and The Contemporary "Crises" of Masculinity." 
must produce tags in order to earn his or her entrance into the community; one must break the law in order to earn street credibility; and the proliferation of sites such as graffiti.org and $12 \mathrm{OzProphet.com}$ enable them to connect with a vast international community.

Nevertheless, the threefold structure of liminality requires its third phase, the completion of experience (postliminal). Should it be achieved, it creates, in short, wisdom; it is the existential path to the most important facet of human knowledge. Wisdom is not won through everyday life but through exceptional circumstances coupled with closure. I question whether or not graffiti involvement actually 'completes' its movement, raising the fundamental issue of whether or not graffiti is ultimately positive.

\section{Four Characteristic Qualities of Liminality}

Alongside the basic structure of preliminal-liminal-postliminal, there are other similar qualities experienced by figures in the central moment of liminal experience, no matter the constituency of the group or the phase's duration. This could be utilized as part of the critique of graffiti involvement. The qualities and states are, first, 'vulnerability and imitation'; second, 'communitas'; third, the figure of the 'trickster'; and fourth, 'schismogenesis.'

\section{a. Vulnerability and Imitation}

Figures in a liminal community by definition stand in opposition to mainstream structures and values. Adolescents, before interest in graffiti, find themselves excluded 
from all the societal powers available to adults while still expected to obey its norms and laws. Adolescent rebellion results in a rejection of mainstream codes. Hence youth are vulnerable since they do not have a well-known 'ground' of codes and history on which to base their thought and actions.

The response to such vulnerability might be 'imitation.' It is a form of regression and psychic defense mechanism. In imitation, the individual follows some other code of action, morals and/or behavior that appeals to them emotionally in order to establish for themselves a new 'firm' foundation. It is an attempt to escape liminality. Herein arises the appeal of youth subcultures like graffiti. Arpad Szacholczai describes this psychic pressure further in "Liminality and Experience":

Under such conditions ... individuals trapped in a liminal situation cannot follow their "rational interests" for two reasons: first, because the structure on which "objective" rationality was based has disappeared; and second, because the stressful, emotive character of liminal crises prevents clear thinking ... Imitation poses particular problems in liminal situations: the key question is who manages to convince others to follow him as a model. (154)

Victor Turner writes about this challenge in his article "Liminal to liminoid in play, flow, and ritual: An essay in comparative symbology." He states that "novices are, in fact, temporarily undefined, beyond the normative social structure. This weakens them, since they have no rights over others" (59). For example, a male youth rejects mainstream codes in an act of rebellion, then finds himself very alone and vulnerable. He then meets a gang of boys who act friendly, perhaps inviting him to be a member. This lures him to join the gang, imitating their lifestyle, even though its codes may actually be less in his 
self-interest than those of the mainstream culture that he is questioning and rejecting. Similarly, any youth first joining graffiti becomes a novice, or 'toy,' falling into a secondary liminal condition alongside his or her initial status as a liminal youth.

\section{b. Communitas}

The aforementioned vulnerability can also engender positive aspects and behavior. Turner witnessed what he called 'communitas,' an emotional bond that strengthened the ties of the individuals as they shared their experience of being liminal. Turner observed this in members of a pilgrimage and the feelings of community developed amongst the pilgrims. Youth in graffiti, though highly competitive, also form strong ties to others such as in the creation of crews and mentorship of new recruits. There are commonplace examples of this as well. Some African-American males refer to each other as 'brothers' in contrast to mainstream white culture, although this is obviously a cliche.

Furthermore, Turner argues in "Liminal to liminoid" that liminality "also liberates them from structural obligations" (59). This liberation is one of the many reasons why youth subcultures tend to incorporate the violation of social norms, such as rules infractions and graffiti vandalism, as part of their performative behavior and means of membership.

\section{c. The Trickster, or Beguiling Ideologies}

Another 'quality' or even 'figure' to emerge is the notion of 'Trickster.' This is purely negative and represents possibly the most critical (if not judgmental) aspect of the 
liminal framework. This quality (or even person) exploits the vulnerabilities of the liminal community and their tendency to imitate leaders as a pseudo-solution to their crises. We might question, then, whether or not the career of graffiti represents the seduction of the Trickster in that the youth, vulnerable in their liminal state, are drawn to it simply because it is forcefully and confidently portrayed (specifically, as a form of masculine and artistic activity). Szakolczai describes the characteristics of the trickster when it emerges in a specific personality:

Tricksters are always marginal characters: outsiders, as they cannot trust or be trusted, cannot give or share, they are incapable of living in a community ... tricksters can suddenly become dangerous: in a situation where the attention of the community is on the wane, in an instant the trickster can capture the occasion and institute a lasting reversal of roles and values, making himself or herself a central figure in place of the marginal outcast. The condition of possibility for such trickster takeovers is a liminal situation where certainties are lost, imitative behavior escalates, and tricksters can be mistaken for charismatic leaders. (154155)

As suggested by Szakolczai, the trickster may take the form of a reactionary personality, offering a 'traditional' backlash to progressive groups and their efforts of societal transformation. Similarly, the term might be expanded to be the reactionary ideology itself which is then wielded by a variety of figures. There is a long history across cultures of individuals (especially, unfortunately, males) asserting traditional values to repress groups. Vladimir Putin gained power in Russia, even as an ex-KGB agent, since his reactionary stances offered a pseudo-firm ground against the liminal 
crises brought about years before from the progressive policies of glasnost and perestroika. Similarly, the United States has experienced large demographic changes, both in its population and legal voting constituency. This created a liminal situation for its mainstream citizens as the influx of diverse peoples transformed the political landscape, the limits of the English language, and many other basic cultural qualities.

In the 2008 presidential campaign, the candidacy of Barack Obama became a symbol for this transformation, both in his physical constitution (his racial ancestry) and political platform. The aforementioned demographic changes resulted in extreme reactionary right-wing political movements (as some individuals have sought security in a reactionary ideology). Consequently, the Republican party found as Obama's opposite the figure of Sarah Palin. She promised security in deflecting the 'socialist inspired' values of the democratic party. Poorly educated, unimaginative, provincial and ambitious, she spoke with absolute certainty as to the nature of Americanism and the role of the United States, its governing bodies, and foreign policy. This air of certainty in a time of decreasing American world power, threats to the environment, and national debt gave many Americans what appeared to be a 'safe' path out of liminality. This is the grounds on which trickster figures as Rush Limbaugh and Anne Coulter thrive, or Tea Parties exist with a secure-sounding set of guiding principles. The final result of the reactionary political movements has been that the United States political realm is trapped in permanent liminality or 'schismogenesis,' since the reactionary right rejected the new, unfolding nation in favor of the comfort of 'traditional values.'

\section{d. Schismogenesis}


Finally, 'schismogenesis' is an important concept in the critical framework since its applicability is so widespread. It serves, in part, as a cautionary element. Turner, in fact, suggested in his studies of pilgrims that their lifestyle and religious beliefs leave them in a state of permanent liminality. This is not inherently negative. Religions embrace schismogenesis, since the continuous confrontation with the unknown results in the nurturing of the depth of one's character. Existential philosophers-Soren Kierkegaard (the 'religious' stance versus the aesthetic or ethical), Jean-Paul Sartre (authenticity versus 'bad faith'), Martin Heidegger (Dasein and fallen-ness), and Simone de Beauvoir (ethical ambiguity) - find in it the grounds for morality. Certain art forms, such as in Abstract Expressionism, celebrate meaning in the unfinished. In fact, I argue that 'transformative art' is born from, and dwells within, the liminal, raising the question whether or not graffiti might be considered transformative (or 'liminal art').

Schismogenesis can also be negative, however, and is layered in its possibilities and effects. Szakolczai, crediting the work of Gregory Bateson, says that entire schismogenic societies result from the failure of reintegration (postliminalitiy) and hence remain in this permanent liminality, as "the schimastic components are forced to stay together, producing an unpleasant, violent, harrowing, truly miserable existence" (155), e.g. Szalolczai considers the period right before World War I as emblematic of liminal crisis, writing that "European thought, weakened by neo-Kantianism, was unable to resist the virus of totalitarian movements and ideologies once, under liminal conditions, the former - greatly ossified - stabilities were taken away" (165). This is also why it is essential, when using liminality as an analytical framework, to question whether or not a 
given individual or group ever emerges from the liminal condition. ${ }^{10}$

Men's studies and men's liberation movements bemoan the fact that males fail to adequately transition from adolescence to responsible adulthood. According to these analyses, men remain, therefore, schismogenic, lacking traditional rituals to achieve the shifts and closure. Graffiti, since it is predominantly male, begs the question whether or not it allows males to transition into non-schismogenic states of male identity at the end of their involvement, even though it is not specifically a rite of passage. ${ }^{11}$ The twentieth century in the United States may be considered also to be an extended period of male liminality — a schismogenic state — interrupted mainly by the male-affirming grounds of the two World Wars (and other military engagements, save for Vietnam, in which case American masculinity was castrated). Reeser, in his book Masculinities in Theory: An Introduction, summarizes this period succinctly:

The late nineteenth century in the United States, for example, is often seen as a historical moment in which shifting definitions of masculinity, from agriculturally based to industrially defined, led to widespread anxieties as the subjective did not

10 The tripartite structure of lived experience that constitutes liminality has appeared in other analyses of culture. Consider, for example, Dick Hebdige's seminal 1979 Subcultures: The Meaning of Style. He argues that subcultures experience a specific structure in their emergence and disappearance, writing that the "cycle leading from opposition to defusion, from resistance to incorporation encloses each successive subculture" (100). His categories are distinctly similar to those in liminal structures and experience: he used the term 'opposition' instead of 'preliminal,' 'resistance' instead of 'liminal,' and 'incorporation' for 'postliminal.' Hebdige also writes how subcultures, via their incorporation into a culture, aid in reinventing it, precisely what Turner argued was the important function of liminality. However, since Hebdige would not have been able to employ more recent research into liminality, such as an awareness of 'schismogenesis' and the Trickster, he was not aware of some of the dangers associated with liminality. He therefore only could celebrate youth subcultures such as Punk while remaining ambivalent to the plight of its former members.

11 Men's studies and men's liberation movements encounter confusion here since early studies in liminality (and more specifically, 'temporal' liminality, since it involved a transition in age) were specifically about male rites of passage into manhood i.e. van Gennep's seminal work. Hence, practitioners in the field either sought to imitate these traditional rituals directly with new ones (such as Robert Bly's drum groups in the forest) or to identify the activities of males in the context of the ritual forms, e.g. in the latter case, one might question how it is that the practices of youth institutions might mirror a traditional rite of passage. 
correspond to the ideology of masculinity that was spreading via industrialization. Numerous other periods have been seen as crises of masculinity. A growing feminist discourse and a growing gay discourse can provoke a masculinity crisis as they transform cultural ideologies of masculinity into something that does not conform to individual experiences. Some say that feminism in the 1970s and 1980s precipitated a crisis in masculinity, and some believe that the visibility of male homosexuality in the last decade or so has put heterosexual masculinity into crises. (27-28)

Men were placed in a liminal crisis because various minority groups (especially women) challenged their hegemony in the public and political sphere. The formerly solid grounds of male identity collapsed. In this state, males shifted into 'imitation' mode and either fell prey to Tricksters (reactionary political movements), sought a rationalization about their experiences (Men's Studies), or attempted to reinvigorate a new sense of themselves by enacting rites and self or group therapy (mythopoeic and men's liberation movements). Graffiti was also born in this time period and represents a return to turn-ofthe-century models of risk-taking masculinity. Its productions, including tags and masterpieces, may also be interpreted as a marring of the new diversity of public space in an act of defiance.

\section{Youth and the Liminal Condition}

All liminal experiences result in a tense, emotional, irrational state. For some youth, this passage through adolescence is not stressful. They are given the means of support from family and community. For others, though, this support is not there, or 
worse, it is the origin of power tensions. Hence their liminal status is further exacerbated by personal conditions beyond the social and biological. Youth drawn to graffiti no doubt represent a part of the segment of early adolescents that are especially vulnerable in this regard, since its danger and vandalism are radical reactions. This hence places them more strongly into an 'irrational' and emotional state of vulnerability.

The time period of adolescence also signifies, developmentally, that cognitive changes emerge in the form of an engagement with values and ideas. This engagement is varied, but exists; youth find principles profoundly important. ${ }^{12}$ It might seem that their behavior is irrational, but it is often guided by ideals. Graffiti is no exception; the youth believe in the elevation of art, the demonstration of courage and the response of community. It is here, though, that adults tend to unfairly judge adolescents in general, ascribing their emotional crises to basic undeveloped, irrational psyches. Their irrationality is not the cause of their crisis; it is the effect of it. It is one of the qualities of the liminal phase (vulnerability), a feature that will affect an adult as well should that adult experience a liminal crisis.

All criticisms of youthful deviant behavior, such as involvement in graffiti, that are ascribed to the irrationality and emotionality inherent in adolescence must therefore be put into question. For example Myra Francis Taylor's "Addicted to the Risk, Recognition and Respect That the Graffiti Lifestyle Provides: Towards an Understanding of the Reasons for Graffiti Engagement" reduces graffiti involvement to the addiction to adrenaline according to chemical brain analysis. I imagine that such criticisms are

12 For examples of youth principles, see Deanna Kuhn's "Adolescent Thinking" and Eisenberg, Morris, McDaniel and Spinrad's "Moral Cognitions and Prosocial Responding," both in the Handbook of Adolescent Psychology, 3rd Edition. Certainly, youth drawn to graffiti are especially motivated by principles, since the practice itself extols the virtues of art and freedom. 
launched by adults who did not have an adolescent crisis, who unsympathetically and detachedly label such youth as moral deviants.

Western youth who find themselves in crisis - many, if not all, of them, to some extent - will engage, therefore, in imitative behavior, one of the signposts of liminality. This imitation may be as simple as acting to "fit in" with the rest of their peers, such as through fashion codes, use of certain brand name devices, and the adoption of phrases and gestures that are easily identifiable.

Corporate marketing in the form of consumer culture, in fact, exploits this vulnerability in youth, utilizing Hollywood personalities for imitation in order to sell a product line. For example, Liz Cohen writes in The Consumer Republic how Pepsi-Cola inserted "their product into the fantasy world of the teenage market segment, dubbed ... in an extraordinarily successful advertising campaign from 1961-1966, the "Pepsi Generation" (319). A similar effort to make themselves representative of rebelliousness was achieved by Apple Computer through its "think different" campaign in the late 1990s, even appropriating historical figures like Einstein. If one buys an Apple device, one may feel communitas with the mathematical genius.

However, some youth resist these mainstream forms of imitation, unconsciously witnessing in them a form of trickster seduction in which a certain clothing line becomes the means to be a part of the esteemed community and hence a means to resist liminality. The youth who are able to identify corporate youth marketing as trickster are aware of themselves as outsiders, as their liminal condition is more pronounced than that of their peers. It is here that we can locate initiates of graffiti, since the graffiti subculture expresses a profound disdain for corporate advertising and the 'sellouts' in their own 
ranks. In fact, one of the practices of graffiti is to 'bomb' billboards and advertising signage by placing graffiti over them.

Youth who reject mainstream codes of conformity might join a youth subculture, like graffiti, with which they identify. They imitate, therefore, the norms and codes within that new youth subculture, itself possibly a form of trickster seduction. In fact, all youth subcultures are heavily marked by performative social elements for visual identification, such as dress codes, which logically follows from the conditions of liminal states. Graffiti dress codes typically feature hooded sweatshirts, a symbol of covert activity. Within the subculture, be it Goth, Punk or Graffiti, the youth therein find themselves a grounds and communitas in which they may feel secure and, most importantly, belong.

Almost all youth subcultures since the late 1940s have struggled with the appropriation and commercialization of their characteristics, i.e. reintegration, documented in Matt Mason's insightful 2008 The Pirate's Dilemma. (For example, Mason notes that advertising did not appear in subways until after graffiti had introduced its tags and piecework therein.) This also logically follows from the fact that youth subculture is in part born from a recognition that corporate marketing is essentially a form of trickster seduction. The members of the graffiti community who agree to produce graffiti-like objects as representations for corporations appear here as especially vile to others in the subculture since they have betrayed the core system's foundational reasons for being.

Liminality is therefore especially applicable to the graffiti subculture. Graffiti's population is composed of youth. Their entrance into the subculture requires a rite of 
passage that is itself a new layer of liminality. Males, too, have experienced changes in the last century that represent a liminal period, especially relevant for the heavily male population that comprises graffiti's practitioners. Through the liminal paradigm, one can understand how graffiti confronts or exploits the experiences of individuals in the liminal phase, such as their emotional vulnerabilities, their desire to imitate their peers and the communitas of the greater graffiti subculture itself.

\section{The Structure of This Essay}

In order to introduce and clarify the phenomenon of graffiti, I analyze it in the next section as it is appears within four elements of its unfolding: the objects themselves, the makers, the tools of the trade, and the audience. This serves as a general foundation for the reader in order to grasp the complex practice.

Subsequently, in Part III, I analyze the gendered nature of graffiti. I establish some of the scholarship specifically about graffiti and masculinity and question how the scholarship defines masculinity and manhood. I argue subsequently that graffiti and the scholarly field of masculinity studies began around the same time, indicating that both are reactions to a specific condition of male liminality. Since male liminality was influenced by changes in corporate marketing efforts, especially after World War I, I include here an analysis of consumer culture. I argue that graffiti arises, and subsists today, due in part to the diversification of public space, particularly through the presence of girls and women; the dangers of 'selling out' one's craft to high-paying corporations for advertising; and the general threat of consumption as an alternative to the liminal condition.

I define the difference between masculinity and manhood and outline the history 
of masculinity studies as a discipline. I include a foundational study based upon Hegel's dialectic. Hegel's dialectic characterizes the liminal nature and mutual determination of interpersonal power relations. I use this throughout the essay, including, but not limited to, issues of male identity, contradictions in the construction of the graffiti marks, and the relationship of mentors to graffiti's new recruits. I shift to the multifaceted layers of graffiti's construction of male identity based upon both the community's anecdotal statements and a critical analysis of the production itself. I argue that the bravado of marking locations with tags undermines itself, since the mark (the actual graffiti) is itself 'mediated' (using the Hegelian term) upon the need for an audience and hence approval. Further, the virility and bonding of the practice, evidenced in its sexualized terminology ('getting up') and its mostly-male pubescent subculture, indicates a tendency towards the homosocial. This is not inherently an issue but represents that which is problematic in homosocial behavior in general: male bonding via destructive acts, the issue of unconscious (psychotic) activity and the need to exclude females and homosexual males.

I also analyze both the gendering of the graffiti practice as well as the gendered discourses about graffiti that circulate within the subculture from a variety of paradigms, weighing the value of each in relationship to the liminal. First, the 'heroic artisan' version of graffiti art production, I conclude, indicates a narrow view of labor and meaning. I deepen Lisa Macdonald's insights about competing masculinities by clarifying what constitutes warrior archetypes. I argue that though the youth may use the term 'warriors,' their actions indicate guerrilla warfare and guile, a form of warriorship which is nuanced. Finally, I consider models of PYD within the context of masculinity, specifically how mythopoeic psychotherapy and even Schiller's aesthetics might be used to understand 
youth graffiti development.

Since adolescent liminality underlies graffiti as a deeper stratum, I focus in Part IV upon how liminality is exacerbated by the status of the legal rights of youth in relationship to their civic powers. I begin with an explication and critique of some of the literature on contract theory and its relationship to adolescence. I then apply a contract theory of adolescence to graffiti with a discussion of the case of 5Pointz in order to illustrate the existing legal status of graffiti. Youth rebellion has deeper roots than the origins of graffiti fifty years ago. I depict the practical complexities of adolescent life, from actual civic limitations they experience to power imbalances within the family. I use John Locke's insights on the hurdle of governmental continuance in a society of consent to reveal ambiguities of tacit consent in youth, even today. Furthermore, I reveal how youth are born with 'natural' rights but are judged by an inherent bias in Western thought that overvalues rationality at the expense of other attributes such as emotions and creativity. This bias was expressed in earlier versions of developmental psychology, such as the work of Piaget and Kohlberg. It was not challenged until comparatively recent developments in feminist care ethics, and has actually been fully abandoned by developmental psychology. Nevertheless, whether a vestige or not of these historical biases, youth are considered irrational until a certain age. I argue that they are disempowered to make judgments about the expression of their rights since they supposedly lack the practical reason to make just moral judgments in relationship to their own civic powers.

I argue that the granting of rights coupled with their restriction and the ambiguity of a definitive 'moment' of full adulthood for obtaining full power over those rights is 
what exacerbates liminality in adolescents. I use Filmer's model of patriarchy as a comparison to illustrate this observation, since we are habituated today to assume incorrectly that rebelliousness and unease in youth have always been perennial human issues. Youth, I argue, respond ethically to their being considered irrational and being deprived of responsibility and latent civic rights by creating youth subcultures as avenues of free contractual consent; by vandalizing property, which is a primal good of society; and by scorning consumer culture as an edifice of money culture, property and the bounds of society. Graffiti, I argue, is appealing especially to youth since it allows them to retain their citizenship when they ultimately enter legal adulthood (when these contradictions will cease) while opening up a horizon of political behavior that meets emotional needs of both rebelliousness and belonging.

In Part V, I shift to an analysis of how graffiti culture unfolds within the process of its participation and production. I review some examples from existing graffiti scholarship in which participation through time is mentioned, even if not intrinsic to that work's argument. I make conjectures modeled on the work of Richard Lachmann, whose seminal essay "Graffiti as Career and Ideology" provides me with one of the few processoriented approaches to the analysis of graffiti. I then shift to an extensive analysis of graffiti in terms of the creative act itself, relying on techniques of art criticism. I raise the question whether or not (or rather, how) graffiti, as an art form, confronts liminality. I conclude that while tagging is born from liminality, masterpieces actually undermine it. Their strict lines and predefined forms result in the creation of a comfortable space of security, not the exploration of a space of ambiguity (save when vandalizing). I contrast the masterpiece with hypothetical examples of works of abstract expressionism in order 
to illustrate this finding. Finally, I use Schiller's concept of the play instinct in order to appreciate that transformations do occur within the inner life or mindset of the practitioners, growing and transitioning them away from the destructive, immature qualities of the practice.

I conclude with an evaluation of the practice of graffiti in the light of liminality. I argue that males of a specific character who tend toward the Schillerian savage find themselves rejecting societal codes due, in part, to the liminality invoked by the unusual invocation of their rights and limitations on their civic powers. Rejecting societal laws and codes, they identify with the savagery and retrogressive masculine virility of graffiti as a flight from liminality, even while still preserving it to some degree. In the process of their involvement and production, such as the disciplined labor of making complex masterpieces, they actually undermine the savage elements that appealed to them at the outset. Their mindset undergoes a transformation as they contemplate what they consider to be the beauty of exceptional graffiti, maturing them out of its illegality into full citizenship. Schismogenic states may sometimes prevail, while others have learned the transformative power of aesthetic contemplation. The main obstacle that remains, then, is the enduring legal record for those who were at some point arrested by authorities. 


\section{THE PHENOMENON OF GRAFFITI}

\section{Introduction}

Graffiti is a complex phenomenon. To introduce it to the reader, I divide its aspects into four general categories. These are, first, the objects, such as the tags, masterpieces and their digital documentation; secondly, the makers, a group comprised principally of male youth; third, the tools of the trade, such as spray paint cans and portable digital devices for documentation; and finally, the purported and actual audience, including the community itself, its enthusiasts and detractors, and the general public. These four basic categories are roughly derived from Aristotle's Aitia or 'four causes,' an early example of how Western thinkers have attempted to think objectively about a phenomenon. ${ }^{13}$ These four categories do not encompass all aspects of graffiti,

13 Aristotle's definitions of each aition are vague yet dense. Aition, often translated as 'cause,' does not specifically signify 'cause' in the sense of the term in English. (For this reason, as a reminder I return often to the original Greek term.) For example, he first defines them in Chapter II of A Philosophical Lexicon (in Metaphysics) as "(1) That from which . . . a thing comes into being . . (2) The form or pattern of a thing ... (3) The starting point of change or rest ... (4) The end, i.e. that for the sake of which a thing is" (4). These are hardly 'causes' as we understand the term. Further elaborations (and complications) include references in his Physics. His intention was to apply these aitia in order to understand both objects of nature and artificial constructions. There may be particular confusion as to how one might apply the formal cause and the material cause, since they refer to similar aspects of an object.

For graffiti, the first of the list, material, "That from which . . . a thing comes into being," I have decided essentially signifies the tools used to make it, such as spray paint, since Aristotle uses bronze and silver as examples of material causes for statues and bowls. The second, the formal, I use to indicate the graffiti object itself, since it may still exist as intellectual property even if buffed. The third, the efficient, "The starting point of change or rest" is clearly the maker, the youth. The fourth, the final, "that for the sake of which a thing is" for graffiti refers to both the audience and other possible motivations for its construction. 
such as its deeper cultural history, issues of rights, and the changes its practitioners experience throughout the process of involvement. However, they do serve as a simple introduction and clarification, since most readers are not familiar with the subculture. They also clarify some of the public conceptions and debates around graffiti, such as its status/non-status as a work of art, the misconceptions of its population of participants, the unappreciated role of internet documentation of graffiti and an introduction to the role of the risks involved in producing it illegally.

More specifically, 'Objects' clarifies the types of graffiti, such as the tag and masterpiece. I discuss also the important relationship that graffiti has with its documentation, as this is the enduring presence of graffiti after the real-world object has been buffed. The narratives about the making of graffiti, such as autobiographical retellings of incidents from the lives of graffiti writers, is also another 'object' of graffiti. Inevitably, though, popular discussions of graffiti revolve around its status as a work of art and its illegal vandalism. For this reason, I clarify some of its ambiguities and misconceptions and explain why it tends to be divisive. I include also a brief discussion of Evan Roth's Graffiti Analysis, mainly due to its popularity.

"Makers" is the perspective of graffiti based on those who construct it. I present the data on the youth who are involved, and shift to a discussion about their concerns over civic freedoms and their moral rights. I analyze the role of masculinity within the subculture as well. These last two aspects, rights and masculinity, are deepened in subsequent sections of this paper.

"Tools of the Trade" features my brief discussion of the various instruments used 
to make graffiti. This includes the digital devices to record the objects (or film their construction) and even tools that are 'not allowed.' Finally, in "Audience," I consider how the reception of graffiti shapes its meaning. This audience includes the general public, the authorities opposed to it, the greater community of fellow writers, and the online world.

I conclude this section with a general discussion of how these various facets of graffiti culminate in policy decisions, youth development and the way in which the culture conceives of itself. There are aspects, though, that are not covered fully in this section. I indicate how they are to be deepened later in this essay.

\section{The Objects}

There are two extreme poles of the variety of objects produced under the category of graffiti. ${ }^{14}$ The fastest and least involved object is the 'tag.' The most ornate and laborintensive is the 'masterpiece.' Tagging, in brief, is the practice of spray painting or using a marker to write a particular moniker (such as "SABER" or "TAKI 183"), typically in visible public spaces. These 'tags' are often made with a single fluid stroke of the pen, marker or spray can and appear as a form of script. The brief stroke and single color allow them to be made just about anywhere and instantaneously. This makes them an easily constructed form of publicly noticeable vandalism, since the simplicity and hence quickness of their execution allows for creation and coverage in multiple locations.

The 'masterpiece,' on the other hand, rests on the opposite pole to the tag. It is both labor and material intensive. It involves minimally at least three different colors, one

14 There are, of course, varied forms within graffiti. Castleman writes in Getting Up that there are "seven basic forms" (26): tags, throw-ups, pieces, top-to-bottoms, end-to-ends, whole cars, and whole trains (26-40). The latter five are essential pieces on a grander scale and will be subsumed under the term 'masterpiece' in this essay. 
serving as the outline (such as of the iconic, stylized 'Wild Style ${ }^{15}$ lettering) while the others serve as filler or backdrop effects. Consequently, the masterpiece requires careful planning. Its makers must design and sometimes practice the composition well in advance of its ultimate execution. Since masterpieces require more colors and more materials, they demand more skill, finances (unless the materials are stolen), and even collaboration. For example, some graffiti members form 'crews' in order to orchestrate the production of complex masterpieces quickly. Masterpieces are sometimes created illegally and sometimes as legal commissions. They appear often in the celebrated form of legal wall murals and/or on the side of highly visible freight and passenger trains, to name only a few locations.

Interestingly, it is the graffiti community itself that has created the terminology of the two poles of 'tag' and 'masterpiece.' This reveals that the community implicitly recognizes the distinction between these two forms in terms of their value, execution and function. Nevertheless, there is much blurring between these two principle terms, both in the form of the actual work created and the individuals involved. This in turn creates challenges for a lucid analysis of the overall practice, since one cannot assume that a graffiti object is one or the other type. For example, the term 'throw-ups' is used for an amalgam of tag and masterpiece, perhaps involving simple lettering and just two colors. Tags may be fairly elaborate, too; and a masterpiece may simply be a developed tag. ${ }^{16}$ In graffiti's long history, other nuanced terms have appeared as well, such as a "roller,"

15 In the early style wars of New York City, "wild style" was used to refer to a style of writing that was incomprehensible. Sometimes this term is used for all graffiti masterpiece lettering.

16 Even the makers have unusual histories, foci, and ambiguities; a street artist may be a former tagger and some taggers never make masterpieces. To complicate the field, there exist Bombers (those who write graffiti on highly visible public places, especially over advertisements), Piecers and Style Masters (writers who focus on graffiti masterpieces), and Taggers (who make primarily just tags). All graffiti producers, however, are subsumed under the general term 'writers.' 
referencing a large-scale masterpiece made with paint rollers; "whole cars," masterpieces that cover an entire carriage on a subway train; and "legals," which, unsurprisingly, are masterpieces made legally. All these objects and any others that are recognized within the subculture are subsumed under the general term 'graffiti.'

I exclude from the term 'graffiti' the extant variety of street art that does not feature aerosol lettering and script. Street art in general features vastly unique forms, such as wheat paste constructions (popularized by Shepard Fairey), stencils (featured in the art of Banksy), sculptural objects, mixed media (visible in the art of SWOON) and photorealist compositions (such as in the art of Fauxreel and Jorge Rodriguez Gerada). Histories of graffiti composed by its early members such as Jay "J.SON" Edlin's Graffiti 365 include such varied compositions under the category of graffiti, perhaps from a desire to be inclusive. My sense of the community as a whole is that such works vary too deeply to fall within the traditional use of the term. In this vein, I am a graffiti 'purist.'

Another important element in the object-hood of graffiti is the 'canvas' on which it is made, typically on visible public surfaces such as building facades. ${ }^{17}$ The canvas has many components, such as its materiality, location and cultural meaning. Materiality encompasses color, texture, surface grains, construction substrate (brick, cement and other building materials) and similar physical elements. Graffiti is almost always created in opposition to this materiality. If the surface is gray, like concrete, then the graffiti in question will be in strong colors that contrast with gray. For example, neon yellows and greens along with white will make the graffiti contrast sharply with gray concrete. In

17 There are many places in which graffiti is made outside public locations. For example, 12ozProphet.com has a forum section entitled 'Paper Chase' where graffiti designers can post digital copies of their graffiti designs. The term 'paper' suggests that they are sketches, preparatory works for eventual on site productions. 
terms of location, the canvas is sometimes dangerous and almost always publicly visible. The meanings of the surface, such as a stop sign or billboard, engender significations also for graffiti. Creating graffiti on a stop sign imbues the graffiti with rebellious, anti-civic meanings. Graffiti that appears on billboard signs - assuming they feature a corporate advertisement—signifies anti-commercial, anti-consumer meanings.

Graffiti in general, and masterpieces in particular, are now frequently digitally recorded and uploaded to the Internet, usually by their producers. This is the next 'object' of graffiti after the initial object in the real world is produced initially. These documents may be collected and posted by their maker under a single anonymous Internet moniker so as to create an online, virtual portfolio. Since real-world graffiti is typically buffed (removed) by authorities, what endures is the virtual documentation, which sometimes includes full videos of a person making the graffiti under disguise. In time, with some effort, a graffiti maker can have a sizable, quasi-permanent virtual collection of documented productions representing his or her oeuvre. In the past, before the Internet, graffiti writers needed to create large quantities of tags in order to give a sense of their production capacity to the community around them. Since today the documentation of their productions endures long after the real world works are removed, there is no doubt that there is less pressure on the writers to continuously make large amounts of graffiti in order to maintain their status, or 'street cred,' within the community.

The digital portfolio is actually aided by the removal of real world graffiti due to the subculture's honor code that dictates one must not create graffiti upon someone else's graffiti. ${ }^{18}$ Without graffiti removal, the practitioners might quickly find that all the best

18 This includes public art murals. Since graffiti producers consider themselves artists, and since graffiti holds the honor code of not making works over others, graffiti makers generally do not vandalize art 
locations for their work — such as highway walls, train depots, and similar highly visible public spaces - are already 'taken' by other graffiti works. If an abatement team buffs the graffiti, however, they create a new 'canvas' on which future vandals can create. New works of graffiti are then digitally recorded while the space awaits the buffing that will again create a blank canvas. The virtual world, of course, is never buffed.

There is a shift here in relevance from the real-world object to its documented form. This creates a metatext that begins in the sketchbook, moves to the real world production and finishes as documentation. This is not new to the overall field of the visual arts. A popular instance is the documented work of environmental sculptor Andy Goldsworthy. His ephemeral, sometimes delicate outdoor creations, such as a spontaneously constructed icicle made to spiral around a tree trunk, typically remain unwitnessed in the "commons" of the wilderness. ${ }^{19}$ The greater public has come to appreciate such creations via Goldsworthy's carefully staged photo-documentation of them, printed in elegant hardcover bound collections such as Passage. A film released in 2001, Rivers and Tides, aesthetically documents his process of constructing these works, making their transitory quality even more appealing. Their appeal is also due, in part, to the fact that they were made by appropriating a natural location. Via the photo documentation, one can insert himself or herself into the natural space by imagining the construction phase retrospectively. The film, for example, exudes the sense of a hermetic life, especially given Goldsworthy's philosophical voice-overs and interviews. Finally, since the materials he uses are often non-invasive and decay quickly (though some are made in stone and endure), his use of documentation enables his ability to share his work

murals. For this reason, mural art has become a key form of graffiti abatement.

19 Goldsworthy has numerous permanent commissions as well, such as his 2000 Storm King Wall at the Storm King Art Center, New York. 
with his audience.

There are also instances in which graffiti is created overtly for its digital form. BLU's 2007 MUTO video features animated images of grafffiti using stop-motion-style photographic progressions. His real-world site, a street in Buenos Aires, Argentina, is appropriated for the eventual digital format. The final work, MUTO, can only be seen online. It would have been impossible for a casual observer in Buenos Aires at any point during the three-month project to have experienced the final work MUTO. In this case, BLU is a video artist, not a graffiti producer, yet the appeal of his video is precisely its use of real street locations and his paintings upon them. This is similar to the appeal of Goldsworthy's art.

The advent of online portfolios as an increasingly important object of graffiti practice calls into question some of the community's arguments in defense of the practice. One defense of graffiti, articulated by Banksy at the beginning of this paper, is that it reclaims public space since it is made on corporate billboards. Another is that it is a work of art made upon unattractive industrial surfaces. If graffiti is buffed, however, this argument is negated. One might also argue that it is negated also when graffiti is targeted for an online audience rather than an audience that will be present in the public space in which the graffiti is produced. Since the documented version endures, one may ask, in the age of the Internet, whether or not the documented graffiti is the true 'object' of graffiti production. Indeed, it is in this sense that I referred to graffiti above as a 'metatext' in which its meaning passes through all of its stages, from the real world production to its final documented form. Likewise, one might question what constitutes the true audience (intentional or otherwise), given online global access. If the true object is its virtual form, 
then graffiti represents the appropriation of property and public space for an international, anonymous online community. (This prospect could haunt the values of some members of the graffiti community that conceive of their practice as a means of artistic expression for their specific, immediate urban community, especially in the context of heightened international concerns over terrorist cell networks.)

Veteran graffiti writers consider also that a narrative element is an object in its own right. This narrative element involves recounting the 'story' of activities, personalities, autobiographical incidences in one's career as a writer and published interviews of practitioners. In this instance, the writer-as-storyteller uses artistic license to recreate the emotional content of their experience making graffiti, exaggerating some aspects that might appeal to the listener or reader. For example, Stephen Powers writes in The Art of Getting Over: Graffiti at the Millennium his thoughts on recounting:

What makes graffiti so great and the attending graffiti magazine so weak are the stories. Graffiti can be divided into two parts; the action and the story about the action. Nine times out of ten, the story eclipses the action because while the action happens once, the story lives on forever, getting stronger (and longer) with each retelling. (82)

Powers makes this statement in the context of his own storytelling. His book not only exhibits old Polaroid photos of the first historical graffiti writers in New York City but intimate details about their personalities and lives. This 'object' is most likely in decline in the age of the digital documentation, since the camera is incorrectly presumed to produce a truth more accurate than a personal narrative.

The two most common object-based criticisms (or even discussions) of graffiti are 
its status as a work of art and its illegal status as vandalism. Both learned and informal discussions about graffiti invariably seem to revolve around these two topics, testifying to their dominating presence. There have even been dissertations debating its art status, such as Russell Jones' 2007 Is Graffiti Art. These criticisms often appear tied together in a single question - whether graffiti is art or vandalism — as if the two cannot occur together. ${ }^{20}$ They shape arts policy as well as embolden defiance within the graffiti community.

The principle issue I have with these debates is that they attempt to reduce all graffiti into a singular category via a blanket judgment. Even if graffiti were completely legal, it would be a mistake to simply declare all graffiti worthy of the status of art. Indeed, there is much variety in graffiti, even before its aesthetic merits can be considered (although originality is hardly a qualification for art status). Despite the apparent familiarity of the straight-lettered and Wild-Style masterpieces in their various incarnations, there is much originality, inventiveness and individuality in the forms. For example, based upon a survey for attributes of the Wild Style masterpiece, Lisa Gottlieb records in her book Graffiti Art Styles: A Classification System and Theoretical Analysis, 2008 that there were over fifty different design elements (like bubbles and arrows) for near limitless variety.

The masterpiece more easily falls under the general term 'art,' since its formal qualities are partially based upon their overall aesthetic appeal. This is obviously a

20 Classifying graffiti in relationship to street art can be muddled as well. Some graffiti is a subset of street art. Street art, which comes in many forms, such as stencils, site-specific installations and impromptu performances, is not a subset of graffiti. Hence not all street art is graffiti, and not all graffiti is street art in that some graffiti is merely a quick mark of vandalism. Exemplary and artistic graffiti is definitively a subset of street art. This odd syllogistic relationship of graffiti and street art has caused endless confusion. Finally, we might exclude graffiti from street art altogether since its function is ultimately antithetical to the spaces it occupies, such as its emphasis on aggressive contrast. Yet, we might consider it performance art, if we consider live video recordings. 
narrow (and formalist) definition of art. Both the tag and the masterpiece - in fact, all productions of graffiti- have strong performative elements to them. It is, however, the masterpiece that has appeared in art collections and art galleries. If one were to accept either the institutional and/or formalist definition of art, then the masterpiece can usually be considered as art. (This does not mean that all masterpieces are hence 'good' art.) The tag, though having 'artistic' qualities, hardly qualifies. However, since the tag and the masterpiece both fall under the general rubric of 'graffiti' (which in turn falls under the general category of 'street art'), the tag benefits from the masterpiece's 'art' status by association. This is one of the origins of the graffiti community's defense of its entire practice as expressive creativity.

The masterpiece is not necessarily created as a free-standing, self-referencing form, however. Its colors are often extremely vivid, emulating the artificial hues of mass production (they are from spray paint cans, not mixed colors on a palette) and computer monitors more than the tempered tones of weathered brick and mossy concrete. As mentioned above, the masterpiece and tag contrast intentionally with most surfaces on which they are painted. This gives them site-specific traits. The contrast engenders several different meanings independent of the form in and of itself. First, it means that the author of the work itself considers graffiti more important than the surroundings; graffiti acts violently in relationship to them. (Public Art projects always consider the effect of the work of art upon the surroundings. Sometimes this includes a violent contrast with them, but sometimes it does not.) If one is a lover of the softer hues in architecture from weatherization and natural decay (such as brick covered in lichen, or the principles of wabi-sabi), then graffiti is often shocking. 
Secondly, since graffiti leaps forward with such contrast, its blatant visibility becomes part of its meaning. Hence both the violence to the underlying surface as well as the strong visibility of its final form indicate a specific relationship of meaning to the world around it. It is no wonder, then, that graffiti is provocational; these two formal qualities make it inherently so.

Only advertisements and legal signage (like 'Buy Coca-Cola' or 'Yield') act in a similar manner, the former for selling a product and the authority-based latter for establishing civic order. Graffiti's formal mimicry (as well as its vandalism) of these two is not a coincidence. Their liminal status, subverted by marketing's attempts to define their needs and interests, finds recourse in the graffiti subculture. For this reason, they mimic, even attack, forms of advertising (such as posters and billboards). In terms of the latter, legal signage, graffitis vandalism of them is an expression of the defiance of authority.

Some graffiti is quality art, some is bad art, and some is not art at all. It is curious, therefore, that the 'debate' over all graffiti is one of two stances, either for or against. It is like debating whether or not all sculpture is art when in fact the real issue is whether or not a particular object that is classed as sculpture succeeds either aesthetically or in its intentions. Whether or not such an object is 'art' or not is pointless; if it is poorly made it is simply 'bad' art. In such an instance, its status as 'art' is irrelevant. The graffiti community rarely defends the tag as a work of art (even though its inclusiveness as graffiti allows it to enjoy the status as art by association), but certainly the more complex productions merit individual criticism and judgment. For this reason, blanket statements such as whether or not graffiti is art ignore the actual works themselves. 
Legal discussions about graffiti often center on its status as a work of art. Due to the influx of site-specific art after World War II, the general public assumes that art, no matter how poorly it is made, deserves to subsist no matter where it is constructed. It is a wonderful stance of tolerance, born from painful public debates over works like Maya Lin's Vietnam Veterans Memorial.

The specific controversy over Richard Serra's 1981 outdoor sculpture Tilted Arc is indicative. Typical of Serra's style, it was a massive, rectangular, monolithic steel sculpture, commissioned for the entryway to the Jacob Javits Federal Building in Manhattan. Tom Finkelpearl, former director of New York City's Percent for Art program, emphasizes in his book Dialogues in Public Art that at the time, Serra was "one of the most powerful and respected artists in the United States" (61). However, Tilted Arc completely blocked the passageway for users (typically foreigners seeking legal residency and work documents) and employees (government workers) of the building. (This antagonism to the federal workers was part of its subtle meaning.) It generated little aesthetic interest or pleasure in these users and passersby, yet its inconvenient presence was navigated until 1989. A long a public hearing culminated in its removal. Finkelpearl writes of a "ripple effect" in the realm of public art programs in which "administrators all over the country revised their procedures for commissioning work... Word was out: 'the public' must be included in the process" (65). What is overlooked by those disappointed by the removal of Serra's sculpture is that much of the debate between Tilted Arc's defenders and detractors revolved around the question of its status as 'art.' Those wishing to see it remain, defended it on lofty grounds; those that wished to have it removed, denigrated its aesthetics. Both, however, realized that its status as art was key to its 
continuance. Similarly, the jury case in Cincinnati about the Contemporary Arts Center's showing of Robert Mapplethorpe's photography decided in favor of the museum since Mapplethorpe's work was venerated as art. Hence if all graffiti is considered art, city officials cannot buff it.

The veneration of the status of art as an elevated form dates back to the Romantic era, if not the Renaissance. It presumed that the contemplation of the beautiful improved moral character. ${ }^{21}$ Kant's Enlightenment-era The Critique of Judgment insinuated that aesthetic experience intuited divine purpose; the artist was a force of nature and a genius. This strain of thought culminated in Schiller's 1796 Letters on the Aesthetic Education of Man, in which the civic realm's essentially contradictory moral demands could only be mediated by the play instinct, in particular that which occurs in the psyche before the Beautiful. More recently, due to the influx of Marxism, art gained a new status as an avenue of critical consciousness for the laboring masses to be more aware of problems in society. ${ }^{22}$ Hence if the state removes art, no matter what the state's motivation, it is in principle a violation of the sanctity of the critical function of the arts. (Note that in this new role, art does not need to imagine a better society; it works through the 'negative' act of attacking the failed realization of civic ideals or through the celebration of heroic victims.) This also concerns, to some degree, legal discussions about whether or not certain street art productions can and should be removed by the state or private individuals. ${ }^{23}$ In general, art became protected in the United States with the passage of the

21 In fact, one may trace this back to ancient Greece, although this means that one must create a rather dubious direct lineage between contemporary culture and 5th Century Athens.

22 Even though Marxism has receded in stature in the past twenty years, art-as-critical found justification in the varied branches of Postmodern theory. This 'critical' role of art still dominates the academy and hence non-profit exhibition spaces. It is also easier to write about, making it appealing to art historians and critics.

23 Personally, I believe that the state should not have a hand in the arts. As a cautionary note, the 20th 
Visual Rights Act of 1990.

Since art is venerated in the West, there are far reaching consequences for both sides of the 'debate.' Declaring all graffiti to be 'art' makes all of it sacred and/or critical. The entire diverse set of practices of the graffiti community, including the most base instances of tagging, ${ }^{24}$ becomes defensible should all graffiti gain this status. Graffiti producers adhere to this point of view. It is what enables them to suspend the ethical, i.e. break the law. For what law stands above Spirit and its child, the arts? They believe they are expressing themselves artistically and meaningfully, even as they put small tags on objects, from stop signs to electrical boxes. They also claim a critical component in

Century witnessed numbing examples of state-sponsored art and censorship in the Soviet Union and The Third Reich. There are alternatives that still enable public art. For example, Percent for Art programs such as New York City's efforts are imposed by the government on new constructions, requiring large-scale art to be created. The artwork selection occurs outside of the judgment of the general public.

24 Evan Roth's Graffiti Blackboard project has confused the understanding of graffiti's aesthetic merits while admirably abstracting some of its performative qualities. Roth placed a small camera on the wrists of graffiti taggers, recording their elegant hand motions while they made their tags. These hand motions were then in turn abstracted by the blackboard software. This abstraction appears in Roth's final short videos: the tag appears through a sinuous, slow, fluid cursive motion while colors splatter outwards aesthetically from the lines created.

A first-time viewer of Roth's project is immediately impressed by the attractive design effects of the motions of the tagger during production. There is, hence, an immediate association between these effects and graffiti tagging. For this reason, one might even consider the tag to be aesthetically meaningful in its own right. Yet, on closer analysis, Roth's videos have little to do with graffiti. One could attach the camera on any small set of hand movements, such as those that occur when one smokes a cigarette, cleans a dish counter, or combs one's hair, and have identical aesthetic effects appear in his blackboard program. Since he only uses it for graffiti, he is able to make the tag appear to be far more than it actually is. So great is Roth's abstraction that his work merits appreciation for what it is, not what it purports to represent visually.

On the other hand, upon viewing Roth's project, one is reminded of the graceful curves that constitute graffiti tagging. The graffiti tag is very often done in a style reminiscent of cursive handwriting and even calligraphy. Since it appears in places like public walls and other surfaces typically dominated by machine-perfect industrial lines and standardized type, one could witness in the production of graffiti a throwback to cursive writing and organic forms. In city centers dominated by order and hard geometric surfaces from the intersection of block planes, the cursive quality of graffiti tagging seems to appear as a chaotic yet 'naturalizing' counter force. This might indicate that some western cities have become too dehumanizing, although the proliferation of graffiti vandalism in a city as beautiful as Paris indicates otherwise.

Roth's project is not performed on the wrists of graffiti makers while producing masterpieces. The masterpiece, in fact, lacks the natural, calligraphic effect of the tag. It is as highly stylized and controlled as the logo and mechanized typeface that it critiques, if not parodies. This is yet another example of how these two extreme poles of graffiti - tags and masterpieces - are so radically different. 
taking back public space when 'bombing' commercial billboards. For this reason, too, (at least unconsciously) opponents of graffiti attack all graffiti as non-art and naturally galvanize its makers.

In a more critically educated society (as if one actually exists), graffiti would simply be treated on an individual basis. No doubt much of it would be buffed, since it is made on surfaces that the public (or the private individual whose property has been vandalized) does not wish to be marred. Yet, if the public as well as the graffiti writers had this general critical approach, the 'debate' would not be about graffiti as a generic term but whether or not a specific work has merits. Certainly, a tag on a stop sign is vandalism. Yet, can we not ask ourselves whether or not the graffiti community is correct in targeting billboards? The massive intrusion of billboards into public space represents the failure of the civic sector and its values to counter the force of economic and commercial interests. ${ }^{25}$ Even so, not all billboards are equal; one may announce a highway exit for a McDonald's, another might alert passersby to a wonderful music concert. ${ }^{26}$ Certainly, all billboards are highly visible, since they are created and illuminated precisely for visibility, and their excessive use of electricity should be a new environmental concern. It is visibility, in fact, to which the graffiti object inherently adheres.

It is also noteworthy that graffiti does not necessarily destroy or damage the object on which it is constructed. This is a frequent argument in defense of graffiti by scholars and criminologists who believe that graffiti should not be classed with other

25 Consider, too, that billboards require lighting. The illumination of billboards is also an environmental hazard.

26 More specifically, the McDonald's billboard is funded by a multinational corporation, incorporating low-quality, addictive fast food produced from inhumane livestock conditions. The local music concert, on the other hand, may be a rare appeal from a non-profit cultural institution whose tickets allow the performers to continue their practice. 
forms of property destruction or deviant acts. For example, Alison Young, in her book Street Art, Public City: Law, Crime and the Urban Imagination, writes:

the motivations for breaking a window or slashing a seat on a train are very different from those animating the production of graffiti. Throwing a stone through a window leaves nothing but smashed glass and destroys the functionality of the window; writing a tag on a wall might be experienced as damage by the property owner, but it does not destroy the functionality of the wall. Both acts alter the look of the object they address; graffiti writing, however, adds a layer of meaning (the presence of the graffiti writer and his or her tag) to the object. (110) Nevertheless, graffiti is made (often) illegally. This means that its makers are violating the law and should expect retribution. (The Visual Rights Act does not protect graffiti from being removed, but does allow its intellectual content from being reproduced without permission of its maker.) Though the graffiti community decries the destruction of some of its exemplary productions (such as SABERONE's The River), its illegality is part of what makes it appealing to the machismo of its makers.

\section{The Makers}

Who makes graffiti? As mentioned at the outset, there are no indications that the graffiti community is dominated by any particular ethnic group or class. There is often much confusion in the public domain as to who, exactly, is a member of the graffiti community, either as vandal or legally practicing artist. Shepard Fairey and Banksy are "street artists," but not members of the graffiti community, even though they are often referred to as graffiti artists and cited in papers like this one for their thoughts about 
vandalism. (Apparently, both began as graffiti vandals.) There are legally working muralists who either are former graffiti vandals or still practice as such. For example, The City of Philadelphia's Mural Arts Program commissioned former tagger Stephen Powers to direct fifty legal public wall murals. ${ }^{27}$

It would be impossible to cite all the instances of basic public misconceptions, yet these perceptions probably influence future recruits. For instance, early adolescents may be inspired to enter into graffiti due to learning about Banksy, though he does not identify as (and typically is not recognized as) a member of the graffiti community.

In terms of race, class and ethnicity, graffiti crosses all boundaries. It is one of the appeals of the practice, even, one might argue, an appealing aspect of the practice. It has appeared in this manner right from its beginnings. In the early 1980s, Craig Castleman wrote in Getting $U p$ that writers "range from the ultra-rich to the ultra poor. There is no general classification of these kids ... Writers come from every race, nationality, and economic group" (67). In an interview for Training Days: The Subway Artists Then and Now, Lady Pink describes the composition of the earliest practitioners:

We had white kids, black kids, Asian kids, and Latino kids all hanging out together and not missing a beat. Most crowds and groups tended to be segregated, and even in school we stuck to our race. The graf kids were a pretty mixed bag . . . Even the economic backgrounds were mixed: we had white kids who were well off and black kids from the ghetto who didn't have two nickels to rub together.

One quality that unites graffiti makers is age. The national anti-graffiti

27 The project is entitled "Love Letter" and is documented on www.aloveletterforyou.com. Powers boasted that he still creates illegal graffiti, no doubt wishing to both reinforce his 'street cred' and also to prevent his work from being vandalized by angry taggers. 
organization Graffiti Hurts compiled information based on police arrest records in order to determine some key qualities of the group's attributes, or at least the attributes of those who are slow-footed. Its web site (www.graffitihurts.org) and their web-based publications ${ }^{28}$ reveal that only $10 \%$ of tagging is gang-related. The age range of writers is typically between twelve and twenty-one, with the heaviest arrests of suburban youth between twelve and nineteen years of age. Though this paper is focused upon the United States, the data complied by Graffiti Hurts is further corroborated by police records in countries like the United Kingdom and Australia. ${ }^{29}$

The young age population represents primarily taggers, not masterpiece makers. Data on the makers of masterpieces is not available, although it probably comprises a greater age spread given that it has a legal incarnation. Since masterpieces can be legal, their makers, such as the aforementioned Stephen Powers, often retire their tagging practice and continue on to professional careers unless some sense of insecurity appears in the face of their commercial turn and they return briefly to tagging for 'street cred.'

For this reason, there exist pseudo-age-oriented critiques of graffiti based upon the issues that young people encounter in Western life, though these critiques ignore the effects of adolescent liminality. For example, one might argue that writers are simply deviant youth, due to family dysfunction, other environmental influences, and/or

28 Examples of its web-based publications are on its secondary site Keep America Beautiful (kab.org), featuring publications such as "Charting the Multiple Meanings of Blight" (May 2015) and its yearly reviews posted since 2001. The latter typically mentions graffiti.

29 For example, an interview in 2011 of the graffiti abatement crew for the British Transit Police magazine The Line, the police state of the typical graffiti maker that they "would put him, and it is usually him, as between 15 and 23, white, and also involved in low level drug use of some kind" (Issue 14, April 2011, page 9). The State Graffiti Taskforce of Western Australia write on their web site (goodbyegraffiti.wa.gov.au) that "Preliminary graffiti research data from WA Police indicates the main offending age is between 12 to 25 years old from all socio-economic environments. The largest percentage of offenders are from mid to high-level income families with a median age of 15 . This is supported by both national and international research." Furthermore, they write that "Police cautioning and arrest data covering the 5 year period from 2005 to 2009 indicates that $46 \%$ of graffiti damage and related offences were committed by males aged 14 to 16 years." 
genetics. $^{30}$

Brain chemicals are even used to explain graffiti involvement. For example, Myra Frances Taylor argues in "Addicted to the Risk, Recognition and Respect that the Graffiti Lifestyle Provides: Towards an Understanding of the Reasons for Graffiti Engagement" that chemicals in the system of adolescents give them thrills that are the primary reason for vandalism. From the standpoint of the humanities, while such investigations no doubt have their merits, they serve to dehumanize adolescents. For example, chemical movements in the brain accompany all human activity. They do not explain the activity in question; they merely add a marker. They are correlative, not causative, one of the most common errors in making interpretive leaps between scientific data and human activity. There is no doubt that Myra Frances Taylor had strong chemicals at work in her brain when writing her paper; their existence has nothing to do with the merits of her argument. Yet, the chemicals in the brains of adolescents are apparently indicative of why some make graffiti.

There are similar statements made generally about the makers of graffiti, such as the notion of 'leaving a mark' and 'ever since the beginning of time, humanity has made murals. $^{31}$ The former evokes an animal making note of its territory via urination, and the latter implies that youth and neanderthals are near-cousins. These follow the aforementioned general Western view that youth are irrational. While it is no doubt true

30 The term 'deviant' implies that the norm is not to vandalize and rebel. (Other arguments assume that it is simply normal to rebel as this indicates a spirit of independence.) In the United States, youth often are not tried as adults until age eighteen (or even sixteen), indicative of the Western belief that they lack the ability to make rational moral judgments.

31 The statements such as 'leaving one's mark' as indicative of a primal human impulse are very common in the visual arts and writing on street art. Harvey D. Lomas' early writing "Graffiti: Some Observations and Speculations" for The Psychoanalytic Review, 1973 is representative. He writes that "wall writing served our prehistoric ancestors, so it served the instincts during a prehistoric epoch in the development of us all" (88). 
that someone in their youth will most likely be more irrational then they will be in their adulthood, it is unfair to ascribe all their claims, beliefs and actions to instinct and irrationality.

The youth themselves, anecdotally, do claim that some of the risk-taking gives them a thrill. But that is not the primary motivation for the vast majority of producers. The thrill of production is not enough to sustain a seven-year career and there are many other ways in which youth may experience thrills that are not illegal. On many forums, web sites, and blogs, graffiti producers argue instead that they are 1) expressing themselves, laying claim to graffiti's art status; 2) asserting their freedom, and 3) acting out of their right to make their productions where they please, ignoring property claims.

Each claim is laden with meaning, far beyond what the youth themselves recognize. The first claim, work of art, was discussed partially above in terms of graffiti's status as a work of art. There is little behind such a claim for the making of a tag, outside of one's initial design. Yet, the expressive and performative production of a tag in risky places is arguably a form of self-expression, if that self is understood as one requiring assertion through risk-taking. Also, even though the tag is reproduced repetitively, one should not ignore the joy born in the process of making it. Its design and name is intimately tied to the maker, and hence the process of its production should not be considered a purely empty mechanical act. The masterpiece is no doubt a far more expressive art form, since it offers a wider range of possibilities and unique forms.

Neither the masterpiece nor the tag require vandalism in order to be creatively 'expressed.' This relates to the second claim of the tagger, freedom. Freedom as a concept belongs to the religious and spiritual sector of life, as it is a metaphysical issue relating to 
one's will, emotions and deeper values in life. However, in common usage it often refers to political freedom. ${ }^{32}$ It is in this latter sense that youth no doubt believe they are acting. In the West, youth live in a transitional period in which they are no longer children yet are not accorded full civic participation. They are bound to their parents, but have some civic responsibilities and expectations. For example, they cannot vote until age eighteen, and they cannot drink alcohol until age twenty-one. Youth, in fact, are very aware of their status as second-class citizens and their lack of civic freedoms.

It is no secret, to youth or the culture at large, that youth are denied civic powers since as a population they are considered as lacking in the wisdom to make proper choices in the exercise of the powers they are specifically denied, e.g. they cannot drink alcohol because they will abuse alcohol. Hence, a youth can either accept this label, enduring the insult, or protest fruitlessly to change the system. The former group represents possibly well-adjusted teens comfortable with the 'system;' the latter simply makes no sense even to exist. For if youth were to organize themselves for more societal powers, the individual leaders heading such efforts would find themselves adults long before any progress might be made; adolescence is too short to accommodate extensive labor to transform its status. And as adults, they may be more interested in curbing the current flock of adolescents.

The third claim of the makers of graffiti is that they are acting out of their moral rights to do so. This has roots in U.S. history. It first appears in social contract theory, espoused in Thomas Jefferson's life, liberty and the pursuit of happiness in the Declaration of Independence (with its roots in Locke's Two Treatises of Government and

32 Since confusion often occurs in this use of the term 'freedom,' political theorists prefer the term 'liberty' instead of 'freedom' to refer to civic freedom. 
life, liberty and estates, amongst other sources). After World War II the notion of human rights surfaced heavily during the Civil Rights movement, the Second Wave of feminism, gay rights and various consumer rights movements. Not coincidentally, it was in the late 60 s that graffiti first appeared, and its claim was in relationship to both the right to take control of public space against consumerism (such as advertising and billboards) as well as the more general right to reject private property. The notion of human and moral rights, or in the language of social contract theory, 'natural rights', indicates a deeper cultural foundation that is uniquely Western. It is based upon private property, the nuclear family and sovereignty grounded in the people.

The category of maker is shaped by gender. Graffiti Hurts also documents that most graffiti vandalism is made by young males. Young females, comprising only about $15 \%$ of the population of taggers, are not as attracted to the practice as males. This is not surprising, given some of the problematic locations and night hours frequented by young male taggers. For example, SPAR ONE, the editor of the web site entitled "@149st" (www.at149st.com) and a (practicing or former) graffiti artist and tagger, writes of the status of female taggers and graffiti artists:

In aerosol art culture women face many obstacles not encountered by men. The late hours and desolate locations in which most writing is done can be particularly dangerous for women. As with many male-dominated fields, the social atmosphere can be extremely harsh. Female writers are often subjected to all kinds of harassment.

In support of SPAR ONE's statement, anthropologists such as Richard Lachmann and his article "Graffiti as Career and Ideology," Tracy E. Bowen and her ethnology 
"Graffiti Art: A Contemporary Study of Toronto Artists," Kara-Jane Lombard and her essay "Men Against the Wall: Graffiti(ed) Masculinities" and Nancy Macdonald in her book The Graffiti Subculture have made similar observations about tagging's investment in its male population and identity. A Google image search of graffiti imagery, though also anecdotal, will reveal its masculine 'gaze' in the way in which gender is represented, such as sexualized females and hooded, aggressive males.

Despite this, or perhaps in response, collections such as Nicholas Ganz's Graffiti Women: Street Art from Five Continents, random online articles like Nikki Hatchett's theguardian.com article "Paint the town: the best women graffiti artists-in pictures" and sites like lagraffitigirls.tumblr.com, all document the efforts of females within the community. They exist and are marginalized, though signifying that there are aspects of graffiti culture that have an appeal that transcend gender. In fact, the three general claims of expression, freedom and rights also concern young females, since these are born from adolescent liminality. (Yarn bombing, an unusual variant of graffiti, is particularly targeted towards females but does not involve property destruction.)

\section{The Tools of the Trade}

One might presume that the primary tool of graffiti is the iconic spray paint can. In fact, graffiti in general is often referred to as 'aerosol culture,' as in SPAR ONE's statement above. The pen and other similar tools are also used, but the spray paint can dominates graffiti lore as primary material. Part of the meaning of these tools in the history of their usage is that they were acquired illegally. For example, Craig Castleman writes in Getting Up that "It is a tradition among most graffiti writers that all materials 
used in writing be stolen" 46).

Yet, if the abiding form of graffiti is its digital documentation, then this digital form must also be considered part of its 'stuff.' The tools, then, are not simply the predrawing and then final work (such as in the case of masterpieces). They also include portable electronic devices with recording technology, such as minirecorders and the photograph and video recording abilities on smartphones. Graffiti makers also include these in their tools, since they document and upload their productions with them. Consequently, one must extend those tools to the computer platform necessary in processing the documentation. ${ }^{33}$

It is difficult to assess when, exactly, the internet and electronic elements became fixtures in graffiti culture. The early Zines of the 1980s began making video interviews, but this was obviously not widespread. Yahoo! Photos and PhotoBucket appeared in 2000 and 2003 respectively, creating a free platform in which graffiti could be recorded and uploaded anonymously. 12OzProphet.com, a frequented web site featuring forums and image uploads, appeared initially in 1993 (as a zine) but later (date not disclosed) became a web site. Graffiti.org, known as 'Art Crimes,' hosting 13,000 web pages as of $2015,{ }^{34}$ first appeared as a web site in 1994. More importantly was the birth of the widespread internet infrastructure which enabled everyday individuals the ability to access sites, such as the appearance in public libraries of network platforms, also around

33 It would be a gross mistake to ignore these elements of graffiti. The digital aspect of graffiti affects an understanding of graffiti in a multitude of ways. First, it becomes part of the process of construction of some works in that their digitial recording and uploading to the internet comprises part of its unfolding. Secondly, the documented form online reaches out to a greater audience than one simply placed on a real-world location, magnifying the yearning its maker has for audience approval. Third, their continuance in time in virtual space allows them to outlive their often-buffed, real-world versions. Finally, the digital upload signifies a level of technology and hence financial status, something that graffiti writers in poorer neighborhoods (or even poorer countries) cannot duplicate.

34 This number was announced in a blog post for 2015, http://graffnews.blogspot.com/2015/01/2015whats-up.html. 
the mid-1990s. In an article for The Villiage Voice in November, 2000, author Richard Goldstein declares that "thanks to the Internet, flicks can be circulated online. By now there are hundreds of graffiti sites, including webzines like artcrimes, bigtime, massappeal, and tagmag. ${ }^{135}$

These dates signify that graffiti has had a pronounced presence on the interent for the past twenty years. Its youthful makers are typically teenagers, meaning that they have come of age in a time of the ubiquity of the virtual world, if not its outright dominance. The use of tools to record and document graffiti online is a natural extension of the practice for the current generation.

Other tools for graffiti include the equipment necessary to aid practitioners in producing their work, much like a carpenter might wear a tool belt. If graffiti is made illegally, these tools are iconic of the stealthy nighttime figure, such as masks and hooded sweatshirts. This is celebrated in graffiti imagery. One often finds graffiti art featuring hooded figures, and even the actual spray cans visually depicted within some masterpieces.

Significantly, there are certain tools that are not present in graffiti for ideological reasons. The stencil, typically used in other street art productions, allows for the rapid reproduction of an image with little effort. Similarly, wheat pastes can be mass produced and then placed on walls in multiple locations, emulating even more than graffiti writing the commercial advertisements they all parody. However, graffiti purists reject these tools since they do not exult the craft and skill of writing. The graffiti community takes pride in the time and skill necessary to make its iconic artworks, especially in the light of

35 This citation was taken from an online edition of the article, http://www.villagevoice.com/news/thejoy-of-bombing-6417074 and accessed on July 2, 2015. 
its redemption of artisanal production processes. ${ }^{36}$

\section{Audience}

There is no real way to reconstruct the "average" New Yorker's understanding of the writing on subways nor their common views of the writers who painted it. No systematic polling ever took place. The authorities who oversee the subways and other public properties, along with many building managers and private property owners, understood all writing to be malicious vandalism. (Austin, Taking the Train, 181)

One possible motivation for the construction of a work of art is to communicate with an audience, even though expressive philosophies imply the artist's emotions as telos. The principle audience for graffiti is, of course, the graffiti community itself, though there are other audiences as well (such as the general public, abatement authorities and enthusiasts). ${ }^{37}$ When graffiti first appeared in the late 60 s and early $70 \mathrm{~s}$, the graffiti community was simply the local individuals who made the productions in a specific geographical area. Productions were viewed by other members of a neighborhood or zone. Producers chose trains since they moved throughout the city, expanding the audience for their work. One needed to engage in large productions in order to make his or her work as visible as possible. Sometimes this audience expanded, either through a graffiti producer traveling to different cities or through fame within the

\footnotetext{
I elaborate on this notion in Part III.E2, The Heroic Artisan: A Variant Masculinity .

Later in this essay, the role of audience has other effects in terms of the creation of meaning in graffiti. For example, in terms of the construction of male identity, graffiti's audience is meant to experience graffiti as a marker for its maker's virility. In terms of contract theory, graffiti takes on a new layer of meaning in that it is first, a means to become a member of the graffiti community, and secondly, as a negation to consent to property rights as codified by mainstream society.
} 
global community. This early conception of graffiti as locally produced for a local audience - in which one makes graffiti so that he or she can have it viewed by other inhabitants of the city — still appears in graffiti discussions today, even though it is outdated.

With the dawn of the Internet, this notion of community and audience radically changed. Today, graffiti writers will typically make something and then document it digitally. The virtual form is then uploaded to web sites like 12OzProphet.com, PhotoBucket.com, Instagram, personal blog sites like utahether.com and many others. 12OzProphet.com has specific forums where anonymous members can create monikers for exhibiting all their documented productions. The result is that the already-anonymous graffiti producer can then have a virtual 'portfolio' of their work. Since the audience for that forum is international, one can say that the audience of any graffiti that is documented is hence a large, international group of individuals. It is likely that the person who posts the work does not know personally the person who observes it elsewhere online, unlike in the beginnings of graffiti and in some of the local connections that still exist presently. And since youth today communicate heavily via the Internet, using social media sites like Facebook, it is not a 'leap' to infer that their graffiti productions, documented digitally, are in fact produced for an online audience.

The change in audience from the immediate locale to a greater, possibly international audience occurred early in graffiti's history. Joe Austin notes that the creation of the aforementioned Zines, starting in the early 1980s, marks this shift. The first of these was the International Graffiti Times, later renamed as the International GetHip times (255). In 1989, VideoGraf appeared, "a half hour of 'live' interviews, often 
taped while the writers were (illegally) painting, along with still shots from photographs, all set to music" (257). ${ }^{38}$ Unlike typical documentaries, these videos were recorded by the graffiti community. For Austin, the still form of pictures in the early Zines meant that masterpieces were more reputable, given that they appeared better in such reproductions. The video documentaries gave bombing crews, captured in the process of vandalism, prestige (260).

Audience also has an effect of validation. Jean-Michel Basquiat and Keith Haring entered public consciousness in the early 1980s. Basquiat began as a graffiti writer with the name 'SAMO.' Once he became involved in the high art echelons, he distanced himself from his SAMO past until his early death in 1988. Yet, his ascension into high art validated graffiti as a career path for aspiring artists. Even after his death his work continues to reach audiences for the benefit of graffiti enthusiasts, such as the current exhibition of his notebooks at the Brooklyn Museum of Art (where his work also appeared in $2005^{39}$ ). Haring, possibly in hope of becoming discovered while avoiding legal incrimination, began his most publicly visible graffiti with white chalk on unused black advertising panels in the New York Subway from 1980-1985. Since he did not actually vandalize adverts, he avoided incrimination and was able to engage directly with the public. From his 1986 Pop Shop to later large-scale public murals, Haring shifted from illegal graffiti to celebrated muralist. He became one of the 'faces' of early graffiti for society at large, and that face was a nondescript suburban white male. Unlike

38 They were "created by Colin Turner and Carl Weston, and assisted by NIC 1 and Sasha Jenkins" (257). However, Joe Austin does not state how the videos of VideoGraf were distributed. I assume that copies were made and circulated by word-of-mouth. Austin hints of this. He writes that "every writer I met knew of at least one zine" (261), implying that their proliferation was not large. Despite this, Austin argues that they were well-known as an entity (even if specific films may not have been seen). To be recorded by the editors of these zines and videos was prestigious.

39 I was fortunate to attend this exhibition since I was studying at Stony Brook University in Long Island. 
Basquiat, he embraced his roots, from the making of political art to his impromptu creativity in mural production.

There are other audiences for graffiti outside the group that identifies itself as the graffiti community. The most attentive and immediate 'audience' are all those who might be generally grouped under the rubric of public authorities opposed to the practice. They include police, detectives, graffiti abatement teams and public officials. They will be far more aware of the presence of graffiti vandalism since their public function is to be aware of it. As an audience, they lend meaning to the performative, gendered aspects of graffiti production in the area of risk-taking, in particular because they represent part of the peril.

Graffiti makers presume that by making a tag in a publicly visible location, their work will be viewed by the general public. It is presumed that the users of a train will observe the graffiti that is placed there, either enjoying or rejecting it. Similarly, a graffiti artist may place a masterpiece on the backside of a highway overpass, assuming that the many motorists in the vicinity will make note of the artwork. Even though it is not the primary reason for making graffiti in such locations, it is one of the motivations-people will observe their efforts in such visible public space.

It is a curious assumption. In urban areas, the typical resident is bombarded by advertising and company slogans. The tendency of city occupants is to filter out this external 'noise.' This results in what university researchers Christopher Chabris and Daniel Simons called 'accidental blindness' in their 2010 book The Invisible Gorilla. Their findings state that it is likely that most individuals, even when graffiti lies within their field of vision, do not 'see' it. Perhaps it is completely invisible, or simply unconsciously 'filed' in the cabinets of their minds under the general category of 'messy 
vandalism'. Using auditory terms, much of the public hears graffiti but does not listen to it. (In the realm of hearing, we differentiate between 'hearing' and 'listening,' but we lack this distinction for the visual field. No doubt this failure of more precise terminology in the visual sphere is due to the undeveloped eye of contemporary peoples, whereas even the most uncultured individual can discern a false note in a melody.)

This creates a rather unusual conundrum for graffiti makers. If the public does not 'listen' to it, and the graffiti makers' online audience is only seeing the virtual form, then one might question why it is so essential to make works that are conspicuously visible in public areas. One key response from graffiti makers lies in the way in which the community defines prowess and the consequent performative role of the tag: if it were simply made in an abandoned building, then it did not require the virility to face the perils of police arrest or bodily harm from a dangerous fall.

People opposed to graffiti claim that the general audience experiences it as illegal, messy 'noise' that generates an overall sense of growing disorder and lawlessness. This in turn makes more lawlessness seem permissible, since it gives an impression that breaking the law is tolerated. A snowball effect arises, then, in which graffiti might engender the presence of drug use and other crimes. The view that the general audience of graffiti reacts in this fashion was formalized under the theory of 'Broken Windows.' It first appeared in an article by James Q. Wilson and George L. Kelling in 1982 and has been invoked by the anti-graffiti sector ever since. In this sense, one might argue that graffiti, independent of its effect on the lives of the youth that make it, is problematic for the general community of youth and results in negative youth development overall (antiPYD). 
There are other orientations towards audience that inspire graffiti's production. One key motivation for youth to create graffiti is to gain membership to the subculture of graffiti. It is not enough simply to be an audience or enthusiast. In such instances one remains on the 'outside.' Graffiti requires 'street cred' in order to maintain the respect of one's peers and the status of one within the community. Hence a final audience-oriented motivation of making graffiti is none other than this desire to belong.

Graffiti is therefore a highly varied practice. It unfolds in an initial real-world object and often finds its culmination as a documented form on the internet. Its young, anonymous, typically-male makers find therein an expression of virility through their confrontation with the perils of production, legal and/or physical, as well as the craft of the more complex masterpieces. Their tools vary, from the actual celebrated aerosol can and black markers to the digital devices used to record, even in the process of production, the objects of graffiti. Its audience, too, aids in defining graffiti, from those opposed to it (as a competing force) to fellow members and enthusiasts approving of its existence.

Its varied forms, and often illegal status, make an assessment of it difficult. In fact, the one conclusion we can accurately make about graffiti is that assessment of it should be difficult. Blanket statements about its art status, made in an effort to conserve it from destruction (as well as redeem, if not glorify, its makers) simply galvanize those opposed to it. Similarly, its detractors galvanize graffiti's practitioners by making blanket statements about its value.

We do know that there are 'gray' areas of graffiti, in which its status as art is debatable, as well as clear-cut aspects of graffiti, in which its production is either a 
nuisance or a clearly made, intentionally attractive artwork. The youth producing graffiti enjoy the title of artist and the experience of outsider status. Certainly, there are individuals opposed to graffiti that have strong emotions about the subculture and its members, perhaps imagining them as misguided miscreants.

We cannot ignore, though, that the first and principle issue in adolescence is liminality itself and how we, as a society, complicate youth liminality. Graffiti is a response to liminality, both in terms of general youth crises as well as male liminality. If one wished to remediate the existence of graffiti, he or she should also turn to the sources of the initial inspiration. These sources, I argue, are in male identity crises and the contradictions in all (both genders) youths' civic rights and powers. When these source are made clear, an appropriate response to graffiti can be imagined and created.

This will also assist in evaluating graffiti from the perspective of PYD. As graffiti stands now in relationship to legal policies, it is mostly detrimental to the youth drawn to the practice. This is especially the case if they are caught and prosecuted by authorities. There are some benefits to involvement in graffiti as well, such as the cultivation of aesthetics, the development of a community (the graffiti community) and the experience of the rigor of the practice. The effects of the process of production are mixed, both in terms of liminality as well as their effect on the psyche of the youth.

The elucidation of the underlying causes of graffiti represents the subsequent goal of this paper. It explores the crises of masculinity in order to appreciate the difficulties that the kind of youth drawn to graffiti face. It subsequently analyzes the powerlessness of adolescents before the peculiar contradictions in their civic powers and rights, appreciating how subcultures, even in their destructive practices, have a rationale for their 
activity. Finally, this paper explores how the process of involvement of graffiti shapes the youth, especially in terms of its creative activities. From there, one can begin to rethink adolescence, their crises, the lure of graffiti, the influence of one's prolonged participation in the subculture and a proper, if not fair, legal stance for addressing its vandalism. 


\section{GRAFFITI IN THE LIGHT OF MASCULINITY}

\section{Introduction}

A form of liminality unique to males has arisen from the social and economic changes that have occurred, and are occurring, in their identity in relationship to other minority groups since at least the 1960s. From Civil Rights and the Second Wave of feminism to changes in the work force and American world power, male hegemony has receded. The result is that males today, no longer easily buttressed by a broad array of second-class others, have faced a liminal crises of identity. They must come to terms with their masculinity and manhood through other means, such as activities which ground their selfhood within themselves. This gendered crisis may be interpreted through the lens of Hegel's Lordship-Bondsman dialectic, in which the dominant figure (or, in this case, the normative man), has lost the assertion of his selfhood through its mediation on subservient figures. ${ }^{40}$ This is an historical and social change of immense proportions. It is indicative in the postmodern difficulty of defining masculinity as well as the more enduring issue of the artificial, socially constructed method of defining manhood.

The psychological, economic and social concerns facing male identity have inspired many responses since World War II, such as the academic field of men's studies, men's liberation movements, mythopoeic psychotherapy and, I argue, graffiti. Scholars

40 Hegel's notion of dialectical mediation (in which the identity of a dominant figure in power relationships is established precisely through the subservient figure) is discussed further in this essay. 
allied themselves with feminism and utilized insights into understanding the status of males, finding mutual grounds in rational deliberation and analysis. The men's liberation movement sought to identify some males with marginalized groups, arguing that males also have struggles within dominant forms of masculinity. The mythopoeics reverted (or subscribed) to Jungian notions of archetypes and the (collective) unconscious in an effort to transform individuals imaginatively via therapy.

These were movements focused on adults, not youth, even though many of its concepts were and are applicable. Male youth, therefore, had layers of liminal crises, both as males as well as adolescents. Graffiti was born in the same time period, initially inspired by the erosion of state power and the assertion of human rights. In time, though, its practice has evolved into a means for youth to construct an identity of masculine prowess and virility independent of those radical 1960s social changes. It celebrates risktaking and warriorship, albeit of a specific type, as well as a nigh-diametrically opposed masculinity grounded in persistence and discipline; it attacks public space and corporate culture, affirming the youth's freedom from their influence; it creates a highly nuanced relationship with liminality, both in evading it as well as affirming it; and it purports to be an art form, allowing its practicants claims of just, pre-societal elevated ethical production in the face of consequently unjust persecution.

Fruthermore, graffiti specifically targets public space and, in the case of 'bombing,' it attacks corporate advertising. The objects of graffiti such as the tag are considered generally to be parodies of marketing logos. Graffiti's animosity to corporations and consumption might be found also in changes since the 1960s, such as the changing face of the civic sector, the suggestive campaign of consumptive citizenship 
and the corporate co-option of youth liminality. Public space has been increasingly diversified in the last century, undermining the hegemony of males in the social sphere; the Keynesian argument to aid one's country by spending (consumption) implicates the spender in support of the social status quo (and hence, ultimately, political consent); and finally, youth may be seduced by clever marketing campaigns as a means to belong (and hence as an inauthentic encounter with liminality).

Graffiti's gendered practice is highly nuanced. Its two principle (if not 'poles') of production, the tag and the masterpiece, suggest a cultivation of diverse (even diametrically opposed) masculine attributes. Graffiti vandalism, represented in the tag, celebrates the virility of daring risks, while the masterpiece is representative of focus and discipline in celebration of steadfastness and perserverance. Furthermore, along with these two poles, the youth make subtle claims to warriorship. The specific term 'warrior' may not be apropos for their style of 'combat' which instead favors the clever, even guerrilla-like tactics of trickster figures.

Graffiti vandalism, embodied in the tag, allows them to assert a regressive notion of masculine virility as a courageous, free-spirited and unconstrained rules-breaker. It is a longing to assert a past form of masculine identity in the face of social changes at the expense of community (and the safety of the graffiti writer). The process of making graffiti, however, simultaneously undermines this assertion, since its mediation (reliance $^{41}$ ) upon audience as an act of boasting represents an insecure yearning for

41 The term 'mediate' is Hegelian. To rely upon a person is unidirectional in its power dynamic; I rely upon or need $\mathrm{x}$ to, say, perform. 'Mediation' highlights the middle ground in a relationship. If my performance is mediated upon you as an audience, then you as an audience is also mediated to be an audience since you require me as a performer. There is therefore a mutual assertion while still affirming the element of reliance which then allows changes to happen between the two elements, e.g. after I perform, I can then reverse the dynamic by questioning the audience; the performance itself may reach a conclusion, in which the audience is transformed, etc. 
approval. In fact, one might engage in risky activity without producing graffiti; graffiti asserts the need to have the risky acts catalogued under a single identity. Furthermore, the graffiti object becomes passive, subject to the gaze. This weakens the very act of producing it, since its purported masculinity is effaced by the masculine gaze of the viewer. This gaze between males producing graffiti objects (for each other) implies a homosocial bonding process at the expense of public space, even connoting a form of sexualized public assault in the light of graffiti's production-term 'getting up.'

The second form of masculine prowess asserted through graffiti is the aesthetic and artisanal practice of making graffiti masterpieces, in particular for those youth who proceed to this level of graffiti production. In this instance, the identification is allied with the idealized artist who (even more than the artisan) represents the pinnacle of Western esteemed poesis. ${ }^{42}$ The process of producing masterpieces is more studious and industrious than that of making tags and throw-ups. Hence it represents a different form of masculinity, grounded in the necessity of discipline, research and work ethics.

The boost to its practitioner's self-esteem, however, relies upon an immature failure to value not the category of work one performs but the mode in which one performs it; independence and uniqueness arise from finding value in whatever one does. For example, one might work as a doctor (an esteemed category of work) but with a flagrant lack of care towards his or her patients (poor mode in which it is performed). Conversely, one might care sensitively for clients at a fast-food chain cash register (a culturally denigrated category of work). Nevertheless, the masculinity cultivated in masterpieces paradoxically shifts the youth away from immature thrill-seeking towards

42 By poesis, I use the ancient Greek term for activity or process. Hence, the artist is esteemed due to the creative process of his or her production. 
the traits necessary for positive youth development, such as resilience, self-esteem and perserverence.

The warrior model, one which espouses combative skills and war-like prowess, seems to inspire the language of youth in graffiti, especially those interviewed by Nancy Macdonald. However, there are more nuanced models than simply those proposed within the language of graffiti youth. From the vast sources of Western imagery such as in fiction and fables, I argue that the figure of the 'trickster' is much better suited to describe graffiti masculinity than the warrior. This kind of masculinity undermines hegemonic masculinity in its mode of expressing power but does not seek to insert itself as the dominant form. (It is not to be confused with the trickster of liminality, discussed at the outset of this essay. The trickster, in the instance in which I propose for graffiti below, is a combatant who achieves power through clever strategies and subterfuge.) Once one recognizes the appeal of graffiti's warriorship and the kinds of individuals who will be drawn to it, he or she can then adapt policies and efforts for prevention and intervention.

For formulating PYD responses to graffiti, I suggest two approaches to understanding involvement in the practice. The first is through Jungian interpretations of the warrior model, in which one appreciates the forms in which youth assume within the archetype of the trickster. This allows educators and counselors to predict which youth will be drawn to graffiti, how and why graffiti appeals to them, and possible options for either prevention or discontinuation. Secondly, Schiller, in his Letters, can be adapted here to further how one might imagine the two extreme attributes of graffiti masculinity, but as part of a conflict of emotions versus moral ideals. From Schiller arises a model that enables one to appreciate the transformative aspects of graffiti's most positive qualities, in 
particular Schiller's awareness of the challenges facing his 'impulsions' of 'sensuous' and 'formal' and their resolution in the 'instinct' of play.

\section{Review of Scholarship}

There are a broad range of works to which I owe my initial thoughts on masculinity. The first and principle scholarly work analyzing graffiti and masculinity is Nancy Macdonald's thorough 2003 ethnography The Graffiti Subculture: Youth, Masculinity and Identity in London and New York. It is the only full book on graffiti in which masculinity is discussed. Confronting the thought of the Centre for Contemporary Cultural Studies in Birmingham, UK, she establishes an early stance of research values, questions the history of subcultural analysis and delineates her approach to her subject matter. She outlines her fieldwork and sources, indicating that she "conducted a total of 37 informal interviews over a period of two and a half years" (50) of which most fieldwork occurred in London (eight weeks in New York). Her sources included twentynine writers for "in-depth interviewing and participant observation" as well as "newspaper articles, graffiti magazines and newsletters, books, police reports, the Internet and graffiti itself" (51).

She focuses specifically upon masculinity in Chapter 6, entitled "Constructive Destruction: Graffiti as a Tool for Making Masculinity.” Her findings are seminal. Basing her work on Messerschmidt's ideas on men and violence, she argues that "risks, dangers and criminality are a common means for boys to establish their masculinity" (97-98). Graffiti offers these elements in the construction of writing. She establishes a "theater of war" between "competing masculinities," namely between the writers and the authorities 
that hinder them. She uses language, clothing and direct statements to support this conflict in which there is even a "bond between them" (119) due to both the similarities of the forms of masculinity and respect for another opponent. ${ }^{43}$ Interestingly, she disagrees with R.W. Connell's notion that the writer's masculinity is contesting the hegemonic version of masculinity imposed by the authorities. She sees it instead as "similar masculinities fighting for potency" (121). The model here is one of warriors on a field of battle. Finally, she includes an analysis of the role of females in graffiti subculture and the obstacles and biases they encounter. I nuance her notion of competing masculinities by offering an alternative definition of the warrior image of masculinity, allowing me to deepen the subtleties between the youth's and the authorities' expressions of power.

Maggie Dickinson argues in her 2008 article The Making of Space, Race and Place that former New York City Mayor Rudolf Giuliani's 1995 war on graffiti, and his characterization of it as "hyper-masculinity" (38) in fact aided the public and youth involved as conceiving it as such. ${ }^{44}$ Also, New York City's "war" on graffiti furthered its conception of male risk-taking and confrontation with authorities, instead of embracing it as a new art form. This is useful for me in that it establishes an historical precedent for how graffiti became associated with masculinity. Other articles have appeared corroborating masculinity and graffiti, even without mentioning the term 'masculine.' For example, Jeff Ferrell and Robert D. Weide co-wrote "Spot Theory" for a special edition of City in 2010 using language that Macdonald identifies as masculine (such as love of

43 Abby Peterson found this to be true in her 2008 article "Who 'Owns' the Streets? RitualPerformances of Respect and Authority in Interactions Between Young Men and Police Officers." However, since it is an analysis of youth-police relationships in Sweden, not the United States, I include it here only in a footnote.

44 She also credits Giuliani's anti-graffiti campaign with the tendency of the public to assume that minorities create graffiti. 
risks) but without explicitly acknowledging it as a factor (or even acknowledging liminality). This simply exposes the limitation on how many males today resist questioning the basis for their identity.

In the last few years, a number of articles appeared specifically about masculinity and graffiti. ${ }^{45}$ Martin A. Monto, Janna Machalek, and Terri L. Anderson co-wrote "Boys Doing Art: The Construction of Outlaw Masculinity in a Portland, Oregon, Graffiti Crew" for the Journal of Contemporary Ethnography. Their methodology was observation within a single graffiti crew (called 'TSA') in Portland, Oregon. Their analysis and conclusions are very similar to Macdonald's, from riskiness to a sense of warfare. However, unlike Macdonald, they do not suggest competing masculinities. This is not surprising since her book, oddly enough, is never mentioned in their article. Even more interesting is their reluctance to embrace a possibly heavily white, middle class characteristic of the typical graffiti practitioner. They write:

A negative interpretation of this graffiti crew could identify them as mostly white, mostly middle-class men who get to have their cake and eat it too, who will benefit from their access to the ideals of hegemonic masculinity but still take advantage of this version of outlaw masculinity to construct their own identities and maintain a sense of authenticity (285).

For this reason, their article falls short of its potential. I find it helpful in that it asserts the findings of Macdonald while failing to explore masculinity further. Kara-Jane Lombard, following up on her analysis of governance in her 2013 article "Art Crimes: The Governance of Hip Hop Graffiti," wrote "Men Against the Wall: Graffiti(ed)

45 Rachel Holmes' article "Risky Pleasures: Using the Work of Graffiti Writers to Theorize the Act of Ethnography," published in 2010, uses writing as a conceptual and philosophical model for understanding her own field, not graffiti, and is hence not relevant for my research. 
Masculinities" for The Journal of Men's Studies in 2014. Her approach, though, is unusual in that she focuses upon the specific instance of graffiti culture and Australia. She links the masculinity to colonial, hegemonic masculinity, perhaps using this term due to the island continent's history. She concedes, like the three authors above, that "contemporary writers today are increasingly middle class, of European descent and from suburbia (187)." However, her contribution is that the masculinity embodied in graffiti is identical to that which was originally marginalized, writing that "these writers, perhaps once the embodiment of that elusive hegemonic masculinity, draw from the same systems that the original writers employed." This observation is very similar to that made by Dick Hebdige's The Meaning of Subculture, although applied to masculinity. She reinforces my notion that the masculinity in graffiti is regressive, more typical of past forms. Her difference with my claims here is simply on the context, since her focus is in Australia.

Other writers have reinforced Macdonald's original insights as well and hence my perception of it as valid grounds of debate and departure. Eyck, Toby A. Ten, and Brette E. Fischer, in their 2012 article "Is Graffiti Risky? Insights from the Internet and Newspapers" for Media, Culture \& Society, use evidence as their title suggests and come to an obvious conclusion. i.e. it is risky. I do not believe it is necessary to use such evidence to make claim that graffiti is risky, since placing tags and throw-ups in dangerous locations is, in fact, risky. Nevertheless, their research supports my general claims here. Ricardo Campos, in his recent 2014 article "Graffiti Writer as Superhero" for the European Journal of Cultural Studies, focuses upon the split between the everyday life of youth within the bounds of society versus their practice within the 
graffiti community. His research occurred in Lisbon, though its insights are relevant in the context of the globalization of the phenomenon, i.e. youth are drawn everywhere to graffiti to affirm a more exciting lifestyle as compared to mundane labor. This, too, accords with my own insights, simply supporting them without offering any nuanced interpretation.

Macdonald's book was published in early 2002, implying that her research was conducted in the late 1990s. Graffiti has been heavily impacted by the proliferation of and ease of access to the internet due to the proliferation of cheap sources of recording and uploading technology. I would like to add to this the simple conjecture that today's youth have matured in the presence of technology in such a way that the virtual realm is a far more important aspect of their identity than an adult in his or her fifties. For this reason, the production of the online forms of graffiti is also bound up with their male identity, even if in subtle ways.

\section{A. Men's Studies and Graffiti: Synchronous Beginnings}

The beginnings of the academic fields Men's Studies and Masculinity Studies (and other practices relating to male identity) coincide with the beginning of graffiti. Both have debatable time periods of initiation, but essentially occurred around the 1960s. I argue that they were responses to a similar set of liminal conditions, namely the changing nature of masculine identity and power in the period in question. ${ }^{46}$ Graffiti is the response

46 It is unclear exactly when Men's Studies began as an academic field. In an interview by editors Josep M. Armengol and Angels Carabi for the 2008 book Debating Masculinity, Michael Kimmel (author of the seminal Manhood in America) suggests the field's beginnings in the 1980s. He writes, "We actually began to label it as men's studies, that is, to talk about masculinity as a factor, quite recently, in the early 1980s. Scholars educated in feminism started noticing that the system of gender had been ignored in the analysis of men (16)." Contradictorily, the aforementioned editors summarize the findings of the Kimmel interview in their prologue, stating that he traces "its beginnings back to the late 1970s" (11). 
of youth, and the divergence in time between graffiti and adult practices represents the failing of the adult realm to enact policies born from Men's Studies research.

Joe Austin states in Taking the Train that "writing did not begin in New York City, but in Philadelphia, perhaps as early as 1959," adding that "most New York City writers usually begin descriptions of their own origins no earlier than the later 1960s" (41-41). Austin, like many enthusiasts, traces this to post-World War conditions of economic depression, inner city crime issues of juvenile delinquency and the excessive blanketing of corporate advertising in public spaces. It is also, though, a period in which various anti-discrimination laws were put into effect due to the Civil Rights movement, up until the assassination of Martin Luther King in 1968. This continued the transformation of American society, reinserting a discourse on rights in relationship to dominant forms of civic identity. The failed intervention in Vietnam emasculated the psyches of American men by the early 1970s, too. In the case of the presence of corporate advertising and the Civil Rights movement, one has both an increase in the power of corporations in the public sphere and, conversely, an erosion of white male upper-class patriarchy in the civic sphere. Since white males still ran the corporations, this see-saw result seems paradoxical.

The 1960s, though, constituted an important liminal period for men in the United

Editors Marlen Elliot Harrison and Phillip Ward Schnarrs of Growing Our Field: Emerging

Perspectives on Masculinities and Men's Lives offer in their introduction that "Men's studies began during the second wave Feminist movement of the late 1960s, when men began to inquire about their own role in society and within the gender order" (7). Yet, the specific date they offer for the birth of the field is of the "first National Conference on Men and Masculinities" (7) in 1975. The perspective is more diverse if one considers conceptions of the field in publications appearing in the 1980s. Harry Brod, editor and contributor of the collection of older 1987 essays The Making of Masculinities: The New Men's Studies, therein looks backward to Talcott Parson's sociological conceptions of sex roles in the 1950s as key in the birth of critical transformations of male identity since Parson's conceptions reversed biological assertions in favor of sociological influences. 
States. Whereas African-Americans had many doctrines for which they fought, and women, too, had a specific group with leaders such as Betty Friedan and Gloria Steinem as their voice, there was no such unified leadership for heteronormative men. They had no charismatic leader to articulate their liminality or the challenges and changes they faced and hence offer productive, positive responses. The consequent mainstream solutions to this liminal crisis were manifold, from an attempt to codify it (academia), rebel and/or act out in some way (such as graffiti), argue for men's victimization (Men's Liberation), or to aid males in affirming a new male consciousness according to $\operatorname{archetypal/mythic~models~(mythopoeic~therapy).~}$

The writings and practices of many of the figures of the liberation and (later) mythopoeic movements, such as Jack Sawyer (in the 1970s) and Robert Bly (in the 1990s), could be understood as corresponding to the activist component of feminism. Their efforts were practical, not theoretical, an important step in relationship to recent trends of PYD, even if they worked typically with adult men. They based their work on very principled frameworks, such as Turner's studies in ritual or Jung's conceptions of archetypal imagery. Michael Kimmel summarizes the early Men's Liberation movement: "Male liberation calls for men to free themselves of the sex-role stereotypes that limit their ability to be human," announced Jack Sawyer in "On Male Liberation" (1970), a founding text of the new men's lib literature. Following his call, dozens of other works poured into the growing field. ${ }^{47}$ (Manhood in America, 202-203) There was reluctance about supporting the early men's liberation efforts; Kimmel

47 Kimmel mentions "Warren Farrell's The Liberated Man (1974), Marc Feigen Fasteau's The Male Machine (1975), Herb Goldberg's The Hazards of Being Male (1975) and The New Male (1979), Jack Nichols's Men's Liberation (1975), and two anthologies, Deborah David and Robert Brannon's The Forty-Nine Percent Majority (1976) and Joseph Pleck and Jack Sawyer's Men and Masculinity (1974)" (Manhood in America, 202-203). I cite these to demonstrate their popularity. 
writes that "Media pundits often excoriated men's liberation as a bunch of middle-class white guys feeling left out of the fun of being oppressed and trying to jump onto the liberation bandwagon" (202). This is unfortunate, since there was a lost opportunity to create policies to assist young men in their growth away from regressive forms masculinity. Kimmel himself, while appreciating some of the efforts of mythopoeics, cannot resist ridiculing them. He writes that these 'weekend warriors' head[ed] off to the woods to rediscover their wild, hairy, deep manhood. . The search for the wild warrior within led men's movement scions to wander through anthropological literature like postmodern tourists, as if the world's cultures were arrayed like so many ritual boutiques in a global shopping mall. . This was all slapped together in a ritual pastiche. $(229-231)^{48}$

Bly, whose 1990 Iron John would appear much later than the aforementioned works, responded to this strife in an interview for the 2000 Spring Paris in defense of his work:

Men we saw took a deep interest in poetry and mythology. I thought it was beautiful. The media dismissed all this work as drumming and running in the woods, which reduced it to something ridiculous. I think the men's seminars were not threatening to the women's movement at all, but a lot of the critics of Iron John missed the point.

Mythopoeics were concerned with the insecurities of manhood in existing adults, yet they seemed to have ignored the challenges facing young men. For this reason, it is

48 Kimmel ignores blatantly the grounds of Jungian philosophy and its use of archetypes. It is the archetype that interests Jungian psychotherapists, not the cultural artifact; the latter is simply a first step to aid in the imagination in accessing them. For this reason, they drew upon other cultures outside Western fables and mythology. 
significant that it is men that are mentioned above, not youth. Had they focused upon educating, preparing and transforming struggling adolescent males (such as recommended under PYD research), their influence may have been more widespread and successful.

Critics of the mythopoeics and men's liberation movement aruged that it enabled already entitled individuals. Such individuals (males) have been empowered by a historically patriarchal order and hence already operate from a position of privilege. Also, critics claimed that men in these movements undermined the real concerns of females and other minorities. In the absence, therefore, of transformative efforts towards youth, youth themselves (we might argue) created their own compensatory strategies in the face of those same social changes via graffiti and similar subcultures.

A key component for graffiti's birth lay in the attack on state power through the assertion of human rights. Jay "J.SON" Edlin, editor of Graffiti 365, writes in the introduction that "Growing up against the backdrop of the civil rights movement, gangs, hippies, and Vietnam War protests gave me a feeling of powerlessness" (iv). This reaction, he writes, is not about his gender, but his age. He states that "... my young age prevented me from participating in any forms of organized rebellion" (iv). Edlin notes, though, by the 1980s, the culture within graffiti had changed, signaled by new dangers such as drugs ("crack and angel dust") and "A writer getting shot or stabbed became a real possibility" (vi). Graffiti appeared in galleries; Keith Haring was popularized; and new forms of street art emerged that utilized stencils and wheat paste murals. At some point, the new culture in Reagan's 1980s America slowly converted graffiti from its antigovernment historical roots to a masculine proving ground of risk and danger with a 
validated aesthetic flair.

\section{B. Indefinable Masculinity, Nebulous Manhood}

Two central issues regarding masculine identity are hence at issue and reflected in graffiti. This first is that manhood is problematic in that it is never established with certainty and finality, a suspension of resolution that has been exacerbated by the changes in American social structure since the turn of the twentieth century. In this sense, the adolescent boys drawn to graffiti may be partially drawn to the practice out of a need to engage in an activity whose very process of construction demands masculine virtues. We might question, then, this as a goal of graffiti membership and, if so, whether or not graffiti attains this goal. This leads to another issue: masculinity as a quality has many possible definitions, definitions that are coded uniquely within any society (and epoch). Since masculinity itself is varied, youth may be further confused as to how to define their identity.

\section{Masculinity, Its Varied Definitions}

It is not clear how one might define the qualities of masculinity, especially since not just males can be masculine. This creates not only the challenge of assessing the form of masculinity in graffiti, but further ambiguity for male youth in general. Crossculturally, David Gilmore in his book Manhood in the Making gives instances in which contemporary Western notions of "stressed" and "pressured" manliness ${ }^{49}$ that is "a prize to be won by fiece struggle" (16-17) seem reversed, such as in the cultures of Tahiti (in

49 Gilmore focuses on manhood, not masculinity, and arguably conflates the two terms. 
which males, for example, are comfortable in reversing sex roles) and the Semai (in the notion of punan, a respect for other's feelings and non-aggression). Females can be masculine as well. Judith Halberstam's Female Masculinity offers a critique of the association between men (the 'male body') and masculinity by characterizing precisely the non-white male masculine personae in recent US history (the past two centuries) and their appearance in creative media. She writes:

If masculinity is not the social and cultural and indeed political expression of maleness, then what is it? I do not claim to have any definitive answer to this question, but I do have a few proposals about why masculinity must not and cannot and should not reduce down to the male body and its effects (1).

By focusing where masculinity is 'culturally displaced' - upon the female body, for example - she claims to be able to highlight its attributes better. For example, she demonstrates in her introduction how James Bond in the 1995 film Goldeneye is far less 'masculine' than Judie Dench's M, along with some other figures in the film who also undermine Bond's masculine persona.

Even amongst males today there are different forms of masculine identity. African-American males sometimes demonstrate a particular form of masculinity that may be rejected by white males. A poor white male living in the countryside of Kentucky exhorts a far different belief in masculinity than a career-driven Wall Street trader. Excellence with computers and information systems is a form of masculinity, though perhaps not one that would resonate where masculinity is still defined in large part by physical strength.

The figure of Q in the recent 2012 bond film Skyfall is an illustration. Q is a soft- 
spoken, physically androgynous technical specialist. He is first introduced to the audience of the film as he sits next to, and verbally spars with, Daniel Craig's rugged Bond in London's Tate Gallery. They debate the meaning of The Fighting Temeraire tugged to her last berth to be broken up, 1838 by J.M.W. Turner and, subsequently, their individual fields of efficacy. On the screen, they appear as equals (a novel idea for the film franchise). Q eventually declares, in an affirmation of his potency, that he can do more at his computer than Bond can in the field—save that Q needs someone to "pull the trigger." Q's power is asserted through his knowledge and skill, not his body. This is the Q of a new generation, different than those past Qs who were often depicted as cute, elderly and bumbling. Suitably, theorists such as Robin S. Johnson have recognized and termed this form of masculinity as 'technomasculinity.' Though the Bond films are a creative fiction, their general acceptance is an example of the changing ways society defines masculinity, and is symbolized in the match of Q and Craig's older Bond.

The male body, too, has undergone changes as a masculine ideal. Michael Kimmel writes in Manhood in America of the value placed on physical weakness in nineteenth-century ideals of masculinity, describing almost perfectly the aforementioned Q of Ben Whishaw:

Even in the mid-nineteenth century, cultural observers venerated a "romantic consumptiveness" as the preferred male body type — composed of a thin physique, pale complexion, and languid air. (Muscular bodies were snubbed as artisanal, a sign of a laborer.) "An American exquisite must not measure more than 24 inches round the chest; his face must be pale, thin and long; and he must be spindleshanked," wrote the venerable observer Francis Grund in 1839. "There is nothing 
our women dislike so much as corpulency; weak and refined are synonymous."

The mid-19th century masculine ideal described here must be understood within the context of class power. To be leisured required wealth, and the body needed to reflect that it did not engage in hard physical labor. Only later in American (and British) history did a shift occur in which a more muscular body became a hallmark of manliness, from the workout program of Charles Atlas to the film career of Arnold Schwarzenegger.

There are hence many forms of masculinity. In order to categorize masculinity and differentiate its various forms with some sense of order, R.W. Connell, in her germinal 1995 book Masculinities, places them in overarching categories based on Foucault-esque power: hegemonic, subordinated, complicit and marginalized. These categories logically presuppose that there are no universal definitions of masculinity and that whatever definitions exist are determined by the group in power. e.g. the hegemonic. For example, she describes hegemonic masculinity as follows:

Hegemonic masculinity can be defined as the configuration of gender practice which embodies the currently accepted answer to the problem of the legitimacy of patriarchy, which guarantees (or is taken to guarantee) the dominant position of men and the subordination of women. (77)

This quote reveals, though, that she conflates masculinity with males and power. Hence subordinate masculinities are tied to the ways in which males might define their masculinity if they are part of a marginalized minority. In this case, she gives homosexuality as a prime example (78). Similarly, complicity is an instance in which mainstream males enjoy the benefits of masculine power without directly engaging in 
hegemonic relationships. For example, a man may believe that he treats women well and does not act in any way to abuse power, yet nevertheless enjoy the benefits of being a man in a patriarchal society. Finally, marginalization is situated in minority groups, where the "interplay of gender with other structures such as class and race" works against masculine privilege (80). Authorization of a groups' masculinity is contingent upon mainstream male masculinity. For example, African-American men are marginalized, even if black athletes are admired and 'authorized ${ }^{150}(80-81)$.

These terms are problematic, however, in that they are defined exclusively in relationship to men. Halberstam's challenge to the conflation of masculinity with males came approximately three years after R.W. Connell's Masculinities was published. This makes Connell's terms problematic. Are 'feminine' males—acknowledging the difficulty of how 'feminine' is coded and defined - an example of marginalized masculinity or one in which, quite simply, males embrace femininity? If one were to associate masculinity with the male body, and state that masculinity as commonly understood is codified in a society based upon hegemonic males and their specific version of masculinity, then one would therefore be justified in stating that such males are, in fact, masculine, just of a kind which becomes coded as feminine due to the dominant males. Yet, this is also a semantic play on terms; why not simply use the term 'feminine' but avoid any pejorative sense of the term when used for males?

Secondly, Connell defined hegemonic masculinity in terms of its oppression of women as well as its dominance within society. This makes it impossible for masculinity to exist in a society in which women are not oppressed. Though this is, of course, a fiction and ideal, it reveals that masculinity in its dominant form automatically assumes a

50 Connell uses the term 'authorization' to denote a form of approval. 
negative character. This is problematic too. ${ }^{51} \quad$ Nevertheless, masculinity is clearly a varied term. There is no universal definition, outside, perhaps, Connell's relational categories. This creates a problem when analyzing a population like the graffiti community.

What remains from the scholarly and academic perspective is to catalog how a group like the graffiti subculture defines on its own terms its maleness, manhood and/or masculinity. ${ }^{52}$ In this regard, a preferred methodology is the ethnography. One observes how a specific population defines masculinity while being attentive to one's position of power, influence, and personal biases as an observer. Macdonald defends this approach in her chapter "Climbing down from the Fence: Locating Our Standpoint and Values:" I used my informants' accounts to understand this unfamiliar subculture and to gain insight into their perspectives as members of this. Their accounts were not always concordant - to be expected in a subculture cleaved by different groups with different attitudes and beliefs. However, I had no wish to judge them as right or wrong ... As I saw it, their accounts were all different, valid and interesting in their own right. (30)

Men's Studies and Masculinity Studies as fields are not simply documentations of how a person or group makes claims to terms like 'manliness' and masculinity. The researcher's and thinker's own values and their effect on the interviewees must be taken into account. This also suggests that a deeper analysis of the cultural grounds of the claims of the participants is important, especially if those grounds are the same as those

51 I have not done the research but assume that there are similar treatises on femininity, such as hegemonic femininity, subordinate, etc.

52 I do not settle on any of those three terms to convey the sense that the inquiry is 'open' when analyzing groups. 
of the researcher, e.g. I, as a writer here, am from the same cultural world as the makers of graffiti, if that world is comprised of Western values, public education, masculinity.

We should also note how mythopoeic efforts like the writings and lectures of Jungians like Robert Moore and Douglas Gilette are in virtual contrast with academic research in terms of foundational principles. Scholars and intellectuals today, under the influence of postmodernism, resist making universal declarations as to what, exactly, constitutes masculinity and manhood. The Jungians, on the other hand, still make claim to deep-seated psychic patterns that can be used as a formula for understanding and transforming males. Not surprisingly, their work is not used in academic research and, similarly, academic research is not used therapeutically. (Nevertheless, the specific efforts of Moore and Gilette are useful in understanding graffiti since there is a strong imaginative component present in the subculture. Graffiti youth use terminology and pictorial representations that lend themselves to an alternate interpretation in the Jungian framework.)

\section{Manhood: To Be or Not to Be}

Logically, confusions about what constitutes masculinity further reinforces the challenge of defining manhood from an individual perspective. A common issue within Men's Studies is, in fact, manhood's indefinite status and its peculiarly social and artificial achievement. Manhood does not necessarily equate with adulthood, but adulthood is certainly a preexisting condition for manhood. Ideally they would occur together, but one can be an adult without feeling himself to be a man. Manhood represents an achievement of some kind, typically determined by the societal context. This achievement, though, 
requires affirmation from an audience, necessarily creating ambiguity in the absence of a performative process. Anthropologist David Gilmore writes of this uncertainty throughout many world cultures:

$[\mathrm{T}]$ here is a constantly recurring notion that real manhood is different from simple anatomical maleness, that it is not a natural condition that comes about spontaneously through biological maturation but rather is a precarious or artificial state that boys must win against powerful odds. This recurrent notion that manhood is problematic, a critical threshold that boys must pass through testing, is found at all levels of sociocultural development regardless of what other alternative roles are recognized. (11)

Since it is determined by conditions outside of an individual in question, it becomes mediated by one's external challenges and relationships. It is not achieved biologically (through basic growth to a certain age), even if sexual prowess and other sexual references might be part of pubescent male machismo. (Sexual feats can, however, be an instance of an expression of power.) Gilmore argues that this is unique to males, stating that "although women, too, in any society are judged by sometimes stringent sexual standards, it is rare that their very status as woman forms part of the evaluation" (11). This further complicates the liminal condition of male youth. They are transitioning from childhood, but are not 'transitioned' by natural forces or a specific, external process pre-coded today in the form of extant rituals.

Even if a male somehow achieves formal recognition for his manhood, it is likely that the status of his manhood remains tenuous and impermanent. One can challenge a male to 'be a man' or 'man up' in various situations. Ideally, a male decides for himself 
what constitutes his manhood, finding within himself what constitutes his personal, essential principles of identity. The ritualized rite of passage to manhood was arguably created in societies so that males would then adopt the positive qualities associated with manhood as taught therein (such as being responsible and caring), feeling that there is no longer any need to 'prove' oneself through more destructive or risk-taking activities. The goal, basically, is to eliminate the insecurity caused by ambiguity and to lead a male out of liminality into a positive role for the community. In fact, in some cultures, some kind of highly visible marker through a socially recognized rite is permanently stamped on a male's body (such as a tribal tattoo on one's face, or a semper fidelis U.S. Marine tattoo) ${ }^{53}$ as a trace of their past masculine performance.

Traditional rituals have lost their force in modernity. ${ }^{54}$ Males, especially young ones, still experience the burden of the ambiguity. The trauma of male youth remains, in part, the transition to manhood, requiring the death of the child and the achievement of something new and unknown. A male adolescent must prove to his audience-from peers to revered adults - that he is both no longer a child and also 'manly.' While it is no doubt true that it is a sign of maturity that a male decides what constitutes for himself his manhood, a self-sustaining set of values is something that one cannot expect from a teenager.

Manhood formation is different than the quality 'masculine' and 'masculinity.' The

53 Here, also, there are many instances in which males seek to make visible their manhood through outward markers. Clothing, tattoos, hairstyles, etc. are all carefully cultivated by Western males to communicate to others their masculinity. The omnipresence of this effort denotes just how tenuous men feel about their manhood and the concerns about how they are viewed by other males.

54 Robert Bly attempted to recreate rites of passage for males in the hopes to rectify the practicants' psyches. He responded in the aforementioned interview about the need for such initiation rites: "I wasn't the first to have discovered that many of the classic fairy tales lay out stages of initiation into adulthood which we've entirely forgotten, that our ancestors apparently knew a lot about. We're reduced to the legal age for drinking or the driver's license." 
two, however, are inextricably linked. Masculinity is integral to manhood; one cannot achieve manhood by behaving in a non-masculine fashion. Hence, to begin, we can assert that masculinity is that which is used to constitute one's manhood. Halberstam, in fact, cites the example of George L. Mosse, in his book The Image of Man: The Creation of Modern Masculinity, when he "defines in [masculinity] his first sentence as "the way men assert what they believe to be their manhood" (49). Masculinity exists independent of manhood, whereas the opposite is not true. Hence, when one identifies masculinity in graffiti, this does not equate to a specific interest in establishing manhood.

A community like that of graffiti has an extant, in-place ideology about what constitutes its masculinity. This is part of the appeal. It is no wonder, then, that youth would gravitate towards accepting it in order to escape liminality.

Much of the discussion about boys, men and manhood revolves around the notion of power and hegemony. This is present within the immediate person-to-person interaction between individuals as well as the structures of greater society. The masterwork that has provided the foundation for much of the philosophical and psychological research of the past two centuries is Hegel's 1807 Phenomenology of Spirit. It is especially relevant for Men's Studies, in particular the person-to-person power dynamic. Since it is grounded in the failure of what Hegel terms as "mutual recognition," its general dialectical structure may serve as a reference for understanding graffiti masculinity.

\section{Males Adrift within/out Hegel's Dialectic}

A number of liberation struggles such as the Civil Rights movement and feminism 
were inspired by the awareness of what it means for one to suffer under a false version of his or her identity established by a dominant group or individual, to be an 'Other' in a subject/object binary, such as in W.E.B. Dubois' writings on the 'double consciousness. ${ }^{.55}$

Dubois was inspired by the Hegel's Phenomenology of Spirit, in particular Hegel's section on the Lordship-Bondsman dialectic (the wording is very similar). This is different than Connell's hegemonic/marginalized distinctions, which tend to be defined as binaries ${ }^{56}$ in a static relationship. For example, hegemonic masculinity is 'monolithic' in its presence as it displaces other forms of masculinity.

Hegel's dialectic denotes intricately how positions of power and disempowerment are, in fact, part of a greater process of mutual affirmation, even if that affirmation is not immediately apparent. ${ }^{57}$ Indeed, Hegel's analysis of consciousness is dense and always two-sided. He argues that one's 'self-consciousness' is based upon both the desire for recognition of one's own self-consciousness and the problem of mutual recognition with another self-conscious individual. This recognition is key, for one may have an awareness of oneself as a reflective, independent consciousness but (using vulgar terminology) this awareness has no sense of 'reality' until it is confirmed by the response of another outside

55 From his 1903 book The Souls of Black Folk of how one experiences a 'double consciousness' in the face of a dominant group, his often-reproduced quote:

It is a peculiar sensation, this double-consciousness, this sense of always looking at one's self through the eyes of others, of measuring one's soul by the tape of a world that looks on in amused contempt and pity. One ever feels his two-ness, - an American, a Negro; two souls, two thoughts, two unreconciled strivings; two warring ideals in one dark body, whose dogged strength alone keeps it from being torn asunder. (4)

56 I consider her model to be related to binaries since the Hegemonic-Complicit are at one pole whereas the Subordinate-Margainalized are at the other. Complicit and Margainalized are nuances of Hegemonic and Subordinate.

57 For example, Dubois writes of a moment of Hegelian synthesis, the results of a movement within the process of overcoming the binary, in which the two selves merge into a higher one: ". . this longing to attain self-conscious manhood, to merge his double self into a better and truer self. In this merging he wishes neither of the older selves to be lost" (6). This, however, is a personalized use of only part of Hegel's complex dialectic. 
of oneself. $^{58}$

To resolve solipsism, he simply defines self-consciousness as requiring the other's self-consciousness, stating that "Self-consciousness exists in and for itself when, and by the fact that, it so exists for another; that is, it exists only in being acknowledged" (111). For example, one does not have a sense of familiarity of self-consciousness when encountering a rock or tree ${ }^{59}$ as compared to that of another human individual. Hegel acknowledges that one can have a self-sustaining, inwardly directed sense of self but that it has not attained the status of 'truth' until it is acknowledge by another selfconsciousness, another person. Since self-consciousness is oriented towards a singular person in contrast with the rest of the world, and in fact requires this recognition of the other self-consciousness, it is necessarily in conflict with the 'other' whom he or she is encountering. (Both seek 'recognition' through the other person, realizing that this is only achievable through such an encounter.) The act of mutual recognition may collapse and result in conflict, since one might not wish to risk failure of recognition. In this case, one becomes dominant, the recognized ("the lord"), the other dominated ("the bondsman"), or recognizer. The state of the latter is one in which one's self-consciousness is denied, by definition, since it is not recognized.

Here, though, Hegel does not simply assert a static power relationship. He reveals that neither position is tenable. The Lord has failed to attain recognition despite his or her

58 I am not sure if this is helpful or not, but there is a religious dimension here in Hegel's writing that could clarify his conception of self-consciousness. I argue that Hegel conceived of the unity of all consciousness as a single consciousness which makes its appearance in our individual separateness. This is why it is possible to 'recognize' something of ourselves in another being - there is the familiar sense of that person possessing the unique quality of self-conscious being. Without this unity, we would be trapped in solipsism.

59 I exclude here fanciful claims such as, "A rock or tree probably has a consciousness like our own, for all we know." 
privileged status in the dialectic. This is because the Lord has denied the Bondsman of any recognition and hence the capacity to properly recognize the Lord:

But it is clear that the object does not correspond to its Notion, but rather that the object in which the lord has achieved his lordship has in reality turned out to be something quite different from an independent consciousness. What now really confronts him is not an independent consciousness, but a dependent one. He is, therefore, not certain of being-for-self as the truth himself. On the contrary, his truth is in reality the unessential consciousness and its unessential action. (117)

In other words, the Lord, in his or her effort to ensure his or her recognition, eliminated its possibility by denying the humanity of the Bondsman. Hegel's philosophy exposes not only the status of the Bondsman but the tenuous status of the Lord. It is here that it is particularly revolutionary: it indicates how a position of power does not actually achieve its goal. Self-consciousness, seeking recognition of its own self-consciousness by dominating the other into recognizing one's own self-consciousness, cannot attain such since the other has had its self-consciousness negated in the process. Since recognition of one's self-consciousness requires this recognition from another self-consciousness, the negation of the other self-consciousness (through the assertion of power in the dialectic) frustrates the endeavor. In short, what emerges for the Lord is that his or her selfconsciousness cannot be recognized since he or she has denied self-consciousness in the Bondsman.

This signifies that all forms of power dehumanize both members of the dialectic. For true self-consciousness to emerge, this conflict must be overcome on a higher level. In fact, their positions of power reverse. The Lord realizes that his or her self-recognition 
as Lord is mediated through the Bondsman, hence Hegel's assertion that "his truth is in reality the unessential consciousness and its unessential action" (117).

Hegel's philosophy (as well as the post-Hegelian thinkers implementing some variant of his thought, such as Marx) was widely read in Europe. The French philosopher Jean-Paul Sartre popularized Hegel's account in his 1943 treatise Being and Nothingness, using his personal rendition with such modifications as 'the look.' Furthermore, Sartre wrote more accessible (and political) applications of Hegel's dialectic in such works as "Réflexions sur la question juive" ("Anti-Semite and Jew," 1943) and "Orphée noir" ("Black Orpheus," 1948). These popular works further influenced revolutionary cultures. Sartre's (and hence Hegel's) influence would find its way into feminism via Simone de Beauvoir's 1949 Le Deuxième Sexe (The Second Sex) and postcolonial philosophy in Frantz Fanon's 1952 Peau Noire, Masques Blancs (Black Skin, White Masks).

Many of these accounts, however, failed to analyze the dialectical relationship from both sides of its emergence, producing a contemporary form of Manicheanism that perceives the world in terms of specific hardened, unchanging dualities, such as good/evil. Its manifestation in critical thought results in the Lord of the dialectic essentially occupying the position of the Evil one and the Bondsman the Good. Once such a judgment occurs, the dialectical movement of recognition and synthesis is lost. The tendency in some of the post-Hegelian thinkers such as de Beauvoir was to only focus upon the 'bondsman' side of the dialectic. The Lord, in fact, faces his or her own issues of identity. One's identity cannot be 'recognized' by the Bondsman.

By way of illustration, the proper Hegelian approach to conflict appears in Simone Weil's analysis of The Iliad. Its warrior analogy is useful in graffiti, since both 
The Iliad and graffiti celebrate power. In the same period around World War II, she wrote her brilliant essay "L'Iliade ou le poème de la force" ("The Iliad, or The Poem of Force," published in 1939). She applies the two sides of the Hegelian analysis of the dialectical interplay upon the figures of the encounters throughout the poem in which one assumes the role of the Lord, the other Bondsman. Sometimes the same figure experiences both Lordship and Bondsman status, such as Hector's triumphs and ultimate loss to Achilles. However, she does not use those specific Hegelian terms; her awareness of the dialectic is so completely internalized and mastered that it is not necessary for her to do so:

Victors and vanquished are brought equally near us; under the same head, both are seen as counterparts of the poet, and the listener as well. If there is any difference, it is that the enemy's misfortunes are possibly more sharply felt ... As for the warriors, victors or vanquished, those comparisons which liken them to beasts or things can inspire neither admiration nor contempt, but only regret that men are capable of being so transformed...

There may be, unknown to us, other expressions of the extraordinary sense of equity which breathes through the Iliad; certainly it has not been imitated. One is barely aware that the poet is a Greek and not a Trojan. (188-190)

What she reveals is how the poem specifically focuses upon the consequences of force (or might) when such force determines human relationships, that which makes them "beasts or things," i.e. Lords or Bondsmen. This, for Weil, is both the allure and the tragedy that occurs in The Iliad. Using the dialectic appropriately, Weil reveals compassion for both sides of the interplay, placing her in perfect sympathy with Homer. 
Fanon also applies the dialectic appropriately in Black Skin, White Masks. He writes about both the consciousness of the white, Western world and its attitudes towards black emancipation as well as the effect this has specifically upon the Africans involved. For example, in the subsection "B. The Negro and Hegel", he writes:

At the foundation of the Hegelian dialectic there is an absolute reciprocity which must be emphasized. It is in the degree to which I go beyond my own immediate being that I apprehend the existence of the other as a natural and more than natural reality. If I close the circuit, if I prevent the accomplishment of movement in two directions, I keep the other within himself. Ultimately, I deprive him even of this being-for-itself.

The only means of breaking this vicious circle that throws me back on myself is to restore to the other, through mediation and recognition, his human reality, which is different from natural reality. The other must perform the same operation. (217)

Fanon uses Hegel's observation that the bondsman must 'fight' for recognition; it cannot simply be given to him or her. Here, too, Fanon confronts the issue of recognition forced upon members of a dialectic defined by recognition. One cannot force recognition of bondsmanship upon bondsman, especially from the vantage point of the Lord, i.e. Fanon did not wish for Westerners to feel pity for Africans and to guide them to self-rule. It is for this reason that he is often cited as stating that conflict was necessary for the independence of African peoples. However, conflict as used in Hegel (and hence Fanon's usage) represents not only the assertion of one's will but the necessary second stage of mutual recognition. 
The middle-class, or even upper-class, white heterosexual male is the ominous 'Subject' or Lord that sometimes appears in critical thought. The use of the term 'other' was never used for middle-class white heterosexual males. Even if they are benign individuals, according to R.W. Connell in Masculinities they are still 'complicit'; in Hegelian terms, they are inescapably Lords. In fact, white men in general are often in the position of the 'culprit' or perpetrator of a wrong in the Subject/Other, Lordship/Bondsman relationship, such as in racism and misogyny. The early criticism (if not outright ridicule) of Men's Liberation as attempting to argue that 'men have issues too' stems from this assertion, for white heterosexual males are summarily classed as all belonging to the Lord, no matter their individual life conditions and experiences. With the demise of Marxism in the late 1980s, even the notion of being from a lower class no longer reclaimed males from this criticism. Masculinity, in fact, is loosely associated with both males and the Lord in the dialectic.

Males, in fact, often react negatively or defensively when labeled as Lords in power relationships. The reasons for this are complicated and may be found within Hegel's dialectic. First, Hegel argued that the Bondsman overcomes his or her status through work, learning and acquiring knowledge from the Lord until he or she is on par with him or her. For Hegel, the Bondsman, in fact, attains a higher status, since he or she ultimately has both the knowledge of the Lord and his or her own pre-dialectical wisdom. This relationship is different when it is between two individuals in which one discursively lays claim to the dialectic while in fact having power within it. ${ }^{60}$ The

60 By 'discursively,' I mean that it emerges in social discourse, from classroom discussions to Kant's idealized state in What is Enlightenment? In this sense, the male is informed through ideas and discussion of his power. This means that the recognition of himself does not arise from within the direct interpersonal dialectic of Lordship-Bondsman, but instead on the level of ideas. 
recognition, so key to Hegel, is flipped; the supposed Bondsman now 'recognizes' the Lord as such. This recognition disempowers the Lord, since they are not the 'recognized Lord' in the active and empowered sense of the term - the very definition of lordship by Hegel. They are therefore not the ones that bring about recognition within the dialectic. In other words, the male is dictated the terms of a relationship which states that he dictated the terms as a male. He is 'told' that he has power, simultaneously denying him of this power of naming (again, this process is justified under the more subtle notion of complicity.) This is a contradiction. One cannot be a Lord without the act of establishing the relationship.

This raises the question as to how a male is to respond to such 'recognition.' It is a curious state - to be disempowered while enlightened of one's actual power. Both sides' experiences are, in fact, true. Males enjoy powers of which they are not aware, as Connell's understanding of 'complicitly' suggests. Yet, to be named a Lord without establishing the naming is an unusual experience. One may become defensive, aggressive, dismissive, or more; in fact, one could find here a precise catalog of the reactions males have had in general to gender studies and the arguments of feminist thinkers, as well as broader assertions of the power of males by minority groups. It is possible that this arises precisely from the above process of recognition.

For Men's Studies, Hegel's observations are also helpful for understanding the challenges for males in recent Western history. Hegel's Lordship-Bondsman dialectic does not occur between a self-conscious individual and a non-individual. In the past, since women were not considered of equal status to men, a male's encounter with a woman would invoke the "Lord' status of the dialectic, and remain in this static state. The 
Lord status, though, is tenuous, since, according to Hegel, it sustains its affirmation via a Bondsman whose self-consciousness has contradictorily been negated. This creates, for males, an incomplete emergence into Truth—a true self-conscious individuality. In the presence of women, men were not men. Therefore, we can assume, first, that the Hegelian dialectic occurred between males, in particular males that were empowered by their society. The conflict and struggle for recognition and self-consciousness has hence a long history in male contact (and might be reinterpreted in that light). In early analysis of rites of passage, such as those by van Gennep and, later, Turner, the emerging consciousness of adolescent males faced the challenges imposed by a male hierarchymale priests and other authority figures - that need to be overcome for the assertion of manhood, which can be understood as a vulgar form of Hegel's 'recognition.'

Secondly, since women were empowered recently, we may also witness the emergence of men seeking recognition from prominent women (and other minorities) holding positions of power. The reciprocity here means that the dialectic may now be applied universally, regardless of race, gender and sexual orientation. In fact, many white males have embraced Hip Hop culture via its dress codes, language and overall culture have sought recognition from African-American males - a longing to be recognized as a fellow 'brother' over and against 'the Man.'

Third, we might witness in the struggles of males the loss of the status of Lord which occurred when individuals (such as women) were in a permanent state of bondsmanship. There has been a diminishment of this role for male self-recognition in the 20th Century in Western nations. In many ways, the World Wars perhaps served in part as a means of affirmation for males facing the erosion of their traditional seats of 
political, social, familial and legal power, to be definitively lost by the end of the Vietnam War. This erosion furthermore meant that the status of male identity was in further need of affirmation, though in many ways this affirmation may still be sought from traditional sources (i.e. through other men).

\section{Gendering the Opposition: Consumption, Society, Public Space}

One of the conceits of graffiti is its ethical attack on corporate marketing. The graffiti tag is often depicted in graffiti manifestos as a parody of the corporate logo. Billboards impose upon public space a false truth about a product; taggers 'bomb' billboards with their own tags. In fact, the narrative of tagging-versus-advertising is one of the key justifications for the moral status of graffiti.

When I first studied graffiti, it occured to me that there was something contradictory about males (especially white males) marring public space. Public space has been the domain of males in the United States through most of its history. However, changes since the 1960s, if not the late 19th Century, have increasingly diversified and transformed the visible civic, urban landscape. It is also a time period (after World War II) in which market segmentation emerges, as well as the category of 'teenage.' I find in this history a possible narrative about graffiti vandalism in which its emergence is in relationship to these public transformations.

In particular, I argue that graffiti's marring of public space is a rejection of public space's recent diversification and commodification, either in terms of its actual legal changes (such as equal rights) or in imagery (such as media depictions of civic life in film and television). Highly visible graffiti vandalism 'reclaims' public space for its male 
makers from these changes via its markers of masculine prowess, as if there is an outright rejection in the policies that have culminated in the new order. Corporations, while gendered as masculine in their power, form a competing masculinity, whereas the actual consumerism which they purport is gendered as feminine. This further explains why graffiti writers attack billboards and adverts.

Consequently, one of the worst betrayals for the graffiti subculture is the commercialization of graffiti productions, such as the 'sellout' amidst their ranks who accepts paid advertising opportunities.

\section{The "Consumer Republic" and Changing Public Space}

Many changes in society from the last century to particular Post-World War II market developments have laid the groundwork for contemporary graffiti: ${ }^{61}$ the anonymity of metropolitan life enabled urban youth to reduce the public to a generic concept (and an ideologically defined one); post-Industrial Revolution labor reforms created the category of the adolescent, consequently leisuring them in society's idealistic defense of its preciosity; the coercive corporate marketing-propaganda machine and its use of advertisements, slogans, and billboards targeted teens as a new consumer group (before which teenagers were never considered a self-conscious consumer group); and the erosion of male public-space hegemony through the empowerment of women created

61 Tagging, in its current form (at least since the 1980s), is a contemporary phenomenon. Graffiti enthusiasts claim that graffiti existed as far back as ancient Egypt and has always existed in some form (such as cave drawings) in an attempt to legitimize it as a timeless phenomenon. Yet, its radical formation as a pseudo-brand, its heavily young male subculture, and its use of mass-produced spraypaint (and marker) technology for the subversion of the technological modern city define it as a uniquely modern practice. 
for male youth a new source of liminality for their masculine identity. ${ }^{62}$

It is not without coincidence that graffiti's birth, and subsequent conflict with consumer culture corresponds with a specific phase in the latter's flowering after World War II. Lizabeth Cohen's A Consumer Republic (2003) is especially apropos in documenting this phenomenon and its relationship with market segmentation and (though she only mentions it briefly) youth subcultures after World War II, espeically in terms of citizenship. According to Cohen and other feminist authors, it is the appearance of the shopping mall — consumerism - that became the first place in which leisured women were able to be unattended (by males) while out in public. Coincidentally or not, part of the justificatory rhetoric of tagging is anti-consumerism and may imply also a further rejection of gender equality (as if consumerism itself is hence female-gendered). The market economy, in fact, has long occupied the thought of social theorists in the market's tendency to reduce all consumers to a generalized type.

It is possible, like the national image of Marianne for France, ${ }^{63}$ that public space and private property in America might be coded as gendered within the graffiti community. Graffiti tagging's focus upon public space is especially relevant in the last forty years for its young male population in their struggle to establish male identity. ${ }^{64}$ Public space, essential for the visibility of exploits, has been characterized by feminist

62 The precursors to graffiti subculture are the dandy and the boheme. In a similar fashion as graffiti practitioners, the dandy and boheme rejected some aspect of the dominant culture in a socially performative fashion. They were also assertions of masculinity in response to what was a new phenomenon in their time, namely urbanization.

63 American patriotist might be coded as masculine, but other countries have different conceptions of national identity. "If America is coded as masculine," writes Reeser, "then my patriotism can affirm, or create, my link to masculinity and help masculinize me by association. In this way, the gendered nation functions psychoanalytically as a kind of parent whom the child takes as a role model in terms of gender ... [In France] the voluptuous figure of Marianne still embodies the nation" (187).

64 For example, it is not in the interest of a market economy to be limited in its growth by ideological limitations such as sexism, racism, etc. This is its curiously progressive aspect. 
thinkers (such as Betty Friedan, John Fiske, and Rachel Bowlby, to name only a few) as male-gendered as opposed to female-gendered private/domestic space. This is in part because socially "respectable" women in the preceding era were discouraged from being present in the public arena unless accompanied by a male. As feminism and other transformations of contemporary society have earned women the rights to be independent and unattended in public space, traditional hegemonic male dominance necessarily receded. Though the process of equal rights and the real sense of women's safety in the public sphere is still in evolution, there have been improvements in the empowerment of women and an erosion of male hegemony over public space. ${ }^{65}$

Furthermore, corporate advertisements and non-profit institutions seek to extend their brands to the entire population. The presence of corporate power in public space has a dual gendered component. The corporation itself is highly masculinized as the elite focus of money power and male privilege. Yet, the advertisements relating to consumption appeal to the (often female) gendered form of consumption itself. The advertisements also create a fiction of public space with idealistic imagery that creates a pseudo-world of total gender equality. Graffiti responds, therefore, by challenging the virility of the corporations and destroying the advert's advancement of consumption.

The net effect upon the psyche of the greater public by anonymous taggers marking the urban landscape is what may be referred to (using Thorstein Veblen's highly masculinist terminology from his 1899 book The Theory of the Leisure Class) as the fear

65 Though Corporate America in its upper echelons (and culture) is still male-dominated, women have populated its ranks and have assumed positions of leadership. Women are members of the Armed Forces, a thing unheard of a century ago. Also, women are able to be alone in public space without society assuming they are prostitutes, as was assumed of women unaccompanied by men in the 19th Century. Finally, respect for diversity has resulted in ad campaigns that depict empowered women; even if one were to consider this depiction illusory, it has an effect upon the psyche of an adolescent in his or her conception of society. 
of the "horde." The seemingly chaotic and random acts of vandalism (that are in actuality specifically and consciously results of youth targeting visible public space) give the appearance of a pre-urban, even uncivilized, "mob" movement in contemporary society. This is, in fact, the topic of Mark Halsey and Allison Young's 2006 article "Our Desires are Ungovernable." They state, for example that "graffiti's authors write in ways which rupture orthodox senses of urbanity — of order, cleanliness, purity, integrity and so forth" (296). The public reaction of militarizing urban settings and furiously working to remove graffiti productions all make the graffiti subculture's "barbaric" personality even more appealing to young male tagger initiates. ${ }^{66}$

\section{Citizenship and Corporate Marketing}

In contract theory, freedom is related directly to 'natural rights' or human rights;

(in the case of Locke) sovereignty remains in the political consent of the governed. (This is discussed heavily in IV of this essay.) Cohen documents how in the United States a narrative appeared in which citizenship was tied to Keynesian economic theory. ${ }^{67}$

66 The campaign against graffiti vandalism is arguably an unnecessary exaggeration. It is even questionable society's designation of it as an illegal practice, a fact on which this article ultimately hinges. There are cities such as the aforementioned Buenos Aires that do not prohibit graffiti. The damage to public and private property is either minimal or severe, depending how one interprets the data and the alternatives to graffiti vandalism for young males vying for the demonstration of aggressive risk taking and exploits. Graffiti Hurts estimates that it amounts to around two billion dollars annually for graffiti clean-up in the United States. If, though, communities were to simply leave tags in their place instead of buffing them, this money could be spent elsewhere. The financial cost of cleaning, however, is justified by the (disputed) Broken Windows hypothesis, advanced by James Q. Wilson and George L. Kelling, in the March 1982 article (entitled "Broken Windows") in The Atlantic Monthly. Unlike anti-graffiti claims based on its removal costs, Wilson and Kelling argued that the proliferation of graffiti vandalism elevates the threshold for further vandalism in a community, creating a snowball effect in the loss of state control and safety. Whether the Broken Windows argument is correct or not, and whether or not communities are excessive in their expensive removal of tagging, such is the status of graffiti today and hence must be calculated in its overall appeal to male youth.

67 For example, it is not in the interest of a market economy to be limited in its growth by ideological limitations such as sexism, racism, etc. This is its curiously progressive aspect. 
According to Keynes, Cohen writes that

the survival of democracy in the world as an alternative to revolution (communism) and reaction (fascism) rested on America's success in reviving Capitalism ... Keynesianism was thought to encourage greater economic egalitarianism because dynamic consumer demand depended on a wide distribution of purchasing power. (55)

This represented a remarkable shift away from the founding ideals of the country as a nation of independent producers. The citizen was now idealized as a consumer and the success of America's democracy (as depicted in Roosevelt's Four Freedoms) entailed a "celebration of the plenitude that American families reaped through their participation in a mass consumer economy" (56).

Particularly relevant for graffiti are the series of changes that occurred in the 1950s that then culminated to the time of graffiti's birth, the 1970s. Market segmentation and Lifestyle were invented and perfected after World War II, and this included the creation of the idea of the teenage consumer, the predominant population of graffiti vandals. Cohen recounts how Eugene Gilbert, while still a teenager, gave impetus to this particular market segment (the teenage focus beginning already during World War II) through surveys, columns, and consulting. (319) This would quickly become a major strategy of corporations. Cohen writes

By the 1960s even manufacturers of mainstream merchandise like RA ... and Pepsi-Cola saw their future profits - even survival — linked to how well they managed to insert their product into the fantasy world of the teenage market segment (319). 
The teenager essentially came to self-knowledge and even legitimacy as a group through the appearance of the advertisements targeting them. This was also the time when graffiti first appeared. Cohen, in fact, argues (radically) that this is partially why the second wave of feminism appeared when it did—because market segmentation made women more aware of themselves as a distinct group of consumers. The way in which advertisements co-opt youth subcultures therefore haunts the graffiti subculture. (One may perceive in Hipsters a parody of this co-option).

The second relevant change was the shift away from the consumer power of men and boys to the market segment of women and girls. Due to the GI Bill after World War II, women lost much of the ground they achieved previously through the expansion of male purchasing power in the public sphere. The GI Bill essentially financially empowered veterans - predominantly males — and reinforced traditional male family roles (such as the breadwinner and decision-maker). The male as consumer was always targeted, but now females were especially targeted as the 'distributor' of the family consumption overall. There arose, therefore, in this time period, an influx of the presence of women in the public eye as consumers-if not the predominant consumer. This gendering of consumption has ramifications, considering the masculinity portrayed in the graffiti subculture.

\section{Production vs. Consumption}

In fact, in terms of masculinity, there arises here the contrast between production and consumption. Graffiti is a form of production. Yet, its production is a parody of advertising, mimicking it and hence also asserting its preponderance, the very advertising 
whose whole existence is to stimulate consumption. It is an unusual logic. The producer, though, has masculine connotations as well. According to Kimmel in Manhood in America, American masculinity was founded upon the self-made man as an ideal; this would come under criticism in the 1960s. (192) Yet what Kimmel also values is the figure at the outset of his book, the "Heroic Artisan" of Colonel Manly. Kimmel describes him as "stiffly formal in his manners with women, stalwart and loyal to his male comrades ... he was an honest toiler, unafraid of hard work, proud of his craftsmanship and self-reliance" (13). The Self-Made man, "a model of manhood that derives identity entirely from a man's activities in the public sphere" (13) is under crises at the time of the second wave of feminism. It is also for this reason that graffiti, a form of highly crafted production that acts as an assault on an increasingly diversified public space and the visible presence of marketing forms to a female-gendered consumerism, would appear at this time. Graffiti, then, appears as the result of a crisis of masculinity, the empowerment of women, the inherent contradictions of Western social contract theory, and the historical rise of market segmentation. It would have made no sense to appear any sooner. ${ }^{68}$ It is also why graffiti purists reject stencils and wheat pastes due to their industrial-style of production as opposed to the artisanal nature of the typical aerosol masterpiece.

This is why one of the most problematic issues facing members of the graffiti

68 This mindset is supported by the research of Susan Willis in her book section "Teens at Work." As cited earlier in a footnote in this essay, she observed how youth seek work that gives them autonomy, mainly to the extent that they are able to leave it at any time. Her observations also extend to how the youth observe labor opportunities in general. All jobs were equal; the youth would state that "a job's a job." Willis notes that

In mouthing this cliched colloquialism, a teen demonstrates how teen employment parallels, and approximates a consumerist society. Jobs, like the brand-name items on the supermarket shelf, are really no different from one another. Consequently, things like working conditions and hours are akin to the details of a product's packaging. Neither is significant - not worth fighting over. (351) 
community is the commercialization of the practice. Derided as sellouts by their community's peers, some graffiti practitioners continue onward into successful careers as graphic designers for corporations marketing their products to youth. For example, a skateboard company may hire graffiti artists to make the decals and decorations on their skateboards so that a new generation, identifying themselves as graffiti enthusiasts, will buy the skateboard. Use of the product signifies, for the youth, an interest in (if not actual) membership to the subculture. The former graffiti writer has betrayed his (or her) subculture fidelity, emasculated himself (or herself) by producing consumer products and aligned himself (or herself) with the enemy, corporate power.

\section{E. Graffiti's Multilayered forms of Gendered Activity}

Graffiti has layers of dialectical engagement. The entrance into the subculture requires a period of subservience to mentors characteristic of the Lordship-Bondsman relationship. Once the mentees have produced enough work, their mentors 'recognize' their status. Yet, this recognition is always bidirectional: the new recruits are necessary to establish the existence of the mentor. Similarly, the process of making graffiti places the graffiti writer's identity as such in mediation with his or her audience, generally other members of the community or even authorities. The audience is then placed in the position of Lord in that he or she is necessary for the object—-the graffiti mark — to be asserted in its gendered nature. This is paradoxical, since the apparent masculinity of risk taking seems to assert its position as the dominant figure. These are the basic foundational issues of graffiti's gendered activity from a Hegelian perspective.

Its fundamental forms of activity, too, have specific gendered qualities. There are 
two variant forms of masculinity present in the practice of making graffiti as exhibited in its two extreme poles of its iconic objects. The first quality appears principally in risktaking. This is epitomized in the production of tags (and throw-ups) in dangerous location which serve as a new layer of liminality, one which serves to gain membership to the graffiti subculture. The second form of masculinity appears in the process of developing and making masterpieces. While the masterpiece is sometimes also made in risky locations, its basic skill set of discipline and diligence represents a more mature form of masculinity which is, in some ways, at variance with tagging's thrill-seeking. In its best instances, it celebrates the 'liminoid' of exemplary creative processes; in its lesser forms, it suspends liminality through its sometimes 'creatively static' mode of production.

\section{Masculine Prowess: Legal and Physical Risks}

Youth in graffiti have adopted regressive, simplistic notions of masculinity in the most elemental terms of taking risks. Macdonald found that the males defined "graffiti's risks and dangers as men's work" (98). Former taggers Jeff Ferrell and Robert D. Weide illustrate the basic gendered attributes of graffiti in their 2010 City article "Spot Theory": Graffiti is not just art-it is also sport, and the fields of this sporting competition are the spots where graffiti is written. Great status is conferred on those writers who can scale the most dangerous structures the city has to offer-signs, billboards, rooftops and highway overpasses. Even greater status is conferred on those writers who can get away with painting graffiti where one is most likely to be caught doing so - major streets, highly trafficked thoroughfares, high on a sign where escape is impossible if detected ... Above all, graffiti writers seek 
recognition, and in order to get the recognition they crave, they need people to see their graffiti. Because of this, each act of writing graffiti involves a deliberate decision weighing visibility, location and risk. (50-51)

Here, the authors do not mention masculinity. The implication is that they act without awareness of how their gendered needs may be driving the desire to take risks. In fact, their use of the term 'recognition' harkens to Hegel's dialectic. The seeking of recognition indicates the absence of self-sustaining consciousness.

Graffiti offers two distinct categories of danger: physical and legal. Some locations embody both of them. Graffiti's orientation towards overcoming one's fear of danger is discussed in articles such as Toby A Ten Eyck's and Brette E Fischer's "Is Graffiti Risky? Insights from the Internet and Newspapers," in which they find that media sources celebrate or caution against the dangers of graffiti; Ricardo Campos' "Graffiti Writer as Superhero," in which youth seek to become engaged in a lifestyle that is more exciting than the mundane via graffiti's risks; Kara-Jane Lombard's "Men Against the Wall: Graffiti(ed) Masculinities," which argues that the masculinity espoused in graffiti reverts to older forms that prize confrontation with danger; and Martin A. Monto's, Janna Machalek's, and Terri L. Anderson's "Boys Doing Art: The Construction of Outlaw Masculinity in a Portland, Oregon, Graffiti Crew" in which a specific crew was observed as taking risks as part of their ethos.

Physical challenges include producing graffiti in locations — such as the "signs, billboards, rooftops and highway overpasses" Ferrell and Weide describe - that require risk and danger of a purely sportive and physical nature. We might extend this to the facades of tall buildings, the vicinity of electrified third rails of train lines, and similar 
challenging sites and urban constructions. ${ }^{69}$ The physical challenge pits the daring and virility of the graffiti maker against harrowing bodily risks. By virtue of the sheer quantity of production, one might become what was once referred to as the "king of the line"- the youth whose output was superior to any other's. The courage to place oneself in a state of peril represents masculine virility; the community even uses the term 'getting up, ${ }^{70}$ a not-so-subtle reference to erections, to describe the importance of production quantity.

The exploits required to attain street credibility, graffiti reknown, and/or selfworth are often emphasized in descriptive narrative retellings. In an early interview of the Fabulous Five, Craig Castleman features a graffiti crew's recital of their experience in the subway when, apparently, the police arrive. The emotional tone is highly indicative of the lure of graffiti:

Then all of a sudden Mono was next to me and he had his hands in my face and he was shouting, "Move, move!" And I said, "What's the matter?" but I answered my own question when I looked behind him, and I seen [sic] big flashlights. So I turned and I shouted, "Slave, Slave," and he was gone in a cloud of dust. He was gone. Mono tripped and fell on the floor; then he got up and started running toward the end of the train. I got under the train and there was another train pulling in next to it that almost hit me. I rolled as far from the moving train as I could, and I had a can of Ferro-Safety Purple in my hand and I threw that under

69 In graffiti terminology, dangerous locations are called 'Heaven Spots,' referencing the final resting place of writers who have been killed while trying to produce graffiti on perilous sites.

70 Interestingly, in Craig Castleman's germinal Getting Up, it never occurs to Castleman to link sexuality to this term ('getting up'), This is like the Spot Theory quote - do you want to address in one centralized location what seems to be the pervasive way observers of graffiti culture use masculinized metaphors without acknowledging the role of gender? despite the obvious relevance to the pubescent male adolescents that make graffiti. He even notes that other terms were first used such as "getting around, getting over, and getting the name out" (19) yet mysteriously getting up was settled upon. 
the train. So under the train I saw these big feet moving, shoes, and I said, "Oh no, cops, I knew it, I knew it." (5) 71

The narrative emphasizes the risks involved in making subway graffiti. The narrator lies on the ground adjacent to the peril of an oncoming train, and his friend falls in an effort to escape the police. (The excitement of the moment is communicated also.) Secondly, the legal dangers are noted, such as his attempt to separate himself from the evidence of his act (the purple spray can) and the arrival of the police via seeing their shoes from a worm's-eye vantage point.

In fact, legal challenges include making graffiti in places where there is great risk of being caught. Heavily monitored security sites or brash locations like the sides of police vehicles are prestigious because of the obvious challenge to the authorities' ability to control space and power. The virility, vigilance, and mental capacities of the authorities, security equipment and programmers are challenged by the masculinity of the graffiti youth.

The locations of graffiti therefore exude a particular character in that they are either inanimate obstacles or are conscious beings, e.g. a dangerous height or police officers. The production of the objects of graffiti, such as a tag or a throw-up, has a very important function in relationship to the confrontation of peril. If a male youth climbs onto the backside of an overpass - an exploit that is both physically risky and illegal—he faces two outcomes, neither of which is appealing. First, he may succeed and not be apprehended by authorities. This means that no one will witness his achievement. Without recognition, he does not achieve the social status that motivated the act. Secondly, he might succeed and be apprehended. This obviously results in a police record

71 The apparent police officers proved to be another graffiti crew. 
and is equally untenable. This is the basic issue that has faced all rebellious youth, namely how they might rebel, vandalize and transgress without also imperiling their legal status as future good citizens. Since securing masculinity in this fashion requires public and social recognition, a youth acting out his virility in such a fashion will not gain recognition and affirmation from it.

Graffiti resolves this dilemma perfectly via the tag and the clandestine identity of its maker. A youth creates an anonymous personality with a specific moniker, his tag, such as COLT45, CORNBREAD, or SABER. On the backside of the highway overpass he writes his tag name. A small audience 'in the know' will be aware of him as the author of that tag and will therefore attribute that specific exploit to him. ${ }^{72}$ The authorities do not know who he is. This is the one of the key functions of the tag: it is a marker of an act of masculine prowess. The tag, then, is a 'trace' of a masculine achievement. The tagger can break the law, avoid capture and gain recognition. He unites multiple acts under one name and can construct an identity of himself within that moniker.

His main frustration is simply that only a limited community will know that it is he who is behind that specific moniker, an apparently acceptable situation. He has rejected mainstream society and found his communitas in the subculture anyway. (Perhaps due to the online documentation of his productions, he holds a belief that somehow, someday, he will receive some kind of acknowledgment of his achievements from a wider public.) The police document all graffiti vandalism in the event that a tagger is captured so that he or she will be held accountable for previous acts of vandalism.

72 There are even cases in which police attention is favorable. Justin Bieber's famous publicity for making graffiti in Brazil in late 2013 may have been staged so that his image would have credibility with youth. In fact, he posted his work on Instagram, even while claiming that he was against vandalism. By making it publicly in Brazil, he could depart the country and avoid prosecution. 
Arrests, perversely, can be a boon, since they make the identity of the othwerwise anonymous tagger known to the greater community. The online portfolio also subsists as a continued source of presence for the international community. Finally, the belief that his vandalism is art means that he imagines himself somehow having hermetic valor as a producing, invisible artist.

As a member of the graffiti community, undercover, he is able to transgress civic laws while retaining his status as productive citizen. This may be especially important if he is either a leisured American adolescent or is performing (what he considers to be) emasculating social activities like part-time service-industry work. ${ }^{73}$ Castleman, writing of the early history of graffiti, observed that "a young person who seems unexceptional in most contexts may be a highly regarded "king" or "master outlaw" in the writing world" (Getting $U p, 76$ ). This is no doubt true today. Riccardo Campos argues that graffiti involvement is more exciting: perhaps in school or work he is an outcast, or overlooked and ignored by his peers; as a tagger, he is able to retain his esteem and hence even cultivate a self-satisfied aloofness in the social sphere.

He keeps his identities of graffiti writer and good citizen separate like the literary figure of Dr. Jekyll and Mr. Hyde, or more appropriately the $20^{\text {th }}$ Century popular culture figure of Batman and Bruce Wayne. There has not been any comprehensive study to ascertain with which he identifies more (in other words, which he would consider the "actual"), nor to what extent his obligatory school studies or part-time work might be treated with indifference. Based on anecdotes from graffiti writers, it is the moniker with

73 Ted Gregory of The Chicago Tribune, using data from the Bureau of Labor Statistics, wrote on June 6, 2010 that "about 33 percent of 16- to 19-year-olds are in the labor force, meaning they are employed or looking for jobs. Thirty years ago, when teen employment was at its peak, almost 60 percent." It is purely this paper's speculation that some male youths may find service-sector work emasculating, in particular those driven to exploit-based tagging vandalism. 
which he identifies. "The name and the tag are one," stated Futura 2000 in an online interview for Illustrator's Magazine, $1997 .^{74}$ " That's what graffiti means: it's about identification, about a personal icon." 75

This form of masculinity may be identified with the most basic hunter-style image of maleness dominant since the late 20th Century. It was the principle motivation of such entities as the early Boy Scouts and relies upon an image of quasi-prehistoric before-theFall virility. There is nothing original in this conception of masculinity; it represents a regression or even retreat to past forms out of insecurity in one's current identity.

\section{1a. Competing Masculinities: Illegality and Militaristic Terminology}

Illegality is a key element to the graffiti subculture and merits its own consideration independent of all others. For example, the tag must be made illegally. It makes no sense outside of its illegal manifestations. The masterpiece can be made legally, and often persists in the form of legal commissions. Sometimes, though, masterpieces are made illegally. Therefore, Graffiti's masculinity is in part bound up with illegality. Monto, Machalek and Anderson begin their article "Boys Doing Art: The Construction of Outlaw Masculinity in a Portland, Oregon, Graffiti Crew" with the

74 This citation is taken from an online article from graffiti.org, written by Pamela Dennant for a BA in 1997. The source is significant in that it is a site frequented by the graffiti community. Dennant cites the following source: Wagstaff, Sheena. "The Name Gone By." Illustrators Magazine 49. (1997): Digital Jungle. n.pag. Online. Internet. 20 Jan 1997. I was unable to locate this reference.

75 This assumes that youth are drawn to graffiti due to the stresses of their liminality, brought upon by their emergence into adulthood and difficulties at school, to name only a couple of possibilities. However, there is some percentage of the members of the graffiti community that join it not to escape liminality but to experience liminality. Turner discusses precisely this quality of leisure and artistic practices in "Liminal to liminoid in play, flow, and ritual." Turner argues that the mundane, repetitive, structures life in modern consumer and capitalist societies engenders the need to escape it in liminal activities. This, for Turner, were the arts and entertainment. It is possible that some youth join graffiti that are not experiencing a crisis of liminality. Some youth are simply well-adjusted. Recalling, for example, Durkheim's seminal work on suicide, or Tonnies' dichotomy of Gemeinschaft and Gesellschaft, suburban youth might experience the reverse pressure that affects urban youth. 
following statement, reinforcing this issue:

Graffiti writers violate core American values by choosing to devote time and energy to an illegal activity that earns them no profit and general hostility from the public, whose property is scarred by their activity. They continue to write despite significant risks to themselves, both physical and legal. (259-260)

There are viable legal alternatives to tagging within the graffiti community that would also involve artistry and public space. For example, 'reverse graffiti' involves making images by carefully removing (in aesthetic patterns) the artificially accumulated grime on urban walls. The result is often subtle monotone works that call attention to urban soot while transforming such surfaces by creative imagination. Mobyspray ${ }^{76}$ and similar practices allow for the projection of digitized imagery on public walls, or virtual digital overlays of real sites viewable only on web sites. Graffiti masterpieces are often legally commissioned, too. However, since none of these options violate the law, they lose the risk-taking edginess of vandalism that some adolescent taggers find so appealing.

Illegality seems to be important to the community as a form of identity. Allison Young found anecdotal statements from various graffiti writers, noting that "For Jaybo, illegality is 'the point', like C215, who commented that legalization of street art would cause him to desist from making it: 'If it was legal I wouldn't do it. Because the poetry would be completely faded' (29)."

The illegality of the practice constitutes an added thrill for young adolescents; however, this is not sufficient to inspire membership in the subculture. There are many illegal acts that a male might perpetrate for thrills; why, then, graffiti? In fact, the

76 Mobyspray "employs the mobile phone as virtual spray can to spray dabs of digital paint onto the physical environment via large-scale projections anytime, anywhere." www.mobyspray.com. 
recurrent claim of graffiti practitioners is that their work is not vandalism but a form of art. Its illegal status, for them, is the failure of the larger order of society, namely of the adult world and its narrow laws. The adolescent graffiti writers believe that they suffer from false persecution. If anything, the contested nature of graffiti's status as a work of art is as important as its actual illegality, since it gives something ethical for which the young males may further battle. This struggle adds moral legitimacy for the youth over the greater population.

Colt.45, a prominent tagger, decries graffiti's illegality in an article for City's special 2010 edition on graffiti. He characterizes the comportment of the subculture succinctly:

Why are we treated so severely by law enforcement? Graffiti does not threaten the structural integrity of any property. Graffiti does not cause violent injury to any victim. What graffiti threatens and injures is nothing more than other people's aesthetic sensibilities. Are other people's aesthetic preferences so sacrosanct that my life and the lives of people like me should be forever ruined by felony records and sentences in state prison to protect them? (156)

The illegality, though, results in males opposing 'animate' forces, such as abatement crews and the police. Both sides claim moral legitimacy, the graffiti writers as artists and the authorities as enforcers of the law. In this sense, Nancy Macdonald argues that the public spaces where graffiti is created compose a 'theater of war' between what are essentially competing masculinities, the youth and the authorities. She refers to this as "a battle of... similar masculinities fighting for potency" (121). This is a return to the importance of audience. In the theater of war metaphor, Macdonald finds that graffiti 
writers use language that recalls military conflict, such as referring to their practice as "hits" or "bombing." The language of the taggers, indeed, is full of militaristic terminology, such as "destroy," "burn," and "kill" (109). Crews (teams of taggers) operate as if conducting military maneuvers; dangerous escapes become a form of boasting; phrases are employed such as the "breaking and entering" of "enemy territory" (113); and crew names may even have pseudonyms recalling battle terminology (such as KIA for Killed in Action (112).

The theater of war metaphor is present in many other writings about and by graffiti writers. Stephen Powers, a renowned graffiti artist, quotes graffiti writer 'Veefer' in The Art of Getting Over: Graffiti at the Millennium that "this is war, and my tags and my throw-ups are my troops and artillery" (26). Alison Young writes about the generally rebellious nature of the activity:

... what is most important is a sense that street art (and graffiti) is 'against something' (mare139) even if there is no clearly defined object of critique. Street art was called 'rebellion', 'rebellious' or 'subversive' by many (Vexta, Ad Deville, John Fekner, Remi/rough, Garrison Buxton, Miso, Just, Nick Ilton, Sparcs). Early efforts at situational art were recognized to be fairly chaotic: 'drunken rampages of tagging' (Nails); and 'being an angry teenager with no intellectual content to it—just fuck you, fuck everything' (Kid Zoom). (29)

This struggle becomes ironic in that it is precisely the efforts of the authorities that allow the writers to have both an audience for their efforts as well as an oppositional force against whom they may prove themselves. The Bondsman asserts the identity of the Lordship side of the dialectic. Without the abatement efforts, graffiti would be virtually 
legal; the only 'test' would be to place graffiti in risky sites in terms of site-specific danger (e.g. a highway overpass). Illegality enables graffiti writers to develop their masculine identity in competition with the authorities as they attempt to occupy the Lordship of Hegel's dialectic. ${ }^{77}$

It follows the basic notion that the development of some kinds of militaristic prowess require an opposing force. There is no more powerful opposing force than that of a worthy foe. In The Iliad, Achilles acquired renown not for slaying Lycaon, who begged on his knees, but for defeating Hector, Troy's greatest hero. (Yet, using the illustration of The Iliad, it is not Achilles who subdues Troy, but the cunning of wiley Odysseus. They manifest two different, unique forms of masculinity. I discuss this later in this section.)

\section{1b. Undermining the Bravado: Objects of the Gaze}

While risky behavior is culturally coded as masculine, at least in the graffiti community, such as its demonstration that one has the courage ('the balls') to climb onto a building and evade authorities, the consequent act is undermining. That second act in the process of making graffiti-namely, the actual, final step of the production of objects like tags, throw-ups and masterpieces - is not commonly analyzed in and of itself.

Surprisingly, no enthusiast or practitioner of graffiti has ever questioned or made declarations about the gendered nature of the tag and masterpiece independent of the risks involved in reaching the locations where they are made.

77 The competition also exists between the makers of graffiti as well. Stephen Powers writes, for example, of the violent early days of graffiti in New York City:

While a fist fight was always part of graff, New York also made beef last longer than the Highlander saga, which was bananas. The idea of fighting the same person every time you saw them is definitely a phenomenon limited to this city. Escalation and retaliation is understandable, but beating a guy down, then terrorizing his house with calls, then tagging a brick and throwing it through his window, then writing about his mother on the door of his apartment is beefing in the sickest possible terms. Plenty of people were guilty of such behavior. (106) 
It would seem impossible to separate the process of constructing a tag or throw-up into two separate, if not disparate elements. These are, first, the act of arriving and attending to a particular location and second, the making of a tag. For example, in the instance of placing graffiti on the back side of a highway overpass, there are two distinct activities, obviously intertwined in their process and meaning: first, climbing up onto the overpass, and second, constructing the throw-up, the function of which is to mark the first act. Indeed, one can climb onto an overpass without making graffiti. ${ }^{78}$ Similarly, a vandal can simply deface a Stop sign instead of marking it with a predefined tag that is part of a performative, audience-centered subculture. In fact, outside of graffiti, youth have engaged, and continue to engage, in simple acts of minor vandalism, trespassing, and risk-taking. $^{79}$

The motivation for climbing onto an overpass is to demonstrate one's courage in the face of peril. The motivation for marking the overpass afterward is to boast. Boasting is the most basic form of insecurity. The tag, on an ideological level, states that its maker is dependent upon others to assert his or her identity, even though, contradictorily, that identity remains secret. Namely, the tagger wishes that his or her acts are viewed and recognized as his or hers. It is not sufficient that he or she, the tagger, is witness to his or her own acts and is hence able to feel confident in his or her achievements. It is not enough to prove to himself or herself that he or she has the courage to climb onto a dangerous highway overpass. He or she marks it because he or she seeks, effectively,

78 For example, the city version of the activity known as 'Parkour,' popularized by David Belle (known for his use of Parkour in the 2004 French film District 13), features individuals jumping, climbing and swinging through a city and over its rooftops in a display of physical strength and adroitness as well as the daring of risking injury and death. No marks are made to note the achievements of Parkour.

79 Juvenile delinquency was the primary impetus for Hall's research into his studies in adolescence because these issues existed, e.g. youth gangs, reinforced by labor practices and inner city crowding, broke rules and vandalized. 
recognition through the tag for both that specific act and all others marked by his or her tag. Since the birth of graffiti, recognition has been inherent in the purpose of its construction. Castleman, for example, in regards to production, writes that "recognition and acceptance of their work by other writers (and possibly the public in general) is dependent on their writing their names prolifically" (Getting Up, 19).

If arriving at a risky location or engaging in a risky act is coded as masculine, the second 'moment' of making graffiti is also gendered. It is an act of negation based upon the Hegelian dialectic of Lordship and Bondsman. ${ }^{80}$ The Bondsman is the unmasculine, the subservient figure in a relationship of power. The moment a youth makes a tag, he or she places himself or herself into the role of the Bondsman while placing the multitude of viewers in the role of the Lord. He or she seeks recognition from them for the act. ${ }^{81}$ The very unmasculine nature of the act of making the tag, throw-up, or masterpiece, then, undermines the masculine risk-taking process of reaching the location itself.

The object of graffiti undergoes another transformation in relationship to the gaze. Our culture codes the gaze as masculine, first analyzed by Laura Mulvey in her 1975 paper "Visual Pleasure and Narrative Cinema." Mulvey argued that cinema, unlike other modes of art in which the framing of the object may vary, "creates a gaze, a world, and an object, thereby producing an illusion cut to the measure of desire" (843). The spectator identifies with the male protagonist, and he (the male spectator) objectifies the female figures both through the protagonist's gaze as well as his (the spectator's) gaze (838). Reeser, in his book Masculinities in Theory succinctly summarizes this thirty-five years

80 One cannot simply declare this second moment as 'feminine,' since the negation of one pole does not necessarily imply the opposite gender trait.

81 In some cases, one could argue for the reverse; namely, that making graffiti places the viewer in a subservient position by nature of imposition. I believe that this is the exception, since graffiti no longer shocks and amazes passersby as it did when first created in the 1970s. Now it is the Invisible Gorilla. 
later, writing that "the male gaze is often though to be a kind of metaphor for-or extension of - the penis. The male eye penetrates the outside world, and especially the erotic female body" (110). The object that is looked at is coded as feminine, as it is subject to the male gaze.

Graffiti objects are created as visual 'receptacles,' and hence are objects for the masculine gaze. They assume the character of something to be looked at, consumed, and judged. Even though graffiti has violently contrasting colors and often features aggressive names (like UZI or COLT45) ${ }^{82}$ these are just means to call attention to be gazed upon, like a brightly costumed dance performer. This passivity of the graffiti productions stands in contrast to the restless, masculine activity required to make them.

When an individual is exposed to the gaze, he or she has the possibility of returning that gaze, engaging in the dialectic of power such as was analyzed by Hegel. Crafted objects and works of art are different, however. Since the status of art is one of graffiti's key claims, the nature of the gaze and art objects merit further elaboration.

Jean-Paul Sartre offers a model. Fascinated by Hegel's phenomenology, he applied Hegel's insights throughout his post-World War II career. Sartre described the lordship and bondsman dialectic in terms of the gaze, and applied it to the contemplation of (the act of gazing at) works of art. Unlike an individual who, according to Sartre, faces the problem of being objectified by the gaze of the other (while at the same time

82 From Monto et. al.'s "Boys Doing Art: The Construction of Outlaw Masculinity in a Portland, Oregon, Graffiti Crew": "The names graffiti writers choose for themselves often have mysterious or menacing qualities. Local artists in Portland, Oregon, the city that was the backdrop for our study, included OMEN, ANGST, ICER, BORE, EVAK, and PAULRUS IS DEAD, among others. Crew names are often downright alarming, with names such as GPK_- "Garbage Pail Kids," ADK_-“All Day Killers," WDK — "Wasteland Dreams Krew," AIDS — “Art Is Dying Slowly," BFC_—"Battle Field Clique," D2K_—“Down to Kill/Krush," PBSK — "Pacific Bombing Squad Krew," KTG_ "Keep them Guessing," KTC_—“Kut Throat Committee, "Kut the Check," or "Kolor the City," NQD_ “Not Quite Dead," HODK — “"Hand of Doom Krew," TMR_—“Tokin' Marijuana Religiously,” TMR_—“Toys Makin' Ruckus," and the infamous OUTLAWS" (266). 
recognizing the freedom of the other's gaze), an artwork is a 'gift,' one which does not intrude upon the viewing of the audience. It requires a similar gift from its audience. In his essay "What is Literature?" he writes of this audience perspective:

$[T]$ he reader's feelings are never dominated by the object, and as no external reality can condition them, they have their permanent source in freedom; that is, they are all generous for I call a feeling generous which has its origin and its end in freedom. Thus, reading is an exercise in generosity, and what the writer requires of the reader is not the application of an abstract freedom but the gift of his whole person, with his passions, his prepossessions, his sympathies, his sexual temperament, and his scale of values. (50)

For Sartrem this form of free interaction requires a certain kind of artwork, one that possesses ambiguity of meaning so that the reader's imagination is allowed to freely interpret its significations. He writes the following about a painting:

The painter is mute. He presents you with a hovel, that's all. You are free to see in it what you like. That attic window will never be the symbol of misery; for that, it would have to be a sign, whereas it is a thing. The bad painter looks for the type. He paints the Arab, the Child, the Woman; the good one knows that neither the Arab nor the proletarian exists either in reality or on his canvas. (10) Sartre's model implies a visit to an art museum, or perhaps viewing art in a book. He did not, nor could not, apply it to street art. Since then, thinkers have attempted to place street art also into this notion of 'the gift,' and perhaps rightly, even as street art sometimes surprises (and arguably forces itself upon) the unsuspecting viewer. For example, Alison Young writes that "Street art is often located within the economy of the 
gift, through which an artist creates an image and places it in public space, to be viewed at no cost by anyone who passes by; to that extent, generosity is a defining feature of street art" (ix). However, she is reluctant to include tagging, even though she believes graffiti vandalism to be unfairly prosecuted. Tagging, in fact, has little to do with artistic productions; defense of the art of graffiti typically involves analyses of masterpieces.

She is incorrect. The tag, and the throw-up, are not created as 'gifts.' They are not created for the viewing pleasure of their audience, since the formal qualities are inherently violently opposed to both their host surfaces as well as colors within their own construction. As a form of marking, they are made as objects that assert their maker's ego, not their audience's identity. This is a crucial distinction in the notion of gazing and gifting. There is no gift here; the tag is an act of narcissistic self-assertion. (The only selfless act that one might perceive is that a graffiti writer makes his or her work also to be a part of the larger graffiti society.)

This self-assertion is also a provocation. By placing the tag or throw-up in a prominent location in public space, the graffiti writer wishes to force the viewer into experiencing the production. This raises the question as to whether or not graffiti vandalism (to use Sartre's term) 'dominates' the viewer. This is something that might be taken on a per work basis, as no doubt certain productions succeed in truly overwhelming their viewers; they are, however, the exception, not the rule. ${ }^{83}$

The relationship of the gaze to the objects of graffiti calls into question the masculinity implied by use of the phallic metaphor 'getting it up' to describe prolific graffiti production. If one extends the prevailing metaphor to the whole process,

83 Furthermore, Sartre's aesthetics predate performance art. Susan Broadhurst's Liminal Acts categorizes such art according to Kant's Sublime, whereas Sartre tends towards more romantic notions of the Kantian conceptions of beauty. 
including its final object, it is, simply, like a youth who climbs to a dangerous spot and, in front of the world to see, exposes his erection for universal judgment and admiration. As he remains there, exposing himself, he is no longer the person who climbed and dared risks, but is instead a half-naked, exposed male expecting for some response and, hopefully, approval from his audience. An erect penis might be an obvious choice as a symbol of masculinity, but one that is exposed and placed in full view for verification undermines its own virility. It becomes a 'receptacle' for the gaze, like a symbolic vagina. $^{84}$

Culturally speaking, there are many instances in which males engage in what might be coded as unmasculine, or even effeminate, if the act chronologically follows some other hyper-masculine activity. In this sense, the male in question is 'safe' in engaging in such acts since in the moments before he has proven himself as man. For example, in American football, players who have scored a touchdown sometimes engage in celebratory dances. This completely undermines the gravitas of the focused athlete, replacing him with a childlike jester incapable of quietly remaining concentrated on the competition. Since the machismo of grinding through muscular, opposing players to score a touchdown has been established (as well as the often oversized, chiseled physiques of the athletes themselves), then the right to act in an unmasculine fashion has been 'earned' as a prerogative of this instance of masculinity.

We can argue this about graffiti as well. The risky location serves as sufficient proof of masculinity that this youth can then boast, such as making a bright, flowery, cursive object such as the graffiti throw-ups. This does not change, however, the

\footnotetext{
84 We may also add to this observation that a graffiti writer who lacks artistic skill (style) will still be respected if he is prolific in getting up (Castleman, Getting Up, 20). This further reinforces the sense of virility underlying the act.
} 
gendered characteristic of the making of the graffiti object. It still remains counter in its gendered coding. This countering therefore means that every act of making graffiti vandalism first reinforces, then undermines its very coding of masculinity.

\section{1c. Graffiti as Homosocial}

Extending the metaphor further also allows us to acknowledge the homosocial character of graffiti. One might liken it to a scenario in which one member of a group of destructive, close-knit males exposes himself to an isolated woman while his friends look on. The male purports to expose himself to the lone woman, but his true audience is composed of the males of his gang, with whom he is bonding. They witness both his exposed penis as well as his relationship with the woman, who comprises only a secondary audience ${ }^{85}$ They are 'allowed' to look at his member because of the presence of the woman, as if she is the true audience. They bond emotionally with each other at her expense. She is reduced to an object, serving as a means for them to make claims both to heterosexuality and to their longing to engage in sensuality with each other.

Eve Sedgewick, in her groundbreaking 1985 work Between Men, referred to this as an erotic triangle, and the bond between males engaging in such triangulation as 'homosocial.' Males in a love triangle redirect their sensual desires away from each other and instead aggressively project them onto a third party where it is permitted according to their identity as heterosexuals. ${ }^{86}$ This triangulation occurs in more subtle inter-male vicarious sensuality, as well. For example, a male may engage in sexual acts with a

85 This is the psychoanalytic definition of the psychotic - the individual who is moved by aggressive, repressed unconscious content. Is there anything more worrisome then a gang of bonded males, moving as a group about urban areas, their gazes hungrily searching outward for some victim?

Their longing is to deepen their emotional relationship with each other. However, since they selfidentify as heterosexual, they will not permit themselves to engage in sexual acts directly with each other. The female serves in this role as their permissible sexualized body. 
woman for the purpose of recounting a detailed narrative of it later to eagerly listening, bonded male friends. The third party — the woman — must be objectified and denigrated; otherwise, it would threaten the males' bond with each other. If one of the males were to fall in love with a woman, he would no longer have the same intense closeness with his male companions. Hence he must directly and/or symbolically denigrate the woman in question so as to ensure that his bond with his male friends remains intact. ${ }^{87}$

This occurs symbolically in the construction of graffiti in which society and public space itself serve as the objectified 'other.' There is the titillation graffiti's makers feel, knowing that the authorities and much of the public find graffiti grotesque. They vandalize, enjoying this subtle reaction while publicly claiming it is unfair. At the same time, they enjoy the admiration they experience from the bond with their community and its enthusiasts. The tag, like the exposed penis, is a form of exposure. It affronts the majority of its audience, and this creates titillation for the males involved. It is not merely a marker for machismo, or a creative act. It is a shared thrill at the expense of a third party.

This process is furthered through documentation. In a symbolic masturbatory act, the graffiti writer turns his own gaze upon his graffiti work via a camera and documents it for the Internet. This is a longing for the world to look at his self-exposure. The world then visits his forum location (or blog, or photo compilation). Following through with this logic, he invites the world to gaze at his productions - his emasculated, sexualized object - through a framing of his own creation, namely his documentation. His

87 It is one of the foundations for gang rape in that the destructive emotional thrills of the males therein require the negation of the female for their bonding experience. According to the U.S. Department of Justice's Bureau of Statistics gang rape occurred 38,520 times in 2006 and from 1994-2010 constituted nearly $10 \%$ of all reported rape cases. 
documented works become the objects of a shared gaze between men (or anyone viewing the graffiti). If we further add the emotional content implied in the thrill-seeking production of graffiti, the framing device becomes one in which one gazes at a passive sexualized object that is symbolically representative of a thrilling emotional experience, itself a metaphor of an erection. It is not so different than when males post pictures and videos of themselves in sexual acts in an attempt to both prove their virility and bond intimately with their male viewers.

Membership in graffiti requires this kind of homosocial bonding. One must make tags and throw-ups that are, via the above inference, essential tools for an emotional relationship between males. The titillation of making something illegal and marking it for the viewing pleasure of other males, all bonding over the transgressive nature of the act, furthers this relationship. If one gazes at graffiti and finds it relatively 'savage,' contraaesthetic, and homogenous, then he or she is rejecting the above described coding of the subculture. He or she assumes the place of its denigrated victim. It is no wonder, then, that graffiti youth have been hostile to the presence of women in their ranks, either harassing them or including them only as girlfriends. Young women put at risk the homosocial quality of the mass-male bonding experience and threaten this contemporary bastion of masculine assertion, much like Shakespeare's Portia breaks the bond between Antonio and Bassanio in The Merchant of Venice. Nor has there ever been a collection of graffiti art made by publicly homosexual graffiti writers. Their presence would threaten the homosocial bond since it would strike too deeply at the hidden meaning of the production.

As noted, triangulation requires the dehumanization of the third in the triangle. 
The 'third' for graffiti is society and public space, especially as they are perceived by the males. To the degree that graffiti affronts the majority of its audience, it creates titillation for the males involved. It is not merely a marker for machismo, or a creative act. It is a shared thrill at the expense of a third party. Whether society today, that which youth reject and then mark, is coded as masculine, feminine or neuter is irrelevant; graffiti, through its bonding over the destruction of public space, enacts a triangulation ritual metaphorically similar to sexual assault.

The sexualized layer of graffiti, in which it becomes part of a homosocial triangulation at the expense of society, cannot endure throughout the career of a graffiti writer. The characterization above is, of course, an extreme example, exaggerating this quality in order to magnify its subtle elements. Through maturation and time, simply producing such objects in this fashion loses its efficacy. Many graffiti writers, in fact, desist making graffiti early and do not progress beyond making tags. The production of the masterpiece, though, represents a different set of qualities. (This is paradoxical, since some masterpieces are made illegally and may also participate in the titillation produced by the faster tags and throw-ups.)

\section{The Heroic Artisan: A Variant Masculinity}

The production of masterpieces embodies another form of masculinity. Unlike tagging, which requires daring, masterpieces require discipline and skill. In this fashion, independent of its production in legal or illegal locations, the masterpiece denotes a greater form of distinction and prowess than the tag. Its complex form, array of colors and combination of lines represent knowledge acquired through cultivation over time 
within the graffiti subculture. This masculinity is also a throwback version, what Kimmel refers to as the 'heroic artisan.' He writes,

Independent, virtuous, and honest, the Heroic Artisan is . . stalwart and loyal to his male comrades. On the family farm or in his urban crafts shop, he was an honest toiler, unafraid of hard work, proud of his craftsmanship and self-reliance.

It is a form of masculinity that in many ways stands at the opposite of the risktaking masculinity of tagging. There is a wild quality to tagging in which its ultimate power is expressed in the virility of mass production in dangerous locations. The masterpiece, however colorful and 'wild' in its initial appearance, is a product of careful planning and spray can techniques. To make a masterpiece requires discipline and perseverance, qualities that mainstream society esteems. ${ }^{88}$

The masterpiece-maker belongs to an exclusive stratum of graffiti society. Prowess is still an important quality for the makers of masterpieces and can be compared, again, to tagging. A new initiate to tagging, perhaps only age twelve, may be able to sneak out to vandalize a stop sign. In short, anyone with the derring-do can make a tag. The ability to compose and produce a masterpiece instead requires the study of other masterpieces, the mastering of the craft of spray painting and the production of numerous drafts. Essentially, it requires a form of skill honed through time, including intangibles

88 Making a masterpiece is also autonomous, even if some masterpieces are made by crews. In this regard, Susan Willis writes in her book section "Teens at Work" the unusual relationship that youth have with labor. She found that autonomy was the most important quality for the work that they sought, not its 'particulars' such as whether it was in merchandise or service-sector work (351). She writes, "Among all the teens I interviewed, the most strongly held notion about work is that horizontal mobility through a variety of meaningless jobs constitutes autonomy" (351). The teens do not wish to be trapped in a particular form of labor, and hence consider the ideal job one which they could quit at any time. It is no wonder, then, that graffiti would be so appealing: it is meaningful, autonomous, and can be abandoned at will. 
such as the aesthetic judgment of the maker. Therefore, by virtue of the very time required to achieve some measure of its perfection, the masterpiece allows some separation between the beginners and the experts.

From the perspective of liminality, the prowess involved in the production of the masterpiece is significant. Like the vandalism of tagging, the masterpiece variant of skillful prowess is both a regression and a progression. In the case of the former, it is a reactionary act of affirmation of another form of old masculinity, i.e. the heroic artisan. One could argue that this form of prowess also falls under the trickster seduction since nothing new is brought into the concept of male identity. It addresses the longing to produce something that is coded as masculine (and valuable) in order to construct one's male identity. Once again, this identity is mediated upon something that is external and socially recognizable.

On the other hand, there are positive qualities that should be celebrated. The masterpiece is made with care and with a cultivation of its aesthetic appeal, however one might judge graffiti. Some are legal and beautiful, enjoyed by the greater public. One learns through the construction of masterpieces the traits of character that are necessary for survival in mainstream workplaces. It is, in this sense, preparatory for the eventual assumptions of adult responsibility.

My only issue is that other forms of daily activity become rejected as either emasculating or neutral. For example, one might imagine a youth working a part-time employment as a cashier, a 'meaningless job' as suggested by Willis and Campos. He considers this to be menial, mere annoyance labor as compared to the splendor of making a masterpiece. Yet, a person can engage in any form of labor and imbue it with meaning. 
There are few forms of labor that are inherently demeaning, if any at all. Viktor Frankl, survivor of the horrors of concentration camps and later a psychoanalyst, writes in his 1959 classic Man's Search for Meaning how a garbage collector retrieved, cleaned and repaired discarded toys in order to donate them to orphanages. This, Frankl considered, is far more meaningful than health care workers who treated their unwell charges like corpses. Every form of labor can be divided into two extreme poles in which the egocentric worker is compared to the one who imbues his or her labor with care. It is a sign of immaturity when one assigns value to labor based on its category instead of the way in which it is enacted.

There are further subtle complications for the makers of masterpieces. They gain status due to the community's stance about graffiti's aesthetics. The graffiti community has prejudged the objects it produces as works of art. Hence, to produce a masterpiece automatically qualifies a male into the role of the great producer of objects, the artist. We can note here, too, how the artist in many ways embodies the qualities of both the emotional tagger and the diligent masterpiece maker: he is passionate, driven, and creative as well as disciplined.

The fact that the creation of masterpieces can combine elements of both the masterpiece and the tag is important for understanding the development of the identity of the makers of graffiti. One can make a masterpiece in risky locations, such as on the entire side of a subway train. In many ways, this is the 'ultimate' achievement in graffiti. The skill and 'moxy' to make a large-scale production in an illegal location is noteworthy.

Nevertheless, illegal masterpieces will be buffed by authorities. There is ultimately a lack of incentive to spend much time developing a masterpiece, only to have 
it destroyed. The inevitable tendency of making masterpieces is to focus upon sites where they can be made legally. This naturally shifts the graffiti writers away from making illegal tags. This, in term, affects their identity in the subculture. Not surprisingly, youth who specialize in masterpieces will return sometimes to tagging and throw-ups in order to reinvigorate their status. The problem which overshadows their legal productions is the necessity to make illegal work - to break the law.

\section{Warriors of Guile and Cunning}

Macdonald argues that the competing masculinities of writers-authorities are similar, basing this upon their own labels and semantic tendencies. For example, she cites David Morgan's 1994 book section "Theatre of War: Combat, the Military and Masculinities," along with many similar instances, in which the warrior archetype is "a key symbol of masculinity" (123). While I concur that the language of the taggers is militaristic, it may be that the concept of 'warrior' is misused. Within the penumbras of her conception and those of the taggers lays a specific, thoroughly Western notion of what constitutes 'warrior.' This notion is not defined by her or her target population, even if she is correct in realizing that they use terminology associated with warfare.

In this sense, one might argue that a true warrior (in terms of the basic Western archetype) confronts his or her enemy directly. If the graffiti population truly wished to be warriors in this sense, they would have found the option to join the military more attractive than an illegal, nighttime practice. Instead, they typify a kind of combat and conflict that does not attempt to battle an enemy directly, since the enemy has greater direct power. Instead, it uses subtlety and cunning. 
In terms of mythology, there are figures like the fox and Loki (of Norse mythology) that are representative of this type of combatent. The fox and Loki use cunning and guile (if not outright deceit) to achieve their ends. The result is that they are equally hegemonic in their respective domains. The fox, like Loki, also figures in mythology, from Japanese deities to basic Western Aesop fables, or in the aforementioned figure of wiley Odysseus. The World War II German general Erwin Johannes Eugen Rommel was known as the Desert Fox for his clever use of battlefield tactics in North Africa. The arts are a form of deceit, if deception is considered a positive quality on a willing subject (according to Oscar Wilde in his 1891 essay The Decay of Lying); hence Loki is the 'god' of the arts.

It is for this reason that graffiti writers are better understood in the domain of Loki. The graffiti tagger is a trickster, not a warrior, and hence uses different tactics to achieve power while not wishing to occupy a hegemonic position. Simply stating that they are warriors fails to elucidate specific qualities relating to graffiti writing. Their psyche is highly nuanced in terms of its relationship with this form of masculinity.

There are advantages to understanding graffiti's identification with the practice of guile. First, it explains in part their interest in associating graffiti with an art form. The arts, in fact, are a form of guile and deception, typically used to positive effect. Secondly, it sheds light on how one might predict what kind of youth will be drawn to graffiti, or are even currently practicing it, e.g. such youth will not be confrontational and aggressive towards their peers but instead seek to establish their interests and power in circuitous, clever fashions. Their masculinity is not 'hegemonic' but at the same time undermines hegemonic masculinity. More importantly, once a certain pattern of masculinity or 
psychic behavior is established, developmental models can be applied to both explain them as well as assist them. This leads to how we might assess masculinity and graffiti from the perspective of PYD with alternate perspectives, such as the Jungian Mythopoeic approach as well as Schiller's aesthetics.

\section{F. Alternative Interpretations for PYD research}

In this section, I propose how the Jungian perspective on masculinity with its grounding in archetypes may be useful for both understanding the character of graffiti youth as well as generating means by which we might either deter its practice or discourage its involvement. This lies in how the archetype of the Trickster appears in its early form in order to focus upon the attributes necessary for its productive development.

I also include an analysis of graffiti from the perspective of Schiller's Letters on the Aesthetic Education of Man. Schiller's approach, like the Jungians' personality attributes within archetypal manifestations, also offers details about character traits, specifically his 'savage' and 'barbarian.' Schiller's "savage" is a form of masculinity different from his rendition of the "barbarian, though both types are practiced within graffiti, with consequences.

\section{Jungian Perspectives}

The Jungians' mode of investigation, though based on decades of performing therapy with males, is founded upon a specific set of modernist values derived from turnof-the-century doctrines about the psyche. Since the advent of postmodernism, we no longer accept universal declarations about archetypes that are presumably valid cross- 
culturally. Clinicians today do not use the armchair psychoanalysis of Freud, since many of his insights have become relegated to his time period's Victorian values and the analogies he created to steam technology (such as repression). Mythopoeic masculinity, though transformative, is considered at best warranted to self-help books for a less educated, less scholarly audience.

Nonetheless, their ideas merit consideration in the context of graffiti practice, in particular the ideas espoused by Robert Moore and Douglas Gilette in King, Warrior, Magician, Lover: Rediscovering the Archetypes of the Mature Masculine. In typical Jungian fashion, Moore and Gilette do not describe the psyche in terms of a fixed type but rather as typical of certain formations that are in various stages of progress and development. For example, one does not simply encounter the 'shadow,' but spends a lifetime in coming to terms with one's 'darker' attributes in an effort to arrive at wholeness. Such 'archetypes,' truly 'formations' in the psyche, follow patterns that they deduced from their work. Hence, they are not so much theoretical as practical. Once a practitioner recognizes an individual's mental and behavioral tendencies within a given set of patterns (such as Warrior or King), he or she may more deeply understand the challenges and opportunities that face the given individual's psyche. Jungian approaches may thus assist in the formulation of intervention strategies for PYD.

Furthermore, Jungian psychotherapy celebrates liminality as something positive, a period in which one begins a soul journey towards knowledge and illumination. The liminal state, for Jungians, is the encounter with the threshold of the 'deeper' self. It is necessary for knowledge and requires technique, practice and, sometimes, assistance.

Jungian philosophy, or rather psychotherapy, is not qualified to 'diagnose' a whole 
community's tendencies. Indeed, mythopoeic therapy and masculinity in the Jungian sense is properly geared toward individual work. I will limit myself to the general notions of graffiti and 'diagnose' them in terms of the basic principles of Gilette and Moore, accepting this cautionary caveat.

The mythic figure that the authors denote as the 'magician' is most apropos for circumscribing graffiti practitioners. Like the other three figures, they claim that the 'magician' has two different manifestations, the 'shadow' side as well as the positive. (This is not meant as a simple false dichotomy, as individuals with this tendency will often exhibit a mix of both.) In youth, it manifests as the 'Know-it-all Trickster.' They define the child version as follows:

The Know-It-All Trickster is, as the name implies, that immature masculine energy that plays tricks, of a more or less serious nature, and then "selling" us on those appearances ... He's always looking for a sucker. He is the practical joker, adept at making fools of us. He is a manipulator ... The Trickster causes a boy (or boyish man) to have an authority problem. Such a boy (or man) can always find a man to hate him and eventually shoot him down. He will readily believe that all men in power are corrupt and abusive ... he is condemned forever to be on the outskirts of life, never able to take responsibility for himself or his actions.

It is a coincidence that liminal studies use the same term, 'trickster,' as Moore and Gillette. The latter use the term to denote different qualities. In liminality, the trickster is one who is able to exploit the vulnerability of individuals in a liminal crises. The Jungians, on the other hand, denote the trickster in this context as one who uses guile, 
cunning and manipulation. No doubt, the liminal trickster does this as well, but it is also possible that the liminal trickster believes that he or she is forthright in his or her views.

In graffiti, the youth embody two personae as part of their manipulation. The guise of the graffiti writer is under a pseudonym and represents the first and essential component of the graffiti subculture. The writer in his or her everyday life seems to abide by the law and hence illustrates how this deception underlies his (or her) whole existence. One is, in this sense, always engaged in deception, even when not writing, due to the anonymity of the use of pseudonyms.

One of the qualities of the magician is his (or her) ability to critique and shed light upon cultural phenomenon. This is one of the banners of graffiti. The defense of the practice is well-articulated and has been discussed here in this essay, such as its defense of public space against the intrusion of corporate advertisement, its free form of barelydestructive creativity, etc. Such arguments are also manipulative. It is true that billboards are an intrusion in public space. This does not justify graffiti writers to intrude into public space with their productions. Similarly, it is possible for creative acts to appear unexpectedly in public space without destroying property. From yarn bombing to green graffiti, there are many possibilities to create without defacement. One simply needs to use one's imagination in order to invent less destructive creations. ${ }^{89}$ The arguments are hence skewed, e.g. deceptively causing one to consider graffiti as opposed to advertising. Nevertheless, the truth of graffiti's observations about billboards and advertising represents the positive force of the magician. In fact, the adult version of the magician is a sagely figure who guides and assists other. This figure is described in positive terms

89 For example, there are youth who use a mixture of living moss and buttermilk (or yogurt) in order to create an organic mix that they are able to use to form their 'tags.' It is known as 'moss graffiti,' though the moss may be used to make any image or script. Other examples are posted on boredpanda.com. 
and as an ideal:

The Magician energy is the archetype of awareness and of insight, primarily but also of knowledge of anything that is not immediately apparent or commonsensical . . keeps us insulated from the overwhelming power of other archetypes. It is the mathematician and the engineer in each of us that regulates the life functions of the psyche as a whole. (Moore and Gillette, 106-107) ${ }^{90}$ Should the know-it-all trickster develop into adulthood, he or she would become 'The Detached Manipulator.' He is described as appearing "whenever we are detached, unrelated, and withholding when what we know could help others, whenever we use our knowledge as a weapon to belittle and control others or to bolster our status or wealth at others' expense" (114-115). ${ }^{91}$ The shadow side of the magician, in adulthood, remains 'cynically' detached from the world, and "stands back from his life and never lives it" (114).

The fundamental concern for a Jungian critique of graffiti's masculinity would be whether or not the practice aids the youth in transitioning from a destructive, tricksterlike form into a more positive, generative and mature form of masculinity. It seems that this is possible, though not inherent. Within the process of construction, as noted above, the focus shifts from pride in youthful risk-taking in tag construction to expertise and persistence in the making of masterpieces. It is possible that this process itself results in a

90 The trickster represents what Connell would have termed a marginalized form of masculinity. This, though, is the nature of the trickster. It cannot be hegemonic in the sense of Connell's definitions, since it acts to undermine and confront by definition whatever mainstream form of masculinity is in operation. It is in this way that it expresses power, much like the modes in which Castiglione's courtiers behave with nonchalance in the face of princely power and praise.

91 "Regrettably, a good example of this can be found in our graduate schools. A number of graduate students - bright, gifted and hard-working — have told us of Shadow Magician experiences with their professors. Rather than accessing the Magician appropriately and thus serving as guides for these young people's initiation into the esoteric realm of advanced studies, these men habitually attacked their students, seeking to crush their enthusiasm" (Moore and Gillette, 111-112). 
cathartic transformation of the youth involved. They experience the joy won from diligence and perseverance, required from making more complex forms of graffiti. Also, the masterpiece may be made legally. The maker experiences the warmth of approval from the community at large and may find in this sentiment the path to returning to community. Since his past vandalism was made pseudonymously, it is possible for him to completely abandon it and start afresh.

The making of something aesthetically attractive also works back upon them, causing further transformations in character. To make a masterpiece requires the research and contemplation of not only other masterpieces, but other works from the long history of art. This self-tutelage is an experience of other exemplary art forms and is especially important for considering the effect of the process of graffiti involvement on the practitioners themselves.

For PYD, the task here is to understand the crises of masculinity in male youth in the context of how they formulate their masculinity in relationship to the archetypal forms. For example, some youth may seek to be leaders, finding in this archetype their identity as males. For such males, we must cultivate qualities such as interdependency and willing empowerment of others. In the case of youth and graffiti, they tend toward the archetype of the Trickster. In this form, they will appear as either 'know-it-all' youth whose tendency in schools will be disruption in the classroom, or perhaps as clowns, manipulators, or detached cynics. When educators perceive these behavoir patterns and traits, they are signposts that such youth may be drawn to graffiti.

The alternative is to cultivate the notion that they may strive to be figures of wisdom. As figures of "awareness and of insight," such youth may be encouraged to be 
leaders of learning and civic participation. They could be enlisted in community events that raise critical awareness about issues relating to social ills (such as fair labor practices), environmental policies (such as the overuse of fossil fuels) and the government funding of education. These are examples of problems that face youth today. Involvement in similar social action might discourage graffiti involvement in that the youth are given a means to both assert their critical insights into public issues as well as cultivate an identity that is critical yet generative.

\section{Schiller's Savages in the Face of Beauty}

There is a more fundamental disposition underlying graffiti masculinity which may aid in assessing, and appreciating, how graffiti might transform the masculinity expressed in its practice. This is first revealed in its anti-authority, anti-structure activity, buttressed by claims of virility. The tagger works out of youthful passion and instinct. His or her practice violates the law in favor of a sphere of rights and artistry. The authorities, on the other hand, destroy the naturalized, emotional creations of these youth out of respect for a 'higher' set of ideals and civic codes. The youthful masculinity is here coded in Western terms as 'savage,' 'irrational' and 'immature.' The savage, as circumscribed by law-abiding citizens, is one whose emotions and instincts overwhelm rationally determined ideals and civic values. Referencing Freud's psychoanalytic perspective on human development, Reeser writes of the savage as follows:

The primitive is considered not to have moved forward in terms of his own cultural development, unlike his Western or European equivalent who moves forward toward a state of increasing civilized perfection. The primitive does not 
develop or advance culturally, nor does he develop an unconscious or superego

which allows him to repress certain elements of his primitive nature. (151)

Repression here implies a positive act of adaptation, the ability of 'Reason' to

overcome instinct in favor of civic life. However, it also implies that one's emotions and instincts are weak enough to be repressed. One might have ideals so strong that they overcome strong instincts, or have instincts so weak that they are easily repressed to be virtuous. The former implies power, the latter lack thereof. ${ }^{92}$ Reeser writes how AfricanAmerican males were (or, in terms of contemporary variations of racism, continue to be) perceived as having instincts that are too strong:

... the image of the man in gender overdrive might be a way to suggest that he is out of control. The African-American man is so gendered or so sexualized, or so the racist logic goes, that he is unable to control himself since he wants to have sex, to break into houses, or to rape women. (149)

This conception of the savage is made by its binary opposite, the figure whose ideals, values, and beliefs dominate his or her passions, even if this 'domination' is not considered as such—it is instead seen as allowing 'freedom' from such passions. The savage, on the other hand, perceives himself or herself as acting passionately and out of virility.

These two poles are representative of the Western psyche according to Friedrich

92 Kierkegaard characterizes the passion of youth in Either/Or's introduction and his thoughts may be used as a rallying-cry for those who find emotions to be surpressed by morality:

Let other complain that the age is wicked; my complaint is that it is paltry; for it lacks passion. Men's thoughts are thin and flimsy like lace, they are themselves pitiable like the lacemakers. The thoughts of their hearts are too paltry to be sinful. For a worm it might be regarded as a sin to harbor such thoughts, but not for a being made in the image of God. Their lusts are dull and sluggish, their passions sleepy...This is the reason my soul always turns back to the Old Testament and to Shakespeare. I feel that those who speak there are at least human beings: they hate, they love, they murder their enemies, and curse their descendants throughout all generations, they sin. (Søren Kierkegaard, Either/Or: A Fragment of Life, 1843) 
von Schiller in Letters on the Aesthetic Education of Man. He refers to them as the aforementioned 'savage' and (in the English translations) 'barbarian,' each defined in relationship to instinct (emotions) and moral ideals. ${ }^{93}$ These two tendencies in human nature were inspired by his study of the French Revolution, and somewhat reflect what he observed. On the other hand, they are apropos as a conceptual tool for understanding tendencies today in the West, since Western countries value reason as a key component for participation in civic society and in fact exclude youth their full civic participation in part for their lack of developed reason. He defined them as follows, with the following selections taken liberally:

Now man can be opposed to himself in a twofold manner; either as a savage, when his feelings rule over his principles; or as a barbarian, when his principles destroy his feelings ... On the one hand, he is seen running wild, on the other, in a state of lethargy; the two extremest stages of human degeneracy ... The child of nature, when he breaks loose, becomes a madman ... The enlightenment of the understanding, on which the more refined classes pride themselves with some ground, shows on the whole so little of an ennobling influence on the mind that it seems rather to confirm corruption by its maxims. We deny nature on her legitimate field and feel her tyranny in the moral sphere. (51-54)

Both the savage and the barbarian make claims to freedom. The savage finds himself or herself free in terms of his or her ability to live a life of sentiment unobstructed by morality. In the highest sense, in the political sphere, he or she will make appeal to natural rights and emotional expression. The barbarian finds freedom in living through

93 The terms 'barbarian' and 'savage' do not reflect common understandings as to their meanings, nor, perhaps, to their use in Schiller's time. 
his or her ideals. He or she finds in their purity and clarity the perfection of life, free of burdensome instincts and transitory emotions. For example, religious individuals might be thought of as barbaric in that they are capable of violence to themselves (or others) for the sake of their immutable beliefs.

This is a far more subtle understanding of the notion of freedom than commonly understood today. ${ }^{94}$ The savage is bound by the causality of instinct and the inherent determinations of material being. Namely, their emotions, feelings and external events are the causes of their actions and emotions, denying them what we would refer to today as 'agency.' Similarly, Schiller, taking from Kant, realizes that the moral life is compounded by 'ought.' Duty compels a person in the moral sphere to act in such a way as to sometimes contradict his or her feelings. There is no freedom within the upholding of what one considers preordained moral law. Law itself determines the action. For example, some Christians believe that their religion instructs them to proselytize, citing specific passages in the Bible in which God declares that one must go out into the world and convert. This command governs their actions. (A more mundane example would be the way in which one reluctantly arises in the morning because he or she ought to attend to their day at work.)

Individuals who fall heavily under the tendency of the savage or barbarian deceive themselves to be free. Even more importantly, they are intimately aware how the opposite

94 Reeser, for example, describes freedom in different terms. He writes,

One paradox of masculinity as ideological is that it often gives the illusion of freedom, the illusion that masculinity itself can be defined as freedom, whereas in fact it is this very imagined freedom that insures subjugation and hides its own arbitrary functioning. The only freedom, in actuality, is the freedom to accept or to reject forms of masculinity (25).

While Reeser is aware that there is a hidden component that contradicts certain versions of masculinity and freedom, he limits himself to categorically relegating freedom to one's choices. Choice, though, from the standpoint of philosophy, is hardly grounds for freedom. Neither the savage nor the barbarian makes free choices, Schiller reveals. 
tendency is deceiving itself, but usually in the most base sense of the term. For example, the savage witnesses in the barbarian the subservience to moral codes. It frames barbaric masculinity as lacking in virility. The barbarian witnesses in the savage the subservience to passions and instinct. It frames savage masculinity as the aforementioned inability to be civilized. The two, in short, critique the other in the negative sense. For graffiti, the youthful writers reject the adult world of the authorities as barbaric. The authorities reject the youth as savage. These are the masculinities in contestation, fundamentally opposed to one another in values, practices and perceptions.

Schiller perceived that the civic world was doomed by these two tendencies and required their transformation through a third movement. "All improvement in the political sphere must proceed from the ennobling of the character, (69)" he writes. To dmeonstrate how character is ennobled, he first further nuances and abstracts the two extremes as 'impulsions' or 'instincts' in the psyche. (This liberates them from being 'types' of people and instead as qualities that we all share.) The savage issues from what he terms the 'sensuous instinct' (or 'sensuous impulsion'), defined as that "which tends to enclose him in the limits of time, and to make of him a material being" (83). The barbarian issues from what Schiller terms the 'formal instinct,' defined as that which "issues from the absolute existence of man, or from his rational nature, and tends to set free, and bring harmony into the diversity of its manifestations, and to maintain personality notwithstanding all the changes of state" (84). These two "impulsions" are only transformed via what he calls the "play instinct" in the realm of the aesthetic. The fullness of his thought appears in his early, elaborate definition of the play instinct:

The sensuous impulsion excludes from its subject all autonomy and freedom; the 
formal impulsion excludes all dependence and passivity. But the exclusion of freedom is physical necessity; the exclusion of passivity is moral necessity. Thus the two impulsions subdue the mind: the former to the laws of nature, the latter to the laws of reason. It results from this that the instinct of play, which unites the double action of the two other instincts, will content the mind at once morally and physically. Hence, as it suppresses all that is contingent, it will also suppress all coercion, and will set man free physically and morally. (91)

The instinct of play, therefore, is key in overcoming the contradictions of either sphere. Schiller had difficulty elaborating exactly what constitutes the play instinct, since its very nature was mobile and fluctuating. For example, he indicates the object of the play instinct (not 'play' itself), was beauty, roughly defined as 'living form' (93). This notion in Schiller arises from his application of Kant's contemplation of the beautiful. In Kant, the beautiful arises from the free play of our two faculties, the Understanding and the Imagination. (It is notable that this 'free play of faculties' in Kant is equally vague.) However, this does not restrict the play instinct to the contemplation of beauty.

The concept of play in Kant and, later, Schiller, is different from how the term is defined today. ${ }^{95}$ One might argue, for example, that the youth in graffiti find it funplayful — to evade authorities and vandalize. This is of course true. Play, though, in Kant, requires a stance of 'disinterested' contemplation, a form of unattachment to the object in question while still being actively and intensely engaged. This is not the case for thrillseeking behavior, which is essentially the 'savage' or 'sensuous impulsion.'

95 For example, Brian Sutton-Smith dedicates an entire book to play's problematic defintion, calling it The Ambiguity of Play. Play can also be placed into a turn-of-the-century division with work and leisure, creating a triad of contrasting displays of power. Leisure is power over not working; play can be peformed even at work; play can occur in the space of leisure; etc. Sometimes childhood is associated with play, and the arts are supposedly a sphere of play. The complications are endless and I avoid them here. 
I believe that free play occurs, or truly begins, once graffiti production shifts towards the masterpiece. It is the masterpiece, in the careful formal considerations of its construction as well as the laborious study of other exemplars in the education of the practitioner, that Schiller's play instinct develops.

Joe Austin, intuitively, writes that graffiti "is art defined as a form of noncommodified play, as aesthetic experiment and experience" (193). This "aesthetic experiment and experience" of the practice of graffiti results in what Schiller would have considered to be an ennobling of character, assuming that it is continued through time. By contemplating and creating the exemplary forms of masterpieces, the youthful makers undergo a cathartic process that is transformational. The barbarian unites with the young savage, and a fuller person emerges.

The specific qualities of this transformation are not defined within Schiller. In the case of youth and graffiti, we could reason that the disinterestedness that slowly arises through aesthetic education ennobles their character in terms of transforming the strength of their emotional ties to thrills and rules-breaking in such a way as to disenchant their affections. Base feelings from the joys of youthful, if not childish, risk-taking activities like tagging vandalism become transformed through the Schillerian barbaric discipline of study and production of masterpieces. A new feeling emerges here, one which reveres profound aesthetic qualities such as invoked from the force of visually compelling artwork. It replaces gradually the compulsion of instinct.

This maturation witnesses the slow death of the savage, the loss of the fantasy world of the child. Veteran graffiti writers like Stephen Powers (The Art of Getting Over), Jay "J.SON" Edlin (Graffiti 365) and SABER (SABER: MAD SOCIETY) reveal in their 
writings the nostalgia for their past activities as youthful taggers as well as the memory of graffiti in its birth. This nostalgia does not represent the failure of transformative practice, but is instead the sign of change and tempering. Backward gazing is itself contemplative like the objective Kantian disinterestedness before aesthetic experience, reflecting on what was once but is now irretrievably lost. It can exist only when a break has occurred. The adult, in this case, innocuously attempts to reclaim some qualities of their youth, not as a vain effort to reassert the savage but as a semi-detached framing of its sensuous impulsion in autobiographical narrative.

As is the case for all human interior growth from savage to barbarian, inner growth occurs in the unfortunate fashion in which Nature makes a symbolic reversal in the human soul: the youthful butterfly becomes the adult caterpillar, reminiscing with fondness upon its days fluttering in the wind from flower to flower. It must confront ever after the melancholic impossibility of a new chrysalis, outside of a profound spiritual transformation. The willful tagger disappears into the adult artist, finding freedom, as well as consolation, in the pursuit of refined creations.

\section{F. Conclusion of Part II}

The initial impetus for graffiti is in the insecurities males face in terms of their male identity. This insecurity is complicated by the broader liminality of males due to social changes in the past century as well as the general liminality experienced by youth. No longer buttressed by the affirmation of their identity through 'bondsman' status peers, young males are challenged to cultivate a new, generative form of masculinity and male identity. 
No doubt many male youth succeed in this regard. A rather specific type of male featuring individuals which identify themselves with cunning and subterfuge (as antihegemonic models of warriorship) is most likely drawn to the masculinity of graffiti. They, like other liminal individuals, imitate other graffiti writers and adopt their ideology and activities. This ideology, though, awards a conception of masculinity that is regressive in its relationship to emerging forms and possibilities. The youthful writers are comforted by their international community and its proffered solidarity (communitas) while actually revealing an inability to transform themselves into a 'generative' or positive form of maleness. The persistence of this image of masculinity is still strong in Western culture and is evident in graffiti culture. The former Hegelian 'Lord' asserts itself through a new method of recognition here instead of past relationships.

According to liminal studies, the imitation of regressive principles by individuals in a liminal crises signifies the presence of the trickster. The trickster, whether a specific charismatic individual or an active ideology, offers individuals in a crisis a form of solace via the strong belief in a philosophy. Even though graffiti makes claims to transgressive behavior, it is here simply affirming 19th Century models of masculinity. For some youth, graffiti represents a seduction in regressive values.

Graffiti's initiatory production style even undermines the very masculinity it purports to express. The making of a tag or throw-up weakens the initial act of daring as the makers seek the approval of an audience. In the light of Hegel's phenomenology, violent, dominating assertions for recognition are themselves failures of self-sustaining activity. Worse, graffiti vandalism, sexualized within the subculture's idiomatic 'getting up,' connotes a semantic form of sexual assault on public space and public sensibilities. 
The subculture, in this light, exhibits itself as a mass form of male bonding at other's expense. The net result is a never-ending assertion of one's male identity without ever truly succeeding. It is like a horse chasing a carrot on a stick, with public space defaced in the pursuit.

Nevertheless, some youth deepen their involvement in the form of making masterpieces. The form of masculinity that is developed in the process of such productions, while arguably also regressive in its need to be identified with the making of culturally 'pre-determined meaningful' objects, is constructive, disciplined and diligent. From a social perspective, it is preparatory for the youth in that it develops traits that are positive for many forms of labor in mainstream society. Also, it is a counter-force to the thrill-seeking 'savagery' of the tagging vandalism, creating a more balanced persona. Should one seek to make beautiful, compelling masterpieces (especially legal ones), they begin a path of self-transformation. One's appreciation of this process can be furthered by Schiller's conceptions of the play of aesthetic activity.

We might argue here that a conception of manhood can emerge that is positive and beneficial. This is especially so since one has confronted already the challenge of facing risks. The early phases of tagging and throw-ups might give one the sense that they have overcome adversity, engaged with their peers and defied authorities. There is hence no need to engage in such behavior as an adult.

Therefore, there is mixed evidence thus far that graffiti addresses fundamental issues of male identity which, in turn, could result in PYD. The youth learn to violate the law as a form of masculine virility, which in turn opens the door to other rules-breaking behavior. Their insistence that they are making art, not vandalism, might assist them in 
conceiving of themselves with higher masculine self-esteem. This also, curiously enough, may eventually lead them to embrace legal activities since it naturally leads to the production of legal murals. Even if the early stages of graffiti vandalism represent regressive notions of masculinity, these notions persist anyway in contemporary culture. Graffiti at least allows for the possibility of developing away from them.

Finally, one may argue that some males live in situations in which the alternatives to graffiti are far worse, such as gang involvement or drugs. In such instances, graffiti is wholly positive. Its extant community and aesthetic production could create a support base which aids them in eventually identifying with some positive elements in their conceptions of masculinity, especially in terms of making attractive murals. Nevertheless, in some aspects of their involvement, they will be encouraged to break the law. This may result in an inescapable police record.

Other subtle influences may affect the appeal of graffiti to males, such as consumer culture and the changes to public space. These aspects apply to females as well. Similarly, females might find risk-taking to be a thrilling activity, challenge corporate power through mark-making, and identify with the image of the trickster. Indeed, there is little to the notion of masculinity and graffiti that makes it exclusive to males, noting again that females can be masculine (other than 'getting up'). Graffiti, in fact, includes females. Only the fact that manhood is undefined, and can be perhaps developed through some kind of act of prowess, seems to make it remain as a viable staple of graffiti activity.

Since females construct graffiti as well, and might identify with the rebelliousness, savagery and anti-corporate destruction, there must exist some deeper 
element that inspires graffiti membership. Age, not gender, is a unifying element of all early subculture involvement and of course is represented in all adolescent rebellion (and juvenile delinquency).

The next section explores how the tensions between the belief in basic moral rights and the delayed granting of the expression and responsibility of the powers to enact those rights is a driving force behind membership in a subculture like graffiti. This shifts away from confining the discussion to gender and towards a philosophical, pragmatical and political analysis of basic Western, American values and their legal manifestation. 


\section{PRINCIPLES AT THE ROOT OF ADOLESCENT LIMINALITY}

\section{A. Introduction}

Ambiguities in basic rights and powers given to adolescents are one of the key sources of youth liminality. One is born with certain rights but does not have the power to gain access to those rights until various confusing age-related markers are attained. Also, the political, social and economic system that youth are forced to inherit through the slow erosion of their 'tacit' consent appears as an unfair imposition. Subcultures, significantly created by youth, allow them to freely join a community that reflects their ideology. Graffiti holds special appeal for youth since it generates an avenue of rebellious, antistructure activities through its vandalism while preserving the latent civic status of its members.

Graffiti writers claim that their productions are works of art. Their art, therefore, merits protection under the Visual Rights Act. However, it is not presumed generally that minor acts of graffiti vandalism such as tags and throw-ups are covered by this protection. Their artistic interest is negligible. One must question, therefore, what rights the producers of graffiti believe they possess when they engage in the process of graffiti vandalism as a whole.

In a more subtle fashion, one might question whether there are rights at the 
foundation of Western society and values that indirectly support the activities of graffiti vandals, implying a subtle political dimension within the activity far beyond any of the current discussions about its political content. It is to this latter question that this essay turns, arguing that youth in general are emboldened by social contract theory's placement of political sovereignty in individuals (instead of monarchs). This sovereignty is an inherent political right, in particular the right to vote, structure society and make decisions about civic welfare. However, the power to enact such rights are denied adolescents who are nevertheless partially treated as adults in a confusing fashion.

It is youth who make the vast majority of graffiti vandalism. Therefore, even before someone chooses the 'career' of graffiti, this status of the rights and powers of adolescents within Western values find their expression in the graffiti subculture as one of many avenues, independent of psychological considerations of general youth misconduct. These issues are therefore independent of graffiti, and serve as one of its foundational motivations for existing. They would stem from the liminal crises of adolescents in their relationship to their rights, both as members of a private nuclear family and as latent members of a greater nation-state.

This paper proceeds by first analyzing current scholarship about adolescent rights before proceeding to a brief history of rights in the United States (and the West in general) in their relationship to adolescence. I review how human rights enter their current recognizable form from Hugo Grotius' early writings on jus until they progress into their manifestation in social contract theory as espoused in Locke's Two Treatises. This culminates in the problem of how society is to transition an individual from political 
dependency (such as a young child) to full political power in adulthood. The adolescent rests in an ambiguous state between the two.

In part $\mathrm{B}$, this paper turns to an explication of this ambiguous state in practice, the present-day legal status of American adolescents. Their various points of access to and prohibitions against exercising their powers, in areas as diverse as juvenile court to the consumption of alcohol, are listed to demonstrate how varied the signposts of adulthood (and hence a focal point of maturity) appears to them. Even though we all have passed through adolescence, it is easy to forget just how confusing the period might be in terms of the ways in which American society views its youth and their ability to make moral decisions.

Next, I discuss how the placement of powers in the hands of parents, the key influence for youth, invariably creates tensions. While some parents are able to sensitively navigate these tensions, the mere fact of needing to have such sensitive parenting is indicative of a compensatory behavior. Namely, conscientious parenting arises because there is a contradiction occurring for the empowerment of youth and it is the burden of parenting to navigate this contradiction. ${ }^{96}$

This section also includes a key discussion on the notion of tacit consent, raised by John Locke. The fundamental problem of contract theories is the issue of societal continuance after the initial 'contract' is created by the founding population (usually hypothetically). To resolve this problem, Locke suggests tacit consent in which an adult's use of common goods indicates their acceptance into the social contract. I believe this to be intuitive, not merely Lockean, and argue that the absence of specific markers of

96 Parental power is necessary for children and to represent the rights of children in relationship to the state, something that might appear problematic when the state wishes, in cases of abuse or neglect, to protect children against their own parents. 
adulthood results in the absence of a recognizable moment of consent to society and its structures. Hence, there is an erosion of the concept of tacit consent that further disempowers adolescents politically as they slowly enter adulthood.

The question of when adolescents consent to their membership in society is problematic not only because of the absence of a clear marker for attaining adulthood but also because traditional understandings of youths' capacity for moral reasoning depict them as cognitively unable to offer meaningful consent. This cognitive capacity was Reason, still in development in youth. Reason, in time, came to be substituted with the term 'rationality,' with far more subtle variances in meaning. The purported irrationality of youth then became a point of study for psychologists such as Piaget, who founded morality upon rationally conceived ethics of moral ideals. I project these views of reason and political liberty onto a four-pole, dual dichotomy scheme, using some terms suggested by Isaiah Berlin, in order to present an appropriate conception of ethical conflicts for youth.

The stance of rationally-based ethics was challenged by feminists in the ethics of care, in particular Carol Gilligan (in which she claimed that females demonstrated ethical awareness in alternative, valid modes such as through empathic responsivity.) I conclude this section with a discussion of care ethics.

In Part D: Consumption and Possessive Individualism, I return to the topic of consumer culture. 'Money culture' also affects youth in the context of social contract theory and human rights. I once again use some of Locke's notions on the role of money since I find them intuitive, namely that money arises as an exchangeable commodity for hard-earned goods, goods that might normally spoil. The exchange of those goods then 
enables a conception of hording that is not at the expense of others. This, for Locke, in turn leads, through time, to the justifiable stratification of wealth. Future generations (such as youth coming to age) face the inherited stratification of society and, since they are unable to adequately judge the full terms of money transmission, find it unfair and unjust. Therefore, they might resist consent to the existence of the structures which justified stratification. Hence, subcultures like graffiti make specific ideological claims against property.

In Part E, I explore the recent destruction of graffiti in the legal case of 5Pointz. The graffiti community sought to defend the masterworks of historical graffiti that had been made with permission from the owners of an abandoned site. Their defense was based upon the Visual Rights Act. The language used within the case presents a prime example of how the graffiti community perceives their art in relationship to property. However, curiously, the failed defense of the location allows graffiti youth to retain their exercise of the rejection of property rights and tacit consent.

In Part F, Adolescent Response: Weapons of the Weak, I describe how many of the features of youth subcultures (particularly graffiti) may be interpreted as responses to the issues inherent in adolescent rights. I argue that youth join a subculture as a form of free consent instead of the tacit consent to membership in mainstream culture. Private property as circumscribed by society is rejected in favor of the notion that all land is available to the extent that one makes it his or hers by acting upon it (such as through creative expression). Since youth are not full members of society, in effect they revert unconsciously to a state of 'nature' in which unused land might be made into one's property through the mixing of one's labor. 
I then conclude the paper with a summary of the arguments and a brief assessment of how these arguments reflect also upon masculinity and graffiti.

\section{Current Scholarship}

Humanist studies upon adolescent rights are unusually sparse and mainly tend towards practical analyses of existing situations. Adolescents are not capable of researching and publishing findings upon themselves. The most recent and perhaps ${ }^{97}$ significant of these, born from a late 2011 conference at Harvard University, is Human Rights and Adolescence, edited by Jacqueline Bhabha (2014). It challenges the notion of adolescence as a period of growth and discovery since adolescents across the globe often need to assume adult responsibilities at an early age. The understanding of adolescence as a formative period prior to such responsibilities presumes, therefore, that adolescents should follow Western values that depict the age as one in which an individual should be leisured to study and explore. Most of the articles in the collection-such Christian Salazar Volkmann's “Poverty, Armed Conflict, and Organized Crime: The Impact of Violence on Young People in Colombia" and Irene Rizzini's and Malcolm Bush's "Rights and Realities for Vulnerable Youth in Urban Brazil: Challenges in the Transition to Adulthood" - detail specific examples of the struggles facing youth worldwide. These studies, though, are not relevant for this paper, since their focus presumes nurturance rights instead of the contradictions in adolescence. I mention this publication, though, since its title seems to relate directly to my discussion.

Before this work, there are other examples that engage the philosophical, such as the aforementioned Martin Guggenheim's 2005 What's Wrong with Children's Rights.

97 I use 'perhaps' here since the impact of this collection of essays cannot be determined yet. 
Guggenheim warns against the dangers of undermining the ability of parents to make decisions for children in the face of external state power, when in fact parents should be supported, e.g. Guggenheim would argue that parents are, in general, interested in their children's well-being. Guggenheim's focus is principally on children, although some of his discussions on the effects of legal proceedings are fruitful. For example, I find that his thoughts on nurturance versus individual rights are insightful and were included in the summary above on the history of children's rights. ${ }^{98}$

I was initially stimulated by the thoughts of two writers whose strong defense of children's rights appear as contributions to the 1980 book Whose Child? Children's Rights, Parental Authority, and State Power. John Holt, in his chapter "Liberate Children," argues for the extension of adult rights to youth since limitations on those rights are not justified. He writes, "I propose instead that the rights, privileges, duties, responsibilities of adult citizens be made available to any young person, of whatever age, who wants to make use of them" (84-85). Ann Palmeri, in her contribution "Childhood's End: Toward the Liberation of Children," echoes Holt's sentiments. She challenges the notion that children are not morally responsible. She argues that there are two assertions that typically underpin the claim, namely that moral responsibility requires rationality and that children are not rational. She also reiterates the problematic history of rights, comparing the issues of youth and the perception of them with the obstacles in other movements:

The "Children's Rights Movement" has clearly drawn its inspiration from the civil

98 Other authors focus upon practical issues, not a philosophical critique of rights per se (and are hence not relevant for this paper), such as Keith Elliot Greenberg's 1995 Adolescent Rights: Are Young People Equal Under the Law? and Rodman, Lewis and Griffin's 1984 The Sexual Rights of Adolescents. The practical issues of Greenberg's work relate to the specific legal laws surrounding issues like abortion; the latter functions in a similar fashion. 
rights and women's liberation movements. Not too long ago, minorities and women were not considered people, all kinds of scientific explanations were offered why this was so (105).

These writings approach rights from the perspective of political theory. However, as noted by Guggenheim, they are tinged with the impractical radicalism of their era and are hence 'suspect' as sources. However, after an initial appreciation, I shifted away from their stance, especially due to their extreme assertions of adolescent rights. ${ }^{99}$

The Handbook of Adolescent Psychology's third edition was reissued in 2009, only five years after the publication of the second edition, which suggests the rapid progression of research in the field. ${ }^{100}$ Its contributions to our scientific understanding of the challenges of adolescents are manifold. Deanna Kuhn, in her section entitled "Adolescent Thinking," concludes that early adolescence represents a critical juncture in human development in which "patterns are established that will be resistant to change later on" (181). For this reason, interventions in early adolescence are a key practical step to make in the pursuit of PYD. She also notes that adolescents think very much like adults: "In the sense of being free agents ... adolescents are more like adults than they are like children" (182). In short, we might make a simplistic summary that youth think about moral issues and, importantly, are vulnerable in their thinking.

Other research demonstrates that adolescents are more sophisticated organic philosophers of rights than is commonly recognize. For example, Judith G. Smetana and Myriam Villalobos, in their section "Social Cognitive Development in Adolescence,"

\footnotetext{
99 By extreme, I refer to how these offers do not argue for a nuanced conception of children's rights; children should have full rights.

100 In my summary of the research of psychology, I am ignoring the contributions in previous editions of the Handbook of Adolescent Psychology (including the 1980 Wiley Series) since the most recent edition represents current research.
} 
reveal that "even early adolescents appear to have relatively mature understandings of different social concepts (such as rights, tolerance, exclusion, or personal choices) when those concepts are presented abstractly or in decontextualized ways" (221). Their article is based upon a broad review of numerous studies conducted throughout the field.

This research is further analyzed by Nancy Eisenberg, Amanda Sheffield Morris, Brenda McDaniel, and Tracy L. Spinrad in their section "Moral Cognitions and Prosocial Responding in Adolescence." They write that the research has been 'meager' in the realm of morality, especially given the challenges to the models proposed by Kohlberg ${ }^{101}$ in the 1980s: "In regard to moral reasoning, there is not yet consensus on the stages of moral reasoning and the degree to which they are qualitative in nature and universal ... Relatively little is known about the socialization of moral reasoning in adolescence" (256). Not surprisingly, McDaniel and Spinrad find that delinquent youth "use a lower stage moral judgment" (235). The takeaway here, too, is that youth struggle with moral issues, much as one might suspect, especially given the rhetoric of the graffiti community and its stance towards art and property vandalism.

In "Conduct Disorder, Aggression and Delinquency," David Farrington reviews the data on the eponymous issues in youth. He notes that, in contrast to work on moral reasoning, the data and research on these issues are extensive and that the three areas mentioned in his title overlap heavily, e.g. a delinquent youth is also likely to be aggressive. Whereas the key "risk factors" such as "low empathy, low IQ and low school achievement ... [and] poor parental supervision" (712) are known, what is "less

101 For those unfamiliar with Kohlberg, he argued that individuals undergo six specific stages in their moral development, "pre-conventional" behavior based on obedience and punishment to "postconventional" moral thinking grounded in universal principles. They are based upon one's ability to reason around issues of justice, which is also their limiting factor. 
established" are "the causal mechanisms linking these risk factors with antisocial outcomes" (712). In short, even if the correlative influences are present, it is not clear what brings about destructive behavior. However, Farrington makes no mention of the status of rights and the possible contradictions therein. Here, too, one unfortunately may place graffiti vandalism with other forms of crime, even if it is not explicitly mentioned by the author.

Brett Laursen and W. Andre Collins view parent-child relationships in their eponymous book section in the second volume of the Handbook of Adolescent Psychology. Their conclusion in a review of the vast research is that "adolescent development can be understood more fully in the context of relationships with significant others and that relationships with parents remain central to these contexts" (35). In fact, there are vast influences on adolescents outside that of their parents. A review of the titles of the contributions in the second volume of the Handbook of Adolescent Psychology indicates siblings, peers, lovers, mentoring, schooling, work, media and citizenship (including issues of poverty and globalization). It reminds one that perhaps G. Stanley Hall was not too far off in his characterization of adolescence as 'storm and stress,' even if his justifications for this characterizations are not considered correct. Positive parenting mediates many of the issues, yet it also appears as causal ${ }^{102}$ (as in the case of parental marital problems). This, too, does not assist with coming to understand the issues of graffiti but might offer at best an indirect explanation as to why some youth are drawn to it. In other words, we might understand why certain youth suffer in their adolescence, but not why they are specifically drawn to graffiti.

This varied research in psychology and further data from neuroscientific

102 By causal, I mean that it is the cause of juvenile issues. 
observations on brain development have consequences for policy and philosophy. In his article "Should the Science of Adolescent Brain Development Inform Public Policy?" (2009) Laurence Steinberg deftly summarizes the debate on how neuroscience could and could not be used in legal reasoning. He argues that it can augment behavioral studies but not substitute for them. He warns against six 'pitfalls': first, that neuroscience may be seen by the layperson as more reliable than behavioral science; second, "Behavioral evidence without neurobiological support is not necessarily suspect" (747); third, neuroscience cannot establish strict boundaries for differences in mental abilities; fourth, the level of what constitutes maturity and its corresponding brain phenomenon is culturally decided; fifth, neuroscience might affect policy but cannot be used in individual cases; and sixth, context influences the way in which specific cases might be judged (746-748). He argues, however, that it is "indisputable" that adolescent brains are less developed than previously understood:

Whether the revelation that the adolescent brain may be less mature than scientists had previously thought - a conclusion that I believe is indisputable —ultimately is a good thing, a bad thing, or a mixed blessing for young people remains to be seen. Some policymakers will use this evidence to argue in favor of restricting adolescents' rights, and others will use it to advocate for policies that protect adolescents from harm. In either case, as scientists, we should welcome the opportunity to inform policy discussions with the best available empirical evidence. (748)

However, despite the interest in adolescent thinking per se (such as Kuhn's aforementioned essay), the main issue with existing scholarship is that it tends to be 
either scientific (such as neuroscience or developmental psychology) or pragmatic. There are few philosophical discussions of the inherent contradictions for adolescents in the philosophy of natural rights within the context of their pragmatic realization. For example, the Handbook of Adolescent Psychology offers categories for understanding how adolescents might encounter moral reasoning, but it does not question how adolescent thinking might be influenced by actual philosophical contradictions within the values themselves. This is a task for the humanities, especially a broad-based approach that views both the philosophical and the practical.

In the same way that studies of adolescence tend to overlook political philosophy, philosophical analyses of specific contract theorists overlook the effect his (or her) theories might have on adolescents. For example, John Locke's oeuvre includes specific writings on the relationship of child to parental authority as well as his practical, affective approach to parenting in his letters Some Thoughts Concerning Education. Scholarship on Locke's view of children includes John Yolton's John Locke \& Education (1971), Nathan Tarcov's Locke's Education for Liberty (1984) and Jacqueline L. Pfeffer's article “The Family in John Locke's Political Thought" (2001). Two examples from the 1979 edited collection Having Children: Philosophical and Legal Reflections on Parenthood include Michael A. Slote's “Obedience and Illusions” and Edmund Leites' "Locke's Liberal Theory of Parenthood.” All of these works, while cognizant of Locke's concerns over the relationship of parental power to children's rights, ignore the unique status of adolescence that emerges within the framework of Lockean principles. These thinkers focus upon the age period in which the child-parent power and care relationship remains relatively uncontested, unlike that of adolescence (in which the ambiguities of one's 
rights and powers are problematic and hence create tensions with one's parents).

Interestingly, Locke was aware of the need for careful parenting given his challenge to state power, long before the psychological research in adolescence began. Locke perceived that there were practical issues in raising youth so that they would become educated gentry of a society (hence his letters, now published as Some Thoughts Concerning Education). These practical issues arose from Locke's philosophical principles, namely that the transition period of adolescent rights is confusing. This is just one of many indicators that there is an inherent issue within rights philosophies themselves - particularly in Locke's thought and in conceptions of the relationship of rights to their practical realization in liberal democracies - that may assist in explaining adolescent rebellion and, by extension, graffiti vandalism.

\section{Human Rights and Adolescence: History and Discourse}

The period of adolescence in general in the West is used as the de facto example to illustrate the meaning of liminality as if liminal youth crisis were commonplace. Indeed, so ubiquitous is this adolescent crisis that one might assume incorrectly that it occurs in any society, cross-culturally and historically. In reality, it is as unique and historically specific as the category of teenager.

According to Richard M. Lerner and Laurence Steinberg, in their overview of the scientific study of adolescence in the 2009 third edition of the Handbook of Adolescent Psychology, even though Aristotle had already divided life periods in terms of seven-year cycles (hence creating a young adulthood period from 14-21), the term "adolescence" did not appear until the fifteenth century (3). Professional study of it did not begin until 1904, 
with psychologist G. Stanley Hall's book Adolescence, Its Psychology and Its Relations to Physiology, Anthropology, Sociology, Sex, Crime, Religion and Education. Hall, like many others in the developing fields of child psychology and sociology, was principally motivated by the appearance of specific issues of juvenile delinquency in urban centers. The adolescent offender, or juvenile delinquent, was a growing problem for late $19^{\text {th }}$ Century Western industrialized nations. ${ }^{103}$ Thus, many, if not all, of the issues surrounding juvenile delinquency, subcultural vandalism, and teen angst are recent Western phenomena.

Youth in graffiti are the inheritors of a history of practices that establish a unique position for minors in relation to human rights. Today in the United States, a child is not always bound to his or her parents' authority. At some point in one's life, one becomes liberated of both the legal powers that his or her parents have over one as well as one's parents' responsibility over one's moral decisions. In a simplistic comparison, the parents of a destructive six-year-old are considered responsible for their child's acts in the eyes of the general public, if not the law; a thirty-year-old who behaves similarly is accountable for his or her own actions. In the case of the latter, he or she is considered to be acting out of his or her own moral base and outside the responsibility of his or her parents, even if the latter may, in the individual's early years, have been a formative cause of the misconduct. This point, I suspect, is obvious.

Though a person might be age fifty, he or she is still technically a child if either of his or parents are alive. Yet, we would never consider parents in such an instance to have any right to powers over their adult children. They hence are not accountable for their

103 The particular concern was, unsurprisingly, with male adolescents, although female adolescents were also examined within the context of gendered roles and expectations. 
adult child's actions. This further extends to a political ideology: no one has such power over an adult in a modern Western state save to the extent that an adult has relinquished some of those basic powers as part of membership in society. ${ }^{104}$ It is a basic human right to be free (ideally) of another's direct control in this manner. Also, at the same time, every adult is considered to be responsible for his or her own actions.

This notion of rights, intimately tied to what is socially just or unjust, is apparently unique to the modern Western world, according to Isaiah Berlin. In his renowned lecture Two Concepts of Liberty, he describes this unique mode of conceiving of freedom and human rights:

There seems to be scarcely any discussion of individual liberty as a conscious political ideal (as opposed to its actual existence) in the ancient world. Condorcet had already remarked that the notion of individual rights was absent from the legal conceptions of the Romans and Greeks; this seems to hold equally of the Jewish, Chinese, and all other ancient civilizations that have since come to light. The domination of the ideal has been the exception rather than the rule, even in the recent history of the West. (129) 105

In the United States, the continuation of this orientation to individual human rights has diverse origins. Perhaps Americans are partially inspired by Thomas Jefferson's use of the discourse of human rights in his heavily-edited ${ }^{106}$ Declaration of Independence, a document whose revered status in contemporary political discourse is

104 Imprisonment is possible since it is conceived that one has relinquished some of his or her rights through criminal acts.

105 Aristophanes caricature of Socrates on youth: "They have bad manners, contempt for authority; they show disrespect for their elders and love chatter in the place of exercise." (The Clouds, 423 BC)

106 Lucas states that the delegation for the Continental Congress "deleted 630 words and added 146, producing a final text of 1,322 words (excluding the title)" (72). Jefferson apparently was disturbed by these changes, even if they were apparently not very strong changes, even publishing in the last years of his life in his autobiography his original copy adjacent to the existing version (Lucas, 72). 
belied by the fact that the Continental Congress, according to Stephen E. Lucas, gave "no hint at the time that it would be more notable than any other of the sixteen papers issued by [them] before July 4, 1776" (70). Yet, it is read and studied throughout American primary and secondary education, and prints of it often sit reverently framed on middleschool walls as if its contents were sacred. We can assume, therefore, that U.S. youth interested in graffiti have either read its contents or are familiar with its assertions due to their pervasive presence in American culture. In an act of rebellious defiance of British power, Jefferson, already the author of the 1774 pamphlet "A Summary View of the Rights of British America," used such terms as 'unalienable rights ${ }^{107}$ and described the ends of participation in society as the protection of "life, liberty, and the pursuit of happiness." The final, revised document succeeded in its goal, namely to inspire American colonists to unite and resist British control.

Such wording on rights has origins in European contract theory. It directly mirrors the purpose John Locke articulated for the existence of government in Two Treatises of Government, namely the protection of life, liberty and "estates." (Jefferson substituted 'pursuit of happiness' for 'estates.') Locke, though, was not the only theorist who inspired the American Founders. In the United States, notions of sovereignty and rights were heatedly discussed in pamphlets at the time of the American Revolutionary War. The intellectual leaders of the initial conflicts, from Samuel Adams to Thomas Paine, were inspired by the vast literature on political theory. This included Roman conceptions of republicanism; discussions of natural law in the thought of Samuel von Pufendorf,

107 In the context of this discussion of adolescent rights, one might note especially the radicalism of Jefferson's opening statement: "We hold these truths to be self-evident, that all men . . . are endowed by their Creator with certain unalienable Rights ... That to secure these rights, Governments are instituted among Men, deriving their just powers from the consent of the governed ..." 
Thomas Hobbes and John Locke; the Scottish Enlightenment thinkers' moral debates such as those by Francis Hutcheson and David Hume; and the radicalism of French philosophes' writings such as Rousseau's The Social Contract and Montesquieu's 1748 Spirit of the Laws.

The notion of human rights, typically referred to as "natural rights" in pretwentieth century thought about "natural law," hence has a long history in the West. According to John Finnis, in his seminal 1980 book Natural Law and Natural Rights, its modern form arguably first appeared in the thinking of Hugo Grotius. Grotius broke with the medieval tradition of referencing natural law and rights in relationship to divine order. ${ }^{108} \mathrm{He}$ instead described them as 'powers' to justify the commerce of the Dutch empire within the res communes of the open sea, for powers, unlike the inherent nature of an act in itself (such as the historical/philosophical use of the term 'just'), can be relinquished. Finnis writes that Grotius modified Aquinas' use of the Roman term jus (just), based upon changes implied by Francisco Suarez:

Hugo Grotius begins his De Jure Belli ac Pacis (1625) by explaining the meaning of the term jus (jure) in his title is 'that which is just; but he then offers an elaborate exposition of 'another meaning of $j u s . .$. which has reference to the person; this meaning of jus is: a moral quality of a person enabling [competens] how to have or to do something justly'. This, he says, is the meaning that hereafter he is going to treat as the word's 'proper or strict' meaning ...jus is essentially something someone has, and above all (or at least paradigmatically) a power or

108 Grotius still believed in a divine order. However, since nature and its laws were created by God, our reasoned understanding of laws was sufficient grounds for establishing rights. In this way he grounded natural law and natural rights in thinking instead of scripture. Just acts were established through the 
liberty. $(207)^{109}$

Scholastic philosophers conceived of 'things' being 'just' (jus) and hence having a relationship with the divine order. The just was objectively understood, such as a just act, e.g. it is just to help one's neighbor because helping thy neighbor is in and of itself a righteous act. The moral obligation rests in the act, not the individual making it. Grotius shifts this focus onto the thinking person, so that what is just stems from an individual's abilities and actions. In this case, using the above example, the just in relationship to helping one's neighbor is understood as the individual having the power, even moral obligation, to do so. The result, though, is that the power resides in the individual, and hence is nuanced in relationship to one's situation (there are instances in which it is not just to help one's neighbor).

From Grotius (and onward), his notion of natural powers and subjective $j u s$ also results as an individual possession that might be partially relinquished upon joining a society. C.B. Macpherson in his book The Political Theory of Possessive Individualism writes that the Levellers in England were amongst the first to argue for property rights (158). Locke, writing after the Levellers, considered the central rights to be life, liberty, and property, where the first two are ultimately nuances of the third, i.e. life and liberty are ultimately forms of property (we possess life and liberty). ${ }^{110}$ Previously, labor was conceived as intrinsic to individuals and their situation, such as the relationship of a serf to the land. The serf was part of the land and his or her relationship to their labor was bound to their role as serf. As a result of Locke's conception, labor came to be viewed as

\footnotetext{
109 One might also conceive of this as an early version of Kant's 'Copernican Turn' two hundred years later in his Prolegomena. Namely, there is a shift slowly away from objects or acts to the perspective of the individual.

110 We may note that the notion of exchange and commodification (as an influence on natural rights) is typical of English political philosophy, evident, for example, in such moral ideals as Bentham's utilitarianism in which ethics is reduced to something that can be somehow weighed and measured
} 
an exchangeable commodity; the serf labored at the land but this labor existed due to the terms dictated by the economic structures. ${ }^{111}$ This culminated in Adam Smith's (radical) remark in the The Wealth of Nations that a worker is empowered by his or her ability to take his or her labor to different employers.

Children's rights were latecomers to these changing meanings of natural individual rights. In the United States, according to Martin Guggenheim in his 2005 book What's Wrong with Children's Rights, transformations in the status of children occurred in two principle periods in the modern era. The first transformation was led by the Progressives around the turn of the twentieth century. The Progressives fought for child labor laws, protecting children from harsh work conditions and long hours. They also established juvenile courts, using its sentencing as a reform instead of punishment. Their conceptions were based on scientific inquiry, perceiving youth behavior from deterministic and behavioral models.

The second shift occurred in the 1960s, when the Children's Rights Movement reoirented the discussion from viewing children in terms of their needs to treating them as full individuals endowed with human rights. Instead of perceiving children as in need of care, the new conception fortified their status as individuals separate from the power of

111 Locke's epistomology in An Essay Concerning Human Understanding also contributed to the emphasis on natural rights. He was an empiricist and sought the origins of consciousness and human action in sensorial and even deterministic sources. Consequently, and continuing the tradition started by Aristotle, Locke argued that there were no innate ideas, that we instead began life as a blank slate (famously referred to as 'tabula rasa,' although Locke did not use the Latin phrase in his writings). Since we begin free of predetermined influences, such as Hobbes' claim of inherent selfishness, the State held a special relationship to human action. Liberty is related to power, writing that "As it is in the motions of the body, so it is in the thoughts of our minds: where any one is such, that we have power to take it up, or lay it by, according to the preference of the mind, there we are at liberty" (II xxi 12). It necessarily follows that political freedom is related to the extent to which individuals are compelled by the State or are empowered to determine their own course of action. The social contract foundations of state legitimacy rested upon the consent of the government and arose from their sovereignty, not the divine origins of kings, hereditary claims to special aristocratic rights from Adam or the compulsion of tyrants. 
their parents and the state. In this sense, Guggenheim writes that "children's advocates sought autonomy and personal freedom for children" (6). The juvenile court, created by Progressives to spare children adult prisons, came under fire since it was perceived as not respecting sufficiently the rights of youth incriminated. "The movement," writes Guggenheim about the Children's Rights period, "has been characterized by three related components: it is dominated by lawyers; it looks to the courts for relief; and it is based on a rhetoric of rights ... this shift from "needs" to "rights" was even manifested in the language of the 1970 White House Conference on Children" (8).

Guggenheim perceives that the tenors of these two periods were virtually opposite of each other. The Progressives enacted laws out of a concern for the care of children. The movement acted in what its leaders considered to be the best interests and needs of children, known in contemporary rhetoric of rights as 'nurturance rights.' The Children's Rights Movement, born in a time of unrest, generational conflict, and extensive activism and protests, rejected the older stance of the Progressives as oppressive and paternalistic.

In fact the discussion of human rights for children is the latest variance of natural rights, appearing in diverse movements (and in a multitude of forms) before and after World War II. The American Civil Liberties Union was formed in 1920 and has been active since then, focusing upon the legal aspects of rights and civil practices. In 1948 The United Nations adopted The Declaration of Universal Rights, stating, for example, in article 2, that "Everyone is entitled to all the rights and freedoms set forth in this Declaration, without distinction of any kind, such as race, colour, sex, language, religion, political or other opinion, national or social origin, property, birth or other status." The 
African-American Civil Rights Movement that culminated in the vigorous protests of the 1960s was based upon its eponymous name: the realization of human rights in the civic realm. Feminism launched a second wave in the same time period asserting the rights of girls and women against traditional sex roles. President Kennedy helped create a Consumer's Rights Bill in 1962, focusing on such areas as safety and proper disclosure of product information for the benefit of the general public. Much later, the Americans with Disabilities Act of 1990 legislated against discrimination based on physical ability.

The importance of these varied movements lies not only in their diversification of the public realm through actions grounded on concepts of rights. They also elevated and amplified the discourse on rights themselves in much the same way as Jefferson's Declaration was worded for its persuasive and rhetorical power. Hence adolescents since the 1960s have been heavily exposed to the rhetoric and notion of rights. It is not without coincidence that contemporary graffiti emerged in the 1970 s, perhaps inspired by the challenges to centralized authority and the empowerment of individuals in the face of these historical changes.

\section{B. Present-Day Status of American Adolescents}

[W]e are likely to give young people of a given age — say, fourteen — the right to drive a car some time before we give them the right to vote, and we are likely to allow them to vote for some time before we give them the right to marry or to manage their own sex lives (John Holt, 85-86).

\section{Introduction: Adulthood Markers}


In the complex ways in which American culture considers one person an adult and another a child, there is no actual 'leap' today from childhood to adulthood. Authors Jennifer L. Woolard and Elizabeth Scott (year) raise the question "to what extent does legal regulation recognize the developmental reality of adolescence as a discrete stage and distinguish between adolescents and children (and between adolescents and adults)" (345). Their response is curt: "not much" as "the boundary between childhood and adulthood varies depending on policy purpose" (345). For example, in the United States, one's sex life as a minor ends at age eighteen ${ }^{112}$; one can drive vehicles unrestricted, under certain conditions and varying by state, as early as age sixteen; one may consume alcohol at age twenty-one; and at eighteen one may enlist in the military (seventeen with parental (adult) consent). The age required to purchase tobacco, like the age for obtaining vehicle licenses, varies by state. In the area of film, the ratings are very specific: PG-13 is for age thirteen and up; R requires age seventeen, although someone younger may enter if accompanied by an adult (i.e. they are not one); and then, of course, there is the former rated ' $\mathrm{X}$ ' level (now termed NC-17) admitting youths of seventeen years. Most importantly of all (politically) is the voting age-lowered, in the 1960s, from 21 to 18 for one then participates in the construction of legislature (Woolard and Scott, 350). Educational institutions vary (such as the end of high school or the earning of a bachelor degree) in terms of a child's age and attendance, and what is required by the state.

Juvenile court prosecutes youth below the age of eighteen. This implies that full moral reasoning has developed roughly by age eighteen, and hence adulthood has been attained. Yet many youth today are tried as adults and sentenced to adult prison systems, a practice that is precisely opposite the Progressive intentions in creating the juvenile

112 Just over the border, in Canada, the sexual age of consent is only 16. 
court system. ${ }^{113}$ Guggenheim writes that a "punitive shift" in the past few decades has caused youth to be sentenced as adults, a change not based so much upon their age but by the type of crime. He writes that "more than forty states allow juveniles fourteen or younger to be prosecuted in adult court; at least twelve of these states set no minimum age for transfer" (253). The results of this have been tragic: "juveniles held in adult jails pending trial rose 366 percent between 1983 and $1998 \ldots$.. juveniles in adult facilities are eight times more likely to commit suicide, five times more likely to be sexually assaulted, and twice as likely to be attacked by inmates or staff' (253). In fact, data compiled by the National Criminal Justice Reference Service (www.ncjrs.gov) reveals, for example, that in New York state, a child of thirteen can be tried as an adult in the case of murder via statutory exclusion from juvenile court; in the case of "certain property offenses" a child of fourteen can be excluded. One cannot drink alcohol at age fourteen, but one can be subjected to the horrors of an adult prison system for life. ${ }^{114}$

Hence the societal laws are not definitive about the threshold between adulthood and childhood, as the granting of access to services and rights varies even in the aforementioned, though cursory, examples between thirteen and twenty-one. There is an obvious tendency to emphasize the age of eighteen, yet this implies that before eighteen, a youth is not an adult, and after eighteen, he or she is a full adult. The ability to drive a vehicle before age eighteen, or to be restricted from drinking alcohol three years afterward, indicates the reluctance of greater adult society to entrust autonomy and

113 According to the Campaign for Youth and Justice, "An estimated 250,000 youth are tried, sentenced, or incarcerated as adults every year across the United States." This number is cited from a report by Arya, Neelum in 2011 called, "State Trends: Legislative Victories from 2005 to 2010 Removing Youth from the Adult Criminal Justice System" of Washington, DC and the Campaign for Youth Justice (i.e. selfreferential). Since I cannot verify this statistic, I include it here in this footnote.

114 As an added note, juvenile court functions from the standpoint of reform, whereas adult prison is purely punitive. 
decision-making to youth at precisely age eighteen. (In the face of alcohol, youth are considered heteronomous.) The United Nations Convention on the Rights of a Child, drafted in 1995 (but not signed by the United States due to its stipulation that children cannot be executed or placed in prison for life ${ }^{115}$ ), states in its first Article that "a child means every human being below the age of eighteen years unless, under the law applicable to the child, majority is attained earlier." This would place greater stresses of identity on adolescents between ages of thirteen to seventeen, since they are definitively considered non-adults due to the emphasis on age eighteen.

Similarly, there is no sudden leap when a pre-teen child becomes an adolescent. The beginning of adolescence may be based upon biological conditions, such as the onset of puberty. If one bases one's definition upon the developmental psychology of Jean Piaget (though this is no longer generally utilized as a marker), entry into adolescence turns upon what he called a 'formal operational stage.' This stage refers to the onset of abstract reasoning. This abstract reasoning, though, is not a definitive moment, as it may vary from person to person. However, it typically begins around age twelve. Puberty might be a biological marker but it, too, varies and may be preceded by cognitive changes. Nevertheless, cognitive changes such as formal operations are slowly, increasingly present and do not appear suddenly in a 'leap' at a specific age, such as at age eighteen, like a moth emerging full-grown from a cocoon. In short, legal policies are representative of what Woolard and Scott call an outdated 'binary approach' (368) of parent/child that no longer reflects scientific research in human development.

115 Article 37.A was rejected by the United States: "No child shall be subjected to torture or other cruel, inhuman or degrading treatment or punishment. Neither capital punishment nor life imprisonment without possibility of release shall be imposed for offenses committed by persons below eighteen years of age." 


\section{State Membership: Tacit Consent}

Lock called adulthood, politically, as the age of consent. Since there is no specific moment in which one 'becomes' an adult, it logically follows that there is no such moment in which one 'consents' to be a full member of society. One might assume that this is the case in terms of citizenship and birth. One does not have a choice to become a citizen. Birth gives citizenship automatically without any sworn oaths (as is the case for immigrants). The issue, though, is not so much the citizenship itself but the automatically granted membership in a society with an already-entrenched set of political, economic and legal structures. These exist (and existed) obviously independent of the new member's consent, if not entirely foreign to his or her very being. Schiller illustrates the character of this psychological realization in his third letter of Aesthetic Education:

When man is raised from his slumber in the senses he feels that he is a man; he surveys his surroundings and finds that he is in a state. He was introduced into this state by the power of circumstances, before he could freely select his own position. But as a moral being he cannot possibly rest satisfied with a political condition forced upon him by necessity, and only calculated for that condition; and it would be unfortunate if this did satisfy him. (46)

This realization is the essential beginning imagined within social contract theory. There is natural law, the form of political society that is pre-political and in which one finds oneself participating in terms of the necessities of material conditions and basic human relationships. We 'naturally' transform land, exchange commodities and relate to other humans. The moral shift occurs when he or she imagines an ideal society and takes 
upon himself or herself to transform the initial 'natural' condition. Youth relive this experience, only that the society in which they find themselves is already part of a long process of transformative acts, a 'thing' that is the embodiment of the imaginations of countless other individuals other than himself or herself.

A democracy implies that individuals all have equal power via their vote in deciding the direction of their society. Yet, the political system created democratically may not be acceptable to specific individuals for various reasons. This is more problematic for those as described by Schiller, i.e. every individual who comes of age and possesses moral reasoning. From the perspective of contract theory, one could argue (at least on an ideological level) that at the birth of every child, some kind of referendum could occur upon the existing social, political and economic organization. The interests of this new individual would be focused specifically upon the well-being of the state's debts, the funding of education, wealth-inheritance imbalances, the health of the environment and various other elements of the infant's long-term prospects. Such interests, however, are not represented, save by the segment of the population that are parents of young children (and, assuming, that they are politically active).

Consequently, one might argue that such a referendum should occur when an incoming member of a state reaches the decisive moment of conscious participation (such as the right to vote). In such a moment, the civic body's actions of the past need to be reevaluated in the context of emerging needs, interests and perspectives. (The immigrant, upon naturalization, is characterized as an adult capable of freely and rationally deciding to join himself or herself to the laws and principles of a nation. $)^{116}$ This proposal is

116 Of course, immigrants are not necessarily free, given the range of possibilities that motivated their arrival, such as dangers and duress in their native country, etc. 
obviously absurd in the face of its impossibility within the current population, but it is far easier to imagine if a nation were only composed of one hundred people.

As if to compensate, contract theory makes claim to individuals agreeing in a hypothetical past. John Rawls, for instance, uses a hypothetical situation known as the 'veil of ignorance.' (He asks one to imagine an ideal society without knowing whether or not one is in the best or worst position within that society. Hence, behind this veil of ignorance, one would certainly wish that the worst off in society are happy in case that becomes one's status.) John Locke, one of the founders of contract theory and an ardent defender of individual rights (and a strong influence on the writers of the American Constitution), realized that necessity of consent was a valid challenge to the legitimacy of a social order in its continuity through time as new members continuously appear. This is especially so since he effectively empowered individuals with both natural rights and sovereignty. One cannot ignore the ongoing emergence of new citizenry. He even declares in Two Treatises of Government that, "a Child is born a Subject of no Country or Government" (VIII, 118).

At some moment in the individual's life, then, he or she becomes a citizen and consents to limitations on his or her liberty for the greater good (as well as his or her own). At some point, one also consents to social inequalities, legal protection of corporate environmental destruction and the problematic aspects of American global policies. Since such a moment does not actually occur, Locke offered a simple solution. He argued that members give 'tacit' consent to their political system when they come of age simply through their use of public goods. For Locke, there is no need to have a specific 'moment' in which one makes a formal statement of acceptance. He writes: 
[E]very Man, that hath any Possession, or Enjoyment, of any part of the Dominions of any Government, doth thereby give his tacit Consent, and is as far forth obliged to Obedience to the Laws of that Government (Two Treatises of Government, VIII, 119).

The scenario described by Locke reminds one of a public forum in which the speaker asks the participating members if there are any objections. Silence signifies acceptance. The comparative moment for a continuous political system and new members would be their coming of age. Yet an exact moment at which one comes of age and attains adulthood does not exist—and hence there is also no exact moment in which tacit consent may be presumed. This means that the stage of adolescence implies also that some form of tacit consent is being given all throughout adolescence, which culminates in a full, consenting adulthood.

This point implies that the adolescents' use of goods and services qualifies as some form of consent, even if partial. It is difficult, if not impossible, to define when this becomes an expression of consent, especially given that he or she has no real choice anyway (and since there is no specific moment when he or she becomes an adult). There is no public referendum when teenagers turn eighteen. Therefore, one might argue that during his or her transition from childhood to adulthood, there is a slow erosion of this basic liberal democratic freedom: one ambiguously passes into the realm of adulthood, finding himself or herself, one day, a consenting, complicit member of society and its structures. Hence one ambiguously erodes his or her own consent throughout adolescence as he or she uses public goods, marking the slow loss of the individual's powerful act of political assertion or negation. 
An objection might be raised that tacit consent is a mere fiction of Locke's and other contractualists' conceptions of societal beginning and continuance. This fiction (one might continue in his or her objection), though certainly philosophically intriguing in that it establishes legitimacy for a specific form of liberal government, in no way affects day to day, real-world interactions.

There are many responses to this objection. For example, currently contract theory and natural rights have returned to the fore of political philosophy due to issues surrounding the rights of indigenous peoples. Aboriginal land rights in Australia or Native American land usage in the United States arise from original tensions between colonizer and colonized in that the land was originally in use. China's recent (2015) reclamation of land in the South China Sea exploits the notion that unused land can be claimed, or in this case actual reclamation from the ocean. Land rights and land use ultimately rely upon notions of consent between peoples.

In the case of tacit consent, consent is implied unless some kind of protest occurs from the consent of members of a community to even the failure of resistance of nonmembers. For example, in typical public hearings, or even weddings, there is an invitation for 'naysayers' to speak before final pronouncements; without any utterance, consent is presumed.

There are ideological responses as well that reveal biases in this regard. One might imagine someone oriented towards republican principles who is displeased at the destructive behavior of delinquent juveniles. ${ }^{117}$ This individual might argue that such

117 By 'republican' I mean civic republicanism and not a reference to the current Republican Party. Republicanism in general represents an orientation towards society in which the state is a horizon on which one might unfold fully his or her identity. Liberal theories reject this as too subordinate to the state and instead stress powers within the individual (rights). 
juveniles are unaware of exactly how much society has given them, such as food, shelter and schooling. This is, in fact, referenced by early political thinkers such as Samuel von Pufendorf, in particular in reference to one's parents. ${ }^{118}$ So great is this debt that the only proper response is humble respect and gratitude towards one's superiors and the greater society that has provided these benefits. Such a stance denotes the sense that since one has had "Possession, or Enjoyment" of "the Dominions," then he or she is, in fact, a member. Though consent is never mentioned in such reactionary statements, it is implied in their judgment towards the youth.

Secondly, the notion of complicity raised earlier in the context of masculinity also applies to the question of tacit consent. Males are complicit in the status of females, even if they claim to respect girls and women. If males do not actively resist male privilege, then they are tacitly consenting to the status of females. Complicity, though, could be a dangerous concept in that it may be extended to any social arena, including the justification of ideological acts of terrorism; a terrorist might claim, for example, that all American citizens are complicit in the choices their government has made overseas. Complicity in its nuanced forms indirectly vindicates the notion of tacit consent as a form of negative affirmation. Since no one was protesting 'x,' they tacitly accepted its continuance.

Nevertheless, the absence of any requirement for some form of direct consent

118 "But when a child has clearly departed from the paternal household, and either established a new household of his own, or attached himself to another, the paternal authority is indeed dissolved, but so, however, that the debt of dutifulness and respect always remains, as something founded upon the merits of the parents, which children are never, or very rarely, thought fully to requite. And those merits consist not only in the fact that children owe to parents their lives, the occasion of all blessings, but also because they undertook their laborious and costly education, by which they have molded them into fit members of human society, and often have provided them with the means of passing their lives in comfort and abundance." -The Two Books on the Duty of Man and Citizen according to the Natural Law, III.8. 
from natural-born citizens while immigrants must give such consent reveals a contradiction. If a liberal democracy gains its legitimacy through the consent of the governed wherein sovereignty itself resides, that consent should be explicitly requested from every new generation. (Locke suggested age twenty-one.) Consent reflects the relationship of individual to state. The parent-child dynamic is also problematic in the issue of rights and transition.

\section{Parental Powers vs. The State}

Parents have legal rights over their adolescent children in relationship to the nation-state. This essentially revolves around the concept of property and responsibility. Children have specific rights as individuals that are considered legally to be their property from birth, including their bodies and their minds. However, they are considered incapable of managing this property. It is typical in every society to entrust this care to parents (although some civilizations enable the caring of children to the whole community, not to the nuclear family). Parents, though, may have religious views that endanger their children, such as principles on medicine and sexual orientation. The state may therefore wish to intervene when it considers parents to be detrimental to children. This creates tensions between the state and the (possibly) ideological interests of parents. For example, the efforts of the Progressives in the United States wrested power from parents and enforced both schooling and limits on work hours. Guggenheim writes that parents at the time wanted their children to work at a young age, but today the notion that youth should attend schooling instead of performing full-time work has become part of our value system. 
As an example, the landmark case Wisconsin vs. Yoder (1971) illustrates the limitations on the power adults have in asserting control over education and religious beliefs before the interests of the greater society. The Oyez Project at Chicago-Kent summarizes the case as follows:

Jonas Yoder and Wallace Miller, both members of the Old Order Amish religion, and Adin Yutzy, a member of the Conservative Amish Mennonite Church, were prosecuted under a Wisconsin law that required all children to attend public schools until age 16. The three parents refused to send their children to such schools after the eighth grade, arguing that high school attendance was contrary to their religious beliefs.

The Supreme Court ruled in favor of the parents. This raises several issues. William A. Galston, in his paper entitled, "Parents, Government, Children: Authority over Education in the Liberal Democratic State," argues that such rulings result either in "inadequate weight to the state's interest in fostering good citizens" (229) or the failure of the parent as 'fiduciary' to protect the child's religious freedom. These two issues denote the split between the private authority of the parent over the child versus the public authority of the state over the rights of its emerging citizens in resisting parental control. Galston notes that the children in question in Wisconsin vs. Yoder were in agreement with the decision of their parents. He writes, though, that had the children wished otherwise, the justices fortunately would have been supportive:

[A] number of justices declared that the adolescent children had liberty claims independent of their parents ... At a minimum, the children's freestanding religious claims imply enforceable rights of exit from the boundaries of 
community defined by their parents (227).

The question, however, is at what age a child would be able to explicitly enact such rights. Certainly within the Amish community, it is common for youth to freely decide to not continue to be a part of it. Yet, the ambiguity about the age at which one can enact one's rights is the issue for youth. There is no specific moment in a child's life when he or she is considered legally free to decide on his or her education. Instead, each state determines by statute the age at which a child may exercise his or her freedom to choose or reject education.

A youth, then, is compelled by society to engage in some form of education as a nurturance right. Nurturance rights imply the inability of the child to make the decision for himself or herself. Education may be conceived as a human right of youth, a nurturance right, and as a duty for one to be engaged in civic studies so as to be better citizens of their commonwealth. This latter is an expression of the right of greater society to have civic-minded citizens. In fact, society has entrenched interests in education, such as the development of citizens' ability to be productive, the cultivation of their character to be law-abiding and the expansion of their knowledge such that their voting power is well-informed for the greater good. This is typically discussed from the perspective of the individual as 'duty,' though it could easily be described as above from the perspective of society as 'its' right.

On the other hand, the rights of all individuals in relationship to education ultimately reflect a spiritual-religious (or even artistic) principle regarding their unique faculties and the development of such faculties. There are many qualities in individuals, such as might surface as radical ideas and ideologies that the greater society may not 
wish to foster in its emerging citizens. For example, it is unlikely that a heavily

underfunded public school system would be able to hire an instructor for Marxist economic theory or an existential philosopher for reflections upon authenticity. The

American public who votes and funds the school system might decry the former as unpatriotic and the latter as useless. Yet, it may be within the interest of the individuality of some children to be instructed in such philosophies. A child experiencing issues of religious or cultural content would benefit from studying existentialism; one could certainly wish the youth involved in Wisconsin vs. Yoder were well-educated in diverse forms of religion and sacred practices. (In fact, existential philosophy is particularly popular amongst undergraduates, many still 'technically' adolescents.) There is, therefore, an inherent antagonism between the interests of the individual and the interests of the state in terms of education. For youth in the United States, this is resolved by placing the trust of defending their interest in the hands of their parents, who may also have views that contradict those of their children. ${ }^{119}$ There are parents who also do not value education at all.

To further create barriers to independence in today's youth, there exist labor laws limiting their ability to work. It is paid labor, in fact, that could render youth economically independent of their parents. The Fair Labor Standards Act of 1938 forbade

119 We might note here that a child has, therefore, two sources of possible oppression in his or her life. The state and greater society might create circumstances that limit his or her abilities, such as the aforementioned school system. He or she has no power to influence the state. There are far more concrete examples as well, such as inequalities of race, class and gender. The second source of oppression might arise from parents themselves. The conception of the nuclear family as an independent unit creates power relationships between its various members within this conception of child trusteeship. This was noticeably taken as a key issue with feminist movements in terms of the status of women or any of the female members of a household. It is also an issue with adolescents, since their primary benefactors and caregivers might also be problematic. Even more so, no matter how ideally parents might attempt to comport themselves in relationship to youth, on principle - and principles are the key factor often for the vulnerable developing minds of youth - parents have this latent power of control. This power may be flexed in the realm of finances and inheritance in order to coerce their children. 
'oppressive child labor' of various forms in response to abuses in factories and other settings. Section 31 further states that labor is not oppressive if "such employment is confined to periods which will not interfere with their schooling and to conditions which will not interfere with their health and well-being." Schooling, and education in general, was seen both to discipline juvenile delinquents by giving them regimented classroom attendance as well as to empower them through knowledge. Nevertheless, the requirements of schooling prevent children from earning funds for independence. It is a two-edged sword.

\section{The Parent-Child Power Dynamic}

The contemporary adolescent therefore has an unusual legal and moral relationship with his or her family. It is understood generally that the role of the family is to safeguard its members. This is, supposedly, something that families naturally do, and hence the emphasis in the United States on the nuclear family as an isolated unit. ${ }^{120}$ This unit's internal concerns, 'domestic,' are generally outside the control of the state except in cases of abuse. Even then, a legal finding of abuse still requires reporting and proper prosecution. The aforementioned United Nations Convention declares in Article 18 that "Parents or, as the case may be, legal guardians, have the primary responsibility for the upbringing and development of the child. The best interests of the child will be their basic concern." There is no reference to the capacity of an adolescent and his or her ability to have his or her own best interests within his or her decision making abilities.

Let us consider once again John Locke's conceptions, in particular how he

120 This is an example of the historical use of natural law-that parents care for their children. 
described the roles of adults and children. His early thoughts on contract theory predict the issues we have today. The agent for transitioning children into full citizens, in Locke's scheme, is "naturally" the child's family. The child's sovereign, like a monarch, is the family. This basic notion as clarified by Locke should sound familiar:

Children, I confess, are not born in this full state of Equality, though they are born to it. Their Parents have a sort of Rule and Jurisdiction over them when they come into the World, and for some time after, but 'tis a temporary one" (VI, 55).

For Locke, the child, logically, must have someone else to make decisions for him or her until he or she reaches adulthood. Locke defines adulthood in political terms as the "age of consent." This age of consent is marked by the developing faculty of "Reason."

Locke was not alone in establishing some measure of independence for children. Samuel von Pufendorf, in his 1682 book On the Duty of Man and Citizen, writes that children are bound to parents until specifically leaving the household. From thence, they are bound only 'dutifully.' He writes:

But when a child has clearly departed from the paternal household, and either established a new household of his own, or attached himself to another, the paternal authority is indeed dissolved, but so, however, that the debt of dutifulness and respect always remains, as something founded upon the merits of the parents, which children are never, or very rarely, thought fully to requite. (3.8)

For Pufendorf, the child is still bound to his or her parents so long as he or she remains in the home. Until he or she physically departs from the domicile of the parents, he or she is "bound to respect the commands and recognize the superiority of parents" (3.1). More specifically, the child is bound to the father, not the mother. 
Locke's and Pufendorf's statements seem obvious to contemporary readers because their views have influenced our value system. To illustrate better the issues created by transitioning children away from parental power, consider the opposite ideas of the patriarchalist Sir Robert Filmer in Patriarchia, the principle object of contention throughout Locke's Two Treatises. For Filmer, youth are always bound to their parents, even throughout adulthood. He writes, concluding his Biblical justifications for monarchies: "I see not then how the children of Adam, or of any man else, can be free from subjection to their parents. And this subordination of children is the fountain of all regal authority, by the ordination of God himself. From whence it follows, that civil power, not only in general is by Divine institution" (57). There is no transition from the 'Rule' of parents in Filmer's conception. Even deep into adulthood, one must submit to the will of one's parents. The monarch takes the place of the original parent and hence also has absolute power over his or her citizenry: "This lordship which Adam by creation had over the whole world, and by right descending from him the Patriarchs did enjoy, was as large and ample as the absolutest dominion of any monarch which hath been since the creation" (58)

This relationship of citizen to monarch creates a static chain of power in relationships, both within the home and in the general population. Children are bound to their parents their entire lives; adults are bound to the monarch their entire lives. There is no transition. Even rights are bequeathed by the monarch whose paternal-child relationship guarantees that he (or she) will always act in the best interest of his or her subjects:

If obedience to parents be immediately due by a natural law, and subjection to 
Princes but by the mediation of a human ordinance, what reason is there that the laws of nature should give place to the laws of men, as we see the power of the Father over his child gives place and is subordinate to the power of the magistrate? If we compare the natural duties of a Father with those of a king, we find them all one, without any difference at all but only in the latitude or extent of them. As the Father over one family, so the King, as Father over many families, extends his care to preserve, feed, clothe, instruct and defend the whole commonwealth. His wars, his peace, his courts of justice, and all his acts of sovereignty, tend only to preserve and distribute to every subordinate and inferior Father, and to their children, their rights and privileges, so that all the duties of a King are summed up in a universal fatherly care of his people. (63)

In this model, there is no transition period between dependent childhood and independent adulthood. One is always bound to those above one in what was, throughout Greek antiquity and the Middle Ages, referred to as the Great Chain of Being. Filmer's conception eliminates the ambiguous period in which an adolescent might find himself or herself on the precipice of independence and dependence. We might wonder, then, if adolescent rebellion or angst ever existed in such a stratified, static conception of life.

Once the patriarchal chain is broken with sovereignty returning to the people, two issues emerge. They are, first, who has the power to make political decisions, and second, when that power might appear. Certainly a newborn is incapable of assuming political responsibility. Again using Locke as an example, one might choose to exclude certain members of society who lack the ability to make wise decisions for their own good. These Locke denied power were "Lunaticks and Ideots [sic] . . Children ... Innocents . . 
. Madmen" (VI.60). The well-being of such individuals would be handled by either families or the state, since they are unable to make decisions for their own good, lacking Reason (with a capital 'R'). Such individuals, though, have no bad will towards the public weal. The criminal, on the other hand, "having renounced Reason, the common Rule and Measure," may be even "destroyed as ... one of those Wild Savage Beasts" (II.11).

Unlike 'Lunaticks' and 'Ideots,' children transition when they reach the age of consent. Barbara Arneil makes especial note of this in her 2007 essay, "Citizens, Wives, Latent Citizens and Non-Citizens in the Two Treatises: A Legacy of Inclusion, Exclusion and Assimilation." She refers to pre-adult male individuals in Locke's conception as 'latent' members, unlike those permanently excluded (such as women) at the time of Locke's writing.

\section{Transitions: Rights and Participation}

By proposing that children are born with sovereign rights that then transition into full citizenry, Locke resolved the tension between two key elements he wished to reconcile: one, the notion of rights that cannot be taken away but are given at birth; and two, the preservation of choice and consent when one becomes capable of doing so. In this way, the individual's rights become protected and the state retains its legitimacy.

The United States' political system is an heir to this Lockean resolution. It seems like a flawless method in response to Filmer. Yet, Locke's system (and hence any political system based upon consent and individual sovereignty, as are social contract democracies) creates an ambiguous period during which, not only is the right to refuse 
consent progressively undermined, but the very structures, rights, and values of society are in continuous change for adolescents since the faculty of reason begins its appearance at an earlier age than the rights granted from that faculty's activity. Namely, youth begin at an early age to reason about morality, but the power to make moral decisions about responsibilities such as selecting political leaders comes much later. Our failure to demarcate a specific moment of adulthood with a corresponding process of acceptance of the social status quo creates an unusual difficulty for principled teenagers. They are neither children nor adults. They are not full members of society, yet are somehow slowly consenting to society's political organization. They have inherent rights at birth that are compromised, by some unknown pact, because they are members of a society that they did not choose. This engenders a profound liminal situation, both as an issue of ageidentity and political status.

The root of this problem is in our bestowing of human rights on individuals essentially at birth but not granting full access to those rights in a later, piecemeal, confusing fashion. The physical and biological changes naturally occurring in youth (such as puberty) only serve to exacerbate this phenomenon. A democracy follows the notion that sovereignty resides in the individual, not the state; hence a child lacks the power to express that sovereignty until he or she comes of age to vote. Consent to a political system signifies the giving up of some of one's basic human rights in order to live peacefully together with other individuals, in particular so as to respect the rights of others. For example, the right of freedom of speech is restricted in progressive societies to communication that causes no direct harm to others (such as 'hate speech'). The actual time of consent - the moment when we accept the existing political system - is not clear. 
Without a clear moment of consent, the issue arises as to how one even agrees freely to be a part of a polity.

Furthermore, we should note that limitations on the powers of an adolescent are not based upon his or her rights or non-rights. It is presumed, instead, that adolescents lack the ability to make proper judgments as to their well-being (and also to society's well-being). We do not give someone at the age of twelve the right to vote since we believe that he or she lacks deliberative reason. Similarly, it is held that someone of the age of sixteen lacks the rational control over his or her instincts to properly judge the use and abuse of alcohol, hence the limit of age twenty-one.

The judgments here rest not so much upon vague notions of wisdom or maturity, since adults also rarely display such qualities. Rather, I argue in the next section that they follow from an ingrained notion that youth lack what Locke termed 'Reason.' Locke, like others of his time, believed this to be a 'faculty,' one which differentiated humanity from the brutes. This 'faculty' is at the heart of liberal contract theory since its legitimacy is based upon the notion that a people may decide its best course of social organization only if all are grounded upon something universalizable: Reason. Through a universalizable faculty, a people can come to an agreement and make peaceful decisions together. It also formed the basis of early theories on child development (such as Piaget's).

\section{The Bias for Rationality}

\section{The Faculty of Reason: A Short History}

The emphasis on reason has a long history in the West. Socrates epitomized the dialectical methodology of philosophical questioning and analysis that remains with us 
today. Plato, his student, hypothesized an idealized republic in which philosopher-kings, the most mentally endowed individuals of the state, would be the ones to rule. Poets, both deceitful and havoc-causing through their use of the emotional manipulation of their audience, should be driven out of the nation for its betterment. St. Augustine saw in reason a tool bequeathed by God and meriting development, even if it should submit to faith. Furthering this trend and inspired by the translation of classical texts, medieval scholastic philosophers from Johannes Scotus Eriugena to Thomas Aquinas considered reason as an essential element in dialectical methodologies. It was always a question of reason versus faith, even as the arts-from poetry to music to the plastic arts - slowly established a venerated field independent of reason.

Essayists (the philosophes such as Hume and Hutcheson) writing during the Enlightenment were preoccupied with finding a rational means of establishing civic society independent of (or at least abstracted from) religion, in part inspired by the long history of religious strife throughout medieval and Renaissance Europe - from the Guelph versus Ghibelline to Protestants versus Catholics. This project was furthered by such thinkers as Immanuel Kant in his Critic of Pure Reason and Critique of Practical Reason (and, notably, his essay "What is Enlightenment," in which social debate should be characterized by rational public dialogue); Hegel in his Science of Logic; and many others, all witnessing the slow erosion of the power of monarchies in their time. The nobility's decision-making, no longer ordained by God, needed to be replaced by a universal force common to all humans upon which they could agree peaceably: reason and the rational mind.

'Reason' was a term laden with meaning in the Enlightenment. For example, 
William Uzgalis writes that, in An Essay Concerning Human Understanding, Locke (though pre-Enlightenment) defines Reason as "the discovery of the certainty or probability of such propositions or truths, which the mind arrives at by deduction made from such ideas, as it has got by the use of its natural faculties; viz, by the use of sensation or reflection" $(689, \mathrm{SEP})$. This is not to be confused with the more common term today of 'rationality,' yet the two in their contemporary use are nearly synonymous. Rationality implies the ability to think without undue influence of the emotions. In comparison, 'Reason' was understood as a faculty (like an organ, or even 'mental' organ), more than a mental state, differentiating humans from animals. It required special mention at the time of Locke's writing onward in order to differentiate it from faith as well as to create an eventual foundation for the empirical method. There must exist some form of universalizable faculty that could serve as grounds for all citizens to find agreement. In the case of monarchies, there is no such need; the will and whim of the monarch is absolute. It is the democracy that requires this element to preserve its actions and decisions from what might be considered the instability of human emotionality. It is the realization of Kant's "What is Enlightenment" essay: a society in which issues are discussed in the public realm in a rational, respectful manner instead of violent, emotional protests and overthrows. By the time social contract theory was reinvigorated by Rawls's $A$ Theory of Justice, however, Rawls completely substitutes rationality for reason. The consequence is that individuals that are labeled as irrational can be denied political participation.

In this conception, the rational mind, in order to be capable of independent, objective thought, must rise above the natural demands incurred by bodily base desires 
and emotions. It gives rise to a false dichotomy, namely the distinction between rational autonomy versus emotional heteronomy. ${ }^{121}$ Youth, encased in a growing, emotional body, are irrational. Therefore, they are not capable of moral judgments and are excluded from power in the civic realm. Reason, on the other hand, was initially established in contract theory as a faculty arising from what is fundamentally human. This faculty is present in youth and hence youth merit some assertion of its existence in the form of clearly defined responsibilities.

\section{Two Dichotomies of Freedom and Liberty}

Rationality is admired for its capacity to rise above the influences of emotions. It is therefore perceived as a form of freedom. Freedom, however, can also be defined in relationship to the state. However, one might reverse this relationship and argue that there is freedom from the oppression of ideals, and freedom to be found through civic participation. This creates tension between four poles, namely one's passions vs. ideals, and law vs. civic well-being. To reiterate: the first dichotomy rests in the relationship one has between one's ideals and one's emotions, both demonstrating forms of freedom (Schiller's savage and barbarian exhibit these two poles); the second dichotomy rests in the relationship between restrictions on political liberties versus the conception of the civic realm as a space in which one's liberty unfolds. This dual dichotomy, four-pole tension creates a double layering of ambiguity, one at the heart of social debates such as welfare for the poor and gun control, or personal moral struggles, such as pressure to

121 We might wonder to what extent there still exists this subtle bias towards the rational mind as that which supposedly embodies the best of the human spirit despite the cruelty enacted by the most rationally devised methodologies of National Socialism in World War II and the subsequent postmodern reaction. 
drive one's career versus the capacity to enjoy the everyday. (Note that not all will experience this 'space' in that some will take ideological stances on social and moral issues.)

It also creates a model for understanding youth. They are placed into the position of extremes in these four poles initially (pre-teen), namely as irrational and barred from political power. Their liminality arises in the confused negotiation between their capacity to live out their ideals, the obstructions created by society that prevent their ability to participate politically, their desire to fully explore their emotions and the belief that the world can be transformed into a better place.

In Isaiah Berlin's famous 1958 lecture, Two Concepts of Liberty, he only recognizes two of the aforementioned poles. However, his definitions of those two are precise, calling them 'positive' and the 'negative.' Writing before the advent of postmodernism yet well into the aftermath of World War II, his ideas reflect the fundamental issues at stake with the notion of freedom within the context of reason: negative freedom is defined by outside interference, or the extent to which society of other individuals interfere with one's capacity to act; positive freedom is defined by inner freedom from base emotions. Typically, freedom within the political sphere is considered 'liberty' as opposed to freedom, whereas freedom from the effect of emotions and instincts is in fact labeled as 'freedom.' Berlin, aware of this distinction, nevertheless uses the terms interchangeably. Positive liberty relates to one's ability to master himself or herself:

The 'positive' sense of the word 'liberty' derives from the wish on the part of the individual to be his own master. I wish my life and decisions to depend on myself, 
not on external forces of whatever kind. I wish to be the instrument of my own, not of other men's, acts of will. I wish to be a subject, not an object; to be moved by reasons, by conscious purposes, which are my own, not by causes which affect me, as it were, from the outside. (131)

Negative freedom he defines as one's relationship to external controls. These are practical obstacles. State restrictions on one's access to public space; the encroachment of one individual upon another's person and property; legally justified limitations on one's ability to vote; and institutional barriers to one's advancement all constitute negative liberties.

These two forms of liberty create a tension between one's ability to uphold an ideal of himself or herself (positive freedom) versus how this ideal is realized in political structures. For example, there may be limitations imposed upon someone based on his or her race or gender, when in fact such limitations are not justified by reason. I may have succeeded in expressing my goals of positive freedom, defining myself as a rational agent. However, if the state restricts my ability to vote, then this negative freedom would not correspond to my faculty and abilities. Therefore in Berlin's model there exists a balance between the acceptance of external controls of society and the capacity of an individual to find within himself or herself the ability to master his or her life. The tensions that might exist between the individual and the state would appear to the extent that the state has not realized the ideals of its best-reasoning citizens.

However, one could define negative freedom instead as the capacity to live an unobstructed life of imagination and emotions, free of rational control and limitations, creating a pole opposite rationality. Freedom from an 'inner' perspective signifies not just 
the power of the mind over emotions but the ability to be free of rationalized, arid ideals. Schiller, in fact, established this dichotomy in his Letters, decrying that the barbarianthe overly rational agent — does violence to his or her feelings.

This split could find its counterpart in the need to balance external (negative) liberties, e.g to establish a pole between restrictions on liberty versus the unfolding of well-being in the civic realm. There are times when one relinquishes freedoms for the common good. For example, in the United States, there exists the right to freedom of speech. However, this must not be practiced in a fashion that is hurtful of others. The consequence is that certain forms of speech are classified as 'hate speech.' The contemporary civic individual must learn to balance where freedom should be given up for the sake of the betterment of others.

In this model there would be two different sources of dialectical tensions. Internal freedom would be a balancing act between emotional experience and rational ideals. Their mediation, referred to by Schiller as the play instinct (as discussed earlier with respect to masculinity), gives birth to an individual's nuanced perception of the human personality. The second tension, the external, is a question of civic liberties, balancing one's power to act freely versus its transgression and harm towards others. This, too, results in a balance. The two emerging balances then establish a third relationship where civic activity and human dialogue take place. Even though such a conception begins with a dichotomy, it overcomes it.

One of the consequences of valuing emotional expression would be an appreciation of those who are perceived as not having the ability to dominate their emotions. This would result in an appreciation of the contribution of adolescents, instead 
of perceiving them as deficient because they are imagined to be irrational. The consequence, though, of failing to value emotional expression is to denigrate it as heteronymous. The 'higher' self becomes the rational. Berlin describes this as part of the heritage of Western philosophy:

This dominant self is then variously identified with reason, with my 'higher nature,' with the self which calculates and aims at what will satisfy it in the long run, with my 'real' or 'ideal' or 'autonomous' self, or with my self 'at its best'; which is then contrasted with irrational impulse, uncontrolled desires, my 'lower' nature, the pursuit of immediate pleasures, my 'empirical' or 'heteronomous' self, swept by every gust of desire and passion, needing to be rigidly disciplined if it is ever to rise to the full height of its 'real' nature. (132)

Berlin also reveals the tendency to equate reason with rationality as the two terms appear nearly interchangeable above.

Once women and minorities were considered to belong to the irrational, denying them full humanity as compared to males. Similarly, adolescents are labeled as irrational and incapable of moral decision-making. The youth that are sent to adult prisons at age fifteen are not considered rational agents but irredeemably heteronymous and immoral.

\section{Psychology's Early Bias and the Ethics of Care}

Contemporary policy regarding adolescents is still shaped by this bias towards rationality, despite the emergence of alternative valuations of the relationship between emotion and reason. In part, this reflects psychology's inheritance of the bias for rationality. Psychoanalysis sought to use the dialectical method in the form of 
communication between the therapist and patient. Freud's expectation was that the therapist, in effect, would serve as surrogate for reason and that discourse itself would illuminate and dominate the suppressed emotions. Words could allow distancing from the emotional and primitive realm of dreams and the imagination.

The editors of the Handbook of Adolescent Psychology write that the professional study of adolescence occurred in three principle phases. The first featured a typical Cartesian split between mind and body, characterized by the work of Hall (1904) until the 1960s. The second phase was then marked by a "focus on individual $\leftrightarrow$ context relations" and "dynamic developmental systems model" (4), inspired by the challenges to false dichotomies by postmodern theory. Its third phase, currently active, seeks to uphold the fundamental question as to what constitutes PYD and hence is deeply "applied" (practical) in nature. Even though science is in this current phase, public policy and school curriculums tend towards outdated, Cartesian notions of human development (Smetana and Villalobos, 221).

Jean Piaget, the first to study developmental stages from the perspective of how they manifest as thinking, was also influenced by the conception of the relationship between reason and emotion. He characterized the 'formal operational stage' of adolescence as a period when abstract reasoning replaces the reliance on 'concrete' objects and instances. This results in the ability to analyze hypothetical situations. Piaget's tendencies to view thinking from the perspective of both reason and political thinking are typified in his book The Moral Judgment of the Child. Observing the ways in which children responded to the social aspects of specially constructed games, he writes: ... what shows most clearly that the autonomy achieved during this stage leads 
more surely to respect for rules than the heteronomy of the preceding state is the truly political and democratic way in which children 12-13 distinguish lawless whims from constitutional innovation. (71)

Piaget inherited the general bias towards rational thought. Lawrence Kohlberg furthered Piaget's work by positing development based upon moral reasoning. Children tend to be in a stage known as 'pre-conventional' in which one's actions were in response to external enforcement or self-interest, i.e. negative liberty and heteronomy. The Conventional stage, one in which obedience to the law might be characteristic, may well typify a pre-adolescent child respecting authority. Most relevant are Kohlberg's highest stages of development, referred to as 'post-conventional,' in which the individual bases his or her actions on abstract principles such as rights. This naturally leads to notions of justice. The emphasis on abstraction, instead of other possible realms of human existence (discussed below), places his works within the same Western tendency visible in Piaget.

These two thinkers, though, are no longer considered accurate by contemporary scientific thinking and experimentation. Nevertheless, their influence remains. Rawls' $A$ Theory of Justice, renowned for having breathed new life into social contract theory, features moral stages directly influenced by Piaget and Kohlberg. For Rawls, the sense of justice cannot arise until a person passes from what he refers to as stages one and two (morality of authority and association) to stage three, a morality based upon principles. These principles are of course rationally determined. He writes, for example, in $A$ Theory of Justice, that "the child lacks the concept of justification altogether, this being acquired much later. Therefore, he cannot with reason doubt the propriety of parental injunctions (463)." 
Only recently has this bias towards rationality been contested, notably in such works as Carol Gilligan's 1982 book In a Different Voice, which launched a whole philosophical movement for the ethics of care, including the writings of feminists such as Virginia Held (1993) and Sarah Ruddick (1989). Care ethics in general challenged the Western bias toward individualist ethics of autonomy, arguing that there has never been a grounds properly created for justifying compassionate behavior towards other individuals. Compassion and empathy are not based upon rationally justified principles. They are born from emotion and an active stance of 'responsivity.' They preclude thought and principles; where there is need, the compassionate person acts. For example, Eva Kittay used her experience with her daughter Sesha, born with intellectual disabilities, to reveal the various forms of spontaneous communication, thinking and care far beyond rational deliberation and rationalized morality. ${ }^{122}$ Furthermore, such caregiving is everpresent for the human species, even if ignored by contract theories based upon the rational mind. We are born dependent and will most likely end our lives in dependency. (Virtue ethics as proposed by Alasdair Macintyre in his 1999 book Dependent Rational Animals, though still emphasizing reason, upheld interactions and empathy within an Aristotelian framework.) ${ }^{123}$

Despite this challenge to child development, the political status of an adolescent

122 On a personal note, I was fortunate to attend a seminar on the ethics of care with Dr. Kittay while attending Stony Brook University's Manhattan program.

123 Psychologists sought to test Gilligan's claims and concluded that they were not possible to confirm in practice. For example, Smetana and Villalobos write in the Handbook that "extensive reviews, as well as a meta-analysis of 80 studies that included males' and females' moral reasoning ... have provided little support for Gilligan's claims. These reviews have revealed few sex differences in moral stages" (189). The tests, therefore, attempted to discern whether or not females reasoned morally in a different fashion than males. What the psychologists did not test, though, is whether or not some males might reason according to the principles that Gilligan set forth. In other words, the researchers could have bypassed the gender restriction (suggested by Gilligan) and expanded their understanding of human empathy and responsive care as another form of moral reasoning open to either gender. Instead, Gilligan was debunked and moral reasoning returned to its usual parameters of understanding. 
remains relatively unchanged in the past seventy-five years, even as Steinberg admits the importance of neuroscience in informing public opinion. The Progressives acted compassionately for all children but assumed that adolescents were too irrational to make their own decisions. The Children's Rights Movement, and such works as John Holt's 1974 declaration "Liberate Children"- in which he states emphatically that "the rights, privileges, duties, responsibilities of adult citizens be made available to any young person, of whatever age, who wants to make use of them" (84-85)—remain exceptions whose influence has only enabled further incarceration of youth in adult prisons by overemphasizing agency (Guggenheim).

Adolescents still exist in a politically dubious state. Unlike marginalized adults who are able to band together over time for sustained efforts to uphold a vested interest, adolescents only briefly belong to a transitional group. In a short time, they become adults, and might quickly distance themselves from their former concerns with the arrival of new personal challenges.

In summary, the adolescent is split into two persons in his or her relationship to the political system and to his or her own self. One is an emerging adult, bound by laws; the other is still a child and bound by the rule of the family. While the former gains legal power and full participation in the nation's political system, he or she loses the power to actually openly consent to that participation. The latter, the child, actually represents the preservation of that natural right, though bound by the family. In terms of development, the onset of adolescence signifies the birth of thinking based upon principles. Yet, adolescents' brains are still developing, signifying a tendency to exaggerate some emotional responses to those ideals. 
This creates the curious issues of independence and sovereignty at the heart of adolescents' the claims. He or she wishes for independence and power, yet the total acceptance of such responsibility disempowers his or her choice to enter society. Likewise, the adolescent is faced with the tension between being bound by the power of the family (as the status of a child) and the inherent lack of power that this indicates. It is, in this sense, a double loss of power, and his or her process of aging enables the tacit consent that then binds him or her to the commonwealth in which he or she will become an adult. The loss of consent is the loss of an initial right received at birth.

This leaves an adolescent with few 'choices' by which to express his or her free political will and human rights. Should a child be psychologically well-assimilated, perhaps from an ideal upbringing coupled with other fortuitous circumstances (parents happy in their marriage, economic well-being, a safe community and positive peer influences), this transition may proceed without issue. The loss of power may be acceptable since the adolescent identifies with the greater political system, as this system has brought about wealth and well-being. Likewise, parenting may be successful, in that parents are aware of the challenges of the adolescent's emergent full individuality and respect his or her needs for self-rule.

Not surprisingly, proper child rearing is essential for Locke, keenly aware of the contradictions his principles had created while not specifically aware of adolescence as a time period of note. His letters to a friend on this subject (Some Thoughts Concerning Education, 1693) eventually became published and an important aspect of his philosophy. Adolescent rebellion reveals that perfect parenting is not sufficient. Despite efforts by psychologists to witness in such rebellion a form of pathology, it is the 
inevitable result of the contradiction of liberal contract theory when transitional ages, powers and choices are not clearly and consistently demarcated. ${ }^{124}$

The adolescent rule-breaker is one of the common tropes of the past century. In fact, it was juvenile delinquency that inspired Hall's work. Unlike the criminal who, according to Locke, is someone who lacks reason and acts with a bad will towards society, the rebel adolescent finds his or her motivating element precisely in principles. The rebellious adolescent acts out of the need to assert his or her liberty in the face of two binding worlds. It is the adolescent's growing capacity to reason (if it is reason that we accept as a moral marker) that drives him or her to react to civil society, for it is the one area of his or her life denied him or her - the capacity to fully participate with his or her reason—until civil society grants his or her status as having reached adulthood. ${ }^{125}$ The thinking, moral faculty is active in youth.

\section{Consumption and Possessive Individualism}

\section{Introduction}

One of the socially problematic aspects of graffiti is its property vandalism. The youth behave as if the property targeted by their writing is, using the terms of social contract theory, part of an original unused commons before the advent of monetary exchange. In Locke's conception of the ethical use of land, one may transform it through

124 Rebellion may also be interpreted as the healthy expression of independence.

125 Not all adolescents rebel; some do precisely the opposite. The reverse possibility is analyzed by Michael A. Slote in his book section "Obedience and Illusions" from the edited collection Having Children (1967). Locke's aforementioned statement that children, when young, long to be governed by their parents is the source for Slote's fundamental claim, namely that once adults, the longing to be governed may still exist. In other words, it is not freedom that asserts itself, but irrationality and the desire to not assume the responsibility of freedom. In short, the adolescent remains comfortable with bondage. This accords with Locke's concern of the paterfamilia and the natural tendency of people to submit to monarchs. 
his or her labor, so long as enough is left for others. The main issue is that one's toils may result in spoilage (such as generating too many farm products). Locke resolves this spoilage conundrum through the exchange of money. The result, though, is the ethical justification of hoarding (as it arises from one's hard work in transforming unused land) and the inevitable stratification of society through inheritance. This stratification faces youth, who may reject the social structures that justified it. Their rejection is therefore to revert to a pre-Lockean world and make claim to any land (property) through the practice of graffiti.

The existence of monetary exchange, and its incarnation in consumer culture, is itself a force in a child's life. A child, while maturing, is frequently faced with the simple matter that some children (even peers) belong to families with vastly superior means than others. One child's family is able to procure the best education, clothing and health care. Another child's family requires him or her to work part time to assist in the financial well-being of the household. The child witnessing this is heir to this stratification as a consenting citizen.

This is a simplistic way of describing one of the reasons why early analyses of youth subcultures used sophisticated applications of Marxist philosophy as their basis. In the Marxian model, the subculture arises through identification and imitation of the poor. Dick Hebdige, for example, argues in Subculture: The Meaning of Style that mods (1960s) were inspired by an impoverished immigrant community (West Indians): "The mods were the first in a long line of working-class youth cultures which grew up around the West Indians, responded positively to their presence and sought to emulate their style" (52). The appearance of rebellious youth in collective groups such as youth 
subcultures was inspired partly by imitating working class and minority culture, especially because it was understood (or presumed) that the youth themselves were of a similar economic class.

Nevertheless, contemporary economic practices (such as the version of Capitalism currently practiced in the United States) rest upon a basic system of values in which labor and goods might be exchanged for money. This raises the question as to whether or not money and human rights have a direct relationship. Here, too, Locke is enlightening. In Locke's Two Treatises, money occupies a special status in the effects it creates upon how human rights are practiced. Even though this is unique to John Locke' conception, this relationship arises from Locke's intuitive assessment of the early forms of capitalism, labor and private property. Unlike the earlier discussions of masculinity in the context of specific changes in the twentieth century, particularly with respect to the rise of the citizen consumers and issues of industrialization and labor, here I make a claim to a more philosophical argument about how rights and money might affect the orientation of youth.

\section{Locke and the Consequences of Money upon Natural Rights}

The existence of money, its inheritance and the eventual problematic stratification of society facing youth today (along with the loss of consent) required justification from early social contract thinkers. Locke created a solution for the inequality of possessions by conceiving of how one might first morally transform land and then, in the event of excess, hoard money.

Locke is typically perceived as defending personal rights and private property, as 
well as defending the public use of the commons against its usurpation by individuals or the state. This begins with his imaginary model of humans transforming the world around them through industrious labor. There are no limits to what one may transform, for the simple fact that excessive production will spoil: "As much as any one can make use of to any advantage of life before it spoils; so much he may by his labour fix a Property in. Whatever is beyond this, is more than his share, and belongs to others" $(290) .{ }^{126}$ This famous 'spoilage' rule is a naturally limiting factor and represents the way in which natural law limits natural rights. One might lay claim to a plot of land in order to grow vast amounts of food. However, the labor expended in transforming that land will mostly go to waste. One can only consume a limited amount of food.

According to Locke, barter naturally emerges as a means to offset this waste and loss, trading what one is able to produce for goods produced by others. Here, then, is the first instance in which one begins to produce beyond what would normally spoil, in violation of the basic tenets of natural law. It is not, though, an egregious situation according to Locke:

[I]f he would give his Nuts for a piece of Metal, pleased with its colour; or exchange his Sheep for Shells, or Wool for a sparkling Pebble or Diamond, and keep those by him all his Life, he invaded not the Right of others, he might heap up as much of these durable things as he pleased; the exceeding of the bounds of his just Property not lying in the largeness of his Possession, but the perishing of any thing uselessly in it. (300)

126 In today's English, he means to say that goods, or land, spoil if not used. If someone works on a section of land, such as a farmer planting crops, he or she 'fixes' his or her labor into the land and hence makes it his or her property. Anything more than what he or she needs would spoil anyway and 'belongs to others.' 
The caveat that Locke suggests here is that the just hording of the fruits of labor exhibits two characteristics. First, the hoarder does not violate the rights of others. The productions of his or her land are traded freely. Secondly, the aim, or even result, of one's trading for goods ought to be the preservation of labor already expended. Instead of allowing his or her goods to perish, he or she freely trades it with another individual for some "shells." The image is similar to an amiable farmer, wishing to cultivate a fancy for shiny objects in exchange for goods from the farm that would spoil unethically. Even in this instance, there are natural limits to the extent in which one might barter, since it relies upon the direct exchange of one good for another.

What transforms this basic relationship is the advent of money. One might now produce massively in excess but prevent spoilage through the exchange of perishables for currency. He writes, "And thus came in the use of Money, some lasting thing that men might keep without spoiling, and that by mutual consent Men would take in exchange for the truly useful, but perishable Supports of life" (300). It is important in Locke's conception that people have agreed 'by mutual consent' to allow for its existence. In fact, the 'original' relationship of limited production due to spoilage slowly passes through stages of transformation, first as barter and then money, in order to justify ethically overproduction and exchange. Not surprisingly, Locke concludes that

[I]t is plain, that Men have agreed to disproportionate and unequal Possession of the Earth, they having by tacit and voluntary consent found out a way, how a man may fairly possess more land than he himself can use the product of, by receiving in exchange for the surplus, Gold and Silver, which may be hoarded up without injury to any one. (302) 
Implicit in Locke's conception is the idea that one is able to horde property through hard work. More so, Locke even implies that the wealthy merit their possessions whereas the poor merit the lack of property. He writes, "God gave the World to Men in Common ... to the use of the Industrious and Rational ... not to the Fancy or Covetousness of the Quarrelsom [sic] and Contentious" (291). The "Quarrelsom," having agreed to the use of money, find themselves in a position of difficulty. The appropriation of land in Locke's England results in a "strain" (293) on the people since, even though "there is Land enough in the World to suffice double the Inhabitants" (293), what land exists lies under someone's possession.

Perhaps those owners are the descendants of an original hard-laboring ancestor, or perhaps they transformed it themselves and were able to sustain its production through monetary exchange. In whatever the case, the advent of money creates an issue in regards to rights. In the pursuit of life, liberty and property, one must have access to the means to basic survival. The appropriation of land by the 'industrious' tramples the rights of those who can no longer access it (what Locke refers to as "enough, and as good left in common for others" (288). C.B. Macpherson, in his book The Political Theory of Possessive Individualism, writes that "The introduction of money by tacit consent has removed the previous limitations of rightful appropriation, and in so doing has invalidated the natural provision that everyone should have as much as he could make use of" (204). Moreover, Macpherson argues that by labeling the producers as "industrious and rational," Locke gave them a moral status of superiority. In Locke's The Reasonableness of Christianity, Macpherson argues that Locke assumes "that the members of the labouring class are in too low a position to be capable of a rational life- 
that is, capable of regulating their lives by those moral principles Locke supposed were given by reason" (224). The two combine to justify morally the stratification of society between irrational, quarrelsome poor laborers and a landed gentry.

Though these thoughts are specific to Locke, the question remains as to whether or not they might be indicative of society's values today. For example, Max Weber argues in The Protestant Ethic and the Spirit of Capitalism that a moral view of labor and accumulated enterprise arose with the emergence of Calvinism. This ethic still informs our society and its social policies today. There exists today, despite efforts of sociologists, psychologists and humanists, the enduring tendency in American society to view the poor as simply not having labored hard enough. What appears early in Locke's thought is still present in American society. ${ }^{127}$

More importantly, this subtle orientation and value system may be an important influence on youth. The unequal distribution of land and property greets the burgeoning mind of the adolescent. He or she is also faced with the notion of consenting to what appears as an unjust relationship in which so many, including, possibly, themselves, are excluded from access to goods. This is one of the possible reasons that youth engage in property vandalism. The defacement of property — any property—appears to represent an act of defiance against what is commonly presented as the most basic natural right of society: the sanctity of property required for the pursuit of happiness. But this interpretation ignores the fundamental limits on access to goods made possible by money, which once did not exist in a presumed natural state. The state of nature is assumed anew by adolescent vandals, in effect negating the power of monetary exchange and property.

127 We might note that there has been a neo-conservative effort to enforce the view of poverty and laziness. 
Hence the act is not necessarily mere delinquency but instead one that emerges in the face of the deeper role of money and property limitations.

This is one such way to confront the loss of consent, the power of property and the money culture used to justify its distribution, and the confusion of basic rights. There are other logical ways as well. Interestingly, these, too, were initiated by adolescents.

\section{E. The Case of 5Pointz}

The debate over graffiti's protection as a form of property came to the fore recently for the New York property complex known in graffiti lore as 5Pointz. Since 1993 it was a site for the production of graffiti masterpieces. The owners of the complex planned for its demolition but faced a legal attempt by graffiti enthusiasts to prevent it. The case is illuminating in that the various conceptions of rights, from society at large (embodied in the final judgment and the owners of the complex) to that of the graffiti community, are demonstrated. The defenders of graffiti sought to protect the graffiti art in the 5Pointz complex as a work of art to be protected under the Visual Rights Act, arguing for its specific historical and international importance. The buildings' owners invoked basic property rights over the structures themselves, and won.

The nearly 200,000 square-feet of various abandoned buildings in the complex of

5Pointz had served since 1993 as a legal 'mecca' for graffiti artists from around the world. In 2013, the owners decided that their well-located real estate could be better used if developed into affordable housing, sparking a strong reaction from the graffiti community. Its destruction would represent the loss of an important (if not iconic) 
landmark in graffiti history. Even more so, its elimination would be a blow to the creative rights of graffiti artists, which they argued were protected under the Visual Arts Rights

Act.

Seventeen artists attempted a legal action to halt the destruction of 5Pointz, filing a complaint (VARA 10102013) on October 8, 2013. The plaintiffs ${ }^{128}$ argued in C.37 $7^{129}$

that the 350 works of graffiti therein were 'works of recognized stature' and hence merited protection under the Visual Arts Rights Act of $1990 .{ }^{130}$ Wording within the document deliberately mirrored that of the Visual Artists Rights Act's defense of artwork. For example, the leading plaintiff, Jonathan Cohen, curator and founder of the location as well as one of its numerous artists, argued that his work 'Drunken Bulbs' was "incorporated in and made part of 5Pointz in such a way that removing it, or any part

128 Jonathan Cohen, Sandra Fabara, Stephen Ebert, Luis Lamboy, EstebanDel Valle, Rodrigo Henter de Rezende, Danielle Mastrion, William Tramontozzi, Jr.,Thomas Lucero, Akiko Miyakami, Christian Cortes, Dustin Spagnola, Alice Mizrachi,Carlos Game, James Rocco, Steven Lew and Francisco Fernandez

129 C.37 refers to the exact location of the quote within the legal document.

130 Here is a reprint of the pertinent wording of the legal code: U.S. Code $\S 106 \mathrm{~A}$ - Rights of certain authors to attribution and integrity. (a) Rights of Attribution and Integrity- Subject to section 107 and independent of the exclusive rights provided in section 106, the author of a work of visual art(1) shall have the right- (A) to claim authorship of that work, and (B) to prevent the use of his or her name as the author of any work of visual art which he or she did not create; (2) shall have the right to prevent the use of his or her name as the author of the work of visual art in the event of a distortion, mutilation, or other modification of the work which would be prejudicial to his or her honor or reputation; and (3) subject to the limitations set forth in section 113 (d), shall have the right - (A) to prevent any intentional distortion, mutilation, or other modification of that work which would be prejudicial to his or her honor or reputation, and any intentional distortion, mutilation, or modification of that work is a violation of that right, and (B) to prevent any destruction of a work of recognized stature, and any intentional or grossly negligent destruction of that work is a violation of that right. (b) Scope and Exercise of Rights. - Only the author of a work of visual art has the rights conferred by subsection (a) in that work, whether or not the author is the copyright owner. The authors of a joint work of visual art are co-owners of the rights conferred by subsection (a) in that work.

(c) Exceptions. - (1) The modification of a work of visual art which is a result of the passage of time or the inherent nature of the materials is not a distortion, mutilation, or other modification described in subsection (a)(3)(A). (2) The modification of a work of visual art which is the result of conservation, or of the public presentation, including lighting and placement, of the work is not a destruction, distortion, mutilation, or other modification described in subsection (a)(3) unless the modification is caused by gross negligence. (3) The rights described in paragraphs (1) and (2) of subsection (a) shall not apply to any reproduction, depiction, portrayal, or other use of a work in, upon, or in any connection with any item described in sub-paragraph (A) or (B) of the definition of "work of visual art" in section 101, and any such reproduction, depiction, portrayal, or other use of a work is not a destruction, distortion, mutilation, or other modification described in paragraph (3) of subsection (a) 
thereof, from 5Pointz would cause its destruction, distortion, mutilation or modification" (C. 70-71).

For the plaintiffs, destroying 5Pointz hence violated copyright law. They specifically invoked 17 U.S.C. $\S 101$ for their productions' status as works of art of stature and 17 U.S.C. $§ 106 A(d)(3)$ for their right to prevent the destruction of their art. 'Stature' is especially important since there had already been precedence in which other graffiti writers attempted to sue for the preservation of their art under VARA but failed. For example, in the case entitled English v. BFC\&R East 11th Street LLC, $1997^{131}$ featured several artists and sculptors who attempted to preserve their works in a playground before the area was to be developed by the city. The artists lost their case both because the work had been created illegally and because it was not considered of any relevant stature.

Unlike the defenders of the artwork in the playground, the plaintiffs of 5Pointz hoped that their situation was unique. The world-renowned stature of the location was well-established. Regarding the latter, the plaintiffs' VARA complaint demonstrated that 5Pointz was listed in every major guidebook covering New York City, and was included in over 100 international travel guides as well (section 59). As further evidence, the Plaintiffs claimed that in any given week, hundreds of tourists from all around the world visited 5Pointz to see the works of visual art displayed there. The attempt to preserve 5Pointz on the basis of its architectural and artistic stature failed. According to a November 2013 New York Times article entitled "Night Falls, and 5Pointz, a Graffiti Mecca, Is Whited Out in Queens," the Landmarks Preservation Commission ruled that "the buildings lacked architectural distinction and the artwork was less than 30 years old .. The City Council approved Mr. Wolkoff's plan, and this month a federal judge ruled

131 WL 746444 
against the 5Pointz group." In short, the buildings themselves were deemed not worth keeping, since they were recently erected industrial structures. The artwork, since it was recently made, could not qualify for the kind of defense employed by the Landmarks Preservation Commission.

Defenders of 5Pointz also argued that the site should be preserved because, unlike other instances in which graffiti artists sought to assert VAWA rights, the works at 5Pointz had been created legally. According to the plaintiffs, the building owner, Gerald Wolkoff, and his management company, G\&M Realty L.P., had given permission to the artists to make their graffiti therein. This second argument was countered, however, by Wolkoff's statement that he had informed the writers of his eventual intention to demolish the buildings even as he gave them consent to utilize the structures. It is for this last reason that the attempted defense of 5Pointz was doomed to fail. Illegal graffiti is protected by copyright laws for its content, not its actual physical existence. An owner of a vandalized building has the right to modify his or her property by removing the graffiti. Even though the 5Pointz artwork was legally made, its preservation was not considered intrinsic to the art's essential qualities (graffiti and murals are transient art) and the owner had informed them of the location's eventual fate from the beginning. As the maker of an intellectual and creative production, the graffiti writer has the right to authorship of the form itself. Namely, the graffiti image (composition) remains his or her property, even if the object itself is not. Hence, the owner of a vandalized structure would not be able to take images of the illegal graffiti and sell them on sweatshirts, even if he or she has the right to buff them into oblivion. In this way, Wolkoff did not violate the rights of the artists, since he merely destroyed the shell of their art. 
One might consider that the lesson of 5Pointz and other similar rulings is the resultant stance on the key issue of rights in the context of the graffiti community. The graffiti makers are protected based on their rights as artists for the creative content of their work, even if the actual production is illegal. This protection is referenced globally as part of the Universal Declaration of Human Rights, adopted in 1948 by the United Nations, in Article 27, section 2. It states that everyone "has the right to the protection of the moral and material interests resulting from any scientific, literary or artistic production of which he is the author." It is a split over property: the form of the art remains the creators' intellectual property, whereas the location is the property of its owner.

5Pointz demonstrates the ways in which property and rights are held in the graffiti community. They believe that art reclaims property and hence could ultimately invalid the existing property owner's rights, especially for exemplary works such as finely created masterpieces. SABER's 1997 Los Angeles River artwork, according to the site ArtNowSF was "a colossal masterpiece measuring 250 x 55 feet - nearly the size of a football field" with "97 gallons of paint." The work, "visible from satellite," was created on the concrete sides of an area that was a neglected city space. Nevertheless, it was buffed in 2009 on the simple basis of its illegality.

What remains for the rights of youth within graffiti is the essential issue of ambiguity. Graffiti is not legal unless commissioned. Hence, the creation of graffiti remains an expression of the ambiguity itself and the rejection of tacit consent. In fact, its illegality, cemented by the landmark 5Pointz battle, enforces this stance, since it means that the production of graffiti deliberately rejects property rights. Graffiti, however, is one 
of many responses to the issues of rights.

\section{F. Adolescent Response: Weapons of the Weak}

\section{Youth Subculture as Free Consent}

In order to challenge the loss of consent in joining mainstream society, youth have created a vast variety of youth subcultures. The members of these subcultures, unlike their tacit consent to mainstream culture, perceive it as an empowering form of consciously, freely chosen membership. The support and containment of the nuclear family becomes partially exchanged for the support and containment of this new group with which they identify. Containment, in fact, is part of a youth subculture; the codes of groups are highly regimented. The strictness of the codes denote that strictness and discipline are themselves not the issues youth have with mainstream society. It is consent, and hence consent to a different set of strictures is acceptable. Also, in order to escape liminality, the youth exchange ambiguity and the challenge to conventional morality for a static set of codes.

The strictness and conformity of subcultures might come as a surprise in their appeal to youth. Graffiti, for example, strictly does not allow a member to paint over another member's production and even uses the denigrating term 'toy' to refer to such ignorant practitioners. Clothing, style, and speech are all clearly delineated, if not regimented, as a form of explicit performance and conditional membership of all youth subcultures. Though these are obviously restricting, the adolescent does not perceive this to be the case since he or she has selected freely to join. In short, the subculture mirrors the choice an adult makes when giving up certain freedoms to join civic society, whether 
it is a suit and tie, traffic laws or the ways in which one cares for personal property.

The birth of youth subcultures corresponds exactly to the same time period as the birth of the professional study of adolescence. Youth subcultures, historically, include Bohemians, Dandies, ${ }^{132}$ Wandervogels, Hippies, Punks, Goths, Surfers, Hip-Hoppers, and, of course, Graffiti. Perhaps this was due to urbanization, since cities created conditions in which youth came heavily into contact with one another. They hence sought both alliances and commonality as well as some means to define their individuality in the face of the emerging, dehumanizing technolopolis.

\section{Property and Vandalism}

Natural rights were historically invoked in relationship to both political power and property. One entered society to have these rights protected better than if they were to remain in a state of nature. Locke, for example, states very clearly and emphatically that the "great and chief end ... of Mens uniting into Commonwealths, and putting themselves under Government, is the Preservation of their Property" (IX, 124) which he defines later as "Lives, Liberties, and Estates" (IX, 123).

Of these three, the third, 'Estates,' is of particular prominence in the thought of Locke and, one might argue, for Western adolescents. ${ }^{133}$ Contract theorists struggle with

132 No doubt it is a stretch to consider dandies and bohemians to be fully identified as youth subcultures, even if youth were particularly attracted to them. As this essay discusses later, it is market segmentation that further aids in teenagers to self-identify as a specific group after World War II.

133 "Lives," like the other two, is a general term. Considering the actual phenomenon of historical adolescent rebellion, we may place under its rubric the desire for self-expression and direction, as well as the occasional tendency towards self-destructive behavior. "Liberties" includes acts of defiance against the law specifically to defy, e.g. "Rebels without a Cause" have, as a cause, rebellion itself, which, understood in the context of natural rights, is liberty for the sake of liberty. "Estates" refers specifically to physical property, such as land, vehicles and public commons. Hence, if an adolescent out of the principle of the violation of his natural rights wishes to defy the dominating power of civic society or his immediate society (family), he must act out his role in these three areas. 
the notion of property and how society may have been hypothetically constructed in terms of one's relationship to it. It constitutes the very pseudo-Lockean-beginning of civil society, as property owners merge their initial holdings (in the hypothetical beginnings of time) in order to create the bounds of a new commonwealth. Rawls suggests a veil of ignorance as a substitute for a pseudo-beginning. Today, one might consider property to be the physical objects which one possesses. The notion in political theory, though, extends beyond such a simple association.

In Locke, for example, property is specifically defined as, firstly, the body of a person (an individual owns oneself). Secondly, the commons becomes personal property because, through industrious labor, the individual mixes his or her self with the common 'stuff.' In this way, he or she makes it his or hers (quote page 288). It is the grounding principle of Locke and thinkers like Pufendorf: property transformed by human industry is radically more valuable than that which Locke referred to as "lying in waste." It becomes much more valuable to the rest of humanity as well. Efficient labor is paramount, and private property efficiently and industriously transformed is hence morally justified due to this elevation of it for the betterment of humanity.

The emphasis on productive labor is hugely problematic for the adolescent. He or she cannot simply become a pioneer, farming land in some unclaimed forest. There is no where he or she can go to establish his or her activity and, more importantly, assert his independence and freedom. Secondly — and this is particularly relevant today — the kind of labor available to the adolescent seems demeaning in relationship to his or her efforts to establish his or her adulthood. For example, many adolescents may be relegated to service or seasonal work, as discussed earlier in this paper on masculinity. The labor 
itself is understood as adolescent or teenage and is hence not a means in which he or she may transform property through his or her productive activity - he or she cannot take some unused section of the Commons and make it his or hers. ${ }^{134}$

Also, if an adolescent simply begins using someone else's property for his or her own interest, he or she violates the natural rights of that property owner. If he or she were acting according to irrational impulses, he or she might do so. However, as this essay argues, he or she is acting according to principles. What remains are the public commons and property owned by abstract, impersonal entities such as corporations.

To act on such property presents further complications. If he or she mixes his or her labor with that of the public commons or businesses, he or she will be considered a criminal and lose his or her latent citizenship. If he or she does it in secret, he or she does not achieve the recording signature of his or her activity so that some part of his community will be aware of his or her restive "political" act; recall here that his or her activity is, in principle, fundamentally political as it relates to rights.

To resolve this, the ideal form of political activity would be to engage in a transformation of property via industrious activity, especially such activity that is considered the most elevated form of industriousness by Western standards (art). Secondly, his or her transformation of property must be illegal, since he or she is acting against civic law; otherwise, it would not constitute a form of resistance to the very codes and laws which threaten his or her basic rights of consent (and which limit his or her activity due to the accords over property). Thirdly, he or she must do so in a way that is both visible and invisible, e.g. he or she must be able to transform property in such a way

134 One may go so far as to claim that such work is really domestic activity and hence should be associated with traditional female labor. Recalling that Locke considered the female to be always irrational, such labor, in principle, would not qualify an adolescent as worthy of adult membership in society. 
that he or she may be selective as to who knows he or she is the perpetrator. Colt.45 illustrates this view in his essay for City:

The reason we are perceived as such a serious threat to law and order is because we do not recognize the most sacred right of modern capitalist society, the right of property. We dare to decorate the urban landscape according to our own aesthetic preferences, without regard for the sanctity of private property. Our steadfast refusal to recognize and abide by others' property rights and aesthetic preferences makes us a perpetual threat to the modern capitalist order and all whose lives are invested in it. However, in our paradigm there is something more important than property rights - our culture.

Though Colt.45, the pseudonym for a graffiti writer, claims not to respect property, the predominant production of graffiti tends to target only public or business property. In fact, graffiti writers tend even to steal all their materials (known as "racking up"), such as the spray paint and markers (Getting $U p, 46)$, as if every aspect of the production must be free of the taint of commercial exchange (note, too, that some writers will construct their own sprays).

It belongs, however, to a longer history of youth subcultures beginning in the late 19th Century. The emergence of subcultures conforms explicitly to the historic growth of urbanization and industrialization. Precisely as the commons disappear and labor becomes demeaning (or simply unavailable) to adolescents (who are even, to some degree, leisured according to labor reform laws and forced into the disciplinary educational system), youth subcultures form. These subcultures have always been, and continue to be, first and foremost, public performances in an identifiable membership 
community. The goal of their constituents is to be visibly at odds with the civic norm, and visibly a member of a community that reacts to the values of mainstream society. Their new association of membership undermines their membership to family and the tacit consent to civic society. Secondly, they often exhibit creativity, as the status of art is the most elevated act of the human spirit within Western principles. ${ }^{135}$ Thirdly, some edginess is a part of the youth subculture, since civic law must be challenged in order to assert their political freedom.

Since the youth may all be arrayed in a similar fashion, they curiously create a system that protects their individual identity, e.g. a punk, to the mainstream viewer, does not appear too different than other punks. Hence a punk person may flee the site of some minor vandalism (not to imply that this is what punks do) and not be easily identified by authorities from other punks. It was, according to the general public knowledge, simply the act of 'some punk.' The dress performance has another function: once citizenship is no longer latent but achieved (i.e. the adolescent is officially and legally an adult), he or she can then change his or her clothing style and become a normative citizen, should he or she so choose. The performative role-switch results in differential treatment, and is itself a public statement of conformity. ${ }^{136}$

The sudden explosion of graffiti as both an art form and premiere activity of

\footnotetext{
135 Art also has the capacity to assimilate beneficially the irrational side of adolescent rebellion, i.e. artists are supposedly passionate and irrational, so an adolescent's mental composition is already on par with the artist. The reverse is probably more accurate.

136 Recent scholarship has questioned the legitimacy of the foundation of former colonies such as Canada, The United States, and Australia. The colonies initially claimed that the natives, such as the American Indians and Aborigines, were not in possession of the land. This current may be found in Locke, although he uses an agricultural approach over conquering. Interestingly, teenage movements have occasionally emulated American Indians, such as the Apache Youth movement in France (see Savage, Jon. Teenage: The Prehistory of Youth Culture, 1875-1945. New York: Penguin, 2008). It is as if adolescents interpreted the problematic legitimacy of countries such as the United States and grounded their claims by identifying with native populations, i.e. the adolescents, like them, are a landless, dominated group.
} 
adolescent rebellion is therefore philosophically explicated in this light. The graffiti tag (an anonymous pseudonym, placed in visible locations), since it has the status of an art object, may be considered by its maker to be an elevated transformation of the commons into personal property. He or she suspends the principles of mainstream culture over property use limitations by taking possession of property as he or she wishes. His or her use of a pseudonym instead of his or her birth name does not incriminate his or her other half which will someday be a full adult citizen (i.e. it conserves his or her latent membership). Graffiti's bright colors makes his or her mark visible. Recently, thanks to the anonymity of the internet, the youth can document his or her various markings online, expanding his or her audience to include the international community—his or her subculture-free-consent-membership in response to the youth's tacit-consent-membership of his or her host society. The online documentation further allows him or her to prove his or her status as freedom fighter since it permanently records the youth's 'performances' and exploits. There are even scholars and thinkers who have argued in defense of graffiti in these terms, ignoring that the population that creates graffiti are doing so since its anonymous form appeals to their impending (latent) membership, e.g their stakes of retaining their adult membership options are high.

Vandalism deliberately flaunts a violation of this code by doing so in highly visible locations. It also allows the adolescent to preserve his or her status as an emergent citizen since he or she vandalizes under a clandestine pseudonym. His or her activities hence have a double significance. They are both a means to qualify for the status of membership of the graffiti subculture, as well as a flagrant attack on property as a symbolic form of the society's fundamental concern. The destruction of property signifies 
a conscious refusal of the codes of membership and is hence, logically, an assertion against the loss of freedom in the use of public goods which enabled tacit consent.

\section{G. Conclusion}

It is commonly assumed that adolescent crises (like liminality) are ultimately explicable via enough studies on organic sources of development, such as the changing growth of brains and the experience of chemicals like adrenaline. However, it is without question that the contradictions inherent in adolescent rights are a factor, if not the factor. Trapped in an in-between state of powers and non-powers, youth experience liminality in relationship to their rights and responsibilities. There are no exact benchmarks for maturity, no clear demarcation for authority over themselves or their parents' judgment, and no proper moment for their express consent to a political and social structure forced upon them. The only fact that is certain is that someday, they will attain these full rights, making their full status 'latent.' For this reason, they may not wish to imperil these full rights while still, somehow, seeking a path of empowerment.

The contradictions in human rights that face youth are inherent to the problem of both bestowing them at birth and giving them access to them in their maturity. This is independent of the conditions brought about in American culture and industry in the past two centuries. Those conditions, such as urban crowding, labor laws and the rhetoric of rights in various movements from the 1960s onward served to exacerbate the existing condition.

Also, before the monolithic, impregnable, immoveable object of contemporary Capitalism and American policies stands the contemporary coming-of-age American 
teenage. Faced with eventual tacit consent to full membership and legal duties and powers, he or she may find troublesome the gross inequalities of the modern world. Even more so, consumer culture bombards the public with new needs, such as attractive vehicles and clothing lines. His or her identity may be swept up by this world, or he or she might reject it. Acceptance of mainstream styles and fashion signify a flight from the liminality provoked by their ambiguous rights. Therefore, to accept and practice such styles signifies that their rights are less important than the emotional succor of 'fitting in.' Subcultures give youth an option that they are free to choose, finding therein a community that conforms to codes and beliefs consonant with their thinking and ideals. Graffiti, unlike other subcultures, further allows for the radical expression of a twofold movement in response to youth liminality: first, the expression of anti-consent, antimoney and anti-power, and second, the preservation of their status as citizens even while breaking the law.

Of the first, graffiti vandalism often targets objects of either authority (such as signage) or billboard advertising as part of its political expression. In this fashion, the youth refuse the limitations to their rights to appropriate land while protesting societal power. In this basic act, they refuse the culmination of what Locke claimed was the result of the accumulation of money in the hands of the few as well as the greater societal powers that hold their rights in check. Since society, from Locke to the Puritans to the present, create an image of the poor and lawless as irrational and immoral, the youth masquerade as this type. It is an easy shift to perform, since they, as youth, are already labeled by social biases as irrational and hence immoral.

The anti-structure acts of graffiti, though, are buttressed by the ability for youth to 
leave the practice as freely as when they entered. Graffiti allows youth to transition out of the subculture and into the mainstream culture by its use of anonymity. The pseudonymous activity creates the best of all worlds. One's good standing as a citizen is maintained while one's desire to assert freedom and consent is asserted. Many youth vandalize and engage in acts of delinquency and minor crime. Graffiti elevates these acts into a multilayered code of ethical art, reappropriation of property and a means of membership into its specialized community. In fact, when seen in this light, graffiti rather brilliantly exaggerates every fundamental concern of adolescence while still preserving the benefits of adulthood. As long as those basic contradictions appear in the powers and rights of youth, graffiti (or some new, difficult-to-imagine form of it) will continue to flourish.

In the light of rights theory, one might argue that graffiti and subculture life in general should be equally of interest to females since they, as full individuals, have the same contradictions facing them as males. This is true. Graffiti holds appeal specifically to males in the area of its dangers, but there is a sizable $(15 \%)$ of the graffiti population that is composed of females. Nevertheless, males are more drawn to graffiti due to specific risk-taking qualities discussed earlier. We can predict, though, that females will find expressions equally of resistance and rebellion in other subcultures that express principles like graffiti.

I suggested in my discussion of Berlin's notions of positive and negative liberty that one might instead use Schiller's definitions of the barbarian and the savage as ways in which a specific individual might confront issues of the two forms of liberty. Considering that Schiller's model also accommodates two forms of masculinity, it seems 
that it could become a strong paradigm for viewing graffiti culture as a whole. The youth therein would psychologically identify themselves with the virility of the 'savage,' living in a state of nature in the emphasis of the freedom of their rights. The 'positive' freedom of self-control as suggested by Berlin can be elaborated to represent what Schiller argued was a self-conception in which one either revered the control of instinct through rational ideals or the freedom of emotions through the strength of vitality. Youth are drawn to the latter, especially those in graffiti who might not have the usual means to exhibit their passions and excellence within mainstream society.

Since graffiti exhibits a process of transformation, both of the male form of identity development and the expression of rights, I conclude my analysis with a discussion on how graffiti may be understood within its unfolding. 


\section{LIMINALITY IN PROCESS: COMMUNITY AND CREATIVITY}

\section{A. Introduction}

It is youth that make graffiti, indicating both a biological (age) and a political (in terms of rights) dimension heretofore established for participation in the subculture. However, it is not just natural aging and the emergence into full adult rights that cause youth to exit the subculture. Its process of construction relies upon preconceptions, ideological assertions and the attraction of emotional bursts to sustain itself, attributes that cannot function long-term. This has a relationship to liminality and the character of the youth involved throughout their participation.

Liminality in general is the emotionally fraught betwixt-between existential state born from specific life conditions. It is not necessarily a fixed state per se but one which an individual experiences in some fashion within its beginning, continuance and (possible) end. Since it is not fixed but varied, persons in a liminal state experience activities that have an effect on their liminal existence. ${ }^{137}$

This section analyzes the process of both involvement in the graffiti community and the production of its objects for their effect on the overall liminal condition of graffiti youth. The first aspect under the category of process, community involvement, initially occurs through mentor-mentee relationships in which the identity of the participant 137

For example, one might subscribe to a radical ideology in an effort to establish secure grounds for their emotions in order to remediate the insecurity of liminality. 
evolves based on his or her role. The new initiate or mentee experiences a new form of liminality with the subculture itself, creating an 'overlay' to their adolescent liminality. This overlay is the rite of passage to earn one's membership in the subculture and recedes once full membership is earned. Full membership in graffiti then serves as a form of security from adolescent liminality in that the youth subcribe to predetermined codes and principles. They are no longer an isolated, insecure youth but a practicant in a grander society. Eventually, as an experienced member, they evolve a new, different outlook on themselves and the practice when their role as knowledgeable veteran and mentor is asserted by new members.

The other process-oriented change in relationship to liminality occurs in the actual production of graffiti. There are two extreme poles for this change represented in the two extremes of the subculture's production of tagging and masterpieces. Tagging represents an avoidance of liminal experience, substituting it with the emotional thrills of risk-taking behavior. The masterpiece, while more methodical, is unlike some creative forms which use liminal space itself within their creative process. Since its hard lines and predetermined form result in a production process that is static and lacking in exploratory insights, it represents a failure to explore the liminal condition as a creative space.

Nevertheless, aesthetic experience, such as that which occurs in the making and contemplation of graffiti masterpieces (however one might judge their merit), is itself transformative, in particular in relationship to their maker's character. Youth contemplate aesthetic objects when researching and making masterpieces which, by Schiller's definition of free play, results in a transformation, if not ennobling, of their character. This is a unique avenue of change available within the graffiti culture due to its emphasis 
on the artistic merits of graffiti and occurs both in relationship to liminality as well as independent of liminality.

Therefore, there are two general transformative effects within the processes of involvement in the subculture of graffiti, namely its path to (and experience of) membership therein and the continued production of its varied objects. These two aspects--membership and production--each lead youth eventually out of the subculture. The first, tagging, generates an ultimately unsatisfying, never-ending quest to assert oneself while making nothing of value. The second and opposite pole, the masterpiece, even with some positive aesthetic elements, offers dwindling emotional returns in its failure to explore liminal creative spaces. The masterpieces limited aesthetic content combined with its strictly circumscribed definition of its type necessarily means that one will either lose interest or cultivate the desire to make street art that is truly original and/or unique.

\section{General Overview}

As Hegel's dialectic is used in the outset of this essay in order to characterize the challenges of male identity, it is fitting to begin briefly with his thoughts about the changing nature of consciousness within the process of encountering another (the Lordship-Bondsman dialectic) to introduce this final section on process. Hegel's analysis of Kant's Critique of Pure Reason featured a rejection of the static definition of Kant's conception of perception and the experience of knowledge. Kant described a form of cognition that, for Hegel, was simply a part of a greater movement of consciousness. Instead of interesting himself in a specific mode of consciousness in time, Hegel 
contemplated what occurs in the 'between' of two consciousnesses as they come to mutual recognition through their process of interaction. This results in a deep awareness of the complexities of process; there are no 'fixed' forms of consciousness but movements and progressions in relationship to other movements. He writes:

Desire has reserved to itself the pure negating of the object and thereby its unallowed feeling of self. But that is the reason why this satisfaction is itself only a fleeting one, for it lacks the side of objectivity and permanence. Work, on the other hand, is desire held in check, fleetingness staved off; in other words, work forms and shapes the thing. The negative relation to the object becomes its form and something permanent, because it is precisely for the worker that the object has independence. This negative middle term or the formative activity is at the same time the individuality or pure being-for-self of consciousness which now, in the work outside of it, acquires an element of permanence. It is in this way, therefore, that consciousness, qua worker, comes to see in the independent being [of the object] its own independence. (Phenomenology of Spirit, 118)

Hegel's formative activity is characterized in the face of the negated consciousness, namely the 'bondsman.' Persistent labor towards the culmination of an object (a project) allows one to experience 'permanence.' In terminology more easily understood (and in the context of liminality), Hegel argues indirectly that a form of diligent work enables one to escape the betwixt-between crisis brought about by liminality. The 'fleetingness' of human liminal experience is averted, albeit temporarily.

This is also the case of the graffiti writer, both in terms of his or her identity as well as the objects and relationships produced. There is no 'fixed' writer per se, but an 
individual who performs and undergoes a series of activities. These activities have a transformative effect upon him or her. ${ }^{138}$ Some activities he or she identifies himself or herself with consciously, others act upon him or her in unanticipated ways. In terms of changes, a graffiti tagger at the dawn of his or her career in the subculture is radically different than the same one at its dusk.

Moreover, for youth, this process of transformation through activity occurs in tandem with transformations associated with experience of adolescence. From the most recent version of the Handbook of Adolescent Psychology, there is ample evidence of behavioral and biological changes for youth throughout adolescence. Youths' brains are still in development; they experience a multitude of behavioral shifts, sometimes as regressions; their social world is in near-constant flux; their bodies undergo puberty and influence their emotions; and they gain access to public goods and legal powers (and responsibilities) at different ages. It is no wonder, then, that one of the few unchanging aspects of their lives - their parents — represent one of the strongest influences, even when that relationship might undergo changes for good or ill. ${ }^{139}$

The typical career of a graffiti practitioner begins in early adolescence and ends by late adolescence, if not much sooner. Biological and sociological factors play a part in this disinvolvement. We might add, too, the insights from this paper thus far, such as the emergence into adulthood for models of masculinity and the assumption of full civic

138 To be precise, I should note that these processes both have a transformative effect upon him or her, and, reversing the passive voice, that the youth act in such a way to transform themselves within a given parameter of processes.

139 According to Brett Laursen adn W. Andrew Collins' section "Parent-Child Relationships During Adolescence" in the Handbook of Adolescent Pyschology, Vol. 2, parent-child relationships "have farreaching implications for concurrent and long-term relationships with friends, romantic partners, teachers, and other adults" (3). Parent/adolescent relationships are varied and many youth may not experience them as unchanging, assuming that the presence of their parents is itself unchanged (e.g. one may have parents that separate). Hence, I am making a generalized assumption. 
rights, which have also been known to make youth concerned about the possibility of prosecution outside juvenile courts. This final section pursues the notion that there are other influences that move individuals slowly out of the subculture. These influences are the effects of both the variety of relationships within the community and the process of making the forms of graffiti.

\section{Scholarly Discussions}

Graffiti is highly performative in its assertion of masculinity, the theatrical display of its constructions, and the emphasis on meaning in its mode of production (over the object produced). For this reason, process is essential in understanding it over the longer duration of one's involvement. The notion of process as a study in and of itself is part of the recently established field of performance studies. A seminal work on performance studies is Richard Schechner's Performance Studies: An Introduction. Schechner was a friend and collaborator with Victor Turner and hence uses some of Turner's framework on both liminality and the liminoid for understanding process and performance.

Schechner's third chapter is dedicated to defining rituals in terms of their performativity; 'play' as an act is reviewed throughout Chapter 4; and 'performativity,' its definition and usage, is defined in Chapter 5. For Shechner and Turner, certain acts are liminal and performative in that they place the audience and actor in a liminal space. This creates a state of play for all involved. Since these liminal spaces are artificially produced, Turner defines them as 'liminoid' as in 'like' the liminal.

For graffiti, as defined for an audience, the production process unfolds 'like' a performance, even if not formally so; in this sense the making of tags is performative. 
Most importantly, performance studies both continues the tradition of Turner's studies in liminality as well as deepens some of its various notions (at least in Schechner's approach within New York University). For example, performance studies (given its roots in theater) brings awareness to elements such as an the limen (or 'threshold,' such as the point in which a stage begins as separate from the audience) and lintel (the 'framing' of the experience, such as the borders of the camera in film) in their relationship to liminal experience. Since Turner created the category of the liminoid as versions of aesthetic experience that are similar to liminal states, performance studies' investigations into these phenomenon have allowed for the expansion of the term to a wider genre. Finally, performance studies offers a sophisticated lens for understanding the nuances of 'play.' In anthropology, Richard Lachmann's seminal Graffiti as Career and Ideology viewed the practice from the perspective of its duration. His insights, though based upon the author's interviews with twenty-five practicants in the early 1980s, confirmed my intuition of how the practice proceeds for the typical writer during his or her involvement. Lachmann charts one of the key influences that guide individuals to progress slowly out of the subculture through time: the effect of the community of relationships. He places heavy emphasis on how the existence of an audience gives meaning to a work, drawing on Howard Becker's pioneering 1963 book Outsiders. Lachmann found that practicing graffiti writers recruited novices two to four years younger than themselves in order to create an audience for their own work. In this way, their identity as mentors (even as graffiti 'kings') was also established. These followers would eventually become competition for the mentor's title (undergoing a rite of passage into the graffiti community through mentorship and graffiti production) and encourage 
the older mentor to withdraw from graffiti. Lachmann writes,

They typically spent two or three months at intensive tagging, cutting school in order to do so, until they could claim the title of "king of a line." At that point, they attracted novices in an effort to ratify their status and then felt secure enough to slacken their own tagging efforts. Over the following months, the novices themselves achieved fame and attracted their own toys, ${ }^{140}$ displacing the old kings. All the taggers interviewed were unwilling "to start that bombing grind again" in an effort to make a comeback in competition with their former disciples, preferring to rest on laurels earned months or even years earlier. (238)

The result was that graffiti writers who typically focused solely upon tagging, "abandon[ed] active writing within eight months" (238). Other groups vying for the services of taggers, such as gangs, created new audiences and hence new motivations for production. The only other way in which membership in the community continued was through the production of murals (masterpieces).

The process of initiation into producing throw-ups and masterpieces was similar. Here, mentorship is even more necessary due to the logistical demands of production. The apprenticed writers assisted their mentors until they felt capable in their own right to make expansive murals. Writers' corners (locations by subway junctures in New York City) provided a place where practitioners of varying skill levels and experience could meet. These writers' corners were later targeted (and decimated) by police, leaving only legal institutions such as galleries as sites for encounters.

140 The idea that novices could attract new initiates in such a short time seems radical today but then it is my belief that the practice has changed drastically since Lachmann first wrote. In his era, there was no internet, either as means for documentation and as a path to other forms of masculinity (such as technomasculinity) that might be appealing to the character of youth drawn to graffiti. The only path to renown was massive production which was probably the assumption of all new practitioners. 
My main concern with Lachmann's research is that it was written some years ago and practices may have evolved since that time. The introduction of the internet has eased the necessity of massive production in order to attain renown by way of enabling documentation. The internet has also created other avenues of recruitment and training which may not result in extensive tagging. However, his description of the socialization of younger initiates was corroborated recently in the article "Boys Doing Art: The Construction of Outlaw Masculinity." For example, the authors write that "the introduction to graffiti is part of a socialization process in which younger boys are introduced to the scene by older, respected boys" (275) and note immediately precursors such as Lachmann. A notable obersvation they add is that masculinity is also a concern, such as in the aggressive choice of pseudonyms. They find it a "masculine culture that values willingness to offend, rebelliousness, and risktaking" (273).

Craig Castleman's 1982 Getting Up is very similar to Lachmann in its observations since they (Castleman and Lachmann) were both recording in the same time period. He observed that in order to establish themselves, writers must write their names "at least a thousand times" (21). This seems like a striking number, but is corroborated by Lachmann's claim that novices could supplant their mentors in a short period of time: ten tags per day over a three month period would reach about the required total.

Castleman also states that "writers are considered retired once they stop writing, and they are forgotten quickly by most of the writers who are still active" (21). This causes some writers to return to the practice occasionally in order to reassert their identity. It is a subtle contrast with Lachmann, whose interviewees seemed content to 'rest on their laurels.' Castleman further traces the overall career of graffiti writers 
through tags, blackbooks (for the development of style), apprenticeship with mentors, and then independent production (24). Hence, this line of thought that traces the typical graffiti career from novice, to tagger-apprentice, graffiti writer and then mentor of novices is well-established.

Nancy Macdonald offers a slightly different narrative of the graffiti career based upon her ethnography for The Graffiti Subculture. She found that in time, youth were more intrigued by style than by fame and getting up. She cites one of the writers, Dax, recounting the basic way he changed his approach to writing:

When I first started, I had less interest in art work, I wasn't really interested in art at all, I was just interested in putting my name out . . . and then, I suppose with the interest in art, the illegality gets less because you can be happy to do a legal wall.

Macdonald observed that younger males practiced the risk-taking form of masculinity whereas older ones were less interested in doing so. She concludes that this is due to the insecurities of young males and their need to establish masculinity, whereas older males outside of graffiti take risks in a different fashion and for different reasons. She observed that the youth were aware that in time they would become assimilated to society. Hence the shift from tags to either masterpieces or the cessation of graffiti production altogether is associated with masculine identity and shifting responsibilities.

Her observations were corroborated in Mark Halsey's and Alison Young's 2006 article "'Our desires are ungovernable': Writing Graffiti in Urban Space." The authors note especially how the affective dimension of graffiti continues to inspire involvement. They observed how authors take pride in the artistic success of their work, a radically 
different emotion to that induced by the simple adrenaline of some of its risk-taking aspects (279).

Today, youth proceed into graffiti practice via the internet as well. One might find forums like 12OzProphet.com and other blogs and use these as a form of mentorship. For example, the graffiti writer LUSH made a video in 2011 called "How To Do a Graffiti Masterpiece." LUSH's first advises the novice graffiti writer to create a nom de plum (such as LUSH) and then to "create your shit talking forums account" on the 12OzProphet.com forums. Only then does one "hit the streets" (Frabetti, novis). LUSH's video and others similar informative videos, such as those by DKDrawing (May 2013), Zombie ART (June 2012) and Graff TipsTV (Oct 2012), may be found easily through a basic Internet search. They reveal just how much some of the older ethnographies such as Lachmann's research may require updating since mentorship may now take the form of virtual guidance, direclty or indirectly.

The above ethnographies essentially argue for what is intuitive, if not obvious. It is to be expected that youth, while very young, would be drawn to mentors and the excitement of the adrenaline aspect of the practice. Likewise, it is intuitive that in time they would be drawn towards the more artistic aspects of the work, should aesthetics in general be appealing to their specific character and should they be drawn to continue in the practice. The studies reviewed here establish that youth are influenced by community, but they do not focus upon the act itself of making graffiti and how this activity might affect the youth in question.

In fact, it is important to ask how the creative process of graffiti, from tagging to making large-scale legal murals, might effect some kind of enduring transformation upon 
the youth's emotions in the process of making them. The analysis necessary to reveal the effects of process lies in some combination of aesthetics and art criticism, tools essential to performance studies. Typically, though, the visual arts approach to graffiti is to focus either upon the biography of a specific practitioner and his or her art (such as Jay "J.SON" Edlin's individual narratives throughout Graffiti 365 and the multitudinous biographies on renowned figures like Basquiat and Keith Haring), or to analyze the overall artistic merits of the objects created (such as Evan Roth's Graffiti Analysis, Carolina Miranda's article "Beyond Graffiti” and Alain "KET” Mariduena's various editions of Graffiti Planet: The Best Graffiti from Around the World). Such approaches ignore the transformational nature of process. It is to this aspect that this essay now turns in hopes of inspiring a discussion for future thinkers and researchers. Process, in fact, emphasizes transformation (relating to PYD) and the changing character of the individuals involved (relating to liminality), two central components of the youthful population that make graffiti.

\section{B. Establishing the Parameters of What is Liminoid Art}

When considering this section, I wondered whether or not the artistic aspects of graffiti had a unique relationship to liminality. For example, I found myself questioning whether tagging was a flight from liminality or a cultivation of it. Similarly, masterpieces, the pride of creative genius within the subculture, must have an effect upon liminality. ${ }^{141}$ I personally admire a form of art that is psychological and transformative as

141 Do the youth seek liminality within the subculture as an escape from boredom? This possibility was proposed by Victor Turner and discussed briefly in this essay (pg 95) in his article ""Liminal to Liminoid, in Play, Flow, and Ritual: An Essay in Comparative Symbology." Its basic proposition is that certain kinds of experience might be sought in order to induce emotional responses that mimic (or 
opposed to simply fashionable or classical; such art, I realize, is, in effect, liminal art. ${ }^{142}$

For this reason, before proceeding, I believe it is important to define as a

foundation what, exactly, constitutes liminal (liminoid) art, both in terms of its

relationship with liminal crises and how it invokes the liminoid. There is, of course,

immense diversity within any definition, since the diversity of audience makes it

impossible to establish universal definitions. One person might have a liminoid

experience before a specific creative production due to his or her background and psyche,

whereas another might not. Hence, the following reflections represent rough guidelines

that will be loosely and cautiously adhered to throughout the rest of this chapter.

\section{The Three Basic Classification of Art Forms in Relationship to Liminality}

There are three principle approaches we may isolate within every work of art that

relates specifically to liminality. The first is that its contemplation and creation tends

towards engendering the liminoid ('like' a liminal state). The second is the opposite; it

tends towards the reverse of the experience of liminality, or even represents its total

are like) liminal states through 'play,' resulting in states he calls 'liminoid' (66). For Turner, these are modern forms of liminality, unlike traditional rituals. One seeks something more exciting than the mundane, or even to infuse the mundane with emotional content.

However, the question proposed above - whether graffiti represents a flight from liminality or a search for it-implies an either/or scenario in which the two possibilities are mutually exclusive. All of the ethnographies discussed in this essay have revealed that there is great diversity in the graffiti community in terms of this liminality/liminoid relationship. There are some practitioners who are, no doubt, an extreme example of one or the other, but many share features of both. For example, a male youth employed in an unexciting service job exhibits the liminal condition of his age and male identity but also seeks the liminoid as a path of escape from his labor. We might also note that anyone interacting with creative phenomenon (from films to books) seeks, to some degree, the liminoid, though this requires further clarification (discussed below in terms of what kind of art constitutes the liminoid).

142 The arts invoke liminoid states, which are 'like' the liminal. However, it seems to be appropriate also to refer to the category of art that interacts with liminality as 'liminal' since its possible characteristics is that it is made or experienced by someone in a liminal crises. The art might invoke a liminoid state in individuals that are not in a liminal crises. I am aware that this is somewhat confusing but I hope it will become more clear as I progress. 
avoidance. We may refer to this as 'anti-liminal' art, or rather, since it is art, 'antiliminoid.' The final possibility is that it has no effect whatsoever in relationship to liminality.

It is perhaps easiest to understand what constitutes liminal art by first observing the characteristics of art that it is anti-liminoid and anit-liminal. Anti-liminoid art asserts the stability and reliability of everyday cognition with stable images and carefully delineated objects in view. If it is a novel, its narrative follows specific conventions, such as the Twilight series and its use of dated gender roles. Similarly, the art of Thomas Kinkade features bland, easily identifiable structures that are themselves comforting in their traditional references, such as lighthouses, churches and cottages. ${ }^{143}$ For a viewer (and hence a receptionist aesthetic), these images evoke (borrowing from Kant's Critique of Judgment) a "charming" experience, one that comforts one's 'everyday' existence and cognition of objects and their meanings. At the risk of elitism, we might include in the anti-liminoid category Hollywood blockbuster escapist films, Harlequin romances, ${ }^{144}$ and much, though not all, of top-40 music. ${ }^{145}$ (Kitsch art such as Pop-Art specifically parodies anti-liminoid art.) ${ }^{146}$

143 I assume here that it is nearly universally accepted that Kinkade's work is bland and the Twilight series is modeled upon the worst of gender stereotypes.

144 By Harlequin romances, I refer to the specific genre of books made by Harlequin, such as Kandy Shepherd's 2015 Hired by the Brooding Billionaire or Susan Meier's A Bride for the Italian Boss, also 2015. No doubt there are titles within the Harlequin series that challenge norms.

145 There are examples of popular culture that succeed since they both assert the everyday while subverting it. Lady Gaga's music might offer typical dance beats with her strong vocals. However, her video productions featured long-established art world costumes, symbols and themes that may have struck the average American viewer as somewhat odd or even disturbing. This aspect was mitigated by her sexualized appearance (for the typical male heterosexual audience). Hence, though I make a broad generalization, there are many exceptions such as Lady Gaga.

146 However, even the most generic art object might invoke a liminoid experience in an individual with little aesthetic experience or particular biographical experiences in relationship to the work's content. Unless one wishes to revert to Kantian notions of taste (in which one must cultivate the ability for refined aesthetic experience), it is better to progress to postmodern celebration of the diversity of human experience (in which Western notions of art and aesthetic experience are subverted in favor of 
The process of creation (and hence from the perspective of expressive aesthetics of the maker) of such anti-liminoid objects is similar. A Kinkade lighthouse is already a lighthouse scene — a lighthouse on some earth with a pretty sky—from the outset of its construction. One can easily imagine the pre-drawing and then basic colors (repeated endlessly throughout all of Kinkade's works) used as filler within predefined proportions that are meticulously obeyed. In short, for the person making a Kinkade lighthouse, there is never any moment in which existence passes away from the firm grounds of everyday experience. They are comforted emotionally as they make the lighthouse since there is never any question as to what the final image will be. The very act of producing (and observing) a Kinkade-style work represents the anti-liminal.

On the other hand, liminoid art embraces the condition of liminality. Its liminoid status may be defined either through its creator expressively, in that the creator is in the midst of liminality while making it or is within a liminal crises during its coming into being (and hence expresses this quality within it). Alternatively, liminoid status may be defined in terms of reception through its audience, dwelling in the liminoid while experiencing the art. Here, too, the diversity of the backgrounds and tastes of the audience determines to what extent such a reaction might take place. In the case of the expressive, for example, an artist might begin with something nebulous and uncertain, itself symbolic of the liminal state. (One can use the techniques of Jackson Pollock, Hans Hofmann and Robert Rauchenberg as examples, if not exemplary ones; even the final form is nebulous.) From there, he or she gives shape to a form which never finalizes in

the celebration of the many forms of cultural delight in creative productions). We should consider ultimately the specific individual within the specific context of the work and whether or not that specific individual is confronted by the anti-liminoid. However, when attempting to analyze graffiti with broad generalizations, I must assume some generic qualities of its makers and audience outside of exceptional circumstances. 
the concrete. For an abstract artist working and creating within process itself, 'discoveries' emerge while making his or her productions. These discoveries are then imitated in subsequent works. Such discoveries require effort and risk, such as Carl Jung's construction of his Liber Novus from 1913 to $1930 .{ }^{147}$ Creativity arises from a perpetual liminoid state within the process of creation. The art critic Harold Rosenberg writes of this effort in The Anxious Object (1964) while defending abstract expressionism:

It is finding the obstacles to going ahead that counts—-that is the discovery and the starting point of metamorphosis. Uniqueness is an effect of duration in action, of prolonged hacking and gnawing. In the course of engagement a mind is created. Apart from that, every kind of excellence can be copied. (20)

The efforts of such an artist result, in time, with a notable style that is actually expressive of the artist in question by default and discovery. Even an untrained observer can instantly recognize a masterpiece by Mondrian. It is specifically 'his' while remaining universally appreciable. First, the style emerges from the liminoid while still retaining its essential elements. Second, it reflects aesthetic qualities as a necessary element for the artist to endure or experience the liminoid process itself (hence shock art is rarely liminoid).

This account assumes that liminoid art is abstract. However, it can also be representational (or take other forms). In such an instance, perhaps the artist might begin with a concrete image. Within the creative process, though, this concrete representation undergoes transformations that then undermine the image's stability. We might include in this category the art of Lucian Freud, Egon Schiele and Oskar Kokoschka, as well as the

147 Jung was in a full liminal crises during the making of Liber Novus. Also, the work invokes liminoid states while studying it. This makes it a premier example of liminoid art. 
Cubist period of Pablo Picasso, to name a few exemplars. In this case, the artist begins with a figurative image but then transforms it into an unstable, emotionally expressive form that undermines the solidity of the depicted individual's existence. In this sense, the liminoid is invoked, unlike, for example, the Hollywood-inspired figurative paintings of Thomas Hart Benton.

The experience of observing liminoid art is similar. For example, if one were to contemplate Robert Rauschenberg's 1959 sculpture/painting Monogram, ${ }^{148}$ he or she would be faced with an enigma that is both unsettling and beautiful. The work breaks away from comforting foreknowledge of what comprises taxidermy, fine art and color use. The possibilities of its various meanings cause one to contemplate the unknown, shifting one away from the stable sensory world of everyday objects. The attractive color relationships, general composition and proportions of the various objects signify a deeper harmony that lures the viewer even further away from stable notions of objecthood. The goat within the composition is repurposed into a symbolic form, adding instability to basic notions of, say, 'goat.' In short, the work beckons a viewer towards liminality. Notably, art of this kind is a 'safe' place to engage in liminality and hence constitutes what Turner would refer to as engagement in liminoid spaces.

Susan Broadhurst's 1999 Liminal Acts specifically focuses upon the reception one has when experiencing what she refers to as liminal art. Broadhurst begins with art that is performative in terms of its classical definition within theater/dance and social happenings, i.e. an art form that is performed specifically for an audience. She argues that a new approach to performative art has appeared since the 1960s which is liminal since it

148 Monogram features the taxidermy of a horned goat with its head through a tire. It is standing on a colorfully painted canvas of collaged images. 
defies the confines of typical theatrical framing. She characterizes its qualities in her introduction as follows:

hybridization, indeterminacy, a lack of 'aura' and the collapse of hierarchical distinction between high and popular culture ... the utilization of the latest developments of media culture ... experimentation, heterogeneity, innovation, marginality, a pursuit of the chthonic and an emphasis on the intersemiotic. (1) Broadhurst believed that performance art exhibiting these qualities cannot be understood within traditional aesthetics. The philosophy of art as commonly utilized in thinkers from Kant to Lyotard, such as its characterization of aesthetic contemplation as an exceptional state, its division into categories like the beautiful and the sublime, and its tendency to reduce art forms into closed categories from sculpture to dance, is inadequate for understanding recent productions like Pina Bausch's Tanztheater (dance theater) and hybrid art of Viennese Actionists.

For example, Bausch's 1991 production of Palermo, Palermo in its Paris premiere featured a wall suddenly collapsing before the audience on the stage. It was not clear whether or not this wall was part of the performance, causing a breakdown between the limen (threshold) of the stage and the audience (70). According to Broadhurst, similar breakdowns between audience and performers have occurred in other events by Bausch, such as her production Arien (Arias), 1979 in which the performers actually interact with the audience. (75)

The breakdown of normative experience by performers results in what Broadhurst considered a special realm of aesthetics. She locates this in Kant's conception of the sublime, finding within Kant's philosophy an avenue for the experience of awe and 
disquiet brought on by liminal acts. This is radically different from the calm, reflective qualities one experiences in the peace-inducing contemplation of typical 'beautiful' artwork. (In this regard, her approach to the experience of the liminoid is similar to my description of how one might experience Rauschenberg's Monogram.) Whereas Kant did not believe that the sublime could appear in the arts (he principally focused upon natural phenomenon), Broadhurst argues that it is the proper starting point for appreciating the effects of liminal performances and liminal art.

The main issue I have is that such art is eventually normalized. Many of the aforementioned qualities she espouses for liminal acts have been incorporated into contemporary art forms. The qualities she lists of the 'new art' were radical in the 1960s, and even up to the publishing of Liminal Acts in 1999, but have by now (sixteen years later) become normalized for contemporary performance arts. It is not surprising to witness video productions in theater, or impromptu street performances of theater groups in city spaces later appearing on YouTube. They no longer invoke disquiet but are instead expected as part of the practice of contemporary art. We might argue that the first appearance of graffiti was part of this wave of liminal acts, causing a sense of unease in its audience in the New York-Philadelphia corridor in the late 1960s and early 1970s. By now, though, it does not stir such a reaction in the viewer and may be relegated to the background noise of the overwhelming impressions of city life.

I agree with Broadhurst that liminoid art, however it appears (and evolves), tends toward the sublime instead of the beautiful, at least in the fashion in which Kant defines the sublime (as unease, disquiet and the unfathomable). Yet, even truly beautiful art in the sense of Kant's definition of aesthetic experience is exalted and difficult to define, 
implying that Kantian categories of aesthetics in general require exceptional art forms. (It is rare that I, as a frequent viewer of creative forms, am deeply moved to describe them as beautiful, and far less likely to perceive them as sublime.)

The sublime, though, and even Kant's notion of the beautiful, are based upon the experience of the creative productions by an audience, i.e. it is a receptionist philosophy of aesthetics. My concern here in this paper, though, is how the making of graffiti affects the liminal state of the graffiti writer, not its viewers. Hence it is principally here that I differ from the goals of Broadhurst.

Also akin to Broadhurst, I find that some art simply does not engage the liminal at all. This constitutes the third type of art in terms of its relationship to liminality and the liminoid. For example, Joseph Kosuth's 1965 One and Three Chairs features a chair, a picture of a chair and the text of a chair. Its goal is to stimulate the viewer to think about an abstract concept. The Kinkade and the Rauschenburg work on the viewer's emotions and represent the emotions of their creators. One and Three Chairs is, by its very definition as conceptual art, devoid of the sentimentality of liminoid and anti-liminoid artwork.

Liminoid art is hence transformative in a specific way. It shapes a person's emotions and character in a fashion that encourages a mode of existence that questions the known through pictorial elements. Among other qualities, it tends to arise from a dialectic between formalized rules of composition and subject matter in relationship to strongly felt, meaningfully expressive elements. A purely static, academic work such as Kinkade's production lacks the liminoid since it does not transmit meaningful emotions. Similarly, Hollywood escapist blockbusters focus upon a superficial emotional 
experience that lacks moral weight. Standardized illustration and cheap entertainment are easy; liminoid art is hard to make.

\section{Observations from Schiller's Letters}

This understanding of liminoid art lends itself to Friedrich Schiller's conception of the play instinct in relationship to his terms of the formal and the sensuous. As discussed earlier in this essay, the formal instinct relates to rigid conceptual and physical laws as well as the moral sphere. ${ }^{149}$ The sensuous refers to the experience of the senses and their effect upon one's emotions, or even emotionality in general. Schiller describes the play instinct as a harmonizing mediation of these two instincts:

It results from this that the instinct of play, which unites the double action of the two other instincts, will content the mind at once morally and physically. Hence, as it suppresses all that is contingent, it will also suppress all coercion, and will set man free physically and morally. (91)

To illustrate these concepts in Schiller, I suggest using the aforementioned distcintion between liminoid and non/anti-liminoid art. A painting by Kinkade follows basic rules of composition and subject matter to invoke superficial feelings in the viewer. There is no play between the formal and the sensuous. Similarly, a work such as One and Three Chairs is simply conceptual or 'formal,' lacking any counterpart for sensual emotional experiences. Liminoid art such as the oeuvre of Robert Rauschenberg celebrates the formal and the sensuous in that the two elements are both present and in

149 The formal instinct as imagined by Schiller was inspired by Kant's struggle with the split between the empirical and the ideal. The ideal realm is a nexus of concepts determined by their inherent meaning. These concepts include the laws of nature as discerned by contemplating the physical world (i.e. scientific investigation). This includes mathematics. For this reason, they are 'causal' and deterministic and why I refer to them as rigid. 
play with each other.

Schiller's notion of the play instinct is especially relevant here in that it also relates directly to the civic realm. He believed that the only possible mode in which human civilization could improve was through aesthetic contemplation of the beautiful. However, since the time of his writings, notions of aesthetics and art have undergone extensive changes. I suggest here reorienting an understanding of Schiller's thought by considering the play instinct as that which occurs within (or in contemplation before) a specific kind of transformative art, liminoid art. (Liminoid art may also be defined as the play of the sensuous and the formal, although this risks becoming a circular definition.) For Schiller, the contemplation of beauty has an ennobling effect upon one's character and is essential for human civilization. Neither a Kinkade nor a Kosuth ennobles a person, even though we might debate or assert their status as art. ${ }^{150}$

Finally, Schiller's thought allows for a specific definition of freedom. For Schiller, the play instinct, or the 'space' that one experiences while the two faculties (formal and sensuous) are in play, is freedom. In this sense, we may argue that liminality is a 'free' state. Should one seek to escape liminality, one also seeks to escape freedom. Likewise, the liminoid is, in this context, an effort to embolden the everyday with freedom or 'freehood.' The freedom of liminality, as per the essential definition of liminality, is difficult to endure, since it also implies a freedom from standardized social norms of morality, conduct and community. Liminoid art hence serves as an opportunity for members of a culture to contemplate this space in order to find expansive ideas and

150 This represents a specific current of thought in the West which finds its expression in German idealism and phenomenological reduction, existential philosophy and the ethics of authenticity, Jungian psychoanalysis and the development of imaginative forms and, of course, the art movement of abstract expressionism, to name a few examples. 
emotions to cultivate and improve the civic realm and their civic or social relationships.

\section{Graffiti Performativity: Liminoid, Anti-liminoid and Play}

With these basic parameters in mind, I turn to the production of graffiti to project a model of its forms and how these influence the lives of the individuals involved. The following section proposes a generalized approach to how some youth enter into graffiti, analyzing each aspect of this activity in terms of how the creative elements of graffiti involvement engage with liminality.

I argue that the the entrance into the subculture represents a period of trial (or rite of passage) which is liminal in its own right. This comprises a layer of liminality over that which is experienced by youth. Subsequently, upon full membership, full indoctrination into the subculture's codes and ideology becomes a flight from the liminal condition of youth. The actual creative process of graffiti in the realm of tagging (and high risk production) also represents avoidance of the liminal condition in exchange for the adrenal rush of thrill-seeking. Even the produciton of the typical masterpiece does not confront liminality, since its form is too predetermined from the outset of its making to embrace creative uncertainty. However, the research, cultivation and production of masterpieces results in a refinement of character which creates more secure emtional grounds within graffiti writers. This could result in the desire for more nuanced work (leading them into original forms, possibly outside of graffiti) or the complete departure from the graffiti subculture (in that they no longer need to identify with its ideology).

\section{Initial Involvement-The Rite of Passage to Community}


It was suggested earlier that there are two possible (extreme) explanations for why a youth is drawn to the graffiti community: to escape the mundane through the liminoid or to come to terms with a liminal condition. The former implies a well-adapted youth who is otherwise bored, leisured and understimulated. He or she seeks the liminoid to escape the everyday, but seeks it in its least elevated forms, such as adrenaline-fueled thrills. The second instance is instead a youth experiencing a liminal crisis. This was the principle focus of my discussion of masculinity as well as adolescence itself, in terms of life changes and political status; in fact, it is rare for an adolescent to be completely free of liminality given the numerous changes endured by youth. There is no need for a sharp distinction between these two extremes, as there is a natural continuum between them in all youth.

Youth today are heavily engaged by the Internet and utilize it as a tool before proceeding in involvement in subcultures like graffiti. Even though it is possible that they may seek entrance to the graffiti community via a mentor, as observed in the 1980 s by Lachmann, it is more likely that a youth will first observe graffiti online (even if initially stimulated by observing its real-world production). He or she is already an audience for this online production, although he or she does not consider it to be merely online content nor consider him- or herself as an audience as such. The youth simply believes that he or she is viewing documented material and not something that is an end in itself. In short, the metatext of graffiti as encompassing an initial real-world object and finishing as a documented form is simply considered by youth as something pointing or indicating the significant real-world production.

His or her next phase is to somehow make some entrance into this community. As 
observed by Castleman and Lachmann, he or she might approach the older youth in his or her school or community and learn that they are taggers and writers. The youth is not yet a member of the graffiti community but begins his or her rite of passage into it. ${ }^{151} \mathrm{He}$ or she begins with the denigrating label of 'toy.' In fact, the label 'toy' is one of the most offensive in the graffiti community, even if it is unavoidable for initiates. The youth sees it posted angrily and scornfully in discussion forums and YouTube comment threads. The toy is the graffiti practitioner who does not abide by the rigid codes of the graffiti underground society, ${ }^{152}$ such as not writing graffiti over another writers' work or simply not copying another person's forms.

The liminal space of graffiti's initiation process stands in relationship to the liminal condition of the youth entering it. This relationship is one of both affirmation and negation. The graffiti community has codes, artwork and styles that are predefined and rigid; they are, in truth, anti-liminal. There is a limited set of forms in which one may create graffiti; there are honor codes by which one must abide; and other subtly coercive elements of conformity. For example, a common dress style may not be a code per se but nevertheless have a coercive effect: one should wear certain clothing like hooded sweatshirts instead of mainstream gym clothes or pink-and-yellow ascots. These signify that a person has submitted to the codes of this subculture. These codes, though born from a strict and hierarchical society, enable him or her to escape the empty abyss of the liminality evoked by adolescence. The vacuum of insecurity and freedom of liminal

151 Even though graffiti is male-dominated, I am using both pronouns due to the presence of females within the community. In the past, females were often involved through taggers that were their boyfriends, making their entrance into the community uniquely different than what is proposed here.

152 We might also consider using the term 'society' for graffiti's massive international participants and supporters instead of 'community,' following Ferdinand Tönnies' celebrated turn-of-the-century distinctions (Gemeinschaft and Gesellschaft). The local group might serve as a community, but the competitive and hierarchical tendency of graffiti practitioners places it more in Tönnies' societal definition. 
adolescence is replaced, slowly, by a carefully crafted cell of opinions, codes, and rules in his or her new subculture.

Nowhere does it occur to this youth that what he or she has done is a contradiction to his or her original disposition, that he or she has simply rejected the strictly imposed hierarchy of mainstream rules and structures in exchange for another. Conceptually, the youth moves from anti-structure to structure, even if that new structure (graffiti) has as its basic stance one of anti-structure. Graffiti and its subculture were in place before he or she was born; they is not of his or her creation. Yet, the youth's belief that he or she is free since he or she 'chose' to be a part of the graffiti subculture makes him or her believe that this new practice is somehow bound up with freedom. The anti-structure of the philosophy of graffiti - its anti-structure in its disregard of laws and private propertymeans that compliance to its structure is somehow a freedom of structure. It is as if one has allied with something simply because it is antagonistic towards one's foe, ignoring that the alliance itself embodies the issues one has with one's enemy.

The youth drawn to graffiti do not have the luxury of Schiller's awareness that the savage - the person who purely rejects codes for the sake of passions — is not truly 'free.' This requires a philosophical leap that a typical adolescent (or even adult) is not likely to be capable of making. There is nothing remotely 'free' about youth drawn to graffiti, other than the initial choice. He or she has escaped liminality and its turbid emotions in favor of the communitas of the mentors and the moral codes of the subculture. The graffiti practitioner, in fact, subscribes to Schiller's 'savage' persona. The youthful practitioners, especially those seeking a liminoid experience out of boredom, act out of the thrill of involvement and the emotions engendered during creative execution of works. 
However, all extremes have a compensatory movement, like an unconscious self that compensates for the imbalance of intense emotional states. The savage emotions and lawlessness of graffiti require its strict honor code and in-society rules. The two stand distinct, though. They are not resolved into a higher form as imagined by Schiller. In other words, there is society and its structures that can be rejected, and then there is the joy of graffiti despite its strict norms. There is no bridge or resolution between graffiti joy and its rigid social codes, and there is no resolution in relationship to society's rigid laws and the joy of graffiti.

This resolves a part of the youth's liminal crisis. He or she wishes to belong to a community, to be supported. He or she has rejected the mainstream. Now, the youth has found a group and wishes to be a part of it. This begins an initial process of transformation, the rite of passage to become a graffiti writer. This is a new liminal state layered over the deeper one arising from the state of adolescence. The youth's growing sense of belonging bolsters his or her self-esteem and the youth feels like he or she is part of something bigger than himself or herself. He or she has a local community of fellow graffiti writers. From them he or she derives emotional support. The youth is now on the threshold of becoming a true member and has exchanged the nebulous liminality of adolescence for the specific ritual liminality of graffiti initiation.

Initiation is a slow process, essentially requiring participation with mentors and eventually acquiring street cred. To achieve this, the youth might join his or her mentors for one of their night runs, as observed by Lachmann and authors Monto, Machalek and Anderson. This experience itself is very powerful in many ways. He or she dresses in dark clothing and sneaks out of the house. It is a symbolic act, and, from the perspective 
of performativity, a ludic one; the youth dons the attire like a mask and enters into the spirit of the subculture. The wearing of the mask of graffiti represents a shift into the liminal space of night graffiti production, its framing (lintel) first beginning with the departure from his or her home.

An example here might serve to illustrate this framing process. He or she perhaps encounters the older youth out in some semi-abandoned location. They travel as a group up to an area with rooftops, and decide that this will be a good location to create a throwup. This is performed, and the group exits the location. They reveal themselves to be a highly organized, tightly knit operation, moving with incredible efficiency and skill. They are an experienced 'crew' and capable of producing elaborate works in little time. Afterward, the youth meet and share in the camaraderie of the act, further cultivating a sense of team spirit. The initiate has been an accomplice to lawbreaking, and this affects him or her in varied ways. The older youth emotionally communicate that the lawbreaking aspects of graffiti are acceptable since they, the youth, are expressive artists and private property should not be respected anyway. The initiate does not wish to be a 'toy' and hence does not question these principles. Later, the youth returns home and, through a change of clothing, returns to his or her normative roles.

Here, too, within the very process of participating in early ritualistic acts, there are layers of liminality and the liminoid. The shift from normative to graffiti initiate and back to normative is itself a ritual and hence liminal. The activity also engenders emotions. The state of becoming a member, of being an initiate, is also liminal within the community itself. Finally, there is always the baseline of adolescent liminality from which the experience of graffiti either frees one or, in the case of well-adjusted youth, 
offers reprieve from lack of stimulation and leisure.

Unlike the general generic culture of consumption, in which one simply purchases something to own it or pays for membership, graffiti requires one to 'earn' entrance into its ranks. (This is part of the masculine appeal.) Our youth in question is not yet even a tagger, let alone a graffiti writer. He or she has simply witnessed the experience of making, but felt himself or herself included in a way the or she does not feel in mainstream culture. The process is thrilling for our hypothetical youth. He or she felt briefly the esprit de corps of being in the group (communitas), even though he or she is not yet 'officially' a member of the tagging community. The attendance was a first step, though, and he or she looks up to the older mentors.

\section{Creation of the Tag and Pseudonym}

The next phase of involvement is to research tags and begin to form his or her own. ${ }^{153}$ The aspiring tagger must create a pseudonym like 'Cornbread' or 'AK47.' The graffiti pseudonym becomes the youth's very first personal creation that is bound up with his or her creative identity. It refers only to him or her and no one else, although its deeper meaning references membership in a greater whole. Its letters, subtle meanings and actual form all can be constructed to be as expressive as possible as his or her selfportrait. Some youth who have a wry sense of humor will use names like CORNBREAD or JELLO, recalling the comportment of sprezzatura of Castiglione's courtiers. ${ }^{154}$ Others,

\footnotetext{
153 This assumes that youth proceed in a standardized fashion. In reality, every youth may progress in their own unique fashion, perhaps beginning with an established tag moniker before observing writers in action.

154 Castliglione's courtiers were disempowered in the courts of the various dukes and ruling lords characterized throughout his seminal 1528 masterwork The Book of the Courtier. Their mode of empowerment was to feign disinterest and unattachment to all things so that the lords seemed to have
} 
more interested in old-fashioned masculinity, may choose militaristic names like

COLT45 or AK47. The possibilities are not infinite, since many names might already have be used or still be in use by someone.

The very form of the tag, in terms of the style of the lines of the script, also may denote the youth's personality. A youth may choose to use a script with many angles, indicative of a 'thorny' tendency towards the world. He or she may also choose to use a script that is softer and rounder, or maybe even a combination of the two. The expressive possibilities here, too, are endless. The lines are designed not only for uniqueness but for ease of execution, since graffiti construction requires speed. This results in a flowing, cursive style of lettering that extends naturally from the hand of the maker, much like calligraphy or an everyday signature.

Since a new member of the community wishes to make a name that is unique to him or her, he or she goes online. A youth might look on forums and other sites to see if the tag name he or she has chosen is already in use. This process has an effect as well. The youth begins to become familiar with the graffiti online community. He or she sees images of masterpieces, tags and bombed billboards. During his or her search, a cursory knowledge of what it means to be a member of the graffiti community continues to emerge. He or she identifies with this notion of membership, and wants the online users and real-world members to identify him or her as one of them.

The youth also freely chooses to make this tag name for himself or herself. No

no power over them. This gave them an air of sprezzatura (a form of graceful disdain) and disinvoltura, roughly (though improperly) translated as 'nonchalance.' The wry humor of youth, especially those of the 'trickster' tendency, falls within this tendency. Funny pseudonyms like Cornbread make it seem that they are not emotionally concerned with the success or failure of their graffiti undertakings. This is, of course, a dissemblance that prevents others from crtiquing them harshly. I believe that the concepts of sprezzatura and disinvoltura as imagined by Castiglione could be used for a widespread understanding of youthful forms of resistance whose signs are humor and the detached 'coolness' of its practitioners. 
one imposes it upon him or her, like the name he or she received at birth. He or she believes also that his or her activities in the graffiti community are somehow free in the terms mentioned above. This freedom is, in fact, a freedom of emotional expression. However, as defined earlier in this essay, it is liminality itself that offers freedom at the expense of security. Since the youth is in a layered liminal state- -here, in the process of earning entrance into membership - this shift into a secure state of values and rules has not yet emerged. It is still sought, and the rewards on the way of this journey are the thrills of production, the early communitas with mentors and the growing sense of personal achievement.

\section{Tagmaking-The Anti-Liminoid through Locations}

It is difficult to communicate the thrills of breaking the law while at the same time feeling that the practice is justified in its existence. It is one of the contradictions on which tagging is constructed. This thrill is contingent on the conditions of the tag locations and the presence of difficulties. ${ }^{155}$ The first tags are not made in risky

155 Thorstein Veblen, in The Theory of the Leisure Class (1899), articulates this notion of prized activities, creating dual oppositions of acts of 'exploit' (prowess) versus acts of 'drudgery.' His distinctions are suitable for graffiti, even if created for a cultural period different than the contemporary one. (In fact, as argued earlier under masculinity, it is precisely notions of masculinity in 20th Century America that appeal to youth, e.g. manliness, risk taking and, eventually, skill of refined craft. For this reason, Veblen is particularly insightful still in understanding this psychology.) Prowess involves activities in confrontation with 'animate' forces, whereas 'drudgery' occurs with inanimate. Veblen defines the animate not as that which is living but which has the sense of willed being, even if that is merely 'primitive':

The term "animate". .. does not cover all living things, and it does cover a great many others.

Such a striking natural phenomenon as a storm, a disease, a waterfall, are recognized as "animate"; while fruits and herbs, and even inconspicuous animal ... are not ordinarily apprehended as "animate" except when taken collectively. The concept includes such things ... formidable by virtue of a real or imputed habit of initiating action ... a distinction between the inert and the active. (10)

To confront animate forces requires more skill and resources than the inanimate. Veblen states that "to deal successfully with such phenomenon is a work of exploit rather than industry. It is an assertion of prowess, not of diligence." (10) Veblen also genders these two types of actions - prowess/exploit vs 
locations. The initiate begins by defacing some easy targets with a marker, such as an electrical box or a STOP sign. After he or she has made these initial tags, the process of production emboldens him or her to take on riskier locations. Perhaps it is a more visible location, near a police station or in full view of a large public, such as a spot on the highway with many cars driving by at all times. As a youth makes these riskier tags, the thrill of the less dangerous locations decreases over time. This is a problem, since the layering of liminality requires this thrill in order to escape the rigid confines of the hierarchy of graffiti itself. Hence, he or she must find more dangerous locations in order to sustain the emotion.

Tagmaking also has the function of affirming identity. The continuous repeated mark means that this society, this external world, that has been so foreign to him or her until now, begins to become part of him or her. Various locations around the city have a deep-seated sense of familiarity, not only because the youth's tag was there, but because he or she had an experience in placing it. The youth's memory becomes full of such places and they become imbued with personal meaning. They also work back upon his or her consciousness as locations that he or she made 'his' or 'hers.'

The notion of taking up something in (supposed) disuse and imbuing it with one's labor is one of the cornerstones of Locke's philosophy of the just transformation of unused land, and arguably begins a process of reclamation of the 'land' (space and structures) in public, even private, use. Locke writes:

diligence/industry, not surprisingly placing exploit as male gendered and diligence/industry as female. Whatever biases existed in Veblen's world view, the activity of the graffiti community evinces that the iconic image of the hunter as male power still persists over that of the diligent planter. We see, therefore, in the youth producing graffiti a fascination with expressing exploit in this fashion and identifying their masculinity with this style. This is equally valid for female producers of graffiti. It is implicit in both the places and methods of graffiti production as well as the claims of graffiti practitioners themselves, as discussed earlier. 
Though the Earth, and all inferior Creatures be common to all Men, yet every Man has a Property in his own Person. This no Body has any Right to but himself. The Labour of his Body, and the Work of his Hands, we may say, are properly his. Whatsoever he removes out of the State that Nature hath provided, and left it in, he hath mixed his Labour with, and joyned [sic] to it something that is his own, and thereby makes it his Property. It being by him removed from the common state Nature placed it in, it hath by this labour something annexed to it, that excludes the common right o other Men. For this Labour being the unquestionable Property of the Labourer, no Man but he can have a right to what that is once joyned to, at least where there is enough, and as good left in common for others. (287-288)

In this sense, the youth may feel that he or she is reclaiming the territory of the city. It is obvious that vandalizing a part of a building does not properly fit into this description of what constitutes the state of 'Nature.' Yet the youth in graffiti feel themselves entitled to do so, arguing against private property. Their strict code states that one should not write graffiti over another writer's graffiti, as if that work was the property of the other writer. The ownership of the building, on the other hand, does not matter. In fact, the tendency of graffiti is to target objects and locations that belong to impersonal entities like the general public and corporations. The facelessness of such entities, and their industrialized, deskilled approach to labor in making objects such as concrete storage buildings allows graffiti youth to distance themselves from the idea that this object is the product of an individual's labor-and hence to distance themselves from the 
notion that they are transgressing against rightfully owned property. ${ }^{156}$

Paradoxically, the youth does not feel that having made a tag on an object makes it his or hers. It is simply marked. He or she knows that the tag will be removed by authorities; the tag merely served to mark the act of prowess. It is intellectual property. Yet it also served to gain entrance into the subculture. He or she wishes to be a member of the graffiti community in order to continue the flight from liminality; making the tags is his or her first key step. The city, then, begins to take on an air of familiarity since its various locations have been frequented by the youth. The youth knows them intimatelyhe or she has marked them at late hours. His or her identity is affirmed through these acts and he or she feels himself or herself close to the community on which they are modeled.

We might also propose here why the use of stencils in the larger umbrella category of street art is not considered true graffiti. The stencil results in less labor, if not a merely mechanical act of using spray paint over the stencil itself. Without raw artisanal labor, as in the production of tags (and later, throw ups and masterpieces), the production of the work fails to capture the Lockean sense of mixing one's labor with physical objects. For this reason, graffiti writers scorn stencils.

However we might imagine the slow transition of an initiate's involvement, at some point he or she feels that he or she is a member of the community. Most likely this occurs through massive production and then affirmation from the community audience. There is obviously no official means to establish it and hence the status of membership remains inchoate. For this reason, the initial thrust to navigate the membership ritual may

156 Graffiti writers tend not to write over legal murals. They view them as works of art. Since graffiti is art, one must not destroy another work of art. The subculture extends its code to all murals, not just graffitistyled murals. It is one of the curious ways in which the labor of the artist is respected whereas the labor of someone simply painting a wall white (or some other color) is not. Not surprisingly, this fact is exploited by graffiti abatement techniques. The City of Philadelphia, struggling to control graffiti production, has commissioned over 1500 art murals. 
well require a massive production, perhaps similar to the early days of graffiti in becoming 'King of the Line.' Yet, today, with the proliferation of the Internet, it is possible that some affirmation of membership occurs through online forums and documented portfolios. The online portfolio survives the removal of the real-world graffiti by authorities, and hence allows one to have an oeuvre perennially intact.

Assuming a successful passage, there are specific effects of the youth's

involvement here through the nature of his or her decisions and acts. First, he or she has escaped the liminality of adolescence in exchange for the values and regimented codes of graffiti. He or she gains community, but asserts his or her status as an outsider of mainstream society. The youth is bound by the rules of this community as well as the necessity to maintain his or her street cred. Also, the youth's identity is mediated through the affirmation of a specific audience, the graffiti community itself. Hence there is always the risk of losing this status, however improbable this possibility might seem (for example, one may 'sell out' to corporate sponsors and provoke the ire of the community).

\section{Masterpiece Murals: The Anti-Liminoid in Process}

In the case of a work of art, the signature is the last thing an artist puts on the object. He or she denotes that the artwork is finished and that he or she, the artist, accepts it as such. From thence the work itself (if it is an object) passes out of his 'world' and into the greater public sphere. Perhaps it will be bought, or donated. The signature marks his or her work and is, for the artist, the least interesting aspect of the creative production. The work itself, assuming it was meritorious, required diligent work, disciplined attention and aesthetic contemplation; perhaps the artist even needed to forget himself or herself 
while making it since its objecthood came to the fore.

There are many kinds of mural masterpieces in graffiti. I consider now, in particular, the masterpieces that feature bold, colorful, stylized productions of the tagger's name. I assume that this is the first form that the masterpiece exhibits. (Some graffiti writers continue onward to making highly complex exemplars in which the focus on the wild-style name alone disappears in favor of original productions, perhaps featuring figurative depictions, nuanced uses of color and shading and even mixed-media while still falling under the category of graffiti art. The unique activity of such creative individuals rests outside the scope of the ensuing description.)

\section{a. Motivations for Making Masterpieces}

In the early research and production of the masterpiece mural, the notion of play undergoes a transformation. ${ }^{157}$ In the production of tags, writers engage in a thrill-seeking form of play known as what Geertz called (from Bentham) 'deep play.' (The Interpretation of Cultures, 432). Geertz considered such play, though apparently irrational, in fact to be based upon "esteem, honor, dignity, respect—in a word . . status" (433). Schechner refers to this as "dark play" which is "'playing with fire,' 'breaking the rules,' 'getting away with murder.' Playing that emphasizes risk, deception, and sheer thrill" (119).

Over time, the status conferred by massive tag production is undermined in the experience of new recruits into the subculture. He or she witnesses that other youth are

157 It is possible that some youth begin their graffiti career by designing masterpieces. Typically, youth first establish their entrance into the subculture by producing tags. One seeks what is often referred to as 'street credibility,' or 'street cred' for short. If a youth were to simply make legal masterpieces, he or she would not have the admiration of the other members as having the 'moxy' to risk his or her life and legal status. 
making quick tags and have matched his achievements. They are younger than him or her and reveal the excitement that he first experienced when he began tagging, an excitement that can only decrease in time as one becomes habituated to the risks and adrenaline. He or she also faces another issue relating to capacity. The youth realizes that making a tag does not require any skill whatsoever. Anyone with enough willingness to risk himself or herself is able to make tags. Secondly, the aforementioned unending pursuit of affirmation and negation results in the contradictory state of feeling bold and yet more dependent upon one's graffiti community for the mediation of one's own identity. In other words, one does not feel truly secure about his or her identity. The emotional content derived from the deep play of tagging dwindles. For this reason, the tag must be superseded by a greater production, a new form of play, one that cannot simply be made by any newcomer to graffiti.

Before a practitioner creates masterpieces, he or she may begin by producing inbetween works called 'throw-ups.' They are essentially more elaborate tags in the shadow of masterpieces. Larger and more complex but with limited colors (usually just an outline with a single filler color), throw-ups essentially demand that a mark that also takes time to create be made in a public location. In this way, a greater risk is encountered. The throw-up is an important step for a practitioner to differentiate himself or herself from the rest of the new graffiti practitioners who are merely making tags. Ultimately, however, the throw-up, like the tag, is really a marker and its aesthetic qualities are secondary. This production, too, while rewarding, becomes repetitive.

In this face of this problem emerges the masterpiece. It is no coincidence that this form of production has this title, since the community itself has named it as such. The tag 
is a marker; 'tag' is appropriate for an object made by fast strokes from spray paint or pens. The throw up is 'thrown up,' indicating also its speedy construction while subtly (if not humourously) demeaning it as vomit. The masterpiece is meant to be a work of art, if not the best that the creative practice offers. It exhibits intentionally constructed formal relationships of its various elements, such as its colors, lines, shapes and dimensions. The masterpiece demands an aesthetic skill that the tag does not. However, both its title of 'masterpiece' and the assumption of its status as an art form create problems for its makers in relationship to liminality.

\section{b. Effects of the Ready-Label of Masterwork}

The first experience of making a masterpiece mural resides in the initial stages of design and planning. This 'play' activity reveals the excitement of researching and designing one's mural. The youth is exposed to other masterpieces, perhaps researching them online. He or she may also study other examples of art from art history, including museum and library visits. He or she goes online and does various searches for masterpieces. The youth frequents specific web sites and blogs in order to become aware of the various approaches to making masterpieces. His or her aesthetic sense becomes educated as he or she studies the relationship of color, line, etc. Lisa Gottlieb's Graffiti Art Styles, in fact, shows that there are over fifty elements in the lettering of a masterpiece. These various elements are in play for the youth and he or she must decide which are most suitable for his or her signature. Like the very cursive script of his or her tag, the masterpiece's colors, arrows, bubbles and thickness of lines are all emblematic of the youth's personality. 
The early sketches on paper are classed as graffiti 'blackbook.' It has even an online counterpart on 12OzProphet.com entitled 'Paper Chase.' Hence one can make a sketch, scan it, upload it, and get feedback from other writers. It is also a way to expand one's online portfolio. This feedback from comments on forum posts reveals that criticism exists as to the forms of the masterpieces. The criticism arises from knowledgeable mentors and veterans of the practice, focusing upon the works originality, effective use of constituent parts (such as its colors and lines) and its function in relationship to its name. ${ }^{158}$

However, this research represents a breakdown of the limen. Whereas with tagging, there is a strict separation between the everyday legal life of a writer versus his or her nighttime graffiti production, the research and study of graffiti murals enters into the flow of his or her everyday life. The breakdown of this original framing of the ritual space of illegal production is furthered later when one makes legal graffiti murals; for now, I assume it only occurs during and throughout research and design.

This crossing of the activities of graffiti into everyday life has an effect on the emotions of the youth. We might assume that it brings graffiti and its production into the light of the everyday, undermining the ritual space of its illegal production. Studying and researching art is a satisfying form of play, and hence a new assertion and motivation for making graffiti may begin to emerge. It is a more mature feeling than the deep play of illegal tag production. It is the early emergence of the transformational force of the aesthetic. It is unlikely that the youth involved are aware of this change as it occurs because its influence is subtle.

158 For example, if a tagger has the name 'KILLER,' then his or her graffiti should be muscular and aggressive. A tagger name like 'CUTIE' might use bright pinks and yellows to authentically engage in its theme. 
Here, too, the graffiti community encounters another paradox. To make a true 'masterpiece' in the standard cultural sense of the artwork terminology (not the label as used in the graffiti subculture) requires a lifetime of skill and practice. Though the use of the label 'masterpiece' in graffiti, like so many other youth subcultures and their terminologies, carries with it an element of irony, it is also the signature work of graffiti in its characterization as an art form. However, if every graffiti 'masterpiece' automatically gains the title of masterpiece in the double sense of an exemplary work of art, then there is nothing for which to strive aesthetically. There is no ultimate standard since the ultimate has been achieved by anyone creating within this style. In other words, the graffiti masterpiece's status as an aesthetic masterpiece is undermined by calling all such works masterpieces. (Undoubtedly this is merely an issue of semantics for some practitioners and does not factor for them.)

Obviously, some effort exists to make an appealing production. Yet, the semantic power of the term has its force here and cannot be dismissed. By making a masterpiece, the graffiti writer becomes an artist without any true standard. He or she enters into the kind of self-defining cycle that Heidegger commented upon in "The Origin of the Work of Art" (1936). Heidegger writes:

On the usual view, the work arises out of and by means of the activity of the artist. But by what and whence is the artist what he is? By the work; for to say that the work does credit to the master means that it is the work that first lets the artist emerge as a master of his art. The artist is the origin of the work. The work is the origin of the artist. Neither is without the other. Nevertheless, neither is the sole support of the other. In themselves and in their interrelations artist and work 
are each of them by virtue of a third thing which is prior to both, namely that which also gives artist and work of art their names - art. (The Continental Aesthetics Reader, 80).

In this case, there are two elements that precede the production of a youth's first masterpiece. The first is the history of graffiti itself. This history documents the presence of graffiti in museums and art galleries, employing the institutional definition of art to raise its status as art. Secondly, the term 'masterpiece' as used by the graffiti community precedes the actual production of his or her masterpiece. Hence, as Heidegger notes in describing the cycle of mutual determination, the following occurs: Graffiti is codified as art, a youth makes a masterpiece that conforms to graffiti's artistic code, ergo he or she is an expressive artist that makes exemplary art. ${ }^{159}$

It would seem that the practitioners of graffiti, therefore, can enjoy the semantic play of the label masterpiece without any negative consequences. However, since the form of the masterpiece was invented by the graffiti community, a graffiti masterpiece must conform to the graffiti society's definition. Otherwise, one risks making something nebulous and hence not automatically artistic. This results in a narrow, specific 'style' to which many masterpieces conform.

For example, there is the highly popularized 'Wild Style' masterpiece. All masterpieces created within the confines of this style seem like variations of a singular type. Despite Lisa Gottlieb's observations of the immense variety within that style, the confines exist. In fact, in an early interview about style, Castleman cites a writer, Fred,

159 This sequence is used to illuminate how the masterpiece falls under the definition of art before it is produced by a particular individual. The graffiti community has declared the masterpiece a work of art in advance by using the term. This then means that the individual is an expressive artist because he or she makes a masterpiece. Hence this is a conceptual statement; it does not refer to the actual production process. 
who states that "[t]here is one main style and that is graffiti itself. When you see it, you know for certain reason that it is graffiti and that makes all graffiti part of a single style" (Getting $U p, 26)$. Should one break too far from this generalized style category, one is not making a graffiti masterpiece. The work becomes a separate thing, some other kind of street art, assuming it is 'art' at all. This question is raised because it has departed from the safe, automatic term of masterpiece given it by the community.

The actual achievement of making a masterpiece in the generic sense of the term as an exemplary form of art over and above similar productions within the genre does not exist for graffiti. The masterpiece is a 'masterpiece' by default of its category. As a result, there are only a few things remaining for which to strive when producing them. The first is approval. If the graffiti society does not approve of one's production, he or she is therefore not making a masterpiece and hence not a work of art. Secondly, since the object automatically earns its art status upon completion, the only remaining goal for which to strive is to make many of them and in visible locations. No wonder, then, that in the graffiti subculture, 'getting up' is so important; nothing else problematic remains as an objective other than sheer quantity of production.

A similar analogy may be with extremist religious membership. Perhaps a practicant makes some fundamentalist declaration as a Christian or Muslim. Having made that declaration, they are now one of God's chosen. The inner movement of transformation, perhaps initiated due to some personal crisis, ends with the mere choice of subscribing to a dogma. The only activity remaining is external, such as proselytizing, persecuting non-members of one's faith, and even martyrdom. Graffiti's artistic movement is, like the religious zealot's, threatens to be merely external. (Not 
surprisingly, graffiti enthusiasts aggressively defend the practice as if everything produced by graffiti writes must be stoutly protected.)

Bertrand Russells oft-quoted observation, "The whole problem with the world is that fools and fanatics are always so certain of themselves, and wise people so full of doubts," is applicable to the arts. The true artist lives in a state of constant questioning. This questioning drives his or her art forward; it is representative of liminality. The graffiti practicants trade this state of humility for one of power, self-assuredness, commitment to an ideology (graffiti), and, not surprisingly, the retro-masculinity that graffiti-making affirms.

\section{c. Compositions and Makings: Further flights from Liminality}

Even the process of sketching and constructing a graffiti masterpiece is radically different than the construction of a painting. An abstract painting, for example, is created partially in relationship to the canvas. Assuming, therefore, an abstract work of art as a point of comparison to graffiti masterpieces (since abstract art has a better relationship with graffiti than figurative art), the painter creates a work in which the whole relates to the four sides. A painting will relate to and fill out the entire canvas in some way. The Golden Ratio, for example, may be employed to subdivide the canvas. A color in one corner may relate to the color in another. Every part relates to other parts and to the whole.

Composition No. 10 (1939-1942) by Piet Mondrian can serve here as an example of the way the whole constitutes a series of specific relationships. The central series of ordered rectangles create a deep sense of equilibrium, including divisions into the Golden 
Ratio (the upper-middle strong central horizontal line bordering on the upper portion of the highest red rectangle). However, this is static. Mondrian breaks up this static relationship by placing various colored rectangles on the right, left and bottom. The three red rectangles create a strong asymmetry, a sort of 'diagonal space' going middle-right downward to the left bottom corner. This diagonal movement is countered by the two yellow rectangles, which move in an opposite diagonal. Since the red and yellow have 'weighed' the piece in this region, the blue rectangle in the upper left then counters the other two colors' effects. A similar effect can be seen in the various black lines. The piece, therefore, reveals a strong classical harmony along with the appearance of disharmony in the colors. This color disharmony, upon further observation, has a greater harmonic relationship. These varied relationships mark the greatness of his work and are what qualify it as a masterpiece of Western art. Mondrian was probably aware of these various layers and manipulated them brilliantly.

Composition No. 10 as a whole is therefore self-relating. Should a curator place this production inside a museum (it is currently in a private collection), he or she must consider how the walls around it will influence what it communicates. For example, he or she would not mount this piece on a red wall, since it would imbalance the effects of the red rectangles. Composition No. 10 dictates to the enlightened viewer that a certain kind of surrounding must be utilized in order to properly display its relationships.

The graffiti masterpiece, on the other hand, must use the outside world as its canvas. Therefore, there is no internal aesthetic relationship to the wall, building, etc. in the same way as Mondrian constructed his colors and lines in relationship to each other. Most graffiti production seeks to contrast radically with the wall on which it is placed, as 
discussed earlier. This is in order to make it more visible. More pertinent to this section is the process of making such a work. Its design, for instance, results in the contemplation of something without any concern to that which is around it other than as destruction and negation, e.g. the cement wall is pushed into the background while the masterpiece leaps to the foreground.

More specifically, one shapes each letter at best in relationship to the others in the composition. For example, assuming a tag name like HYPO, the ' $\mathrm{H}$ ' might be shaped in relationship to the YPO and the other letters in turn to the rest. The form of the 'O' exists because an 'O' is necessary to form the pseudonym 'HYPO.' He or she makes the various letters pointy, or colorful, with shadowing and other three-dimensional illusion effects. The lines in one letter are not meant to create a formal harmony with the lines elsewhere, creating a balancing effect like in Mondrian's work. Lines are repeated simply because one letter's style is extended to the others. The only aesthetic technique revealed here is repetition, undermined due to the use of different lettering. Also, there is no interest as to whether or not these harmonize with the objects and buildings surrounding it. On the contrary; if it harmonizes too much, it is therefore not sufficiently visible. (Even other graffiti pieces on the same wall are problematic, since one wishes his or her masterpiece to stand out more than theirs.)

Site-specific artworks of all types relate, in fact, to the space in which they are created. This is part of the definition of such works. An artist of such works will typically respond to the location in terms of subject matter (layered meanings) and formal elements of his or her artwork. Graffiti, however, is not truly site-specific. Its only formal relationship with the walls and other surfaces on which it is created is contrast; the site's 
meanings are simply based around risk. ${ }^{160}$ The form is pre-established and the meaning is, quite simply, the preponderance of both the identity of its creator as well as the subscription to an ideology. Color contrast and risky production do not constitute sitespecific art any more than an activist who uses bright pink sheet colors for his or her transgressive political fliers. (Such an activist, unlike the graffiti writer, is at least focused upon a cause other than himself or herself.)

The masterpiece is built in time so as to produce an object with which the writer both identifies himself or herself and which the graffiti community identifies it with its author. It does not matter if anyone else identifies with it, or identifies it with its author. However, since it belongs to a type, it is instantly identifiable as graffiti. Here, too, is an example how the production of exemplary art and graffiti differ. Mondrian's art, for example, is both wholly unique (a true expression of the artist and his or her style) while at the same time aesthetically universal. A canvas by Mondrian is instantly recognizable as his. There is something about Mondrian's work with which any viewer can identify, obviously some more than others. There is nothing about a tag that is universal, but its participation as an object in the field of graffiti means that it constitutes a general 'type.' Despite the early style wars of graffiti, and the stylistic differences within graffiti itself, the writing style is sorely limited.

There are really only two key requirements of one's masterpiece: boldness, and 'apparent' uniqueness. Boldness simply requires the most basic awareness of color contrast, such as how red is the opposite color of green, or yellow is the opposite color of

160 While some variation will be based on location, such as size, color and dimensional relationships, the integral form of the work remains fixed. It will be, always, something that contrasts violently with the surface in order to be seen. Some masterpieces will violate this general rule, of course, but then such work also begins to be classed outside my limitations of how I have defined the masterpiece for its analysis in this section. 
purple. Uniqueness arises from the study of other masterpieces, and means that this specific one must reveal its own combination of lines and shapes that are different than another production. Uniqueness is also site-specific; if other masterpieces on the same wall use reds and greens, the new one will stand out if its author switches to purples and yellows.

Neither of these two requirements is difficult to achieve, yet both require some time and knowledge of other masterpieces. This raises the question as to what effect this research of time and understanding accomplishes for the consciousness of writers. Knowledge of a community's style and production is uniquely part of learning and understanding a community's tastes, aesthetic preferences and artistic history. When one observes graffiti continuously, an awareness does develop as to what constitutes good and bad graffiti. ${ }^{161}$

A fair question, though, is how such limited research influences one's aesthetic knowledge. A student of art at a conservatory studies the entire history of art, coming under the influence of a broad range of cultures and styles. (This occurred within the early years of graffiti's history.) Within those styles and cultures there appear, inevitably, certain forms and creations that specifically appeal to him or her. From there, one begins the long process of learning to extricate from himself or herself a unique, personal production. Today, a writer likely falls under a single line of inquiry—-the graffiti masterpiece — and, within those extreme limits, makes a production that is barely expressive. The restriction to a stylized form results in a restricted, stylized production.

This limit to one's artistic style is self-imposed by graffiti, though justified by the

161 I can personally attest to this fact. Since I started studying graffiti, I have become aware of 'good' graffiti versus 'bad' graffiti. 
graffiti ideology. The history of art offers many analogies. Up until the late 20th century, sculpture was dominated by the classical tradition of the 5th Century Athenian Greek figurative art. The greatness of the Renaissance arises in the effort of the modern consciousness to break from this stricture while still remaining within it; there are few sculptors of note up until the rupture finally occurs with the classical figure. In fact, there is something monotonous about subsequent Neoclassical sculpture. Despite some of the technical achievements of some craftspeople, there productions are generally repetitive. No doubt those Neoclassical sculptors, like graffiti practitioners, believed that they were making something very personal and representative of their selfhood.

The same issue surfaces here with the graffiti masterpiece. Like the expert marble artisan of Carrara, trained to make a certain kind of form (like a human form draped in cloth), the graffiti maker is keenly aware of the uniqueness of his or her efforts. Yet, to the outsider, the narrowness of the style reveals the broader narrowing confines of the art form. What if graffiti writers today, instead of limiting themselves to graffiti, actually went far beyond its confines in their efforts and research? What if one encountered the whole history of art and culture? The key result would mean that he or she would escape the confines of the masterpiece of graffiti and, at the same time, abandon the comfort of the label of masterpiece. That label also gave him or her the automatic label as artist. He or she would therefore be forced into the nebulous realm of having to create something truly unique, ex nihilo. He or she would enter, in short, into a liminal space, precisely that which the youth fled when he or she entered the graffiti subculture. Therefore, this is unlikely to happen. (When it does, such an individual—and there are numerous 
instances ${ }^{162}$ - enters into the broader realm of 'street art' and the productions that fall under this greater category. He or she may also continue within the graffiti tradition and make elaborate, unique wall murals.)

State art also may serve as an analogy for how stylistic demands suppress uniqueness. Imagine that a State declares that for something to be an artwork, it must look like 'x.' It must use specific qualities, themes, shapes and lines; should it do this, it is, according to the State, a work of art. The final object does not matter; it simply must follow the means of production as designed by the State. The Stalinist-era art of the USSR Union of Artists is infamous; a stroll through the mid-20th Century collection of paintings of the Gosudarstvenny Russky Muzey (State Museum of Russian Art, St. Petersburg) is a depressing affair. Similarly, works made under the tutelage of the Third Reich, after the destruction of Entartete Kunst, were formally stiff and unimaginatively executed (such as Nazi triumph architecture and the various public sculptures by Arno Brecker). Mussolini's commission for the Stadio dei Marmi in the Foro Italico in Rome depicts imposing, muscular, male athletic statues, created to appeal to a patriarchal, nationalist image of power. However, they are so decidedly homoerotic that they evince how strongly ideology overwhelms even basic visual cues. Some Social Realist art survives today in the history books, but mainly as an historical object. Similarly, the graffiti masterpiece seeks approval from a 'state.' That state, though, is the nebulous graffiti society. The reasons why graffiti practitioners do not believe that they are conformists are twofold: this graffiti 'state' has no specific governing body, and graffiti itself is illegal in its host state.

Even the production sequence of masterpieces is unusual. Unlike the artist who

162 Swoon, Shepard Fairey, Banksy and many more street artists all began as graffiti muralists. 
must first make a work of which he or she is proud and then sign it, the graffiti writer begins with his or her signature. Since the signature is the starting point, its aesthetic qualities are ultimately secondary elements; it does not really matter if the colors coordinate well, or if the lines really function to delineate an aesthetically pleasing form. In a great work of art the ego of the artist recedes to the background, appearing through the nigh-accidental appearance of a style. In graffiti, the ego of the artist is in the foreground. The graffiti writer begins with his pseudo-identity and traces this as his primary act. The style is mimicked from a pre-existing style.

The goal of the masterpiece is, like the tag, to be a highly visible public production. Its colors and lines must stand out, like the person who must boast of achievements in order to fool himself or herself that those achievements are not vacuous. The masterpiece has only one aesthetic task and that is to be visible. This is not a difficult achievement; one need only use bright neon colors, since most building structures are made of cement, brick, wood, or other such low-key colored materials — or are even white. The colors within the masterpiece can clash as well, creating a greater cacophony of visibility. The graffiti writer already begins with a masterpiece and simply personalizes it. It is generic, with little individualization. It should be no surprise that the mainstream viewer remains on the outside, much like one feels in the presence of an extreme narcissist whose self-esteem and artistic justification stands firmly rooted in a massive, extensive, online internet society aggressively ready to defend the practice from outside criticism.

The process of making the graffiti masterpiece is therefore vastly different than that of making an art masterwork. It is, firstly, affirming of the ego of its maker, since it 
is intimately bound up as an expression of the maker. It is, in fact, his or her signature. The lines relate centripetally to the others, unlike the way in which an abstract painting could relate to the whole that is the canvas. As the graffiti writer traces the various lines of the masterpiece, he or she never needs to truly exert himself or herself in order to balance line, color and form. There is a strange freedom in making the masterpiece in that there is little to no critical restraint during its construction. The criticism is oriented towards the outside audience of other graffiti makers. The concern is not whether the work in question is ultimately aesthetically successful, but whether or not it is ultimately acceptable by the rest of the graffiti society. In many ways, it is the product of the mindset of a herd, but here the herd self-identifies as a wolf pack.

This, then, is where the youth of late graffiti production finds himself or herself. He or she has designed and made some masterpieces, the designs on sketches and the actual masterpieces in abandoned buildings. He or she enjoys the thrill of the production of tags, throw-ups and these greater works. There is never any moment of self-doubt, since the ideology of graffiti is immune to such ambiguity. He or she holds himself or herself in esteem, since the youth believes he or she is an artist and his or her work is even, somehow, political and revolutionary. However, since the work lacks any true interiority, his or her security is illusory. As soon as new graffiti writers appear, he or she feels a sense of competition—competitiveness being the earmark of the superficial creator. It is competition that drove him or her away from mere tags in order to differentiate himself or herself from new recruits. In time, he or she recognizes that there are also other people making masterpieces as well. This drives him or her to raise the stakes in the productions of masterpieces. 


\section{d. Furthering Risks, Legal Constructions}

The ultimate illegal and skillful act in the graffiti community is to construct a masterpiece in an illegal location. In its early history, this took the form of entire train cars covered in complex graffiti logos, usually requiring an entire team of youth (the crew) acting in concert (and under the direction, often, of a leader).

To produce a complex masterpiece in an illegal location that is highly trafficked by security personnel is not an easy task. For example, the iconic train depot features security cameras concentrated on several key locations, making any unobserved access to the site nearly impossible. Worse, the site is patrolled, perhaps hourly, by paid security guards. The train depot authorities are aware of graffiti vandalism and have taken basic steps to thwart future writers. This presents an exciting challenge to crews. The authorities constitute the ultimate Veblenian 'animate forces' to overcome. ${ }^{163}$ They must plan, like an elite military force, how they will enter a compound and elude the authorities, all while spending nearly an hour to assemble a pre-designed masterpiece.

Perhaps they assemble for a practice run and carefully observe cameras, check the times of the security personnel and calculate how it might be possible to enter unobserved. Whether it is through obscuring certain cameras, or finding blind spots, the youth's crew is able to outsmart the authorities.

163 Veblen defined 'animate' forces (as opposed to 'inert' forces) as "striking natural phenomenon as a storm ... such things ... formidable by virtue of a real or imputed habit of initiating action ... imputes an unfolding of activity directed to some end" (10) which is then accorded teleological, human-like agency. These animate forces, unlike inert forces (such as "fruits and herbs, and even inconspicuous animals, such as house-flies, maggots, lemmings, sheep" (10)), "have to be met in a different spirit and with proficiency of a different kind from what is required in dealing with inert things" (10). Veblen writes that "to deal successfully with such phenomena is a work of exploit rather than of industry. It is an assertion of prowess, not of diligence" (10). This notion of prowess typifies the masculinity of graffiti and requires confrontation with 'animate' forces. 
It is the greatest graffiti achievement. The tag, when made in a dangerous location, marks a basic act of risk-taking. Yet, the tag is quick and easy to make. The throw-up, its more developed incarnation, further pushes the notion of needing to spend some time in risk locations, such as on a highway overpass, extending the danger of being caught by police. The masterpiece, requiring often an hour to assemble, is the ultimate risk: it requires skill, uniqueness, timing, coordination, and, most importantly, daring.

The relationship to the liminal here is telling. The focus, as in other thrill-seeking efforts, is external. There is both a return to 'deep play' that is risky and an assertion of some aesthetic experience. However, since the act is illegal, the aesthetic radically recedes. There is simply no time to contemplate the production and shape carefully its aesthetic qualities. The focus of the illegal production needs to be about speed. For this reason, the production falls under the anti-liminoid, reversing some of the strides that the youth may have experienced while developing an inclination for making the aesthetically oriented masterpiece.

The process of production is not simply based upon the actual making of the masterpiece. We might assume that the youth document this effort today, especially since there is a massive proliferation of inexpensive recording equipment. Perhaps a video is made and uploaded to a graffiti site. The upload of the video, though, is far less daring then the extended thrill of the making of the masterpiece. In fact, it belies the makers' neediness for his or her work to gain approval and recognition, effectively undermining the very bravery and panache required to make it. This does not occur to the makers, of course, since they feel that they have earned more than enough credibility to boast of the 
achievement.

The busywork of uploading, commenting upon and counting internet 'hits' acts as a counterforce to the adrenaline-inducing risk-taking run with the crew. Like the nature of the tag itself, this is the double-effect of illegal masterpieces and their documentation. The very production of them undermines their force; the documentation to the internet furthers the dampening effect. The result is that over time, even as one might organize productions, the youth feels like he or she still has not 'achieved' something that is solid and noteworthy. As noted earlier in this essay, the very act of making something for the sole purpose of audience approval undermines the act itself, especially when the function of the initial act is related to power. No matter the online accolades, the fact that he or she requires such accolades undermines the very effectiveness of the act. Only an extensive online portfolio rescues a writer from this never-ending assertion and negation, since the portfolio will virtually continue to assert the past productions without the need to actually make them.

Legal commissions, though, are the opposite. The audience approval occurs in part at the outset, as evidenced in the offer of the commission. Perhaps because a youth in graffiti considers himself or herself an artist, and likes the possibility of making some small amount of money to fund his or her greater efforts, the youth decides to accept the legal commission. Legal commissions also serve to boost one's reputation. The youth, no doubt, hides the fact that he or she makes graffiti illegally, producing some basic sketches for the opportunity. His or her knowledge of aerosol cans and their effects and archival durability on walls becomes very useful for public commissions.

The process here is important as well. Upon completing the commission, the 
general community appreciates the youth's efforts. Perhaps it appears in a small local newspaper, or mainstream blogs, wherein his or her art skills are lauded. It is not 'buffed' by authorities; on the contrary, many make efforts to see that it is conserved. (The graffiti community does not write over it, since that is one of the basic honor codes.)

This approbation for one's work from the mainstream community must also have some kind of influence over graffiti writers in the process of their careers. Unlike illegal graffiti, the youth meets his or her audience. This audience knows who he or she truly is, not the pseudonym. Perhaps other businesses approach him or her to make a mural. Graffiti abatement theorists have argued that the best way to deter graffiti vandalism is to commission murals, since the graffiti writers will not write over them. Therefore, there is a market out there for a writer's new work, a market created by individuals like him in his tagging days.

I suspect that these opportunities create mixed feelings. On the one hand, the youth is benefiting greatly from them. He or she receives money, praise, a sense of acceptance from the mainstream community he or she has rejected, and even some renown. On the other hand, the youth might feel like he or she is selling out. Hence, while making these commissions, he or she may continue in the former activities, such as occasionally heading out at night to produce throw-ups and tags, making illegal masterpieces with a crew, writing on forums, and commenting on other producers' works.

From the perspective of liminality, though, there is a twofold break with the limen. The first is the activity of making a masterpiece that was reserved for the liminal space brought about by nighttime, since the illegal activity is shifted into the mainstream light of day. This blurs the boundary of the limen of traditional illegal graffti and the 
everyday civic life, causing some confusion within how one might perceive ensuing productions. For example, the identical activity performed in making an illegal masterpiece at night (and as vandalism) is performed while making a legal one in daylight (and commissioned locations), making the illegal activity less 'sacred.'

Secondly, the liminal condition of outsider status is undermined by public acceptance of the legal productions. The graffiti writer experiences that their productions that are aesthetically pleasing have a beneficial effect upon their community. There is no need to have a split between their creative, illegal self and their everyday mainstream persona. The positive acceptance and affirmation from the mainstream community therefore causes a mending of the rupture that initially began with the youth's entrance into the illegal aspects of graffiti tag-making. We might assume that a youth making masterpieces is already in the later stages of adolescence, if not already in his or her early twenties. For this reason, adolescent liminality as such is already at its closure. The remnant of this liminality was the participation in illegal graffiti. The production of legal murals represents the final break with one's early youth.

Here, too, we might speculate on new changes in the process of making graffiti. Assuming one ventures deeply into a career as a muralist, a graffiti writer is then challenged to enter into a far more unique and noteworthy production than simply making graffiti masterpieces. The writer needs to confront the uniqueness of art-making and the insecurity occasioned by facing the possibility of constructing art that fails. Before, a masterpiece was a masterpiece by the default of working within the constraints of a predefined style. Now, he or she must make headway into new, original forms that are truly expressive of his or her skill as an artist. To do so requires a venture into the 
abyss of liminality. It requires abandoning the safety of the label of graffiti, and hence, ultimately, departure from the graffiti underworld. For as one progresses more deeply into an authentic art—an authentic liminal or liminoid space — he or she recognizes that a major part of graffiti is a flight from the liminal, not its affirmation. One cannot identify, then, with young teenagers making tags, or older ones boasting of illegal throw-ups. It is no wonder, then, that in so many instances, the graffiti career comes to an end.

The veteran, aging Schillerian savage becomes in time more balanced as he or she engages in hard work and sacrifice. The labor of making and refining artwork shifts the writer away from his or her youthful emotions. The contemplation of the beautiful becomes the new form of 'play,' in such contrast to the risky deep play of the writer's early adolescence. Nevertheless, I believe that all ex-graffiti writers hold a deep nostalgia for the thrills of their early youthful productions. The memory of an unbridled instinct might become a metaphor or even marker for past virility. Perhaps those same memories might dwell upon the camaraderie born from sharing real dangers with their former crews. Like soldiers facing PTSD, certain ex-graffiti writers might never truly grow out of their past productions, even if their actual lifestyles no longer exhibit any trace of their graffiti history. It would be too extreme to describe this as a schismogenic state, yet I propose here the possibility. We might note that SABER's 2007 monograph SABER: MAD SOCIETY or Stephen Powers' The Art of Getting Over are examples of this reverence for the past.

\section{Conclusion}

The process of involvement in the graffiti community and the process of 
creatively constructing graffiti both have the effect of gravitating youth through and then away from the practice. A youth begins as a novice and is driven to become a member through involvement with others. Upon becoming a member, he will find, in time, that he is not able to differentiate himself from new members unless he raises the stakes of his abilities within the practice. Similarly, the tag itself, once prolifically created, loses its appeal as one no longer finds its risk-taking elements to be as exciting as they initially were. The creative excitement of developing masterpieces is eventually undermined by the anti-liminal elements of the masterpiece itself - its hard lines, negation of its locations and predetermined form. The contradictions inherent in the creative process of a masterpiece either drive a youth away from the practice, toward perfecting the masterpiece as a unique object in and of itself (and constructing public commissions) or making massive masterpieces illegally.

The illegal masterpiece is the ultimate expression of the contradictions of the process of graffiti involvement. The creative aspect is not satisfying enough to be selfsustaining, so risk is added to the emotional content. Similarly, simply risking oneself to make tags and throw-ups is not enough, so the masterpiece is added. This, though, does not resolve any contradictions, such as the object's limitations, its predefined status as a work of art and the mediation of its meaning through an outside audience. The contradictions persist within every subsequent development. Hence, the process of involvement in graffiti naturally results in its termination. Unlike the involvement in drugs, in which increased use causes addiction and further use, graffiti actually selfdestructs. Only the most creative individuals, those who are able to move outside the standardized styles, and psychotics, whose attachment to thrills or general antisocial 
tendencies are extremely pronounced, will continue within the subculture, like the retrogressive, retrospective sixty-something hippies visible today.

The liminal condition of the adolescent represents a continuous test of the stages of graffiti involvement. One creates an initial layer of liminality as he or she begins the rite of passage to become a member of the community. Once a member, one's adolescent liminality is distanced through acceptance of the codes and ideology of the subculture. Through time, though, the writer witnesses new initiates and realizes that the uniqueness of his or her practice is easily reproduced. This might reintroduce the liminal condition as the writer feels insecure about his or her identity. The masterpiece emerges, then, as a means to deepen one's identity in the subculture as one of its master producers, assuming he or she has not simply exited that subculture. Yet, the masterpiece's static form and predefined style, despite the attempt of the youth to make it uniquely his or hers, also prevents a mature investigation into liminality as creative process. Its legal variant brings the youth into relationship with the mainstream community; it breaks down the liminally induced barriers between their graffiti world, the process of creation and a new, affirming audience—-mainstream society. 


\section{CONCLUSION}

Liminality affects adolescent male identity in response to changes in American culture as well as to their identity as youth. My findings indicate that male youth are drawn to graffiti due to its appeal as a throwback form of masculinity similar to that traditionally featured in American culture. This masculinity is based upon both risktaking behavior and autonomous production of skilled, inherently meaningful activity such as artisanal works or artworks. Should a graffiti writer extend his or her involvement throughout the full possibilities available within the graffiti community, from tags to masterpieces, he or she will probably find that the model of masculinity constructed at the extreme ends of this spectrum are at odds. The masterpiece requires patience and skill versus the raw (if not repetitive) production of tags. The two find their union in the illegal production of large-scale masterpieces. Nevertheless, the model of masculinity in graffiti undermines itself through the very production it proposes. Boasting, or in this case markmaking, is symptomatic of insecurity. Tags undermine their purpose in that they negate what they affirm: the tag asserts a masculine act of prowess while undermining it in the making of the tag. Once a masterpiece becomes a self-sustaining object of construction without external constraints, it shifts away from this problematic affirmation and negation. Finally, while graffiti might be coded as masculine, and hence have specific 
appeal to males, there is no reason why females should not also find it appealing.

Adolescent liminality is symptomatic of all youth, though, not just males. Youth face ambiguity in the realization of their basic rights formed at birth. Since the power to express or realize those rights is not explicitly and positively established through a clear system of development, youth find themselves confused as to their identity as adults or children. Also, their basic consent to a political and economic system is presumed within their very participation in society itself. For this reason, it is completely logical that youth rebel. The rebellious behavior asserts their rights and powers as well as their ability to consent to social structures.

Graffiti is simply one instance of how youth might rebel while asserting something that corresponds to their need to belong. It is ideal in that it allows them to preserve their status in mainstream society (via its anonymity) as well as engage in radical behavior. Its extant system of codes and norms allows the youth involved to consciously consent to a society and participate in a community of their own choosing. Likewise, they can consent to leave it at any time. Graffiti, though, is not the only anonymous way in which youth might rebel while still keeping a real-world persona intact. In fact, I suspect that the continued proliferation of the Internet will create other opportunities for rebellious youth through its anonymity, such as in the abusive practice of SWATing and the antagonistic bullying in virtual forums.

The transitioning into and out of the subculture of graffiti is highly nuanced. There are layers of liminal involvement and liminoid production that have a relationship to each other and possibly affect an individual's long-term involvement in the community. A youth in a liminal crisis might seek graffiti as an 'antidote.' He or she 
passes through an initiation to become a full writer, adding a secondary layer of liminality while suspending the deeper adolescent one. This temporary, secondary layer is also mitigated by the 'deep play' of risky production in the early form of graffiti, tagging. Once a youth establishes himself or herself as a tagger through massive production, the secondary liminal stage of initiation into the community mostly ceases. Time has an effect here in terms of community as well as practice. The youth passes into the community's established echelon and also witnesses the arrival of new recruits. He or she may then identify himself or herself differently, and seek to establish a new level of graffiti prowess through more sophisticated productions like masterpieces. Given that the thrill-seeking aspects can only decline through time, the production of masterpieces can therefore assert a new level of power and prowess within the community.

My analysis of the creative process of the masterpiece demonstrates that it tends towards the anti-liminal in its use of predefined, hard lines, and pre-established standards of quality (masterpiece as a work of art) and in its problematic relationship to the spaces in which it is created. However, like all creative objects that unfold and change through time, there is much possibility of variance. The first investigations and designs of masterpieces represent a renewal of emotions and interest for the youth involved. No doubt the initial interest in designing and constructing masterpieces allows a youth to overcome the form's inherent problems as described above. I believe that the need to make illegal masterpieces is in response to this inherent lack of liminality within the creative process. Hence the use of risky 'deep play' returns in order to bolster the experience. In the long term, only the most creative youth and those capable of obtaining legal commissions will find themselves continuing as writers. 
The crisis of masculinity, while specific to events in the United States over the past 150 years, also has elements that are better informed by social contract theory. Masculine norms of adolescent behavior are partially caused by issues of rights and consent; they simply assume a specific gendered form in response to them. The production of graffiti, while apparently ideal as a solution to youth and male crises, undermines its goal. Nevertheless, the performance of graffiti aids youth, and males in particular, in encountering the issues of male (and young adult) identity. An analysis of the creative processes of graffiti demonstrates how youth both engage in a destructive act — vandalism of property — while attempting to positively construct their relationship to a larger community and the general society's demands of consent. This is especially the case in regards to legal graffiti.

Our values and our laws encourage, if not engender, adolescent liminality. It is possible that if youth liminality is somehow addressed in the civic sphere, then male identity will also be remediated. I believe that creating precise markers of adulthood that form a graduated transformation within specific conditions will remediate many of American youth's issues of rebellion. It is, in fact, the conclusion proposed in Woolard and Scott's article for the Handbook; they suggest that, "in some contexts, adolescents might benefit from a probationary period in which adult skills can be acquired, with protection from the costs of inexperienced choices" (368). For example, instead of creating the right to vote at age eighteen, a system of voting may be created at age twelve, fifteen and eighteen. The votes of youth at age twelve would have no effect upon mainstream politics but would still be analyzed as a possible factor of public sentiment, like a poll. Their vote could affect inessential school-level issues such as cosmetic 
elements. At age fifteen, youth should be able to vote upon issues that directly affect them in local politics, such as school funding, environmental protection, juror judgment and punishment for juvenile transgressions, even in a limited format. The resultant full right to vote at age eighteen would be more successful in that new citizens will have had six years of civic participation to inform their new powers. Similar benchmarks might be created in all areas where hard-set age limits exist. For example, instead of limiting military involvement to age eighteen, one could join a one-day military boot camp at age twelve and a three-day version at fifteen. These younger, early versions would simply feature mostly athletic practices and light exposure to soldiering without any true risks. The point, though, would be to assert the right of youth to make decisions. Their decision at age eighteen would then be well-informed. Driving, alcohol consumption and other current legal markers based on age could equally have graded opportunities of involvement in order to create markers of maturity and consent.

Corporate advertising, manifested in the culture of consumption, is polarizing for youth. Youth in a liminal crisis may recognize it as a mere palliative to liminality (in its attempts to appease a superficial range of emotions and appeal to belonging through style) or subscribe to it. A thorough education in the arts and humanities, especially if it is about transformative creations, could offer all youth recourse from their liminality. This would aid in creating a new citizenry that would support the arts, not the Walmarts.

An application of Schiller's Letters allows for an appreciation of graffiti involvement and an assessment of its best forms. It reveals the character of those likely to rebel against mainstream structures (the 'savage') and the inherently political stance contained within their psychological disposition. The savage values his personal privilege 
of rights and powers, the strength of his emotions, and, in the same vein, his virility. Graffiti appeals to the character of the savage in that exults this virility and emotionality while asserting an anti-structural stance. We may also add that Schiller asserts the role of the aesthetic as transformative. The practice of graffiti, even if it ultimately shifts away from what I consider to be a more authentic form of liminal art, still results for the youth involved in what they consider to be aesthetically pleasing objects. This aspect, combined with the potential rigors of producing masterpieces, works back upon the characters of the youth making them. It refines their youthful 'savage' nature with 'barbaric' tendencies of discipline, sacrifice and form.

Today, the Adolescent Handbook of Psychology considers Positive Youth Development to be a key litmus test for judging youth activities. Hence it is important to assess graffiti from the perspective of PYD. It is difficult to make a broad-based judgment on graffiti, since there is so much variety in the kinds of youth and the times of involvement. We can conclude, though, that there are obvious problematic elements as well as positive ones. First, the risk-taking aspects are highly problematic in that the youth may actually injure themselves, or even die. Vandalism is also an issue because it involves breaking the law. However, based on my observations in the political and philosophical realm, I believe that youth will invariably rebel, and even destroy property. Graffiti simply creates a highly visible, regimented and organized approach to breaking the law. Even without the existence of graffiti, youth engage in the destruction of property as a form of adolescent rebellion. One might defend graffiti on the grounds that the objects vandalized are not actually destroyed, and sometimes an aesthetic cultivation occurs. The main danger of graffiti is to those making it. 
The codes of graffiti mirror the codes of mainstream society. The experience of the community can serve as a knowledge base for operating in other sectors of mature society. One might learn skills in resource management, leadership and planning. Also, the artistic features of the practice might foster creativity in individuals who might otherwise not have the opportunity to express and explore this aspect of their character.

As demonstrated in the final section of this paper, the very practice of graffiti leads its members away from the community. Whether it is the decline in the thrill of making tags, or the anti-liminal tendencies of masterpiece production, the practice engenders its own end in its members. Very few-perhaps the most creative, or even the few extremists - continue the practice into adulthood. Since the youth are able to simply quit the activity and assume normal civic roles, it is even possible that graffiti enables this transition better than other forms of rebellious activity. For example, some youth might smoke marijuana in order to rebel against social injunctions. This results in their connection to a drug underworld, the temptation to become dealers and the possible addiction to the drug itself. Graffiti, on the other hand, simply makes claim to creative works and even respects extant murals.

In fact, I further believe that there is a very specific character of youth that is drawn to graffiti. The real question for PYD is what would occur with these youth should graffiti not exist as a means for them to establish their identity, as (probably) males, as members of a society, and as creative individuals. The longing for thrills might find more destructive outlets; their outsider status might result in violence towards more mainstream males in an effort to assert their virility; and they might join gangs in order to feel themselves supported. In fact, many graffiti practitioners have noted that graffiti has 
actually enabled some youth in difficult neighborhoods to find a more generative, productive path in life.

The two biggest dangers to PYD in graffiti stand at opposite poles of responsibility. The clearest danger, stated above, is the risks themselves. The opposite pole is the way in which society punishes youth in graffiti. Here, occasional police brutality and extensive prison sentences create issues for PYD that are not inherent to the practice, even if its illegality adds appeal to its masculine risk-taking. In this sense, it is society that should consider how the public can affect its approach to graffiti in order to make it at least potentially more positive. Eliminating graffiti, or enacting harsh laws against it, will not prevent youth from emerging that would find graffiti expressively appealing. Instead, laws should be enacted so that youth caught making graffiti are not put in jail, but instead demanded to enact community service. This community service could be none other than making murals. 


\section{REFERENCES}

“12ozProphet.com.” Web. 25 June 2011.

Acker, Christian P. Flip the Script. Berkeley, CA: Gingko Press Inc., 2013. Print.

Aho, Kevin. "Simmel on Acceleration, Boredom, and Extreme Aesthesia." Journal for the Theory of Social Behaviour 37.4 (2007): 447-462. EBSCOhost. Web.

Aristotle. Physics. Ed. David Bostock. Trans. Robin Waterfield. Oxford; New York: Oxford University Press, 2008. Print.

Armengol, Josep M., and Angels Carabi, eds. Debating Masculinity. Men’s Studies Press, 2009. Print.

Arneil, Barbara. "Citizens, Wives, Latent Citizens and Non-Citizens in the Two Treatises: A Legacy of Inclusion, Exclusion and Assimilation.” Eighteenth Century Thought 3 (2007): 207-233. Print.

---. John Locke and America: The Defence of English Colonialism. Oxford University Press, USA, 1996. Print.

---. “John Locke, Natural Law and Colonialism." History of Political Thought 13.4 (1992): 587-603. Print.

Audi, Tamara. “As Their Work Gains Notice, These Painters Suffer for Their Art.” Wall Street Journal 26 May 2011. Web. 8 June 2011.

Austin, Joe. “Academics Don’t Write: A Few Brief Scribblings and Some Questions.” Rhizomes: Cultural Studies in Emerging Knowledge 25 (2013): n. pag. Web. 13 Dec. 2014. 
---. "Knowing Their Place: Local Knowledge, Social Prestige, and the Writing Formation in New York City." Generations of Youth: Youth Cultures and History in Twentieth-Century America. Ed. Joe Austin and Michael Willard. New York: New York University Press, 1998. 240-252. Print.

---. "More to See than a Canvas in a White Cube: For an Art in the Streets." City 14.1/2 (2010): 33-47. EBSCOhost. Web.

---. Taking the Train. New York: Columbia University Press, 2001. Print.

Austin, Joe, and Michael Willard, eds. Generations of Youth: Youth Cultures and History in Twentieth-Century America. New York: New York University Press, 1998. Print.

Bailyn, Bernard. The Ideological Origins of the American Revolution. Enlarged edition. Cambridge, Mass: Belknap Press, 1992. Print.

Baker, C. Edwin. "Sandel on Rawls." University of Pennsylvania Law Review 133.4 (1985): 895-928. JSTOR. Web.

Banksy, dir. Exit Through the Gift Shop. Paranoid Pictures, 2010. Film.

Barry, Peter. Beginning Theory: An Introduction to Literary and Cultural Theory. 3rd ed. New York: Manchester University Press, 2009. Print.

Bataille, Georges. "Sacrifices and Wars of the Aztecs." The Consumer Society Reader. Ed. Juliet Schor and Douglas B. Holt. New York: New Press, 2000. 229-232. Print.

---. The Acursed Share : An Essay on General Economy. New York: Zone Books, 1988. Print.

---. Visions of Excess : Selected Writings, 1927-1939. Minneapolis: University of Minnesota Press, 1985. Print.

Beauvoir, Simone de. The Second Sex. Trans. Constance Borde and Sheila MalovanyChevallier. 1st ed. Vintage, 2011. Print. 
Becker, Howard S. Outsiders: Studies In The Sociology Of Deviance. New York: Free Press, 1997. Print.

Beikirch, Hendrik ECB. Blurring Boundaries : Extending the Limits of Graffiti. Cologne, Germany: Publikat, 2014. Print.

Bennett, Andrew. "Subcultures or Neo-Tribes?” The Consumption Reader. Ed. David B Clarke, Marcus A. Doel, and Kate M.L. Housiaux. New York: Routledge, 2003. 152-156. Print.

Benson, Thomas W., ed. "Justifying America: The Declaration of Independence as a Rhetorical Document." American Rhetoric: Context and Criticism. Carbondale: Southern Illinois University Press, 1989. 67-130. Print.

Berger, Maurice. Constructing Masculinity. New York: Routledge, 1995. Print.

Berlin, Sir Isaiah. Four Essays on Liberty. London, New York etc.: Oxford University Press, 1990. Print.

Berzofsky, Marcus et al. Female Victims of Sexual Violence, 1994-2010. Bureau of Justice Statistics, 2015. Print.

Bhabha, Jacqueline, ed. Human Rights and Adolescence. Philadelphia: University of Pennsylvania Press, 2014. Print.

Blankenstein, Andrew. “Taggers Attacking Outdoor Areas near MOCA Museum’s ‘Art in the Streets' Exhibit in Little Tokyo, LAPD Says [updated] - Latimes.com.” L.A. Now. N.p., 14 Apr. 2011. Web. 8 June 2011.

BLU. MUTO. Saatchi \& Saatchi New Director Showcase, 2008. Film \& Animation. YouTube, May 23, 2009. Web. July 12, 2015.

Bly, Robert. Iron John: A Book About Men. Reprint. Da Capo Press, 2004. Print. Boehm, Mike. "Chaka, from Graffiti to Gallery | Culture Monster | Los Angeles Times.” N.p., n.d. Web. 2 Mar. 2011.

Bois, William Edward Burghardt Du. The Souls of Black Folk. Unabridged edition. New York: Dover Publications, 1994. Print. 
Bordin, Elisa. "Expanding Lines: Negotiating Space, Body, and Language Limits in Train Graffiti." Rhizomes: Cultural Studies in Emerging Knowledge 25 (2013): n. pag. Web. 13 Dec. 2014.

Bowen, Tracey. "Graffiti as Spatializing Practice and Performance." Rhizomes: Cultural Studies in Emerging Knowledge 25 (2013): n. pag. Web. 13 Dec. 2014.

Bowen, Tracey E. "Graffiti Art: A Contemporary Study of Toronto Artists." Studies in Art Education 41.1 (1999): 22-39. Print.

Bowlby, Rachel. "Commerce and Femininity." The Consumption Reader. Ed. David B Clarke, Marcus A. Doel, and Kate M.L. Housiaux. New York: Routledge, 2003. 168-172. Print.

Boyd, Stephen B., W. Merle Longwood, and Mark W. Muesse, eds. Redeeming Men : Religion and Masculinities. 1st ed. Louisville, KY: Westminster John Knox Press, 1996. Print.

Brake, Mike. Comparative Youth Culture: The Sociology of Youth Cultures and Youth Subcultures in America, Britain, and Canada. Boston: Routledge \& K. Paul, 1985. Print.

Brizee, Allen, and J. Case Tompkins. "Gender Studies and Queer Theory (1970sPresent)." Purdue OWL: Literary Theory and Schools of Criticism. N.p., 08:25:59. Web. 23 Feb. 2011.

Broadhurst, Susan. Liminal Acts: A Critical Overview of Contemporary Performance and Theory. A\&C Black, 1999. Print.

Brod, Harry. The Making of Masculinities: The New Men's Studies. Routledge,an imprint of Taylor, 1987. Print.

Bruns, Matthew. "Compiled Interviews." Rhizomes: Cultural Studies in Emerging Knowledge 25 (2013): n. pag. Web. 13 Dec. 2014.

Buckley, Cara, and Marc Santora. "Night Falls, and 5Pointz, a Graffiti Mecca, Is Whited Out in Queens - NYTimes.com.” New York Times 19 Nov. 2013. Web. 18 Feb. 
2015.

Butler, Judith. Gender Trouble: Feminism and the Subversion of Identity. 1st ed. Routledge, 2006. Print.

---. "Imitation and Gender Insubordination." The Lesbian and Gay Studies Reader. Ed. Henry Abelove, Michele Aina Barale, and David M. Halperin. New York: Routledge, 1993. 307-320. Print.

Campbell, Joseph. The Hero with a Thousand Faces. New York: Pantheon Books, 1949. Print.

Campbell, Martin. GoldenEye. MGM Studios, 1995. Film.

Campion, Jane. Bright Star. Pathé Renn Productions, 2009. Film.

Campos, Ricardo. “Graffiti Writer as Superhero.” European Journal of Cultural Studies 16.2 (2013): 155-170. ecs.sagepub.com. Web.

Cardenas, Jose. “Tagger's Fall Will Be Lesson for Students.” Los Angeles Times 2 July 1998. Web. 8 Dec. 2011.

Castiglione, Baldassarre. The Book of the Courtier. Trans. Thomas Hoby. Gardners Books, 1974. Print.

Castleman, Craig. Getting Up : Subway Graffiti in New York. Cambridge Mass.: MIT Press, 1982. Print.

Çelik, Zeynep, ed. Streets : Critical Perspectives on Public Space. Berkeley: University of California Press, 1994. Print.

Chabris, Christopher. The Invisible Gorilla. 1st ed. New York: Crown, 2010. Print.

Chalfant, Henry, and Sacha Jenkins. Training Days: The Subway Artists Then and Now. New York, NY: Thames \& Hudson, 2014. Print.

Chang, Richard S. “An Artist's Career Writ Large, With Spray Cans on Subway Trains.” New York Times 29 Apr. 2011. Web. 8 June 2011.

Chelala, Cesar. "Urbanization: Out of Balance and Growing." The Epoch Times. N.p., 22 Jan. 2010. Web. 25 Nov. 2011. 
Chin, Elizabeth. Purchasing Power : Black Kids and American Consumer Culture.

Minneapolis, MN: University of Minnesota Press, 2001. Print.

“Christie's Art Sale 'Highest in Auction History."” BBC 16 May 2013. bbc.co.uk. Web. 22 May 2013.

Chuang, Angie. "Fall Injures Alleged Tagger." Los Angeles Times 12 June 1997. Web. 8

Dec. 2011.

Clarke, David B, Marcus A. Doel, and Kate M.L. Housiaux, eds. The Consumption Reader. New York: Routledge, 2003. Print.

Clemans, Shantih E. "The Lost Boyz: A Dark Side of Graffiti.” Social Work With Groups 35.4 (2012): 390-392. CrossRef. Web.

Cocroft, Wayne. War Art: Murals and Graffiti -- Military Life, Power and Subversion. York: Council for British Archaeology, 2006. Print.

Cohen, Jonathen. "5 POINTZ | The Institute of Higher Burning.” Web. 18 Feb. 2015.

Cohen, Lizabeth. A Consumers' Republic: The Politics of Mass Consumption in Postwar America. 1st ed. New York: Knopf, 2003. Print.

COLT.45. “Our City Is Your Crime.” City 14 (2010):156-157. Print.

Connell, R. W. "Hegemonic Masculinity.” Gender \& Society 19.6 (2005): 829-859. Print.

---. Masculinities: Second Edition. 2nd ed. University of California Press, 2005. Print. "Convention on the Rights of the Child, 1989 -Text | Humanium for Children's Rights." Web. 20 Feb. 2015.

Craw, Penelope J. et al. “The Mural as Graffiti Deterence.” Environment \& Behavior 38.3 (2006): 422-434. EBSCOhost. Web.

Cremonese, Marcus. "Gutenberg, Garamond, Graffiti, Grunge - the Many Faces of Type." Journal of Audiovisual Media in Medicine 23.1 (2000): 22. Print. Curtis, Cassidy. "Graffiti Archaeology.” Graffiti Archaeology. N.p., n.d. Web. 13 Dec. 2014. 
Danto, Arthur C. "Flyboy in the Buttermilk: Jean-Michel Basquiat." Nation 280.18 (2005): 25-28. Print.

De Certeau, Michel. “The Practice of Everyday Life.” The Consumer Society Reader. Ed. Juliet Schor and Douglas B. Holt. New York: New Press, 2000. 259-266. Print.

Doty, William. Myths of Masculinity. New York: Crossroad, 1993. Print.

Droney, Damien. “The Business of 'Getting Up': Street Art and Marketing in Los Angeles." Visual Anthropology 23.2 (2010): 98-114. EBSCOhost. Web.

Edley, Nigel. Men in Perspective: Practice, Power, and Identity. New York: Prentice Hall, 1995. Print.

Edlin, Jay (J.SON). Graffiti 365. New York: Abrams, 2011. Print.

Edwards, Ian. "Banksy's Graffiti: A Not-so-Simple Case of Criminal Damage?” Journal of Criminal Law 73.4 (2009): 345-361. EBSCOhost. Web.

Ehrlich, Dimitri, and Gregor Ehrlich. "Graffiti in Its Own Words." New York 39.24 (2006): 48-124. Print.

Eisenberg, Nancy, Amanda Sheffield Morris, Brena McDaniel, and Tracy L. Spinrad. "Moral Cognition and Prosocial Responding in Adolescence." Handbook of Adolescent Psychology, Volume 1: Individual Basis of Adolescent Development. 3rd ed. Vol. 1. Hoboken, New Jersey: John Wiley \& Sons, Inc., 2009. 229-265. Print. 2 vols.

"Employment and Unemployment Among Youth Summary." The United States Department of Labor Bureau of Labor Statistics. 22 May 2013.

England, Ralph. “A Theory of Middle Class Juvenile Delinquency.” The Journal of Criminal Law, Criminology, and Police Science 50.6 (1960): 535. Print.

Eyck, Toby A. Ten, and Brette E. Fischer. "Is Graffiti Risky? Insights from the Internet and Newspapers." Media, Culture \& Society 34.7 (2012): 832-846. mcs.sagepub.com. Web.

Fanon, Frantz. Black Skin, White Masks. Trans. Richard Philcox. Revised edition. New 
York : Berkeley, Calif.: Grove Press, 2008. Print.

Farrell, Susan and Brett Webb. Art Crimes. www.graffiti.org. Web. July 15, 2015.

Farrington, David P. “Conduct Disorder, Aggression, and Delinquency.” Handbook of Adolescent Psychology, Volume 1: Individual Basis of Adolescent Development. 3rd ed. Vol. 1. Hoboken, New Jersey: John Wiley \& Sons, Inc., 2009. Print. 2 vols.

Ferrell, Jeff. "Urban Graffiti: Crime, Control and resistance.(Special Issue: Youth and Resistance)." Youth \& Society 27.1 (1995): 73. Print.

Ferrell, Jeff, and Robert D. Weide. "Spot Theory.” City 14.1/2 (2010): 48-62. EBSCOhost. Web.

Filmer, Robert. Patriarcha and Other Political Works. Ed. Peter Laslett. New York: Transaction Publishers, 1949. Print.

Fineman, Martha L. A. “Taking Children's Interests Seriously.” Child, Family, and the State. Ed. Stephen Macedo and Iris Marion Young. New York: New York University Press, 2003. 234-242. Print.

Finkelpearl, Tom. Dialogues in Public Art. MIT Press, 2001. Print.

Finnis, John. Natural Law and Natural Rights. 2nd ed. Oxford ; New York: Oxford University Press, 2011. Print.

Fiske, John. "Shopping for Pleasure: Malls, Power, and Resistance.” The Consumer Society Reader. Ed. Juliet Schor and Douglas B. Holt. New York: New Press, 2000. 306-328. Print.

Foner, Eric. Tom Paine and Revolutionary America. New York: Oxford University Press, 1976. Print.

Frabetti, A.C. Reciprocity between Graffiti Vandalism and its Virtual Documentation," gnovis, Volume XII Issue I, 2011. Web.

---. "Perspectives on the 2BUCK Interstate 65 Graffiti Tag and the Responding Rhetoric." The Journal of Kentucky Studies, Vol. 28 September. 2011. 114-122. Print. 
Franklin, Clyde. The Changing Definition of Masculinity. New York: Plenum Press, 1984. Print.

Frankl, Viktor E., William J. Winslade, and Harold S. Kushner. Man's Search for Meaning. 1 edition. Boston: Beacon Press, 2006. Print.

Friedan, Betty. The Feminine Mystique. Reprint. W. W. Norton \& Company, 2001. Print. ---. "The Sexual Sell.” The Consumer Society Reader. Ed. Juliet Schor and Douglas B. Holt. New York: New Press, 2000. 26-46. Print.

Friend, Celeste. "Social Contract Theory." Internet Encyclopedia of Philosophy (2004). Web. 1 Dec. 2013.

Fyfe, Nicholas. Images of the Street : Planning, Identity, and Control in Public Space. New York: Routledge, 1998. Print.

Galston, William A. "Parents, Government, and Children: Authority over Education in the Liberal Democractic State.” Child, Family, and the State. Ed. Stephen Macedo and Iris Marion Young. New York: New York University Press, 2003. 211-233. Print.

Gane, Nicholas. Max Weber and Postmodern Theory: Rationalisation Versus ReEnchantment. Palgrave Macmillan, 2002. Print.

Ganz, Nicholas, Nancy Macdonald, and SWOON. Graffiti Women: Street Art from Five Continents. New York: Harry N. Abrams, 2006. Print.

Gardiner, Judith. Masculinity Studies \& Feminist Theory : New Directions. New York: Columbia University Press, 2002. Print.

Garelick, Rhonda. Rising Star : Dandyism, Gender, and Performance in the Fin de Siècle. Princeton N.J.: Princeton University Press, 1998. Print.

Gastman, Roger, and Caleb Neelon. The History of American Graffiti. Harper Design, 2011. Print.

Gastman, Roger, Rowland, Darin and Sattler, Ian. Freight Train Graffiti. Paw Prints, 2008. Print. 
Gaus, Gerald, Shane D. Courtland, and David Schmidtz. "Liberalism.” The Stanford Encyclopedia of Philosophy. Ed. Edward N. Zalta. Spring 2015.

Geertz, Clifford. The Interpretation Of Cultures. Basic Books, 1977. Print.

"Geneva Declaration of the Rights of the Child, 1924 | Humanium for Children's Rights." N.p., n.d. Web. 20 Feb. 2015.

Gennep, Arnold van. The Rites of Passage. Trans. by Monika B. Vizedon and Gabrielle L. Caffee. University Of Chicago Press, 1961. Print.

Getis, Victoria. “Experts and Juvenile Delinquency, 1900-1935.” Generations of Youth: Youth Cultures and History in Twentieth-Century America. Ed. Joe Austin and Michael Willard. New York: New York University Press, 1998. 21-35. Print. Gilligan, Carol. In a Different Voice: Psychological Theory and Women's Development. Cambridge: Harvard University Press, 1998. Print.

Gilmore, David. Manhood in the Making : Cultural Concepts of Masculinity. New Haven: Yale University Press, 1990. Print.

Goldman, Albert, and Lawrence Schiller. Ladies and Gentlemen - Lenny Bruce. New York: Random House, 1974. Print.

Goldstein, Richard. "The Joy of Bombing.” Village Voice. N.p., n.d. Web. 2 July 2015. Goldsworthy, Andy. Passage. London: Thames \& Hudson, 2007. Print.

Gottlieb, Lisa. Graffiti Art Styles : A Classification System and Theoretical Analysis. Jefferson, N.C.: McFarland, 2008. Print.

“Graffiti Hurts.” Web. 16 Sept. 2010.

Graffiti Hurts. Stamford, CT: Keep America Beautiful, Inc., 2002. Print. Greenberg, Keith Elliot. Adolescent Rights: Are Young People Equal Under the Law?. New York: Twenty-first Century Books, 1995. Print. Issues of Our Time.

Gross, Daniel D., and Timothy D. Gross. "TAGGING: Changing Visual Patterns and the Rhetorical Implications of a New Form of Graffiti.” ETC: A Review of General Semantics 50.3 (1993): 250-264. Print. 
Grotius, Hugo. On the Law of War and Peace. Library of Alexandria, 2009. Print.

---. The Free Sea. Indianapolis: Liberty Fund, Inc., 2004. Print.

---. The Truth of the Christian Religion, with Jean Le Clerc's Additions. Indianapolis:

Liberty Fund Inc., 2012. Print.

Guggenheim, Martin. What's Wrong with Children's Rights. Cambridge: Harvard University Press, 2007. Print.

Halberstam, Judith. Female Masculinity. 1st ed. Durham, NC: Duke University Press Books, 1998. Print.

Hall, G. Stanley. Adolescence, Its Psychology and Its Relations to Physiology, Anthropology, Sociology, Sex, Crime, Religion and Education. New York: D. Appleton \& Company, 1904. Print.

Halsey, Mark, and Ben Pederick. "The Game of Fame: Mural, Graffiti, Erasure." City 14.1/2 (2010): 82-98. EBSCOhost. Web.

Halsey, Mark, and Alison Young. “'Our Desires Are Ungovernable': Writing Graffiti in Urban Space." Theoretical Criminology 10.3 (2006): 275-306. Print.

Harris, Cheryl. Theorizing Fandom : Fans, Subculture, and Identity. Cresskill N.J.: Hampton Press, 1998. Print.

Harrison, Marlen Elliot, and Phillip Ward Schnarrs, eds. Beyond Borders: Masculinities and Margins. Men's Studies Press, 2011. Print.

---, eds. Growing Our Field. Men's Studies Press, 2011. Print.

Hartz, Louis. The Liberal Tradition in America: An Interpretation of American Political Thought since the Revolution. San Diego: Harcourt, Brace Jovanovich, 1983. Print.

Hatchett, Nikki. "Paint the Town: The Best Women Graffiti Artists - in Pictures." The Guardian 5 Mar. 2014. Web. 13 Dec. 2014.

Hathaway, Nan. "Graffiti and Guerrilla Art." Arts \& Activities 141.3 (2007): 38-54. Print. 
Haworth, Billy, Eleanor Bruce, and Kurt Iveson. "Spatio-Temporal Analysis of Graffiti Occurrence in an Inner-City Urban Environment." Applied Geography 38 (2013): 53-63. EBSCOhost. Web.

Hebdige, Dick. Subculture : The Meaning of Style. New York: Routledge, 1991. Print. Hegel, Georg. Phenomenology of Spirit. Oxford: Clarendon Press, 1977. Print.

Hegel, Georg Wilhelm Fredrich. The Science of Logic. Trans. George Di Giovanni. Reprint edition. Cambridge University Press, 2015. Print.

Hegert, Natalie. "Radiant Children: The Construction of Graffiti Art in New York City." Rhizomes: Cultural Studies in Emerging Knowledge 25 (2013): n. pag. Web. 13 Dec. 2014.

Heidegger, Martin. "The Origin of the Work of Art." The Continental Aesthetics Reader, First Edition. New York: Routledge, 2000. 80-101. Print.

Hénaff, Marcel, and Tracy B. Strong, eds. Public Space and Democracy. Minneapolis: University of Minnesota Press, 2001. Print.

Hermer, Joe, and Alan Hunt. "Official Graffiti of the Everyday.” Law \& Society Review 30.3 (1996): 455-480. Print.

Holmes, Rachel. "Risky Pleasures: Using the Work of Graffiti Writers to Theorize the Act of Ethnography." Qualitative Inquiry 16.10 (2010): 871-882. EBSCOhost. Web.

Hulliung, Mark. The American Liberal Tradition Reconsidered: The Contested Legacy of Louis Hartz. Lawrence, Kan.: University Press of Kansas, 2010. Print.

---. The Social Contract in America: From the Revolution to the Present Age. Lawrence: University Press of Kansas, 2007. Print.

Hume, David. Essays, Moral, Political, and Literary. Indianapolis: LibertyClassics, 1987. Print.

Hutchins, Aaron. “Bieber's Easy, Breezy Graffiti.” Maclean's 126.45 (2013): 33-33. Print. 
Hyman. Rodman. The Sexual Rights of Adolescents: Competence, Vulnerability, and Parental Control. New York: Columbia University Press, 1984. Print.

Iveson, Kurt. "The Wars on Graffiti and the New Military Urbanism.” City 14.1/2 (2010): 115-134. EBSCOhost. Web.

Jefferson, Thomas. A Summary View of the Rights of British America. 1774.

Jeffreys, M. John Locke: Prophet of Common Sense. London: Methuen, 1967. Print.

Jones, Russell. Is Graffiti Art? Bowling Green, Ohio: Bowling Green State University, 2007. Print.

Jung, C. Psychological Types. New York: Pantheon Books, 1964. Print.

Jung, C. G. The Red Book. Ed. Sonu Shamdasani. Trans. Mark Kyburz and John Peck. 1st edition. New York: W. W. Norton \& Company, 2009. Print.

Kant, Immanuel. Critique of Judgment. New York: Hafner Pub. Co., 1951. Print.

---. “What Is Enlightenment?” Trans. Mary C. Smith. Web. 9 Feb. 2011.

---. Critique of Practical Reason. Trans. Werner S. Pluhar. Indianapolis: Hackett Publishing Company, Inc., 2002. Print.

---. Critique of Judgment. Trans. Werner S. Pluhar. 1st edition. Indianapolis, Ind: Hackett Publishing, 1987. Print.

---. The Metaphysical Elements of Justice: Part of The Metaphysics of Morals. Indianapolis: Bobbs-Murill for the Library of Liberal Arts, 1965. Print.

Katz, Wendy, and Thomas Kinkade. Thomas Kinkade: Masterworks of Light. Boston: Little, Brown and Company, Inc., 2000. Print.

Keller, Lisa. The Triumph of Order : Democracy \& Public Space in New York and London. New York: Columbia University Press, 2009. Print.

Kelling, George L., and James Q. Wilson. "Broken Windows.” The Atlantic Mar. 1982. The Atlantic. Web. 23 July 2011.

Kennedy, Randy. "Los Angeles Museum of Contemporary Art Paints Over Mural." ArtsBeat: The Culture at Large, NY Times. N.p., 13 Dec. 2010. Web. 8 June 2011. 
Kierkegaard, Søren. Either/Or. Garden City, New York: Doubleday, 1959. Print.

Kimbrell, Andrew. The Masculine Mystique: The Politics of Masculinity. 1st ed. New York: Ballantine Books, 1995. Print.

Kimmel, Michael. Manhood in America: A Cultural History. 3rd ed. Oxford University Press, USA, 2011. Print.

Kittay, Eva Feder, and Licia Carlson, eds. Cognitive Disability and Its Challenge to Moral Philosophy. Malden, MA: Wiley-Blackwell, 2010. Print.

Kittay, Eva Feder, and Ellen K. Feder, eds. The Subject of Care: Feminist Perspectives on Dependency. Lanham, MD: Rowman \& Littlefield Publishers, 2003. Print.

Kohlberg, Lawrence. The Philosophy of Moral Development: Moral Stages and the Idea of Justice. San Francisco: Harper \& Row, 1981. Print.

Kosuth, Joseph. One and Three Chairs. Wood chair, black and white photograph, and text, 1965. Musee National d'Art Moderne, Centre Georges Pompidou, Paris, France.

Kramer, Ronald. "Moral Panics and Urban Growth Machines: Official Reactions to Graffiti in New York City, 1990-2005.” Qualitative Sociology 33.3 (2010): 297311. EBSCOhost. Web.

Kriegel, Leonard. “Graffiti.” American Scholar 62.3 (1993): 431. Print.

Kuhn, Deanna. “Adolescent Thinking." Handbook of Adolescent Psychology, Volume 1: Individual Basis of Adolescent Development. 3rd ed. Hoboken, New Jersey: John Wiley \& Sons, Inc., 2009. 152-186. Print. 2 vols.

Kurlansky, Mervyn. The Faith of Graffiti. New York: Praeger, 1974. Print.

Kutner, Max. 'Rare Look Inside Jean-Michel Basquiat's Private Notebooks at Brooklyn Museum.” Newsweek.com 1 Apr. 2015. Web. 2 July 2015.

Lachmann, Richard. "Graffiti as Career and Ideology." The American Journal of Sociology 94.2 (1988): 229-250. Print.

Lam, H. K., and J. Prada. "Interpretation of Handwritten Single-stroke Graffiti Using 
Support Vector Machines” International Journal of Computational Intelligence \& Applications 8.4 (2009): 369-393. Print.

Lau, Joyce Hor-Chung. "King of Kowloon Finally Gets Respect.” New York Times 4 May 2011. Web. 8 June 2011.

Laursen, Brett and Andrew Collins. "Parent-Child Relationships During Adolescence." Handbook of Adolescent Psychology, Volume 2: Contextual Influences on Adolescent Development. 3rd ed. Vol. 2. Hoboken, New Jersey: John Wiley \& Sons, Inc., 2009. Print. 2 vols.

Lehmann, Falk. Maclaim: Finest Photorealistic Graffiti. Maidstone: Amalgamated Book Services, 2006. Print.

Leites, Edmund. Having Children: Philosophical and Legal Reflections on Parenthood. Ed. Onora O’Neill and William Ruddick. New York: Oxford University Press, 1979. 306-318. Print.

Lennon, John. “An Interview with The Freedom Painters.” Rhizomes: Cultural Studies in Emerging Knowledge 25 (2013): n. pag. Web. 13 Dec. 2014.

---. "Interview with Julien Breton.” Rhizomes: Cultural Studies in Emerging Knowledge 25 (2013): n. pag. Web. 13 Dec. 2014.

Lerner, Jacqueline V., Erin Phelps, Yulika Forman, and Edmond P. Bowers. "Positive Youth Development." Handbook of Adolescent Psychology, Volume 1: Individual Basis of Adolescent Development. 3rd ed. Vol. 1. Hoboken, New Jersey: John Wiley \& Sons, Inc., 2009. 524-558. Print. 2 vols.

Lerner, Richard M., and Laurence Steinberg, eds. Handbook of Adolescent Psychology, Volume 1: Individual Basis of Adolescent Development. 3rd ed. Vol. 1. Hoboken, New Jersey: John Wiley \& Sons, Inc., 2009. Print. 2 vols.

Ley, David. "Urban Graffiti as Territorial Markers." Annals of the Association of American Geographers 64.4 (1974): 491. Print.

Light, Andrew. Philosophy and Geography II : The Production of Public Space. Lanham: 
Rowman \& Littlefield Publishers, 1998. Print.

Light, Ben, Marie Griffiths, and Siân Lincoln. “'Connect and Create’: Young People, YouTube and Graffiti Communities." Continuum: Journal of Media \& Cultural Studies 26.3 (2012): 343-355. EBSCOhost. Web.

Locke, John. An Essay Concerning Human Understanding. Oxford: Clarendon Press, 1924.

---. Some Thoughts Concerning Education. Ed. John W. Yolton and Jean S. Yolton. Oxford University Press, USA, 2000. Print.

---. The Educational Writings of John Locke. Ed. James L. Axtell. 1ST ed. Cambridge University Press, 1968. Print.

---. The Educational Writings of John Locke, Ed. by John William Adamson. Ed. John William Adamson. Cambridge University Press, 1922. Print.

---. The Reasonableness Of Christianity As Delivered In The Scriptures. Whitefish: Kessinger Publishing, LLC, 2010. Print.

---. Two Treatises of Government. Ed. Peter Laslett. Cambrdge: Cambridge University Press, 1960. Print.

Lofland, Lyn. A World of Strangers: Order and Action in Urban Public Space. New York: Basic Books, 1973. Print.

Lomas, Harvey D. “Graffiti: Some Observations and Speculations.” Psychoanalytic Review 60 (1973): 71-89. Print.

Lombard, Kara-Jane. “Art Crimes: The Governance of Hip Hop Graffiti.” Journal for Cultural Research 17.3 (2013): 255-278. EBSCOhost. Web.

---. "Men Against the Wall: Graffiti(ed) Masculinities.” Journal of Men's Studies 21.2 (2013): 178-190. EBSCOhost. Web.

Loukaitou-Sideris, Anastasia. Sidewalks : Conflict and Negotiation over Public Space. Cambridge Mass.: MIT Press, 2009. Print.

Low, Setha. On the Plaza: The Politics of Public Space and Culture. 1st ed. Austin: 
University of Texas Press, 2000. Print.

Lunau, Kate. "Fighting Graffiti, with More Graffiti.” Maclean's 122.31 (2009): 25. Print. Macdonald, Nancy. The Graffiti Subculture: Youth, Masculinity and Identity in London and New York. Palgrave Macmillan, 2003. Print.

Macedo, Stephen, and Iris Marion Young, eds. Child, Family, and the State. New York: New York University Press, 2003. Print.

MacGillivray, Laurie, and Margaret Sauceda Curwen. "Tagging as a Social Literacy Practice." Journal of Adolescent \& Adult Literacy 50.5 (2007): 354-369. Print. MacIntyre, Alasdair. Dependent Rational Animals: Why Human Beings Need the Virtues. Chicago: Open Court, 2001. Print.

Macpherson, C. B. The Political Theory of Possessive Individualism: Hobbes to Locke. Reprint edition. Oxford: Clarendon Press, 1962. Print.

Madanipour, Ali. Whose Public Space?: International Case Studies in Urban Design and Development. Routledge, 2010. Print.

Mailer, Norman. Cannibals and Christians. New York: Dial Press, 1966. Print.

Mailer, Norman, and Jon Naar. The Faith of Graffiti. It Books, 2009. Print.

Mariduena, Alain "KET." Graffiti Planet: The Best Graffiti from Around the World. London: Michael O’Mara Books, 2007. Print.

Marx, Karl. "Production, Consumption, Distribution, Exchange (Circulation)." The Consumer Society Reader. Ed. Juliet Schor and Douglas B. Holt. New York: New Press, 2000. 251-254. Print.

Mason, Matt. The Pirate's Dilemma : How Youth Culture Reinvented Capitalism. New York: Free Press, 2008. Print.

Maston, Cathy et al. Criminal Victimization in the United States, 2006 Statistical Tables. Bureau of Justice Statistics, 2008. Print.

Mattelart, Armand. Advertising International : The Privatisation of Public Space. Rev. English language ed. New York: Routledge, 1991. Print. 
Mauss, Marcel. "The Gift and the Potlatch.” The Consumer Society Reader. Ed. Juliet Schor and Douglas B. Holt. New York: New Press, 2000. 227-229. Print.

Mcauliffe, Cameron. "Graffiti or Street Art? Negotiating the Moral Geographies of the Creative City.” Journal of Urban Affairs 34.2 (2012): 189-206. EBSCOhost. Web.

McAuliffe, Cameron. "Legal Walls and Professional Paths: The Mobilities of Graffiti Writers in Sydney." Urban Studies (Sage Publications, Ltd.) 50.3 (2013): 518537. EBSCOhost. Web.

McCarthy, Anna. Ambient Television : Visual Culture and Public Space. Durham: Duke University Press, 2001. Print.

McCole, John. "Georg Simmel and the Philosophy of Religion." New German Critique 94 (2005): 8-35. Print.

Megler, Veronika, David Banis, and Heejun Chang. "Spatial Analysis of Graffiti in San Francisco." Applied Geography 54 (2014): 63-73. ScienceDirect. Web.

Mendes, Sam. Skyfall. Eon Productions, 2012. Film.

Mensch, James. "Public Space.” Continental Philosophy Review 40.1 (2007): 31-47. CrossRef. Web.

Messerschmidt, James. “Doing Gender.” Gender \& Society 23.1 (2009): 85-88. Print.

---. "Making Bodies Matter: Adolescent Masculinities, the Body, and Varieties of Violence." Sage Family Studies Abstracts 22.3 (2000): n. pag. Print.

---. Masculinities and Crime : Critique and Reconceptualization of Theory. Lanham, MD: Rowman \& Littlefield, 1993. Print.

Mettler, Margaret L. "Graffiti Museum: A First Amendment Argument for Protecting Uncommissioned Art on Private Property.” Michigan Law Review 111.2 (2012): 249-281. Print.

Meyer, Stephenie. Twilight. Little, Brown Books for Young Readers, 2006. Print. Mickel, Emanuel J. “Baudelaire's 'Peintre De La Vie Moderne.” Symposium 38 (1984): 
n. pag. Web. 6 Dec. 2011.

Miller, Ivor. Aerosol Kingdom : Subway Painters of New York City. Jackson, MS:

University Press of Mississippi, 2002. Print.

---. Aerosol Kingdom : The Indigenous Culture of New York Subway Painters. N.p., 1992.

Print.

Miller, Jon. "Hugo Grotius.” The Stanford Encyclopedia of Philosophy. Ed. Edward N. Zalta. Spring 2014. N.p., 2014. Stanford Encyclopedia of Philosophy. Web. 1 Mar. 2015.

Miranda, Carolina A. "Beyond Graffiti.” ARTnews 2011: n. pag. Print.

Mondrian, Piet. Composition No. 10. N.p., 1939. Print.

Montesquieu, Charles Baron De. The Spirit of Laws. Trans. Thomas Nugent. Cosimo Classics, 2011. Print.

Monto, Martin A., Janna Machalek, and Terri L. Anderson. "Boys Doing Art: The Construction of Outlaw Masculinity in a Portland, Oregon, Graffiti Crew." Journal of Contemporary Ethnography (2012): 0891241612465981. jce.sagepub.com. Web.

Moore, Mandy. Yarn Bombing : The Art of Crochet and Knit Graffiti. Vancouver: Arsenal Pulp Press, 2009. Print.

Moore, Robert, and Douglas Gillette. King, Warrior, Magician, Lover: Rediscovering the Archetypes of the Mature Masculine. Reprint. HarperOne, 1991. Print.

Moreau, Terri, and Derek H. Alderman. "Graffiti Hurts and the Eradication of Alternative Landscape Expression.” The Geographical Review 101.1 (2011): 106. Print.

Morgan, David. The Sacred Gaze: Religious Visual Culture in Theory and Practice. 1st ed. University of California Press, 2005. Print.

Morgan, David H. J. "Theorizing Masculinities.” Theater of War: Combat, the Military, and Masculinities. Thousand Oaks, CA: SAGE Publications, Inc., 1994. 166-183. SAGE Knowledge. Web. 15 Dec. 2014. 
Mosse, George. The Image of Man : The Creation of Modern Masculinity. New York: Oxford University Press, 1996. Print.

Moughtin, Cliff. Urban Design : Street and Square. 3rd ed. Boston, MA: Architectural Press, 2003. Print.

Moynihan, Colin. “Beneath an Overpass, Hints of a Suspect's Obsession.” New York Times 15 Feb. 2011. Web. 8 June 2011.

---. "For Suspect, Ties to Possible Path to Escape." City Room: Blogging From the Five Boroughts, The New York Times. N.p., 14 Feb. 2011. Web. 8 June 2011.

Mulvey, Laura. "Visual Pleasure and Narrative Cinema." Film Theory and Criticism: Introductory Readings. Ed. Leo Braudy and Marshall Cohen. New York: Oxford University Press, 1999. 833-844. Print.

Nagourney, Adam. “Admirers Call It Art, but the Police Call It a Problem.” New York Times 22 Apr. 2011. Web. 8 June 2011.

Nayak, Anoop. "Race, Affect, and Emotion: Young People, Racism, and Graffiti in the Postcolonial English Suburbs.” Environment \& Planning A 42.10 (2010): 2370_ 2392. EBSCOhost. Web.

“NCT Interview by Aprocks and Dsyple.” N.p., n.d. Web. 2 Mar. 2011.

"A Piece of History Is Gone Forever. RIP SABER LA River Piece" Art Now SF. N.p., 12 Nov. 2009. Web. 8 July 2015.

Neef, Sonja. "Killing Kool: The Graffiti Museum.” Art History 30.3 (2007): 418-431. EBSCOhost. Web.

Neelon, Caleb. Saber: Mad Society. Ed. Roger Gastman. Berkeley: Gingko Pr Inc, 2010. Print.

Nelson, Steffie. “Tag, He’s It.” New York Times Magazine (2011): 44. Print.

Nietzsche, Friedrich. Basic Writings of Nietzsche. Trans. Walter Kaufmann. New York: Modern Library, 1968. Print.

O’Neill, Onora, and William Ruddick, eds. Having Children: Philosophical and Legal 
Reflections on Parenthood. New York: Oxford University Press, 1979. Print.

Orum, Anthony. Common Ground?,Readings and Reflections on Public Space. New York: Routledge, 2010. Print.

Othen-Price, Lindsey. "Making Their Mark: A Psychodynamic View of Adolescent Graffiti Writing.” Psychodynamic Practice 12.1 (2006): 5-17. EBSCOhost. Web.

Pabon, Jessica N. "Shifting Aesthetics: The Stick Up Girlz Perform Crew in a Virtual World.” Rhizomes: Cultural Studies in Emerging Knowledge 25 (2013): n. pag. Web. 13 Dec. 2014.

Paine, Thomas. Common Sense, and Other Political Writings. Ed. Nelson F. Adkins. New York: Liberal Arts Press, 1953. Print. American Heritage Series (New York, N.Y.) ; No. 5.

---. Rights of Man, Common Sense and Other Political Writings. Ed. Mark Philp. Oxford: Oxford University Press, 1995. Print.

Pani, Roberto, and Samanta Sagliaschi. "Psychopathology of Excitatory and Compulsive Aspects of Vandalistic Graffiti.” Psychological Reports 105.3 (2009): 1027-1038. EBSCOhost. Web.

Parsons, Talcott. The Social System. First. Free Press, 1951. Print.

Pateman, Carole. The Disorder of Women: Democracy, Feminism, and Political Theory. 1st ed. Stanford University Press, 1990. Print.

Pfeffer, Jacqueline L. “The Family in John Locke’s Political Thought.” Polity 33.4 (2001): 593-618. JSTOR. Web.

“Philadelphia | Mural Arts Program.” The City of Philadelphia. Web. 6 Apr. 2011. Phillips, Susan. Wallbangin': Graffiti and Gangs in L.A. Chicago: University of Chicago Press, 1999. Print.

“Philosophy of Education.” Stephen Hicks, Ph.D. N.p., n.d. Web. 22 June 2013.

Piaget, Jean. The Moral Judgment of the Child. New York: Free Press, 1997. Print. Pipkin, Whitney. "Making Graffiti a'Gift' to the Community." Parks \& Recreation 48.8 
(2013): 38-39. Print.

Plate, S. Brent, ed. Religion, Art, and Visual Culture: A Cross-Cultural Reader. New York: Palgrave Macmillan, 2002. Print.

Pleck, Joseph. Men and Masculinity,. Englewood Cliffs N.J.: Prentice-Hall, 1974. Print. ---. The Myth of Masculinity. Cambridge Mass.: MIT Press, 1981. Print.

Powers, Lyon A. "Whatever Happened to the Graffiti Art Movement?" Journal of Popular Culture 29.4 (1996): 137-142. Print.

Powers, Stephen. “A Love Letter For You.” A Love Letter For You. Web. 26 June 2011.

---. The Art of Getting Over. 1st edition. New York: St. Martin’s Press, 1999. Print.

Pufendorf, Samuel von. On the Duty of Man and Citizen (1682). Trans. Frank Gardner Moore. Two. New York: Oceana Publicatons Inc., Wildy \& Sons Ltd., 1964. Web. 1 Mar. 2015.

Quinn, Francis. "Robert Bly, The Art of Poetry No. 79." The Paris Review, Spring No. 154 (2000). Web Magazine Article.

Raphael, Ray. The Men from the Boys : Rites of Passage in Male America. Lincoln: University of Nebraska Press, 1988. Print.

Rauschenberg, Robert. Monogram. Freestanding combine, 1955-1959. Moderna Musset, Stockholm.

Rawls, John. A Theory of Justice. Revised edition. Cambridge, Mass: Belknap Press, 1999. Print.

Rebel Without a Cause. Warner Bros. Pictures, 1999. Film.

Reeser, Todd W. Masculinities in Theory: An Introduction. 1 edition. Malden, MA: Wiley-Blackwell, 2010. Print.

Riedelsheimer, Thomas. Andy Goldsworthy's Rivers \& Tides. Docurama, 2004. Film.

Rodman, Hyman, Susan H. Lewis, and Saralyn B. Yn B. Griffith. The Sexual Rights of Adolescents: Competence, Vulnerability, and Parental Control. New York: Columbia Univ Press, 1984. Print. 
Rosenberg, Harold. The Anxious Object. Chicago: Univ of Chicago Press, 1983. Print.

Rosen, David. The Changing Fictions of Masculinity. Urbana: University of Illinois Press, 1993. Print.

Roth, Evan. "ER: Bad Ass Motherfucker." ER: Bad Ass Motherfucker. Web. 2 Mar. 2011.

---. "Graffiti Analysis.” Graffiti Analysis v3.0. N.p., n.d. Web. 7 June 2015.

Rousseau, Jean. Discourse on the Origin and the Foundations of Inequality among Men. New Delhi: Global Vision Pub., 2006. Print.

Rousseau, Jean-Jacques. Jean Jacques Rousseau: His Educational Theories Selected from Émile, Julie and Other Writings. Ed. R. L. Archer and S.E. Jr. Frost. Woodbury, N.Y.: Barron’s Educational Series, 1964. Print.

---. The Social Contract. Baltimore, MD.: Penguin Books, 1968. Print.

Ruggiero, Vincenzo. "Social Disorder and the Criminalization of Indolence." City 14.1/2 (2010): 164-169. EBSCOhost. Web.

SABER. "Saberone.com - Graffiti Artist.” SABER ONE. Web. 12 Dec. 2011.

Sanchez, Jesus. "Graffiti Artists Prepare for Grand Opening of Echo Park Spray-Paint Can Store.” The Eastsider. N.p., 24 Sept. 2010. Web. 28 Mar. 2011.

Sandel, Michael J. What Money Can't Buy: The Moral Limits of Markets. New York: Farrar, Straus and Giroux, 2012. Print.

Sartre, Jean-Paul. Anti-Semite and Jew: An Exploration of the Etiology of Hate. Reissue edition. New York: Schocken, 1995. Print.

---. Being and Nothingness. Trans. Hazel E. Barnes. Reprint edition. New York: Washington Square Press, 1993. Print.

---. Black Orpheus. Trans. S. Allen. Paris: French \& European Pubns, 1948. Print. Sartre, Jean Paul. What Is Literature. Trans. Bernard Frechtman. New York: Philosophical Library, 1949. Internet Archive. Web. 15 Dec. 2014. Savage, Jon. Teenage: The Prehistory of Youth Culture, 1875-1945. New York: Penguin, 
2008. Print.

Schechner, Richard. Performance Studies: An Introduction. 3rd ed. London: Routledge, 2013. Print.

Scheible, Jürgen. "MobiSpray.” N.p., n.d. Web. 23 June 2015.

Scheible, Jürgen, and Timo Ojala. "Mobispray: Mobile Phone as Virtual Spray Can for Painting BIG Anytime Anywhere on Anything." Leonardo 42.4 (2009): 332-341. Print.

Schiller, Friedrich. Aesthetic and Philosophical Essays. BiblioBazaar, LLC, n.d. Print. ---. On the Aesthetic Education of Man. Trans. Reginald Snell. Mineola, N.Y: Dover Publications, 2004. Print.

Schillmeier, Michael. "The Social, Cosmopolitanism and Beyond." History of the Human Sciences 22.2 (2009): 87-109. Print.

Schor, Juliet, and Douglas B. Holt, eds. The Consumer Society Reader. New York: New Press, 2000. Print.

Scott, James C. Weapons of the Weak: Everyday Forms of Peasant Resistance. Reprint edition. New Haven: Yale University Press, 1987. Print.

Seay, John Eric. "You Look Complicated Today: Representing an Illegal Graffiti Artist in a Copyright Infringement Case Against a Major International Retailer.” Journal of Intellectual Property Law 20.1 (2012): 75-86. Print.

Sedgwick, Eve Kosofsky. Between Men: English Literature and Male Homosocial Desire. Reprint edition. New York: Columbia University Press, 1985. Print.

Serra, Richard. Tilted Arc. N.p., 1979. Print.

Shalhope, Robert E. The Roots of Democracy: American Thought and Culture, 17601800. New York: Rowman \& Littlefield Publishers, Inc., 1990. Print.

Simmons, A. John. The Lockean Theory of Rights. first Princeton printing. Princeton University Press, 1994. Print.

Sinopoli, Richard C. The Foundations of American Citizenship: Liberalism, the 
Constitution, and Civic Virtue. New York: Oxford University Press, 1992. Print. Sliwa, Martyna, and George Cairns. "Exploring Narratives and Antenarratives of Graffiti Artists: Beyond Dichotomies of Commitment and Detachment." Culture \& Organization 13.1 (2007): 73-82. EBSCOhost. Web.

Slote, Michael A. “Obedience and Illusions.” Having Children: Philosophical and Legal Reflections on Parenthood. Ed. Onora O’Neill and William Ruddick. New York: Oxford University Press, 1979. 319-326. Print.

Smetana, Judith G. and Myriam Villalobos. "Social Cognitive Development in Adolescent Thinking." Handbook of Adolescent Psychology, Volume 1: Individual Basis of Adolescent Development. 3rd ed. Vol. 1. Hoboken, New Jersey: John Wiley \& Sons, Inc., 2009. 187-228. Print. 2 vols.

Soldatenko, Gabriel. "The Politics of Writing on Walls.” Rhizomes: Cultural Studies in Emerging Knowledge 25 (2013): n. pag. Web. 13 Dec. 2014.

Solomon, Henry, and Howard Yager. "Authoritarianism and Graffiti.” Journal of Social Psychology 97.1 (1975): 149. Print.

Sorkin, Michael, ed. Variations on a Theme Park: The New American City and the End of Public Space. 1st ed. New York: Hill and Wang, 1992. Print.

Steinberg, Laurence. "Should the Science of Adolescent Brain Development Inform Public Policy?" The American Psychologist 64.8 (2009): 739. Print.

Stern, Sherry, and Mike Boehm. "MOCA's 'Art in the Streets' Exhibition Brings Unwanted Neighborhood Effect: Graffiti Vandalism - Latimes.com.” Culture Monster, LA Times. N.p., 14 Apr. 2011. Web. 8 June 2011.

Susman, Elizabeth J. and Lorah D. Dorn. "Puberty: Its Role in Development." Handbook of Adolescent Psychology, Volume 1: Individual Basis of Adolescent Development. 3rd ed. Vol. 1. Hoboken, New Jersey: John Wiley \& Sons, Inc., 2009. 116-151. Print. 2 vols.

Sutton-Smith, Brian. The Ambiguity of Play. Cambridge: Harvard University Press, 2001. 
Print.

Synnott, Anthony. "Theorizing Men: Heroes, Villains and Victims." Beyond Borders: Masculinities and Margins. Ed. Marlen Elliot Harrison and Phillip Ward Schnarrs. Men’s Studies Press, 2011. 38-66. Print.

Szakolczai, Arpad. "Liminality and Experience: Structuring Transitory Situations and Transformative Events.” International Political Anthropology 2.1 (2009): 141172. Print.

Tarcov, Nathan. Locke's Education for Liberty. Chicago: University of Chicago Press, 1984. Print.

Taylor, Myra Frances. "Addicted to the Risk, Recognition and Respect That the Graffiti Lifestyle Provides: Towards an Understanding of the Reasons for Graffiti Engagement.” International Journal of Mental Health \& Addiction 10.1 (2012): 54-68. Print.

Taylor, Myra, and Umneea Khan. "A Comparison of Police Processing Reports for Juvenile Graffiti Offenders: Societal Implications.” ECU Publications 2012 (2012): n. pag. Web.

“Teen Graffiti Artists Defend Their Creative Space.” New York Amsterdam News 94.37 (2003): 18. Print.

Ten Eyck, Toby A, and Brette E Fischer. "Is Graffiti Risky? Insights from the Internet and Newspapers." Media, Culture \& Society 34.7 (2012): 832-846. EBSCOhost. Web.

“The Keith Haring Foundation.” Web. 2 July 2015.

Thomassen, Bjorn. "The Uses and Meanings of Liminality.” International Political Anthropology 2.1 (2009): 5-28. Print.

Tomas, Paus. "Brain Development." Handbook of Adolescent Psychology, Volume 1: Individual Basis of Adolescent Development. 3rd ed. Vol. 1. Hoboken, New Jersey: John Wiley \& Sons, Inc., 2009. 95-115. Print. 2 vols. 
Tönnies, Ferdinand. Community \& Society: (Gemeinschaft Und Gesellschaft). Trans. Charles Price Loomis. New York: Harper \& Row, 1963. Print.

"To Sell or to Sell out: Graffiti Goes on the Auction Block." New York Amsterdam News 91.25 (2000): 6. Print.

Trattner, Walter I. Crusade for the Childrer: A History of the National Child Labor Committee and Child Labor Reform in America. Chicago: Quadrangle Books, 1970. Print.

Tuckness, Alex. "Locke's Political Philosophy." The Stanford Encyclopedia of Philosophy. Ed. Edward N. Zalta. Winter 2011.

Tully, James. A Discourse on Property: John Locke and His Adversaries. Cambridge [Eng.] ;;New York: Cambridge University Press, 1980. Print.

---. An Approach to Political Philosophy: Locke in Contexts. Cambridge [England] ;;New York NY USA: Cambridge University Press, 1993. Print.

Turner, J.M.W. The Fighting Temeraire Tugged to Her Last Berth to Be Broken up. N.p., 1839. Print.

Turner, Victor Witter. "Liminal to Liminoid, in Play, Flow, and Ritual: An Essay in Comparative Symbology.” Vol. 60. Houston, TX: William Marsh Rice University, 1974. 53-92. Web. 66 vols. The Rice University Studies 3.

---. The Drums of Affliction: A Sudy of Religious Processes among the Ndembu of Zambia. Ithaca, NY: Cornell University Press, 1968. Print.

---. The Ritual Process: Structure and Anti-Structure. Chicago: Aldine Pub. Co., 1969. Print.

"United Nations Treaty Collection.” The United Nations. Web. 20 Feb. 2015.

Uzgalis, William. Locke's “Essay Concerning Human Understanding”: A Reader's Guide. New York: Bloomsbury Academic, 2007. Print.

Valle, Imuris, and Eduardo Weiss. "Participation in the Figured World of Graffiti." Teaching and Teacher Education 26.1 (2010): 128-135. ScienceDirect. Web. 
Van Gennep, Arnold. The Rites of Passage. Chicago: Univ. Press, 1975. Print.

Veblen, Thorstein. "Pecuniary Emulation." The Consumer Society Reader. Ed. Juliet Schor and Douglas B. Holt. New York: New Press, 2000. 233-237. Print.

---. The Theory of the Leisure Class: An Economic Study of Institutions. New York:

Modern library: Electronic Format on Kindle, 1934. Print.

Vlasov, Aleksey. "Moss Graffiti: The Coolest DIY Project Ever | Bored Panda." boredpanda. N.p., Oct. 2014. Web. 19 Dec. 2014.

Walkowitz, Daniel. Contested Histories in Public Space : Memory, Race, and Nation. Durham [NC]: Duke University Press, 2009. Print.

---. Memory and the Impact of Political Transformation in Public Space. Durham N.C.: Duke University Press, 2004. Print.

Weber, Christina. “'I Mean It's Awkward Anxiety': Exploring the Role of Sociohistorical Context in Men's Negotiation of Masculine Subjectivity." Cultural Studies Critical Methodologies 10.4 (2010): 337-346. Print.

Weber, Eric Thomas. "Dewey and Rawls on Education.” Human Studies 31.4 (2008): 361-382. JSTOR. Web.

Weber, Max. The Protestant Ethic and the Spirit of Capitalism. S.1.: BN Publishing, 2009. Print.

Weil, Simone. Simone Weil: An Anthology. Ed. Sian Miles. First Edition Thus edition. New York: Grove Press, 2000. Print.

Weinberger, David. "Bringing on the Info Overload.” KM World 19.2 (2010): 1-22. Print.

"Who Are the Most Likely Offenders of Graffiti." Goodbye Graffiti. N.p., n.d. Web. 6 June 2015.

Wilde, Oscar. The Decay of Lying and Other Essays. London; New York: Penguin Books, 2010. Print.

William Aiken and Hugh LaFollette, eds. "Childhood's End: Toward the Liberation of 
Children." Whose Child? : Children's Rights, Parental Authority, and State Power. Totowa, NJ: Littlefield, Adams, 1980. Print.

---, eds. "Liberate Children." Whose Child? : Children's Rights, Parental Authority, and State Power. Totowa, NJ: Littlefield, Adams, 1980. Print.

---, eds. Whose Child? : Children's Rights, Parental Authority, and State Power. Totowa, NJ: Littlefield, Adams, 1980. Print.

Willis, Susan. "Teens at Work: Negotiating the Jobless Future." Generations of Youth: Youth Cultures and History in Twentieth-Century America. Ed. Joe Austin and Michael Willard. New York: New York University Press, 1998. 347-357. Print.

Wisconsin v. Yoder. The Oyez Project at IIT Chicago-Kent College of Law. 11 July 2015. $<$ http://www.oyez.org/cases/1970-1979/1971/1971_70_110>.

Wong, Natalie. "Mark of Defiance as Cops Chase Ai Artist.” The Standard. N.p., 20 Apr. 2011. Web. 25 Nov. 2011.

Woolard, Jennifer L. and Elizabeth Scott. "The Legal Regulation of Adolescence." Handbook of Adolescent Psychology, Volume 2: Contextual Influences on Adolescent Development. 3rd ed. Vol. 2. Hoboken, New Jersey: John Wiley \& Sons, Inc., 2009. 345-371. Print. 2 vols.

Yolton, John. John Locke \& Education. [1st ed.]. New York: Random House, 1971. Print.

Young, Alison. "Negotiated Consent or Zero Tolerance? Responding to Graffiti and Street Art in Melbourne." City 14.1/2 (2010): 99-114. EBSCOhost. Web.

---. Street Art, Public City: Law, Crime and the Urban Imagination. 1 edition. S.1.: Routledge, 2014. Print. 


\section{CURRICULUM VITA}

\section{Name}

Alton C. Frabetti, also as sculptor Alton Falcone (pseudonym)

\section{Address}

41 Glidden St., Beverly, MA 01915

\section{Education}

2015 PhD, Humanities Doctoral Program: Aesthetics and Creativity, University of Louisville, KY

2007 MFA, Sculpture, Stony Brook University, NY

MA, Philosophy, Stony Brook University, NY

Advanced Graduate Certificate in Art and Philosophy, Stony Brook University, NY

1992 BA, Double-major STPEC/Philosophy incl. Siena, Italy Exchange Program, UMASS/Amherst

Grants/Fellowships/Awards

2010 University Fellowship Award, University of Louisville, KY

2007 Best in Show of Best of SUNY Student Art Exhibit, New York State Museum, Albany

Annual Provost Office Incentive Prize winner, Stony Brook University, NY

Dialogues Across Differences Grant, Art Healing Space IV: Reinterpretations, Stony Brook University, NY 
2006 Annual Provost Office Incentive Prize winner, Stony Brook University, NY Special Recognition, 8th Annual Judeo-Christian International Online Juried Art Exhibition, Upstream People Gallery

Earthstock Recycled Art Show (Juried), Second place, Stony Brook University, NY

2005 Third Place, 1st Annual Juried Art Show, Gallery 4222, Port Jefferson, NY Dialogues Across Differences Grant, Assistant Curator, Art Healing Space III, Stony Brook University, NY

2005-7 TAship Program in Writing and Rhetoric

Teaching Experience

Fall 2011- Summer 2013 Humanities Doctoral Program, HUM 151 Creativity and the Arts, University of Louisville, KY. Instructor (TA).

2010 The Princeton Review, Cincinnati, OH. Instructor training. 2005-7 Program in Writing and Rhetoric (WAC), Stony Brook University, NY. Instructor (TA).Taught four courses to approximately eighteen students (each course) over a two-year academic period in introductory and advanced writing, rhetorical style, formal academic discourse and personal voice.

Spring 05 Art Department, 256 Foundations of Sculpture, Stony Brook University, NY. Instructor (TA).Independently instructed 17 students in the fundamentals of 3D art. Created a large-scale project/performance called Art Healing Space: The Lights that was highly publicized, meaningful and engaging. Exhibited student work from classroom project in local exhibition.

Fall 04 Art Department, Foundations of Drawing, Stony Brook University, NY.

Teaching Assistant.

Lectures, Panels \& Seminars

2010 Lecture, 'Process Art', ' Fitton Center for the Arts, Hamilton, OH Lecture, 'Role of the Beholder', Fitton Center for the Arts, Hamilton, OH2009 Lecture, 'Thought \& The Arts', Art Academy of Cincinnati, $\mathrm{OH}$ Guest lecturer, 'Process Art and Criticism', Art Academy of Cincinnati, OH 
Panels: Artist Statements, Art Academy of Cincinnati, OH;

Art at the X, Xavier University;

Gender Maze (moderator), Sandra Small Gallery, Covington, KY

2001 Lecture, 'Conceptual Anatomy', Kristiansand, Norway

Conferences

2011 “Graffiti Tagging: Critical Agency or Rite of Passage?”, Gender Matters, Governor State College, IL.

"Misconceptions of Graffiti Tagging," Kentucky Philological Association, KY

Panel Chair, "Visual Arts and Criticism", Literature and Culture, University of Louisville, KY

-, "Disintegrating Masculinities"

2010 "From Beautiful Polis to My Tag: Aspects of Emarginalization and Emasculation in the White Male Graffiti Artist," PCAS/ACAS, Savannah, GA

Publications

2011 "Reciprocity between Graffiti Vandalism and its Virtual Documentation," gnovis, Volume XII, Issue I

"Perspectives on the 2BUCK Interstate 65 Graffiti Tag and the Responding

Rhetoric." The Journal of Kentucky Studies, Vol. 28 September.

2010 'Gateways: Kim and Robinson,' $A E Q A I$, October

'Diaphanous Negation", AEQI, May

'Notes on Graffiti", AEAI, April feature article

'Shephard Fairey: Propaganda, and the Preempting of Criticism," AEQAI, March feature article

Ongoing reviews for $A Q A I$ : Adumbrationes, news and reviews in brief

2009 'Jungian Perspectives," AQAI, November feature article

'Elegy and the The Romantic Mood,' $A Q A I$, Oct

'The Aesthetics of Confronting Loss,' $E Q A I$, Sept

'Some Effects of Small Scale,' AEQAI, June

'The Eureka Effect,' $E Q A I$, March feature article

'Reflections on NeoPorkopolis,' AEQI, January 
13 reviews for $E Q A I$ : Adumbrationes, news and reviews in brief

'On Drawing,' text for 4th International Drawing Annual catalog, Manifest

Creative Research and Drawing Gallery, Cincinnati, OH

2008 'Unquelled Persona: Encountering the Artwork of Anthony Quinn,' ArtsEditor

feature article, May

'Layered Mimesis: Seeing the Artwork of Wlodzimierz Ksiazek,' ArtsEditor

feature article, June

2002 Introduction for catalogue of painter David Lara

\section{Curatorial Experience}

2007 Founder \& Curator, Unbound, Stony Brook University, NY

Curator, Art Healing Space IV: Reinterpretations. Charles B. Wang Center, Stony

Brook University, NY

2006 Founder \& Curator, Unbound, Stony Brook University, NY

Assistant Curator, Art Healing Space III: Mantra, Charles B. Wang Center, Stony

Brook University, NY

Solo Shows

2009 Different Directions, Carnegie Visual and Performing Arts Center, Covington,

$\mathrm{KY}$

2006 Corrosion, MFA Library Gallery, Stony Brook University, NY

Trisagion, MFA Library Gallery, Stony Brook University, NY

1997-03 Year-round exhibition in San Gimignano, Italy with 50-100 daily gallery visitors from across the globe

Group Shows

2010 Palling Around With Socialists, U-turn Art Gallery, Cincinnati, OH Macro/Micro, Northern Kentucky University, KY

Conjoined Twins, Art Beyond Boundaries, Cincinnati, $\mathrm{OH}$

2009 After the Pedestal, The Sculpture Center, Cleveland, OH

Dante 100x100-Purgatorio, Sala Francesco Virga del Centro Servizi per la 
Cultura e l'Impresa del Comune di Inveruno (Milano), Italy

2008 Dante 100x100-Purgatorio, Chiostro dei glicini dell'Umanitaria, Milano, Italy Best of SUNY Student Art, Governor's Mansion, Albany, NY

2007 Best of SUNY Student Art Exhibition, New York State Museum, Albany, May College Art Association, MFA Exhibition, February, Hunter College/Times Square Gallery, NY

Art Healing Space IV: Reinterpretations, April, Charles B. Wang Center, Stony Brook University, NY

MFA Thesis Show '8', March-April, Stony Brook University, NY

Unbound, April, Stony Brook University, NY

"Play it as it Lays," MFA Library Gallery, Stony Brook University, NY

2006 "Winter works IV," Gallery 4222, Port Jefferson, NY

SUNY Student Art Exhibition Series, Albany, NY

The Third Annual Marge Brown Kalodner Graduate Student Exhibition, The Clay

Studio, Philadelphia, PA

Gallery 4222, Self-Portraits, Port Jefferson, NY

Unbound, Stony Brook University

Art Healing Space III: Mantra, Charles B. Wang Center, Stony Brook University, NY

Annual Judeo-Christian International Online Juried Art Exhibition, Upstream People Gallery

Earthstock Recycled Art Show, Stony Brook University, NY

2005 Gallery 4222, The Winter Works III, Port Jefferson, NY

Art Healing Space II: Seeing Through Sixty Years, Charles B. Wang Center,

Stony Brook University, NY

Juried Group Show, Gallery 4222, Port Jefferson, NY

3.75 oz., May 3-18, MFA Library Gallery, Stony Brook University

The Sun Never Sets, Stony Brook University SAC Gallery, May 6-18

2003 Disegnosogno II, San Gimignano(SI) and Varese, Italy

Associazione Artiste Artigiane Rhapsody in Blue, San Gimignano, Italy

2002 Disegnosogno I, San Gimignano (SI) and Varese, Italy 
Associazione Artiste Artigiane Autoritratti, San Gimignano, Italy

2001 Associazione Artiste Artigiane Sotto il Cielo Azzurro, San Gimignano, Italy

1999 Two-man show with painter Tiziana Fulceri in Volterra, Italy

\section{Performance}

2007 Karlheinz Stockhausen's Musik Im Bausch: constructed sculpture, Bridgeport, CT and Stony Brook University, NY

2006 Turner Dance, Latent Image, sculpture/props, St. Mark's Church, NY, NY

Karlheinz Stockhausen's Musik Im Bausch: constructed sculpture, Stony Brook

University, NY

The Happy Prince, performance sculpture for children, Symphony Space, NY, NY

2005 Art Healing Space: The Lights, Charles B. Wang Center, Stony Brook University, NY

The Happy Prince, performance sculpture for children, Charles B. Wang Center, Stony Brook University

2003 Echoes II, Saratoga Springs, NY

2001 Echoes I, Boston, MA and Saratoga Springs, NY

Vannfestival in Kristiansand, Norway

Special Projects

2001 Ricordare, limited edition booklet with Pietro Toesca (produced image), printed by Associazione Artiste Artigiane di San Gimignano, Italy

1999 Casaraghy booklets with poets Gaetano Blaiotta and Giulio Marziaoli

Press

2009 Art Word: Alton Falcone Interview, Cincinnati Art Snob (Blog), June 25

CityBeat, To Do (brief commentary on work and image), Wednesday, April 8

2008 December E-News, City of Covington

RACCOLTOEDIZIONI, Catalog, Dante 100x100 Purgatorio, Milano, Italy

2007 On poster, Best in Show of Best of SUNY Student Art Exhibit, New York State Museum, Albany 
"SUNY Chancellor To Award Best of SUNY Student Art," SUNY News, May 24 Cockroft, James. "MFA Thesis Exhibition 2007." Review, Stony Brook Online Graduate Magazine

Warren, April. "Stony Brook Celebrates Unbound Arts Festival." Stony Brook Statesman, May 16

Das, Nanditha. "MFA Thesis Show." Review, Stony Brook Statesman, May 19

Das, Nanditha. "Reinterpretations: Art Healing Space IV." Stony Brook

Statesman, May 26

2006 Cockroft, James. "Corrosion." Review, Stony Brook Online Graduate Magazine Naydan, Lila. "A Corroded Aesthetic." Interview, Stony Brook Online Graduate Magazine

Hayes, Stephanie. "Trisagion." Review, Stony Brook Press, February Marjanovich, Nada. "L.I. Artists You Need to Know, A thru Z." Long Island Pulse, September

"Turner Dance 10 year anniversary: Latent Image," Edge New York, edgenewyork.com

Bradshaw, Larry. Juror's Statement, 8th Annual Judeo-Christian International Online Juried Art Exhibition

2003 Chiodetti, Mario. "Artisti in Movimento," review of Disegnosogno, Varese Web

Professional Experience

2008-2010 EQAI, Cincinnati, OH. Founder, Designer, and Editor. Founded monthly e-journal for critical thinking, review and reflective prose on contemporary art in the Greater Cincinnati region. Designed, constructed and registered web site. Formed a strong team of writers and brought them together for monthly meetings for determining article content. Began process of establishment of non-profit status, including the writing of bylaws and registration with the Secretary of State. Wrote founding principles, information page, and various articles. Integrated Blogger platform for subsections of ongoing short reviews and artist calls. Creatively integrated the community by enacting artist image hosting and web site links. Used social media platforms (Facebook) to expand 
readership and develop a forum. Worked with a designer to create an elegant PDF print version. Organized a highly successful end-of-year fundraiser.

1997-pres Self. Various locations.

Developed a successful, professional career as a sculptor under the name of Alton Falcone. Exhibited artwork in a permanent exhibition in Italy for seven years. Creatively collaborated with poets and writers for performance series such as Echoes $=$ Sculptor $\mathrm{x} \mathrm{Poet}^{2}$ in Boston and New York state. Won awards for artwork, including Best in Show of Best of SUNY Student Art, 2007. Created acclaimed installations such as Trisagion, 2006 and Dolce Invasione, 2007 at Stony Brook University. Currently with studio and projects in Covington, KY. Designed and maintained personal web site www.altonfalcone.com. ArtsEditor, Boston, MA. Contributor.

Wrote two highly acclaimed feature articles that ran from May until September.

Widgery Inc., Medford, MA. Assistant.

Redesigned web site of renowned public works artist Catherine Widgery into a more accessible and simplified format. Reviewed text and other marketing initiatives, giving valuable advice for successful public work proposals.

2006-07 Graduate Student Organization, Stony Brook University, Stony Brook, NY. Vice-President.

2003-07 Campus Residences, Stony Brook University, Stony Brook, NY. Building Coordinator.

1997-03 Studio D'Arte 'La Rocca,' San Gimignano, Italy. Founder and Director. Founded a self-sustaining art gallery in a foreign country. Hosted approximately 50 exhibitions as well as three permanent exhibitions. Developed all budgeting, accounting, packing and shipping in accordance with international legalities. Accurately organized all invoicing, tax work with tax consultants and fiscal receipts. Maintained gallery operations on 
a day-to-day basis such as direct sales. Trained and supervised gallery workers, including the new gallery director, temporary artist assistants and interim attendants. Won the respect of the local community in a foreign country by respectfully and tactfully interacting with all levels of citizenry. Gave lectures on conceptual anatomy in Norway and Italy.

1994-6 Art Gallery San Giovanni, San Gimignano, Italy. Director. Successfully transformed the private gallery of the artist Gordon Breckenridge into a profitable gallery business. Designed and reorganized the entire gallery display area into a welcoming and attractive space. Aided in the production of small prints to alleviate operating costs. Sold over three hundred original paintings, involving the invoicing, packaging and shipping worldwide. Assisted in the exhibition of the artist's work in Nyon, Switzerland. Rewrote basic artist information such as vita and biography. Trained and supervised gallery attendants.

$1993-4$ Resident Counselor.

Professional Service

2006-7 Vice President, Graduate Student Organization 2005-6 Senator, Graduate Student Organization, Stony Brook University

1999 Founding Member, Associazione Artigiani Artiste di San Gimignano, Italy 1999 Official Translator, Metastudio. Poggibonsi, Italy

\section{Technical Abilities}

Fundamental sculptural skills (woodworking, plaster, mouldmaking, wax modeling, welding, ceramics)

Blackboard, Photoshop, Adobe Illustrator, Microsoft Office

Web site design (CSS/XML)

Environmental Awareness and Hazardous Waste Management

Art Safety (OSHA Regulations)

Sexual Harassment Awareness 


\section{Languages Read/Spoken}

English (Native), Italian (Fluency), German (Introductory Reading) 